\title{
Solution-focused support of people with intellectual disabilities
}

Citation for published version (APA):

Roeden, J. M. (2012). Solution-focused support of people with intellectual disabilities. [Doctoral Thesis, Maastricht University]. Maastricht University. https://doi.org/10.26481/dis.20121219jr

Document status and date:

Published: 01/01/2012

DOI:

10.26481/dis.20121219jr

Document Version:

Publisher's PDF, also known as Version of record

\section{Please check the document version of this publication:}

- A submitted manuscript is the version of the article upon submission and before peer-review. There can be important differences between the submitted version and the official published version of record.

People interested in the research are advised to contact the author for the final version of the publication, or visit the DOI to the publisher's website.

- The final author version and the galley proof are versions of the publication after peer review.

- The final published version features the final layout of the paper including the volume, issue and page numbers.

Link to publication

\footnotetext{
General rights rights.

- You may freely distribute the URL identifying the publication in the public portal. please follow below link for the End User Agreement:

www.umlib.nl/taverne-license

Take down policy

If you believe that this document breaches copyright please contact us at:

repository@maastrichtuniversity.nl

providing details and we will investigate your claim.
}

Copyright and moral rights for the publications made accessible in the public portal are retained by the authors and/or other copyright owners and it is a condition of accessing publications that users recognise and abide by the legal requirements associated with these

- Users may download and print one copy of any publication from the public portal for the purpose of private study or research.

- You may not further distribute the material or use it for any profit-making activity or commercial gain

If the publication is distributed under the terms of Article $25 \mathrm{fa}$ of the Dutch Copyright Act, indicated by the "Taverne" license above, 


\title{
Solution-Focused Support of People with Intellectual Disabilities
}

\author{
John Roeden
}


The research presented in this thesis was conducted at the Governor Kremers Centre - Maastricht University Medical Centre, and the Baalderborg Group.

\section{GKC GمОШ caphri Maastricht UMC+}

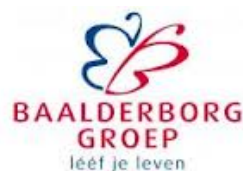

The studies in this dissertation were funded by the Governor Kremers Centre and the Baalderborg Group.

(C) 2012 John Roeden, Bruchterveld ISBN: 978-90-6455-7156

Technical realisation: Pirola, Schoorl uitgeverij

Photography: Marian Maaskant, MaasBrug fotografie

Financial support of the printing of this thesis was kindly provided by: Baalderborg Group. 


\title{
Solution-Focused Support of People with Intellectual Disabilities
}

\author{
PROEFSCHRIFT \\ ter verkrijging van de graad van doctor \\ aan de Universiteit Maastricht, \\ op gezag van de Rector Magnificus, Prof. dr. L.L.G. Soete, \\ volgens het besluit van het College van Decanen, \\ in het openbaar te verdedigen \\ op woensdag 19 december 2012 om 12.00 uur
}

door

Johannes Marie Roeden 


\section{Promotor:}

Prof. dr. L.M.G. Curfs

\section{Copromotor:}

Dr. M.A. Maaskant

\section{Beoordelingscommissie:}

Prof. dr. G. Kok (voorzitter)

Prof. dr. H.C.M. Didden (Radboud Universiteit Nijmegen)

Prof. dr. J.P.H. Hamers

Prof. dr. N.K. de Vries 



\section{CONTENTS}

Chapter 1 (p.9-26)

General introduction

Chapter 2 (p.29-50)

Solution-Focused Brief Therapy with People with Intellectual Disabilities. Journal of Policy and Practice in Intellectual Disabilities, 2009, 6, 253-259.

Chapter 3 (p.53-70)

The Views of Clients with Mild Intellectual Disabilities Regarding their Working Relationships with Caregivers.

Journal of Applied Research in Intellectual Disabilities, 2011, 24, 398-406.

Chapter 4 (p.73-95)

Solution-Focused Brief Therapy with People with Mild Intellectual Disabilities; a Case Series.

Journal of Policy and Practice in Intellectual Disabilities, 2011, 8, 247-255.

Chapter 5 (p.97-121)

Processes and effects of Solution-Focused Brief Therapy with People with Intellectual Disabilities; a Controlled Study.

Submitted for publication.

Chapter 6 (p.123-138)

Assessing Client-Caregiver Relationships and the Applicability of the 'StudentTeacher Relationship scale' for People with Intellectual Disabilities.

Research in Developmental Disabilities, 2011, 33, 104-110. 
Chapter 7 (p.141-165)

Solution-Focused Coaching of Staff of People with Severe and Moderate Intellectual Disabilities; a Case Series.

Journal of Policy and Practice in Intellectual Disabilities, 2012, 3, 185-194.

Chapter 8 (p.167-179)

The Nominal Group Technique as an Evaluation Tool for Solution-Focused Coaching.

Journal of Applied Research in Intellectual Disabilities, 2012, accepted.

Chapter 9 (p.181-202)

Processes and effects of Solution-Focused Coaching of Staff of People with Intellectual Disabilities; a Controlled Study.

Submitted for publication.

Chapter 10 (p.205-221)

General discussion

Summary (p.222-226)

Samenvatting (p.228-232)

List of publications (p.234-236)

Dankwoord (p.238-239)

Curriculum Vitae (p.240) 



\section{CHAPTER 1}

GENERAL INTRODUCTION 


\subsection{Introduction}

Solution-Focused Brief Therapy (SFBT) is a short-term, goal-focused and behaviourally oriented therapeutic approach that helps construct solutions rather than focus on problems (De Shazer, 1985). SFBT also is suitabale, with adaptations, for clients with intellectual disabilities (ID). The starting point for SFBT are the everyday problems experienced by clients with ID.

Solution-Focused Coaching (SFC) follows the same principles as SFBT (Furman, 2007), but involves the staff members of teams supporting people with ID. The starting point for SFC are the support problems experienced by such teams. These intervention methods have rarely been used with people with ID. The aim of this thesis is therefore to investigate the processes and effects of SFBT and SFC in the support of people with ID.

This research draws on three sources of inspiration. First, the aim is to help improve the quality of life of people with ID. The second goal is to contribute to the development of good working relationships between people with ID and staff. A third aim relates to the empowerment of people with ID. Each of these facets are discussed in more detail below.

\subsubsection{Quality of life}

The concept of quality of life has evolved within ID research since the $1980 \mathrm{~s}$ (Verdugo et al., 2005; Zuna et al., 2009). Quality of life is associated with human values, such as general feelings of well-being and opportunities to achieve personal potential (Cummins, 1991; Schalock, 2000). The quality of life of people with ID is seriously threated by the high prevalence of psychosocial problems among this population. Prevalence figures vary due to differences in the composition of population samples and measurement instruments (Didden et al., 2009). However, there is evidence that the prevalence of psychosocial problems is high (10 to $45 \%$ ) in both children and adults with ID (Einfield et al., 2006; Strømme \& Diseth, 2000). In some subpopulations (children and adolescents with ID, and adults with severe ID), prevalence figures are even higher compared to non-disabled peer groups (Whitaker \& Read, 2006). 
Despite this high prevalence of psychosocial problems, people with ID still have little access to psychotherapeutic services (Willner, 2006; WHO, 2008). This is in contradiction with the United Nations human rights treaties for people with disabilities, including the right of people with ID to expect and receive accessible and effective psychotherapeutic and social services (United Nations, 2006).

Clearly, there is a pressing need for and a formal right to effective, evidence-based services for people with ID to improve their quality of life. SFBT and SFC may be options in the case of psychosocial problems in people with ID. With their focus on strengths, previous successes and desired future (see 1.2 and 1.3), SFBT and SFC may help to reduce difficulties in the lives of people with ID and thus to improve their quality of life.

\subsubsection{Cooperative relationships}

Research over the last 20 years has increasingly pointed to the importance of positive relationships between clients with ID and staff. This is a precondition for the good quality of life of clients (Clegg \& Lansdall-Welfare, 1995; Schuengel et al., 2010) as well as serving to reduce problem behaviour (Hastings, 2005, Noone et al., 2006).

Research in the general population has demonstrated that the clients' positive opinions on the quality of the working alliance are a strong predictor of positive treatment outcomes (Bachelor \& Horvath, 1999). This may be true for clients with ID as well. The declaration drawn up by the first Dutch congress of clients with ID, held in 1994, and the self-advocay organization of persons with ID, underlined that "staff must really listen to clients and respect them. Clients in turn must be allowed to decide on issues that are important to them, and should be given the opportunity to make and correct mistakes themselves" (Manifest of the first congress of people with intellectual disabilities, 1994; Westveer, 2006).

\section{Note}

Terminology: the terms 'client(s)', 'persons' and 'people' with intellectual disabilities (abbreviated as ID) are used interchangeably in this thesis. This is due, among other things, to varying usage of these terms in different situations and/or cultures. The term 'client(s) with ID' 
is not regarded by some non-Dutch speakers as a respectful term for people with ID. In the Dutch language area it is. The term 'client(s)' is used in the case of situations in which people with ID are engaged with the services of professional organisations and so are thus 'client'.

In the solution-focused approach, the importance of positive working alliances between professionals and clients is widely acknowledged. Trepper et al. (2012) described the nature of the solution-focused working alliance as follows: "With SFBT, the therapist is seen as a collaborator and consultant, there to help clients [or teams] to achieve their goals. The overall attitude [of the therapist or coach] is positive, respectful and hopeful. There is a general assumption that people are resilient and continuously utilise this resilience to make changes. Further, there is a strong belief that most people have the strengths, wisdom, and experience to effect change" (p. 23). It can be hypothesised that the general attitudes of solution-focused therapists correspond with the views of clients with ID on their preferred way of receiving support.

\subsubsection{Empowerment}

Successive visions have ensured increasing attention for the empowerment of people with ID. Over time and between cultures, people with ID have been seen variously as inferior to supernatural (Feudtner \& Brosco, 2011; Mans, 1998). From the turn of the 20th century until about 1970, the emphasis in the Western-oriented world lay on the individual deficits of the 'mentally handicapped' in the 'medical model'. It was assumed that people with ID could not live in normal society. Instead they were seen as 'patients' with a diagnosis (oligophrenia) and were cared for and treated in separate institutions. In the subsequent 'development model' (until around 1990) the 'patients' of the medical model became 'people with development possibilities'. Within the development model, a varied set of special provisions and programmes were offered to train and develop these possibilities. For adult and elderly people the developmental model is less relevant. For them, staff attention is not primarily focused on the development of skills, but on maintaining the acquired skills. This is called the 'model of social balance' (Mandemaker, 1986). 
From 1990, the citizenship paradigm served as the guiding principle in the support of people with ID in the Western-oriented world (Luckasson et al., 1992; Van Gennep, 1997). Within this paradigm, people with ID became 'citizens'. The paradigm is based on the following four principles: (1) people with disabilities participate as full citizens in society, (2) with self-direction and choices, (3) with support rather than care, and (4) with guarantees concerning their quality of life.

According to Van Regenmortel and Embregts (2012) and Wehmeyer and Bolding (2001), the quest for empowerment can be considered part of the prevailing citizenship paradigm. They argue that the empowerment of people with ID should engender "the development of skills that lead to increased selfawareness and self-determination in the clients themselves" (p. 123).

The empowerment of people with ID is enshrined in legislation. In the Netherlands this includes the Clients' Right of Complaint (Care Sector) Act (WKCZ: Van Wijmen et al., in press), the Clients of Care Institutions Participation Act (WMCZ; Van Wijmen et al., in press) and client participation in research (Nierse et al., 2007). The growing attention for empowerment can also be seen in the organisation of national and international 'empowerment conferences' (Tøssebro et al., 2012; Van Beek \& Schuurman, 2010), in which people with ID themselves discuss, study and decide on the help and support they need.

Section 1.2 describes the principles and rationale underlying the use of SFBT. It shows that the principles of SFBT are well suited to the quest for empowerment of clients with ID.

\subsection{Solution-Focused Brief Therapy}

\subsubsection{Description}

The Solution-Focused Brief Therapy Association (SFBTA) founded in 2002 maintains the official treatment manual of SFBT. The Research Committee of the SFBTA identifies three components as representing SFBT (Lipchik et al., 2012): 
(1) use of conversations centred on clients' concerns;

(2) conversations focused on co-constructing new meanings surrounding clients' concerns;

(3) use of specific techniques to help clients co-construct a vision of a preferred future and to draw upon past successes and strengths to help resolve issues.

Other reviews of SFBT have identified the following techniques (Bannink, 2010a; Franklin et al., 2012; Macdonald, 2007):

Pre-session change. Since most clients have tried other possibilities before connecting with a therapist, the therapist can ask whether what changes have already occurred before the first session. Key question: 'Have there been changes for better or worse since you decided to take action?'.

Goal setting. The setting of behavioural, concrete and realistic goals in an important component of SFBT. The client is considered expert of his own life. Goals are formulated through SF-conversation about what the client wants to be different in the future. Consequently, in SFBT, the client set the goal. Key question: 'What will it be like when the problem is solved?', 'What will you be doing instead?'.

Exploring exceptions. There are always times when the problem is less severe or absent for the client. The therapist encourages the client to describe what different circumstances existed in that case, or what the client did differently. The aim for the client is to repeat what has worked in the past. Key question: 'What are you doing when the problem is not happening?'.

Scaling. The poles of a scale typically range from 'the worst the problem has ever been' ( 0 or 1 ) to 'the best things could ever possibly be' (10). The client is asked to rate his or her current position on the scale, and questions are then used to help the client identify resources. Scaling questions help the client to move away from all-or-nothing goals toward manageable and measurable steps. Key questions: 'Think of a scale from 1 to 10 with 10 being the best; 
where are you now?', 'What number is acceptable for you?', 'What is the next step?'.

Competence questions. By using competence questions, self compliments are being provoked with the client. Key question: 'How do (did) you do that?'.

Feedback. During the session, the client provides information about himself or herself and his or her situation. It is the client, not the professional, who brings about change. The feedback organises and underlines aspects of the information that are useful to the client in the realisation of his or her goal. The feedback has a fixed structure and consists of three components:

- Compliments. Compliments are forms of positive reinforcement. They affirm what the client finds important and confirm his or her successes and competences;

- Bridge. The bridge connects the compliments to the homework tasks;

- Tasks. The assignment of one or a few tasks to the client. They fall in two categories: observational and behavioural tasks.

\subsubsection{Applications}

SFBT is applied and investigated widely in the mental health field, for example in alcohol abuse (De Shazer \& Isebaert, 2003) and in the treatment of anxiety and depression (Beyebach et al., 2000). In addition, SFBT is used and investigated in a variety of settings such as schools (Franklin et al., 2012), psychiatry (Panayotov et al., 2012), forensic care (Lee et al., 2012) and social work (Sundmann, 1997).

\subsubsection{Rationale for using SFBT in clients with ID}

Although some therapists have started to develop and adapt SFBT for use with adults with ID (Bliss, 2005; Murphy \& Davis, 2005; Stoddart et al., 2001) the representation of the SF-model remains scarse in the therapeutic and research literature. There is, however, a need for therapy in people with ID given the high prevalence of psychosocial problems in the ID population. Recent reviews have highlighted that there is evidence that psychotherapy in people with ID is 
at least moderately effective (Prout \& Nowak-Drabik, 2003; Prout \& Browning, 2011). Therefore, effective psychotherapeutic interventions should be more frequently considered in the support of clients with ID.

Didden et al., (1997), Didden et al., (2009) and Willner (2005) provided overviews of effective psychotherapeutic interventions for people with ID. These interventions involve a wide range of strategies including cognitive behavioural approaches, psychodynamic approaches, approaches based on attachment theories, and behavioural interventions by staff. Within this range of approaches, Willner (2005) has described the benefits of 'selfmanagement'. According to Willner, self-management defined as, "obtaining the skills involved to change one's behaviour, and providing intervention for oneself", has traditionally been viewed as beyond the capabilities of people with ID. However, the evidence suggests that "self-management may be one of the more effective treatments, falling in the upper third of the range of efficacies" (Willner, 2005; p. 75).

SFBT has a number of attributes which may be relevant for use in clients with ID. These include focusing on skills rather than deficits and providing the client with expert status, and hence a sense of self-efficacy, within the therapeutic relationship. The SFBT focus on clients' strengths and cooperation fits with the growing emphasis in the Western world on empowerment and self-advocacy for people with ID.

In addition, SFBT can be seen as an intervention based on selfmanagement. Self-management in SFBT involves processes such as selfmonitoring (e.g., by means of discovering 'exceptions'), self-evaluation (e.g., by means of 'scaling') and self-reinforcement (e.g., by designing specific homework tasks). In SFBT, self-management is considered a technique that lies within the capabilities of people with ID.

\subsection{Solution-Focused Coaching}

\subsubsection{Description}

SFBT is not possible with people with profound, severe or moderate ID, because they lack sufficient verbal and cognitive abilities to describe their 
goals, perform homework assignments and evaluate their progress. In these instances, SFC from the staff side may provide an alternative.

In the context of this thesis, SFC is in fact the same as SFBT, but the people involved in SFC are not individuals (with ID), but staff members of a team (for people with ID). In this process the professional is referred to not as a therapist, but as a coach. Solution-focused coaching has recently been defined by O'Connell and Palmer (2007) as being a outcome-oriented, competence-based approach. They claim that SFC "helps clients to achieve their preferred outcomes by evoking and co-constructing solutions to their problems" (p. 278).

Similar to SFBT, SFC minimises emphasis on problems and focuses on a team's strengths, previous successes and desired future of a team.

Additionally, in SFC the team is the expert; the team formulates the goal and a strategy to reach this goal. As in SFBT, scaling questions help the team to move from all-or-nothing goals to manageable, behavioural steps.

SFC uses the same core components as SFBT: pre-session change, goal setting, exceptions, scaling, competences and feedback (see 1.2.1). More details about SFC are given in chapter 6, 7 and 9 and form part of the research questions and answers in this thesis.

\subsubsection{Applications}

The solution-focused model is applicable and widely used in coaching in the general population (Furman, 2007; McKerkow, 2012). It has multifunctional, applications, helping to reach a broad range of goals such as teambuilding, effective decision-making and organisational change (Bannink, 2010b). In this thesis, SFC focuses on solving the support problems of clients with ID, as experienced by staff (e.g., staff dealing with aggressive behaviour in a client with ID).

\subsubsection{Rationale for using SFC with staff}

Recent research has shown that staff supporting people with ID experience moderate levels of burnout (Skirrow \& Hatton, 2007). Violent client behaviour 
(Hatton et al., 1995), high support needs (Dyer \& Quine, 1998), imbalanced relationships with clients (Van Dierendonck et al., 1996), and challenging behaviour (Chung \& Harding, 2009; Jenkins et al., 1997; Prosser et al., 1997) were all associated with higher levels of burnout and other negative psychological outcomes. In dealing with all these support problems, SFC is a viable option which is investigated in chapter 7, 8 and 9.

\subsection{Research questions and outline of the thesis}

Combining the key issues of the previous sections it can be concluded that there is:

- an evolution of empowerment of people with ID;

- a necessity to build positive relationships between professionals and clients;

- a need for effective therapies to reduce emotional problems in clients with ID;

- a need for effective coaching to reduce support problems in staff of clients with ID.

The aim of this thesis is to investigate the processes and effects of SFBT and SFC in the support of people with ID. Special attention is paid to issues surrounding the client-caregiver relationships. The following main research questions have been formulated:

\section{SFBT:}

(1) What are the adaptations of SFBT that make it useful for the IDpopulation?;

(2) What do clients with ID find important in the client-caregiver alliance?;

(3) How can SFBT be used with clients with ID?;

(4) What are the processes and effects of SFBT with clients with ID, compared to care as usual?;

SFC:

(5) What is the applicability of the 'Student-Teacher Relationship Scale (STRS)' to relationships between clients with ID and caregivers?;

(6) How can SFC be used in teams supporting clients with ID?; 
(7) How is SFC judged by teams supporting clients with ID?;

(8) What are the processes and effects of SFC, compared to coaching as usual?

Research question 1: adaptations of SFBT

Chapter 2 provides an overview of the adaptations of SFBT that make it useful for adults with ID. This chapter also describes the assumptions, types of problems, and settings addressed by SFBT, as well as the interventions, indications and research findings of SFBT in general.

Research question 2: opinions on client-caregiver alliances

The goal of the study described in chapter 3 is to gain insight into what clients with ID find important in their relationships with caregivers. Their opinions are evaluated by means of the Nominal Group Technique. Attention is also paid to whether the views expressed by clients correspond with the core assumptions in SFBT.

Research question 3: the use of SFBT with clients with ID

Chapter 4 contains an exploratory case series of SFBT-procedures with 10 clients with mild ID (MID), who were experiencing emotional or adjustment difficulties. The SFBT protocol is presented and illustrated using a case exemplifying how SFBT can be used in practice.

Research question 4: processes and effects of SFBT

Chapter 5 provides the results of a controlled pre- and post-test study with 18 people with MID receiving SFBT and 18 people with MID receiving care as usual (CAU). To investigate the effects of SFBT the following outcome variables are used: (1) progression towards the therapy goal, (2) quality of life: psychological and social functioning, (3) resilience: social optimism and autonomy, and (4) maladaptive behaviour. The results of the SFBT group are compared to the results of the CAU group. 
Research question 5: assessing client-caregiver relationships Chapter 6 investigates the psychometric properties of the 'Student-Teacher Relationship Scale (STRS)' and examines the applicability in an ID-population.

Research question 6: the use of SFC with teams

Chapter 7 contains an exploratory case series of SFC-procedures with 13 teams of staff members who were experiencing support problems with clients with severe or moderate ID. The SFC protocol is presented and illustrated by means of an example case of the use of SFC in teams.

Research question 7: opinions on SFC

Chapter 8 evaluates SFC by means of the Nominal Group Technique. It reports on the strengths of SFC as well as staff recommendations to improve SFC.

Research question 8: processes and effects of SFC

Chapter 9 reports on a controlled pre- and post-test study with 18 teams receiving SFC and 18 teams receiving coaching as usual (CAU). To investigate the effects of SFBT the following outcome variables were used:

(1) progression towards the team goal, (2) quality of the client-caregiver relationships: closeness, conflict and dependency and (3) proactive thinking of staff. The results of the SFC group are compared to those of the CAU group.

\subsection{Study population}

The participants in the studies were clients of a service provider for children and adults with ID (serving approximately 900 people) in the Netherlands. People enrolled with this provider use various services, such as day care, and home care. All participants of SFBT were adults, lived semi-independently and had MID. The care as usual (CAU) offered to clients with MID by staff, consisted of individual support ranging from 2 to 14 hours per week. This support included for example help with housekeeping tasks (e.g., cleaning and cooking), with financial tasks (e.g., banking), and with social-emotional tasks 
(e.g., dealing with other people and conflict management). This service provider employs, among others, qualified psychological therapists, and one of the services offered is SFBT.

The teams of staff members involved in these studies in chapters 7 and 9 supported clients with severe and moderate ID (S/MID). All these teams experienced difficulties in supporting these clients with S/MID, such as aggressive behaviour towards staff and difficulties interacting comfortably with a client.

\section{References}

Bachelor, A. \& Horvath, A.O. (1999). The therapeutic relationship. In M.A. Hubble, B.L. Duncan \& S.S. Miller (Eds.), The heart and soul of change: What works in therapy (pp. 133-178). Washington: American Psychological Association.

Bannink, F.P. (2010a). 1001 solution-focused questions. New York: Norton.

Bannink, F.P. (2010b). Oplossingsgericht leidinggeven; 101 tips voor optimaal samenwerken. Amsterdam: Pearson.

Beyebach, M., Rodrigueze Sanchez, M.S., Arribes de Miguel, J., Herrero de Vega, M., Hernandez, C. \& Rodriguez-Morejon, A. (2000). Outcome of solutionfocused therapy at a university family therapy center. Journal of Systemic Therapies, 19, 116-128.

Bliss, V. (2005). Common factors, a solution focus and Sarah. Journal of Systematic Therapies, 24, 16-31.

Chung, M.C. \& Harding, C. (2009). Investigating burnout and psychological well-being of staff working with people with intellectual disabilities and challenging behaviour. The role of personality. Journal of Applied Research in Intellectual Disabilities, 22, 549-560.

Clegg, J.A. \& Lansdall-Welfare, R. (1995). Attachment and learning disability: a theoretical review informing three clinical interventions. Journal of Intellectual Disability Research, 39, 295-305.

Cummins, R.A. (1991). The Comprehensive Quality of Life Scale-Intellectual Disability: an instrument under development. Australia \& New Zealand Journal of Developmental Disabilities, 17, 259-264. 
De Shazer, S. (1985). Keys to solution in brief therapy. New York: Norton.

De Shazer, S. \& Isebaert, L. (2003). 'The Bruges Model: a solution-focused approach to problem drinking'. Journal of Family Psychotherapy, 14, 43-52.

Didden, R., Duker, P.C. \& Korzilius, H. (1997). Meta-analytic study on treatment effectiveness for problem behaviours with individuals who have mental retardation. American Journal of Mental Retardation, 101, 387399.

Didden, R., Collin, P. \& Curfs, L. (2009). Psychopathologie bij mensen met een verstandelijke beperking [Psychopathology in people with intellectual disabilities]. In W. Vandereycken, C. Hoogduin, \& P. Emmelkamp (Eds.), Handboek Psychopathologie [Handbook of Psychopathology] (pp. 614-637). Houten: Bohn Stafleu van Loghum.

Dyer, S. \& Quine, L. (1998). Predictors of job satisfaction and burnout among the direct care staff of a community learning disability service. Journal of Applied Research in Intellectual Disabilities, 11, 320-332.

Einfield, S., Piccinin, A., Mackinnin, A., Hofer, S.M., Taffe, J., gray, K.M. et al. (2006). Psychopathology in young people with intellectual disability. Journal of the American Medical Association, 296, 1981-1989.

Feudtner, C. \& Brosco, J.P. (2011). Do people with intellectual disability require special human subjects research protections? The interplay of history, ethics, and policy. Developmental Disabilities Research Reviews, 17, 52-56.

Franklin, C., Kim, J.S. \& Brigman, K.S. (2012). Solution-Focused Brief Therapy in school settings. In C. Franklin, T.S. Trepper, W.J. Gingerich \& E.E. McCollum (Eds.), Solution-focused Brief Therapy; A Handbook of EvidenceBased Practice (pp. 231-246). New York: Oxford University Press.

Furman, B. (2007). Change through cooperation. Helsinki: Brief Therapy Institute.

Hastings, R.P. (2005). Staff in special education settings and behaviour problems: Towards a framework for research and practice. Educational Psychology, 25, 207-221.

Hatton, C., Brown, A., Caine, A. \& Emerson, E. (1995). Stressors, coping strategies and stress-related outcomes among direct care staff in staff houses for people with learning disabilities. Mental Handicap Research, 8, 252-271. 
Jenkins, R., Rose, J. \& Lovell, C. (1997). Psychological well-being of staff working with people who have challenging behaviour. Journal of Intellectual Disability Research, 41, 502-511.

Lee, M.Y., Uken, A., Sebold, J. (2012). Solution-Focused Model with CourtMandated Domestic Violence Offenders. In C. Franklin, T.S. Trepper, W.J. Gingerich \& E.E. McCollum (Eds.), Solution-focused Brief Therapy; A Handbook of Evidence-Based Practice (pp. 165-182). New York: Oxford University Press.

Lipchik, E., Derks, J., Lacout, M. \& Nunnaly, E. (2012). The evolution of Solution-Focused Brief Therapy. In C. Franklin, T.S. Trepper, W.J. Gingerich \& E.E. McCollum (Eds.), Solution-focused Brief Therapy; A Handbook of Evidence-Based Practice (pp. 3-19). New York: Oxford University Press.

Luckasson, R., Coulter, D.L., Polloway, E.A. Reiss, S., Schalock, R.L., Snell, M.E., Spitalnik, D.M. \& Stark, J.A. (1992). Mental Retardation. Definition, Classification and Systems of Support. Washington: AAMR.

Macdonald, A.J. (2007). Solution-focused therapy. Theory, research \& practice. London: Sage.

Mandemaker, T. (1986). Ontwikkelingen binnen de dagopvang voor oudere geestelijk gehandicapten. Tilburg: IVA.

Manifest of the first congress of people with intellectual disabilities. 1994. www.arduin.nl.

Mans, I, (1998). Zin der zotheid. Amsterdam: Bakker.

McKergow, M. (20120). Solution-focused Approaches in Management. In C. Franklin, T.S. Trepper, W.J. Gingerich \& E.E. McCollum (Eds.), Solution-focused Brief Therapy; A Handbook of Evidence-Based Practice (pp. 327-341). New York: Oxford University Press.

Murphy, J.J. \& Davis, M.W. (2005). Video exceptions. An empirical case study involving a child with developmental disabilities. Journal of Systematic Therapies, 24, 66-79.

Nierse, C.J., Abma, T.A., Broerse, J.E.W., Caron-Flinterman, J.F., Heuvelman, C., Smit, J., Zeeuw, M., Dijk, J. van, Widdershoven, G.A.M. (2007). Partners in wetenschap. Mensen met een verstandelijke beperking doen mee in onderzoek. Nederlands Tijdschrift voor de Zorg aan mensen met verstandelijke beperkingen, 33, 2, 84-95. 
Noone, S.J., Jones, R.S.P \& Hastings, R.P. (2006). Care staff attributions about challenging behaviours in adults with intellectual disabilities. Research in Developmental Disabilities, 27, 109-120.

O'Connell, B. \& Palmer, S. (2007). Solution-focused coaching. In S. Palmer \& A. Whybrow (Eds.), Handbook of coaching psychology: A guide for practitioners (p. 278). London: Sage.

Panayotov, P.A., Strahilov, B.E. \& Anichkina, A.Y. (2012). Solution-Focused Brief Therapy and Medication Adherence with Schizophrenic Patients. In: C. Franklin, T.S. Trepper, W.J. Gingerich \& E.E. McCollum (Eds.), Solution-focused Brief Therapy; A Handbook of Evidence-Based Practice (pp. 196-202). New York: Oxford University Press.

Prosser, D., Johnson, S., Kuipers, E., Szmikler, G., Bebbingtom, P. \& Thornicroft, G. (1997). Perceived sources of work stress and satisfaction among hospital and community mental health staff, and their relation to mental health, burnout and job satisfaction. Journal of Psychomatic Research, 43, 51-59.

Prout, H.T. \& Nowak-Drabik, K. M. (2003). Psychotherapy with persons who have mental retardation. An evaluation of effectiveness. American Journal on Mental Retardation, 108, 82-93.

Prout, H.T. \& Browning, B.K. (2011). Psychotherapy with persons with intellectual disabilities: a review of effectiveness research. Advances in mental Health and Intellectual Disabilities, 5, 53-59.

Schalock, R.L. (2000). Three decades of quality of life. In M.L. Wehmeyer \& J.R. Patton (Eds.), Mental Retardation in the $21^{\text {st }}$ Century (pp. 335-356). Austin: Pro-ed.

Schuengel, C., Kef, S., Damen, S. \& Worm, M. (2010). 'People who need people': Attachment and professional caring. Journal of Intellectual Disability Research, 54, 38-47.

Skirrow, P. \& Hatton, C. (2007). Burnout amongst direct care workers in services for adults with intellectual disabilities. A systematic review of research findings and initial normative data. Journal of Applied Research in Intellectual Disabilities, 20, 131-144.

Stoddart, K.P., McDonnel, J., Temple, V. \& Mustata, A. (2001). Is brief better? A modified brief solution-focused therapy approach for adults with a developmental delay. Journal of Systematic Therapies, 20, 24-40. 
Strømme, P. \& Diseth, T.H. (2000). Prevalence of psychiatric diagnosis in children with mental retardation: data from a population-based study. Developmental Medicine \& Child Neurology, 42, 266-270.

Sundmann, P. (1997). Solution-focused ideas in social work. Journal of Family Therapy, 19, 159-172.

Tøssebro, J., Bonfils, I.S., Teittinen, A., Tideman, M., Traustadóttir, R. \& Vesala, H.T. (2012). Normalization Fifty years Beyond-Current Trends in the Nordic Countries. Journal of Policy and Practice in Intellectual Disabilities, 2, 134-146.

Trepper, T.S., McCollum, E.E., De Jong, P., Korman, H., Gingerich, W.J. \& Franklin, C. (2012). Solution-Focused Brief Therapy Treatment Manual. In C. Franklin, T.S. Trepper, W.J. Gingerich \& E.E. McCollum (Eds.), Solutionfocused Brief Therapy; A Handbook of Evidence-Based Practice (pp. 20-36). New York: Oxford University Press.

United Nations (2006). Convention on the rights of persons with disabilities. http://www.un.org/ disabilities/convention/conventionfull.shtml.

Van Beek, F. \& Schuurman, M. (2010). Eigen Kracht-conferenties: kansen en mogelijkheden in de zorg aan mensen met een verstandelijke beperking. Nederlands Tijdschrift voor de Zorg aan mensen met verstandelijke beperkingen, 3, 197-208.

Van Dierendonck, D., Schaufeli, W.B. \& Buunk, B.P. (1996). Inquity among human service professionals: Measurement and relation to burnout. Basic and Applied Social Psychology, 18, 429-451.

Van Gennep (1997). Paradigma-verschuiving in de visie op zorg voor mensen met een verstandelijke handicap;oratie. Maastricht: Universiteit van Maastricht.

Van Regenmortel, T \& Embregts, P.J.C.M. (2012). Regie over het eigen leven voor mensen met een verstandelijke beperking. Nederlands Tijdschrift voor de Zorg aan mensen met verstandelijke beperkingen, 2, 120-127.

Van Wijmen, F., Proot, I. Houben, Y \& Curfs, L. (in press). Naar nieuwe vormen van cliëntenraadpleging. Nederlands Tijdschrift voor de Zorg aan mensen met verstandelijke beperkingen. 
Verdugo, M.A., Schalock, R.L., Keith, K.D. \& Strancliffe, R.J. (2005). Quality of life and its measurement: important principles and guidelines. Journal of Intellectual Disability Research, 49, 707-717.

Wehmeyer, M.L. \& Bolding, N. (2001). Enhanced self-determination of adults with intellectual disability as an outcome of moving to community-based work or living environments. Journal of Intellectual Disability Research, 45, 371-383.

Westveer, W. (2006). Nothing about us without us? Journal of Applied Research in Intellectual Disabilites, 10, 225.

Whitaker, S. \& Read, S. (2006). The prevalence of psychiatric disorders among people with intellectual disabilities: An analysis of the literature. Journal of Applied Research in Intellectual Disabilities, 19, 330-345.

Willner, P. (2005). The effectiveness of psychotherapeutic intervention for people with learning disabilities: a critical review. Journal of Intellectual Disability Research, 49, 73-85.

World Health Organization; WHO, (2008). Policies and practices for mental Health in Europe. Meeting the challenges. www.euro.who.int/document / e91732.pdf.

Zuna, N.I., Turnball, A. \& Summers, J.A. (2009). Family quality of life: moving from measurement to application. Journal of Policy and Practice in Intellectual Disabilities, 6, 25-32. 



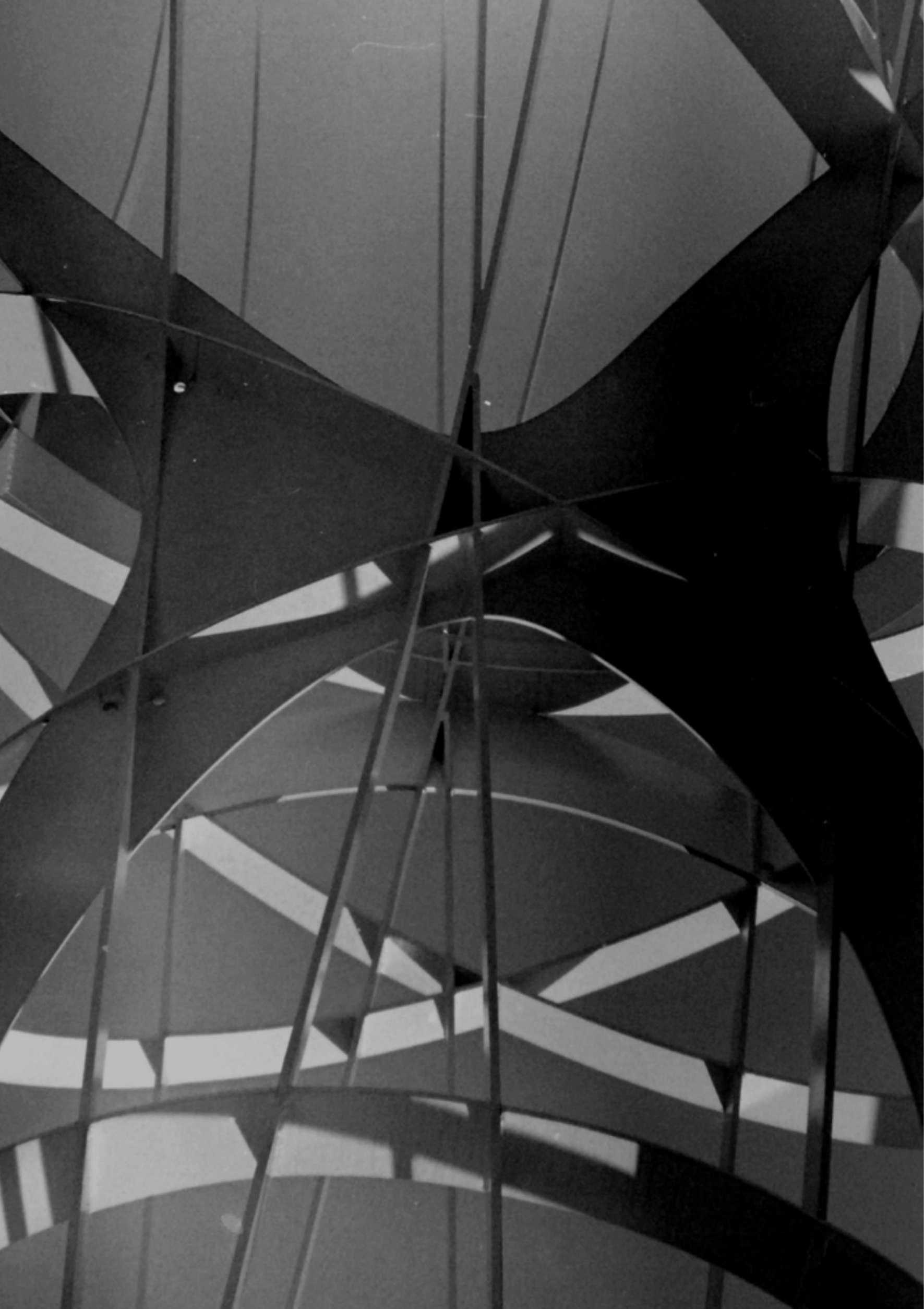




\section{CHAPTER 2}

\section{SOLUTION-FOCUSED BRIEF THERAPY \\ WITH PEOPLE WITH INTELLECTUAL DISABILITIES}

Roeden, J.M., Bannink, F.P., Maaskant, M.A. \& Curfs, L.M.G. (2009).

Solution-Focused Brief Therapy with Persons with Intellectual Disabilities. Journal of Policy and Practice in Intellectual Disabilities, 6, 253-259. 


\begin{abstract}
Solution-Focused Brief Therapy (SFBT) is a short-term, goal-focused, and client-directed therapeutic approach that helps the client construct solutions rather than dwell on problems. SFBT has rarely been used with clients with intellectual disabilities (ID). The authors discuss how this relatively new form of therapy in an adapted form can be made suitable for clients with ID. The assumptions of this therapeutic approach, the types of problems and settings addressed by SFBT, and a description of the interventions used in SFBT are considered. Indications and contraindications for SFBT and empirical data on the effectiveness of the therapy are discussed both with regard to clients with or absent ID. The authors suggest that tailoring SFBT to clients with ID can be done by using simple language, modified interventions, and inserting other adaptations into the therapy process. In practice, even though clinical practice experience with SFBT has shown great promise, empirical research into SFBT applications with clients with ID is lacking. Research is thus needed to demonstrate whether SFBT with this target group can yield sufficiently effective results and to what extent SFBT is valued by clients and their caregivers.
\end{abstract}

\title{
Keywords
}

Behaviour therapy, Intellectual Disabilities, Solution-Focused Brief Therapy 


\section{Introduction}

Psychological problems frequently occur in people with intellectual disabilities (ID). Compared with the general population, they are reported to experience behaviour problems and/or psychiatric disorders twice as often (Cooper, Smiley, Morrison, Williamson \& Allan, 2007; Crews, Bonaventura \& Rowe, 1994; Menolascino, Levitas \& Greiner, 1986). As therapeutic interventions, various therapies have been developed to positively influence behaviour, such as environment adaptation, behaviour therapies, and family therapy. These are all branches of psychotherapy that can also be used for clients with ID. Recent research and clinical practice experiences have shown that clients with ID can benefit from individual, couple, family, and group psychotherapy. For example, Beail and his colleagues (Beail, 2001; Beail, Kellett, Newman \& Warden, 2007; Beail, Warden, Morsley \& Newman, 2005; Newman \& Beail, 2002) posited that psychotherapy has efficacy with persons with ID and demonstrated reductions in psychological distress and interpersonal problems and increases in self-esteem, and tendencies toward lower reoffending rates. Prout and Nowak-Drabik (2003) examined 83 cases of psychotherapy involving persons with ID. Their meta-analysis pointed to a moderate degree (a mean of 3.15 on a scale of $1-5$ ) of positive changes in outcome measures (e.g., a reduction in anger, anxiety, depression, and weight-related problems and an increase in social, relaxation, and problem-solving skills, as assessed by objective instruments) and a moderate degree (a mean of 2.72 on a scale of 1-5) of effectiveness (e.g., an increase of perceived self-esteem, autonomy, locus of control-as reported by clients). Nevertheless, clinicians (e.g., Roeden \& Bannink, 2007a; Royal College of Psychiatrists, 2004; Smith 2005, 2006; Stoddart, McDonnel, Temple \& Mustata, 2001) have recommended modifying regular therapeutic approaches when working with individuals with ID, adjusting these therapies in accord to their developmental level (through the use of simpler language and modified interventions), as well as via other adaptations (including drawings, symbols, photographs, dolls, stories, or other narrative approaches) to the therapy process. One approach used in general practice, termed Solution-Focused Brief Therapy (SFBT; de Shazer, 1985, $1988,1991,1994)$, has gained popularity over the past 20 years. SFBT represents a short-term, goal-focused, and client-directed therapeutic 
approach that helps clients focus on solutions rather than problems. In SFBT the client is considered an expert with regard to his or her own situation. One of the central assumptions is that the goal of the therapy is defined by the client and that he or she has the competences and resources to realize this goal. In this, the therapist is expert in asking solution-focused questions that stimulate the client to formulate his or her goal rather than suggesting or prescribing the solutions. The attitude of the therapist is one of 'leading from one step behind' and 'not knowing' (meaning that the therapist asks questions and does not give advice). Some therapists have started to develop and adapt SFBT for use with adults with ID (e.g., Bliss, 2005; Cooke, 2003; Lloyd \& Dallos, 2006, 2008; Murphy \& Davis, 2005; Roeden \& Bannink, 2007a, 2007b; Smith, 2005, 2006; Stoddart et al., 2001; Westra \& Bannink, 2006a; 2006b).

In this paper the focus is on (1) describing the adaptations of SFBT that make it useful with adults with ID; and (2) providing an overview of the application of these adaptations. Also the paper contains a description of the assumptions, types of problems, and settings addressed by SFBT, as well as the interventions, indications, and research findings of SFBT in general. With respect to the adjustments to the SFBT approach when used with clients with ID, we note what attention was paid to indications, contraindications, and empirical evidence. There is a reflection on future directions in research and practice of SFBT with clients with ID.

\section{Method}

A literature search was performed to examine the nature and evidence of the use of SFBT in general and with persons with ID. Relevant literature was retrieved from Medline, PsycInfo, and ERIC. Keywords in the search were 'intellectual disabilities'(being the mesh-term), 'SFBT,' and 'Solution-Focused Brief Therapy'. 


\section{Results}

\subsection{Assumptions for SFBT}

SFBT is a short-term, goal-focused, and client-directed therapeutic approach that helps the client in therapy realize his or her goal by constructing solutions rather than analyzing problems. Elements of this preferred future are generally already present in the client's life and form the basis for ongoing change. SFBT is usually concluded within six sessions. SFBT therapists work with individuals and/or groups. The following are considered seven of the most important solution-focused assumptions (Selekman, 1993).

Considering the client's behaviour as resistance is not useful. It is important to approach each client in a cooperative manner rather than from a position of resistance, power, or control. To reach the defined goal of the client, the therapist matches the questions and therapeutic tasks with the client's unique way of reacting. The therapist further enhances the cooperation process by using the client's competences and recourses, his words and opinions.

Change is inevitable. The question is not whether but when change will occur. The client is invited to make positive self-fulfilling prophecies. A direct relation appears to exist between talking about positive change and realizing this change. It is helpful to talk about successes in the past, present, and future.

Only a small change is necessary. As soon as the client is encouraged to notice and value small changes, he or she will start believing that other, perhaps more important changes can also occur. Often the beginnings of a solution already lie in the client but remain unnoticed. These are illustrations of the exceptions to the problem (hidden successes) and give insight into which positive actions could be enacted to a greater extent or more often.

Clients have the strengths and resources to change. Everyone has strengths and resources. Any past successes of the client can serve as models for present and future successes. 
You do not need to know a great deal about the problem to solve it. SFBT assumes that no problem is always present to the same extent. The solutionfocused therapist will not explore and analyze the cause or details of the problem but will look at what the client is doing differently when the problem is not there or there to a lesser extent.

The client defines the goal of the therapy. Treatment is based on the goal of the client, not on that of the therapist. The client is invited to create a detailed picture of what his or her life will be like once his or her goal is reached. Ideally, the client's description will contain the 'who, what, where, when, and how' of goal attainment.

There are many ways of looking at a situation; one is no more 'correct' than another. There are no definitive explanations or descriptions of reality. Solution-focused therapists are not attached to their own theories but rather focus on the client's theory of change.

\subsection{Types of problems and settings addressed by SFBT}

SFBT is increasingly used for helping clients with a wide range of problems including alcohol abuse (Berg \& Miller, 1992), sexual abuse (Dolan, 1991), eating disorders (Jacob-Doreleijers, 2001), posttraumatic stress disorder (Bannink, 2008a; Berg \& Dolan, 2001; Dolan, 1991; O'Hanlon \& Bertolino, 1998), depression (Berg \& Steiner, 2003; Cladder, Nijhof-Huysse \& Mulder, 2000; O'Hanlon \& Bertolino, 1998), personality disorders, and psychoses (Bakker \& Bannink, 2008; Bannink, 2008; O'Hanlon \& Rowan, 2003). In addition, SFBT is used with children and adolescents (Bannink, 2006b; Berg \& Steiner, 2003; Metcalf, 1995; Selekman, 1993, 1997) as well as with groups (Furman, 2007; Metcalf, 1998).

The solution-focused model is also effective in management and coaching (Cauffman, 2003), in education (Franklin, Biever, Moore, Clemons \& Scamardo, 2001; Goei \& Bannink, 2005), in organizations (Stam \& Bannink, 2008), and in mediation (Bannink, 2006a, 2008a, 2008b). Most recently SFBT has been used with people with ID (Bliss, 2005; Cooke, 2003; Lloyd \& Dallos, 2006, 2008; Murphy \& Davis, 2005; Roeden \& Bannink, 2007a, 2007b; Smith, 
2005, 2006; Stoddart et al., 2001; Teall, 2000; Westra \& Bannink, 2006a, 2006b).

\subsection{SFBT in practice}

As part of the six-session process, generally a solution-focused conversation contains certain specific elements. The first element is the opening question. Through the therapist's opening question (e.g., 'what brings you here?') the client may describe his or her problem, or he or she may immediately indicate the goal of the therapy. The second element is pre-session changes. As most clients have tried other possibilities before connecting with a therapist, the practitioner can ask whether and what changes have already occurred before the first session. The third element is goal setting, where a clearly formulated goal is developed and the client is invited to describe what will be different in his or her life once his or her goal is reached. This could be done by means of the 'miracle question' - 'imagine a miracle occurring tonight that would (sufficiently) solve the problem . . . what would be different tomorrow?' The therapist may also suggest that changes are possible (e.g., 'When you look forward and things have improved, what will you be doing differently? How will other people know that things have improved?'). The therapist may also indicate with the question 'What else?' that there is more to come. Clients often respond to this simple query by giving more information and ideas.

Exploring the exceptions. The therapist asks questions regarding the moments in the client's life when the problem does not occur or is less serious and who does what to bring about these exceptions. The therapist may also ask questions relating to moments that have already met (to a degree) the goal of the client and how the client facilitates these moments taking place.

Scaling questions. In order to measure progress during therapy and to measure and stimulate hope, motivation, and confidence that the goal can be reached, scaling questions ( $10=$ very good, $0=$ very bad $)$ are used. They help the client to move away from all-or-nothing goals toward manageable and measurable steps. Competence questions The therapist uses competence questions whenever possible, which are indirect compliments (e.g., 'How did 
you know that was the right thing to do?') to stimulate the client to figure out the resources used to achieve success.

Assessing the client-therapist relationship. During the session the relationship (visitor, complainant, or customer) with the client is assessed. In a visitorrelationship the client is mandated or referred by others. He does not voluntarily seek help and is not suffering emotionally. In a complainantrelationship the client does have a problem and is suffering emotionally, but he or she does not (yet) see himself or herself as part of the problem and/or the solutions. Another person (or something) needs to change rather than himself. In a customer-relationship the client does see himself or herself as part of the problem and/or solutions and is motivated to change his or her behaviour. In the visitor-relationship the therapist may ask what, according to the client, the person referring him or her would like to see changed in his or her behaviour and to what extent the client is prepared to cooperate. In the complainant-relationship the therapist acknowledges the client's suffering and gives suggestions for observing the moments when the problem is or was there to a lesser extent. In the customer-relationship the therapist relates to the existing motivation and stimulates change by giving the client suggestions for behaviour corresponding with the goal (e.g., 'if it works, continue with it,' 'if it does not work, do something different,' or 'act as if the miracle has already happened').

Feedback. At the end of every session feedback with compliments and usually some homework suggestions are given. The compliments emphasize what the client is already constructively doing to reach his or her goal. The suggestions indicate areas requiring the client's attention or possible further actions to reach his or her goal. The therapist may also ask the client for feedback. (e.g., by using the Session Rating Scale developed by Duncan, Miller \& Sparks, 2004).

Indications for SFBT. SFBT applications are suitable if (1) the client has a goal before treatment or is able to formulate one during therapy; (2) the client is able to communicate (if not, SFBT can still be used with the caregivers of the client); and (3) the therapist does not see himself or herself as the expert and does not advise the client. 
3.4 Empirical evidence from the use of SFBT

In their overview of 15 case studies of SFBT therapy, Gingerich and Eisengart (2000) distinguished between methodologically well-monitored and less wellmonitored research. Five well-controlled studies revealed successful outcomes (i.e., reduction of depression, improvement of parenting skills, improvement of psychosocial adjustment after injury, decrease of recidivism of prisoners, and decrease of antisocial behaviour). Four moderately controlled SFBT studies demonstrated that better outcomes were achieved compared with no treatment or standard institutional services (i.e., increase of students' goal achievement, improvement of counseling skills with school-age children, reduction of oppositional behaviour in children, and improvement of marital satisfaction). Despite the methodological limitations of the remaining six studies, they showed positive outcomes. Stams, Dekovic, Buist and de Vries (2006) carried out a meta-analysis of 21 SFBT studies, including some 1,421 clients, to achieve quantitative evidence for the efficacy of SFBT. The average effect size (Cohen's $d$ ) for the influence of SFBT was 0.37 ( $95 \%$ confidence interval: 0.19-0.55), indicating a slight positive effect on the reduction of problems. The effectiveness of SFBT proved to be greater with clients treated in residential settings $(d=0.60)$ than for clients in non-residential settings (families, $d=0.40$; schools, $d=0.23$ ). Also, SFBT proved to be more effective with clients with behaviour problems $(d=0.61)$ than for clients with marital ( $d$ $=0.55)$ or psychiatric problems $(d=0.49)$.

\subsection{Adaptations of SFBT for use with individuals with ID}

SFBT has a number of advantages that make it attractive for use with clients with ID, including (1) a focus on skills rather than deficits; (2) a unique intervention for each client based upon his or her particular skills and needs; (3) an expert status for the client and hence a sense of self-efficacy within the therapeutic relationship; (4) a focus on empowerment, thus on competences and resources; and (5) a perceived effectiveness for clients in residential settings. Several authors have suggested adjustments to SFBT from those originally described by de Shazer $(1985,1988,1991,1994)$ because of the 
specific needs, developmental levels, and abilities of individuals with ID (Corcoran, 2002; Lentham, 2002; Murphy \& Davis, 2005; Roeden \& Bannink, 2007b; Smith, 2005, 2006; Stoddart et al., 2001; Teall, 2000; Westra \& Bannink, 2006a, 2006b). Specifically they have recommended a greater use of simple language, a flexible approach to questioning, alterations to engagement and in exploring exceptions, and adaptations in goal setting and scaling.

The use of simple language. Workers have recommended that sentences should be short, clear, and simply constructed. Table 2 summarizes some of the main solution-focused questions using only three, four, or five words. They have also recommended that the therapist use the terminology of the client as much as possible and monitor whether the client has understood the message. Flexibility in questioning. Recommendations have evolved that the client with ID be offered sufficient time to answer questions and develop ideas and be encouraged to reflect during and between therapy sessions. The concentration span of the client will influence the duration of the session. Some clients may require sessions longer than an hour, while others may be limited to half an hour. In addition, the sequence of the questions may vary so as to obtain useful responses for further exploration. The therapist can only use those aspects of the solution-focused repertoire that the client understands and finds useful and that make a difference. Because of this, the repertoire may have to be reduced for clients with ID. 
Table 2: Shortened solution-focused questions

\begin{tabular}{|c|c|}
\hline Interventions & Key questions \\
\hline Acquaintance & $\begin{array}{l}\text { Who are you? What do you like? What are you } \\
\text { good at? What are you proud of? }\end{array}$ \\
\hline Pre-session change & $\begin{array}{l}\text { What has already changed since ... ? } \\
\text { What is better since . . . ? }\end{array}$ \\
\hline Goal seeking & $\begin{array}{l}\text { What do you do instead (of the problem)? } \\
\text { What are you hoping for? What difference } \\
\text { would that make? What else? }\end{array}$ \\
\hline Exceptions & $\begin{array}{l}\text { When is/was it less serious? When is } i^{\mathrm{a}} / \text { was it }{ }^{\mathrm{a}} \\
\text { better? What do/did you do differently? } \\
\text { What did you try? What was helpful? What } \\
\text { else? }\end{array}$ \\
\hline Scaling & $\begin{array}{l}\text { When } 10 \text { is . . }{ }^{b} \text {, When } 1 \text { is . . }{ }^{b} \text {, } \\
\text { Where are you now? How did you do that? What is your } \\
\text { next step? What is your next sign of } \\
\text { progress? How can you get there? }\end{array}$ \\
\hline Competences & $\begin{array}{l}\text { How do/did you do that? How did you } \\
\text { succeed? How do/did you manage? How } \\
\text { are/were you able to . . . ? }\end{array}$ \\
\hline
\end{tabular}

${ }^{a}$ It is the problem as described by the client.

b Preferably: one word.

Engagement. There is common recognition that mutual engagement between the client and the therapist is of great importance. This begins with the therapist making small talk with the client; the therapist may, for example, inquire into the client's work, study, hobbies, interests, and musical taste. When the client is referred by others for behaviour problems ( $a$ common occurrence), he or she is usually engaged in a visitor-relationship. In this context, adaptations of engagement strategies are even more important in facilitating the development of a cooperative spirit between client and therapist.

Adaptations in exploring the exceptions. Many clients with ID may experience cognitive difficulties in exploring the past to retrieve exceptions. Therefore, the 
workers have recommended the use of partly nonverbal techniques such as topographic analyses, video exceptions, drawing, and role-play, which can help bring past exceptions into concrete and present focus. Topographic analysis describes specific behaviour at a specific time and place, and the focus is on the exceptions-that is, when did undesired behaviour not occur or occur to a lesser extent? This context can be described by the client as well as drawn from important helpers (such as family members or other caregivers). Recording video exceptions (Murphy \& Davis, 2005) is another useful technique in which day-to-day situations in the client's life are filmed. The video matter is edited to include only instances of successful and desired behaviour (which are 'the exceptions'). Once an exception is discovered, the film is shown to the client and relevant contextual details can be explored using solution-focused questions. On viewing his own successful behaviour, the client is stimulated to increase such behaviour (self-modeling). Also, the use of drawing and role-play (Corcoran, 2002) can make successful strategies concrete. For example, the client may draw and/or role-play a successful morning ritual (e.g., brushing teeth, getting dressed, eating breakfast), showing his ability to get ready effectively in the morning (and thus, for example, showing exceptions to the undesired behaviour of lingering).

Adaptations in goal setting. Many workers have noted that the 'miracle question' may often be too complicated for the client with ID. Therapists applying SFBT should try to shorten or change this question. Some examples of alternative questions are: 'What will it be like when the problem is solved?', 'What will you be doing instead tomorrow morning?', 'How do you describe yourself on a really good day?', 'What is your best hope?', 'What will be different then?' , 'What are you wishing for?' Table 2 provides a case example of the dialogue between a therapist and a client. 


\section{Table 2: Solution-Focused case}

Ann has been feeling depressed for weeks. The day before the session she did little else but dejectedly lie on the couch. To develop a clearly formulated goal she is asked about her preferred future. Part of the dialogue is as follows:

Therapist (T): 'How would you describe yourself on a really good day?' Ann (A): 'I would be cheerful and active.'

T: 'How could I see that you are cheerful and active?'

A: 'Then I laugh more often, I am more active.'

T: 'How could I notice that you are more active?'

A: 'Then I would make cards to send to people' (shows handmade cards).

$\mathrm{T}$ : 'Well, they are real works of art! What else do you do when things are going better?'

A: 'Then I will have tidied up my room better and made a meal for myself again.'

T: 'That is excellent! How will you achieve this?'

A: 'I will do that together with my coach.'

T: 'How will you go about that?'

A: 'Step by step.'

T: 'What could be the first small step? What are you thinking of?'

A: 'I won't just be sitting on the couch watching TV anymore.'

T: 'How will you get back into the swing of things?'

A: 'I would try to get some fresh air before doing necessary things.'

T: 'Good idea. How would you do that?'

A: 'I will walk my dog Winny again.'

T: 'So you must be feeling responsible?'

A: 'Yes, that will make Winny very happy.'

T: 'How would you notice that in Winny?'

A: 'Ooh then she will jump up at me. She is always cheerful, also when I am grumpy.'

T: 'How does that help you?'

A: 'Uh . . . she helps me get through it.'

T: 'Well, then you have chosen a good housemate. What else helps?' 
Adaptations in scaling questions. Stoddart et al. (2001) are credited with modifying the scaling technique from a 10-point to an easier 3-point scale. However, other options have also been presented for scaling, including the use of visual aids, emoticons, ladder rungs, a thermometer, stepping stones, or circles divided into sections (indicating happy or sad) (Lentham, 2002; Roeden \& Bannink, 2007a).

Involvement of the client's social environment. The involvement of others (caregivers, family) in the therapy process plays an important role for clients with ID. The use of other professional and family support in therapy is needed not only to encourage and explain homework assignments (to be carried out between sessions) but also to define topics to be addressed (Stoddart et al., 2001; Teall, 2000). However, well-meaning, over involved caregivers should be invited to adopt an attitude of 'leading from one step behind' (Smith, 2005, 2006).

Adaptations in homework assignments. Because some individuals with ID often cannot remember assignments (especially those of a cognitive nature), the use of prompts and/or written or visual aids provided by caregivers may help. To prevent the client from becoming overwhelmed, assignments should be simple, realistic, and few in numbers. The task can be given to both the client and his or her caregivers. It may also be given as an experiment; thus, the pressure to be successful is reduced.

\subsection{Indications and contraindications for SFBT with clients with ID}

SFBT seems to be the most successful for clients with mild ID rather than moderate to profound ID; clients who are self-referred; clients who are supported in the therapeutic process by others; clients with behaviour problems; and teams of caregivers (Roeden \& Bannink, 2007a; Stoddart et al., 2001; Westra \& Bannink, 2006b). SFBT seems to be less useful for clients with autism because of their poor understanding of the future and difficulty in differentiating between fantasy and reality (Lloyd \& Dallos, 2006). 
3.7 Empirical evidence on SFBT with clients with ID

The research literature on the use of SFBT with clients with ID is scarce and suffers from methodological limitations such as small sample sizes, lack of statistical power, poorly controlled studies, and vague or omitted outcome data. Stoddart et al. (2001) reviewed outcomes of 16 clients with mild to borderline ID receiving SFBT in which clinicians rated the degree to which the outcome was successful on a five-point Likert scale (1 = unsuccessful to 5 = very successful). Data were ascertained from client records. Using this method, problems relating to poor self-esteem, family relationships, and bereavement were most successfully treated in SFBT (success ratings 3.75.0), whereas depression and anxiety, couple conflict, and independence issues were the least successfully improved (success rating 2.0-3.3). However, these success ratings were not compared with controls.

Client satisfaction and length of SFBT were compared with clients receiving traditional psychotherapy. SFBT took significantly less time than traditional therapy (a mean length of 118 days vs. 372 days registered in service; $p<0.001$ ), with shorter waiting times until the beginning of the therapy (a mean length of 230 days as opposed to 312 days for regular therapy; $p<0.05)$.

According to six-month follow-up questionnaires regarding SFBT, clients and their caregivers were equally satisfied with the services when compared with traditional psychotherapy.

Murphy and Davis (2005) used a solution-focused intervention (video exceptions, see previous section) with a 9-year-old boy with moderate ID. This client displayed no vocal communication, and his expressive language was limited to about 12 highly functional 'single signs' from American Sign Language. Before treatment, the client's use of sign language to express his needs had dropped to unacceptable levels (he would resort to pointing, grunting, hitting, or yelling). The mean percentage of 10 -second intervals in which the client signed (preferred behaviour) during 10-minute observation periods increased from $23 \%$ at baseline to $71 \%$ during intervention. Follow-up observations 1 month after the intervention revealed that the client's signing still was markedly improved, namely in $64 \%$ of the intervals measured. No statistical information was given in this case study. 
Roeden and Bannink (2007b) described how a solution-focused and a traditional behaviour therapy were combined to treat a 21-year-old woman with a dysthymic disorder and borderline ID. The goal of the treatment (as formulated on basis of the miracle question) was to be happy and active. The exploration of exceptions gave clues about the client's competences and strategies for success. Depressive symptoms were measured before and after treatment using validated instruments developed for use with clients with ID (depression interview - Roeden, Helbig \& Zitman, 1995 - and the mood scale of the temperament questionnaire-Blok, Van den Berg \& Feij, 1990). By the end of the treatment, the progress made by the client meant that she no longer met the criteria for having a dysthymic disorder.

With regard to socioeconomic groups, Macdonald (2007) found no significant differences in the effects of SFBT. This is an important finding as all other psychotherapies are more effective for clients from higher socioeconomic groups (Meyers \& Auld, 2006). This has particular relevance as individuals with ID often belong to the lower socioeconomic segments of the community.

\section{Future research and practice in SFBT}

Psychotherapy is useful with persons in the general population and with persons with ID. However, adaptations (such as drawings, symbols, photographs, role-plays, and narrative approaches) are necessary for the latter group. Beail (2003) reviewed several studies on cognitive behavioural and psychodynamic psychotherapy research and noted several (methodological) shortcomings in these studies. Beail noted that "placing people in no treatment conditions without statistical power to detect differences is poor and unethical". He also stated that getting informed consent from persons with ID may be difficult, 'especially when random allocation is involved,' and that study groups seemed to be rather heterogeneous. Studies also tend to be performed in clinical practice, and thus are practice based instead of evidence based. Regarding Beail's comments, it indeed may be difficult to get consent from clients with ID because they may not understand the full impact of the therapy. For SFBT, however, usually consent is obtained easily as the client defines his or her own goal for treatment and the course of action. SFBT, in an adapted form, may be a promising therapeutic approach that focuses on what 
clients with ID want to have instead of their psychological problems (their preferred future). However, thorough research examining the effectiveness of SFBT ID applications with adults with ID has not been carried out. Future research with sufficient statistical power and controls should emphasize elements from evidence-based and practice-based research. In the first, the emphasis lies on the question 'What works in SFBT?' Such research into the effect of SFBT on clients with ID can be carried out on an individual and a group level, as well as with staff working with clients with ID. Practice-based research primarily revolves around the question 'What works for this specific client, in this specific situation, at this moment?' To address the efficacy of SFBT approaches, research should include questions focusing on the effect of SFBT on clients with ID, on the opinions of clients with ID and of professionals about SFBT, and on the therapeutic cooperation.

\section{References}

Bakker, J.M. \& Bannink, F. P. (2008). Oplossingsgerichte therapie in de psychiatrische praktijk [Solution focused therapy in psychiatric practice]. Tijdschrift Voor Psychiatrie [Journal for Psychiatry], 50, 55-59.

Bannink, F. P. (2006a). Oplossingsgerichte mediation [Solution focused mediation]. Amsterdam: Pearson.

Bannink, F. P. (2006b). Oplossingsgerichte vragen. Handboek oplossingsgerichte gespreksvoering [Solution focused questions. Handbook solution focused interviewing]. Amsterdam: Pearson.

Bannink, F. P. (2008a). Posttraumatic success: Solution focused brief therapy. Brief Treatment and Crisis Intervention, 7, 1-11.

Bannink, F. P. (2008b). Solution focused mediation. Conflict Resolution Quarterly, 25, 163-183.

Bannink, F. P. (2008). Vergelding of verzoening [Retaliation or reconciliation]. Forum voor Conflictmanagement [Forum for Conflict Management], 1, 26-28.

Beail, N. (2001). Recidivism following psychodynamic psychotherapy amongst offenders with intellectual disabilities. British Journal of Forensic Practice, 3, 33-37.

Beail, N. (2003). What works for people with mental retardation? Critical 
commentary on cognitive behavioural and psychodynamic psychotherapy research. Mental Retardation, 41, 468-472.

Beail, N., Kellett, S., Newman, D. W. \& Warden, S. (2007). The doseeffect relationship in psychodynamic psychotherapy with people with intellectual disabilities. Journal of Applied Research in Intellectual Disabilities, 20, 448-454.

Beail, N., Warden, S., Morsley, K. \& Newman, D. (2005). Naturalistic evaluation of the effectiveness of psychodynamic psychotherapy with adults with intellectual disabilities. Journal of Applied Research in Intellectual Disabilities, 18, 245-251.

Berg, I. K. \& Dolan, Y. (2001). Tales of solutions. New York: Norton.

Berg, I. K. \& Miller, S. D. (1992). Working with the problem drinker. A solution focused approach. New York: Norton.

Berg, I. K. \& Steiner, T. (2003). Children's solution work. New York: Norton.

Bliss, V. (2005). Common factors, a solution focus and Sarah. Journal of Systematic Therapies, 24, 16-31.

Blok, J. B., van den Berg, P. Th. \& Feij, J. A. (1990). Handleiding bij de Temperamentsschaal voor Zwakzinnigen (TVZ). [Handbook for the temperament questionnaire for the intellectually disabled]. Lisse: Swets \& Zeitlinger.

Cauffman, L. (2003). Oplossingsgericht management \& coaching. Simpel werkt het best. [Solution focused management \& coaching. Simple works best]. Utrecht: Lemma.

Cladder, J. M., Nijhof-Huysse, M. \& Mulder, G. (2000). Gedragstherapie met kinderen en jeugdigen. [Behaviour therapy with children and youths]. Lisse: Swets \& Zeitlinger.

Cooke, L. B. (2003). Treating the sequelae of abuse in adults with learning disabilities. British Journal of Developmental Disabilities, 49, 2328.

Cooper, S. A., Smiley, E., Morrison, J., Williamson, A. \& Allan, L. (2007). Mental ill-health in adults with intellectual disabilities: Prevalence and associated factors. British Journal of Psychiatry, 190, 27-35.

Corcoran, J. (2002). Developmental adaptations of solution-focused family therapy. Brief Treatment and Crisis Intervention, 2, 301-313. 
Crews, W. D., Bonaventura, S. \& Rowe, F. (1994). Dual diagnosis. Prevalence of psychiatric disorders in a large state residential facility for individuals with mental retardation. American Journal on Mental Retardation, 98, 724-731.

De Shazer, S. (1985). Keys to solution in brief therapy. New York: Norton.

De Shazer, S. (1988). Clues. Investigation solutions in brief therapy. New York: Norton.

De Shazer, S. (1991). Putting difference to work. New York: Norton.

De Shazer, S. (1994). Words were originally magic. New York: Norton.

Dolan, Y. (1991). Resolving sexual abuse. New York: Norton.

Duncan, B. L., Miller, S. D. \& Sparks, A. (2004). The heroic client. A revolutionary way to improve effectiveness through client-directed, outcome-informed therapy. New York: Jossey-Bass.

Franklin, C., Biever, J., Moore, K., Clemons, D. \& Scamardo, M. (2001). The effectiveness of solution-focused therapy with children in a school setting. Research on Social Work Practice, 11, 411-434.

Furman, B. (2007). Change through cooperation. Helsinki: Brief Therapy Institute.

Gingerich, W. J. \& Eisengart, M.A. (2000). Solution-focused brief therapy. A review of the outcome research. Family Process, 39, 477-498.

Goei, S. L. \& Bannink, F. P. (2005). Oplossingsgericht werken in remedial teaching [Solution focused interviewing in remedial teaching]. Remediaal, Tijdschrift voor Leer- en Gedragsproblemen in het vo/bve [Dutch Journal of Learning and Behaviour Problems], 5, 19-26.

Jacob-Doreleijers, F. (2001). Solution focused recovery from eating distress. London: BT Press.

Lentham, J. (2002). Brief solution-focused therapy. Child and Adolescent Mental Health, 7, 189-192.

Lloyd, H. \& Dallos, R. (2006). Solution-focused brief therapy with families who have a child with intellectual disabilities. A description of the content of initial sessions and the processes. Clinical Child Psychology and Psychiatry, 11, 367-386.

Lloyd, H. \& Dallos, R. (2008). First session solution-focused brief therapy 
with families who have a child with severe intellectual disabilities. Mothers' experiences and views. Journal of Family Therapies, 30, 5-28.

Macdonald, A. J. (2007). Solution-focused therapy. Theory, research \& practice. London: Sage.

Menolascino, F. J., Levitas, A. \& Greiner, C. (1986). The nature and types of mental illness in the mentally retarded. Psychopharmacology Bulletin, 22, 1046-1054.

Metcalf, L. (1995). Counseling toward solutions. A practical solution-focused program for working with students, teachers, and parents. San Francisco, CA: Jossey-Bass.

Metcalf, L. (1998). Solution focused group therapy. New York: Free Press.

Meyers, J. M. \& Auld, F. (2006). Some variables related to outcome of psychotherapy. Journal of Clinical Psychology, 11, 51-54.

Murphy, J.J. \& Davis, M.W. (2005). Video exceptions. An empirical case study involving a child with developmental disabilities. Journal of Systematic Therapies, 24, 66-79.

Newman, D.W. \& Beail, N. (2002). Monitoring change in psychotherapy with people with intellectual disabilities: The application of the assimilation of problematic experiences scale. Journal of Applied Research in Intellectual Disabilities, 15, 48-60.

O'Hanlon B. \& Bertolino, B. (1998). Even from a broken web: Brief, respectful solution oriented therapy for sexual abuse and trauma. New York: Wiley.

O'Hanlon, B. \& Rowan, T. (2003). Solution oriented therapy for chronic and severe mental illness. New York: Norton.

Prout, H. T. \& Nowak-Drabik, K. M. (2003). Psychotherapy with persons who have mental retardation. An evaluation of effectiveness. American Journal on Mental Retardation, 108, 82-93.

Roeden, J., Helbig, G. \& Zitman, F. (1995). A new, DSM-IV-compatible, structured interview for the diagnosis of depression in adults with Down syndrome. European Journal on Mental Disability, 2, 23-30.

Roeden, J. M. \& Bannink, F. P. (2007a). Handboek oplossingsgericht werken met licht verstandelijk beperkte cliënten [Handbook solution focused interventions with clients with intellectual disabilities]. Amsterdam: Pearson. 
Roeden, J. M. \& Bannink, F. P. (2007b). Hoe organiseer ik een etentje? Oplossingsgerichte gedragstherapie met een verstandelijk beperkte vrouw [How to organise a dinner? Solution focused behaviour therapy with a woman with intellectual disabilities]. Gedragstherapie [Behaviour Therapy], 40, 251-268.

Royal College of Psychiatrists (2004). Psychotherapy and learning disability (Council report 116). London: Author.

Selekman, M. D. (1993). Pathways to change. Brief therapy solutions with difficult adolescents. New York: Guilford.

Selekman, M. D. (1997). Solution-focused therapy with children. Harnessing family strengths for systemic change. New York: Guilford.

Smith, I. C. (2005). Solution-focused brief therapy with people with learning disabilities. A case study. British Journal of Learning Disabilities, 33, 102-105.

Smith, I. C. (2006). Ideas for solution-based working with people who have intellectual disabilities. Solution News, 2, 21-25.

Stam, P. \& Bannink, F. P. (2008). De oplossingsgerichte organisatie [The solution focused organization]. Tijdschrift voor Kinder- en Jeugdpsychotherapie [Journal of Youth Psychotherapy], 35, 62-75.

Stams, G. J., Dekovic, M., Buist, K. \& De Vries, L. (2006). Effectiviteit van oplossingsgerichte korte therapie. Een meta-analyse [Effectiveness of solution focused brief therapy. A meta-analysis]. Gedragstherapie [Behaviour Therapy], 39, 81-94.

Stoddart, K. P., McDonnel, J., Temple, V. \& Mustata, A. (2001). Is brief better? A modified brief solution-focused therapy approach for adults with a developmental delay. Journal of Systematic Therapies, 20, 24-40.

Teall, B. (2000). Using solution-focused interventions in an ecological frame. A case illustration. Social Work in Education, 22, 54-61.

Westra, J. \& Bannink, F. P. (2006a). 'Simpele' oplossingen! Oplossingsgericht werken bij mensen met een lichte verstandelijke beperking, deel 1 ['Simple' solutions! Solution focused interviewing with intellectually disabled clients, part 1]. Psychopraxis, 8, 158-116. 
Westra, J. \& Bannink, F. P. (2006b). 'Simpele' oplossingen! Oplossingsgericht werken bij mensen met een lichte verstandelijke beperking, deel 2 ['Simple' solutions! Solution focused interviewing with intellectually disabled clients, part 2]. PsychoPraxis, 8, 213-218. 



\section{CHAPTER 3}

THE VIEWS OF CLIENTS WITH MILD INTELLECTUAL DISABILITIES REGARDING THEIR WORKING RELATIONSHIPS WITH CAREGIVERS 


\section{Abstract}

Background. Research studies into the effect of therapies have shown that a good relationship between the client and his caregiver is a key factor in a positive treatment outcome.

Method. The Nominal Group Technique (NGT) has been used in this study to discover what clients with ID feel contributes to a successful working relationship with caregivers.

Results. The research reveals that from the clients' perspective the way in which caregivers deliver their support (a reliable, empathic and nonpatronizing attitude) is important. The particular types of support seem to be less influential in terms of treatment success. Furthermore, the results show that the clients' preferred ways of receiving help correspond with the basic assumptions in Solution-Focused Brief Therapy (SFBT).

Conclusions. This research project demonstrates that the NGT is a valuable instrument in bringing to the fore the opinions and priorities of clients with ID. Comparisons with studies into the client-professional working relationships among children and adults without ID reveal similarities to the outcomes of this research project.

\section{Keywords}

Client Views, Relationships, Nominal Group Technique, Solution-Focused Brief Therapy 


\section{Introduction}

Research into the effects and processes of therapies has increasingly underlined the importance of developing good relationships between clients and professionals. General research studies (Orlinsky et al., 1994, 2004; Duncan et al., 2004) into the working alliance between clients and professionals have revealed that interventions are more successful if:

- the client identifies the relationship with his professional as positive;

- the professional actively involves the client in the support process;

- the professional is perceived as empathic, non-judgmental, helpful and genuine.

Furthermore, research has demonstrated that the client's positive opinion about the quality of the working alliance is a much stronger predictor of a positive treatment outcome than the opinion of the professional involved (Bachelor \& Horvath, 1999). This also holds true for clients with intellectual disabilities (ID). In the declaration drawn up by the first Dutch congress of clients with ID, held in 1994, it was underlined that caregivers must really listen to their clients and respect them. Clients in turn must be allowed to decide on issues that are important to them and they should be given the opportunity to make and correct mistakes themselves (Anonymous, 1994). Roelink et al. (2002) analysed the desired relations and interactions between clients with severe intellectual disabilities and their caregivers on the basis of video observation. The authors concluded that client autonomy is ensured if the caregiver continually focuses on discovering the wishes, preferences and development opportunities revealed by the clients.

As far as the authors of this article are aware, no research has been conducted into the ways in which clients with ID perceive the working relationships with their caregivers. This is remarkable, considering that these interactions tend to be lengthy and intensive. In addition, clients with ID frequently receive practical help, for example with domestic chores and social skills. It is therefore desirable for them to form a positive working alliance, given its likely impact on a successful treatment outcome and/or on the client's emotional well-being.

At present, the citizenship paradigm is central in viewing clients with ID. In this view, 'empowerment', 'support' and 'inclusion' are key principles 
(Westveer, 2006; Llewllynn \& Northway, 2008; Van Gennep, 2009). It is thus also relevant to ask clients their opinion on how to achieve a fruitful relationship with their caregivers.

In recognition of the beneficial impact of a positive and cooperative client-caregiver relationship, many treatment programs strive to encourage this, including Solution Focused Brief Therapy (SFBT, Bannink, 2009). This aim is apparent in a number of core assumptions in SFBT (Selekman, 1993):

- the client is considered an expert; he has the competences to determine his goal and the road to achieving this;

- together with the client, the professional searches for solutions that the client (usually) already (unconsciously) knows, building upon his strengths and competences;

- the position of the professional is one of 'not knowing': he adopts a modest attitude, is interested in the client's opinion and is open to being informed by the client.

When certain conditions are met, SFBT is also suitable for clients with ID (Stoddart et al., 2001; Roeden \& Bannink, 2007; Roeden et al., 2009). It is thus useful to examine which aspects of the support provided by caregivers, clients with ID find important, and whether these aspects also connect with the assumptions in SFBT.

The goal of this study is to gain insight into the conditions and aspects clients with ID value in their relationship with caregivers. Attention also focuses on whether the views expressed by clients correspond with core assumptions in SFBT and if so, how. Thus, the key questions to be addressed are:

(1) What do clients with ID find important in the client-caregiver alliance?

(2) To what extent do the opinions of clients with ID on the client-caregiver relationship correspond with the core assumptions in SFBT?

\section{Method}

\subsection{Participants}

Eighteen clients of a Dutch organization providing support to people with ID were invited to take part in this research project. All clients lived alone in assisted housing, receiving several hours of domestic, social and private 
support each week (for example assistance with cooking or visiting friends) from the service center. They were visited in their homes by the first author (JR) and were asked whether they would like to assist in a research program. The clients were previously unknown to the first author. Detailed information about the nature of the proposed research was not divulged in order to avoid the risk of participants being influenced, should they discuss the project with others (clients, caregivers, acquaintances or family members). However, the clients received general relevant information. They were informed that the researchers were interested in their experiences and means of coping with all kinds of everyday problems in supported living settings.

The guarantee of anonymity with regard to personal and research data was emphasized to all taking part in the program. All eighteen clients that were approached were willing to cooperate. The participants were divided by the first author into three research groups, each consisting of six people. Geographical proximity was a prime factor in establishing the groups, in order to keep travel time to a minimum. It was ensured that none of the clients had a caregiver in common so that they could not discuss the approach of a shared caregiver and thus influence one another. On the research day itself one participant was unable to attend due to illness, bringing the number participating to seventeen.

The age of participants ranged from 25 to 56 years (with an average age of 41) and all had IQ's between 50 and 85 (15 participants had mild ID [IQ: 50/55-70] while 2 participants had intelligence scores in the borderline range [IQ's: 76 and 80]). The participants possessed good receptive and expressive verbal competences and suffered from no severe emotional problems or multiple disabilities. Permission for the research program was given by the Client Council (made up of clients with ID) and by the organization's Client Representative Council (family members or representatives of clients with ID). The research proposal corresponded with the local organizational guidelines for carrying out research projects involving people with ID.

\subsection{Measures}

The Nominal Group Technique (NGT) provides a structured method for collecting and organizing the thoughts of a group of people with regard to a 
single question. This method is used, for example, as a curriculum evaluation tool and for identifying problem-solving strategies among consumer groups (Lloyd-Jones et al., 1999; Dobbie et al., 2004). So far, in professional support to clients with ID, the NGT has only been employed to a limited extent. However, it has now been used to detect problem areas that clients with ID experience (Bostwick \& Foss, 1981) and to explore viewpoints in the final life phases of clients with ID (Tuffrey-Wijne et al., 2007).

The objectives of this technique are met by ensuring that each person in the group contributes to the group product. All group members are given an equal opportunity to participate. After introducing the single question (The Nominal Group Technique (NGT) provides a structured method for collecting and organizing the thoughts of a group of people with regard to a single question.) the procedure continues with four basic steps:

(1) generating individual ideas (writing down as many responses to the central question as possible);

(2) round-robin listing of individual ideas (all responses are collected and given equal importance);

(3) clarification of ideas within a limited time frame (unclear suggestions are discussed and clarified);

(4) selecting and ranking the ideas (each participant is asked to rank what they consider the five most important ideas on a scale of 5 (most important) to 1 (least important).

\section{Nominal Group Technique modified}

Some elements of the NGT were modified for use with participants with ID. Step 1: Generating individual ideas. Instead of writing down ideas independently, participants in this study work alongside interviewers. These interviewers in no way influence participants. No doubts are cast on the responses put forward, there is no discussion and no suggestions are made. The interviewers emphasize the importance of all ideas and ensure that all are written down. Participants are free to generate as many ideas as they like. The central NGT-question may be clarified by relating it to everyday situations that might be experienced by the participants. For example, interviewers could ask what emotional or social problems clients have recently experienced, followed 
by an enquiry into how the clients and their caregivers dealt with these problems.

Step 2: Round-robin listing of individual ideas. In this phase as many ideas as possible are collected, to be narrowed down to the most important ones in the next phase. All ideas are read aloud by the participants (or by the interviewers should a participant be illiterate) and recorded on a flip chart. When an idea listed on the chart causes group members to think of new ideas, these are also accepted and written down. Discussions or questions about the ideas are not allowed in this phase. Each idea is confirmed and validated.

Step 3: Clarification of the ideas. One of the interviewers reads out the ideas and where necessary asks for their meaning to be clarified. This phase is not about resolving differences of opinion or about being accountable for ideas. Rather, it ensures that the content of each idea is clear to all. In order to clarify the ideas to participants with ID, examples derived from daily life can be given. The clearest examples are generally those put forward by the originator of the idea.

Step 4: Ranking the ideas (voting). The interviewers combine largely similar ideas and where necessary simplify the terminology used. When dealing with the individual responses of participants with ID, it is important to remain as close to the original ideas as possible, wording them only slightly differently. Each idea is then written down on an index card. All participants are asked to select up to 7 ideas that they deem the most valid. Usually, NGT offers room for 5 ideas, but in this study a maximum of 7 ideas was allowed since it was expected from previous studies (Bostwick \& Foss, 1981; Tuffrey-Wijne et al., 2007 ) that participants would select more than 5 ideas and would perhaps find it problematic to be restricted to only 5 . Each idea then receives a score, from 7 (most important) to 1 (least important). The votes are posted in separate ballot boxes, which are also numbered from 7 to 1 . Where needed, interviewers assist in the selection process, for example by reading out the ideas and asking: 'do you want to rank this idea, yes or no'? For those able to read well all cards with ideas can be spread out on a table, so as to give an overview and enable participants to choose the 7 best ideas to be ranked. 
Interviewers

The three participating interviewers were trained in carrying out the NGT and in employing conversation techniques (see below) derived from solution focused conversations and from research projects with clients with ID. All interviewers had long track records in working with people with ID (on average twelve years), were experienced in interviewing clients with ID and had received further vocational training. None of the interviewers worked in direct professional support services, so as to guarantee independent positions.

\subsection{Procedure}

A PowerPoint presentation introduced participants to the research theme. (Table 1). 


\begin{tabular}{|c|c|c|}
\hline Slide no. & Slide title & Description \\
\hline Slide 1 & Photo: setting & Introducing (arbitrary) setting \\
\hline Slide 2 & Photo: caregiver & $\begin{array}{l}\text { Introducing (arbitrary) caregiver } \\
\text { assisting ambulant client }\end{array}$ \\
\hline Slide 3 & $\begin{array}{l}\text { Photo: help } \\
\text { situation }\end{array}$ & $\begin{array}{l}\text { Illustration of an administrative task } \\
\text { undertaken by client and caregiver }\end{array}$ \\
\hline Slide 4 & $\begin{array}{l}\text { Photo: help } \\
\text { situation }\end{array}$ & $\begin{array}{l}\text { Illustration of client and caregiver doing } \\
\text { housework }\end{array}$ \\
\hline Slide 5 & $\begin{array}{l}\text { Pictograms of } \\
\text { problem areas }\end{array}$ & $\begin{array}{l}\text { Presentation of emotional and social } \\
\text { problems people may suffer from, from } \\
\text { time to time }\end{array}$ \\
\hline Slide 6 & $\begin{array}{l}\text { Examples of } \\
\text { personal problems }\end{array}$ & $\begin{array}{l}\text { Participants (briefly) identify problems } \\
\text { shown in the previous slide or other } \\
\text { problems they suffer from, from time to } \\
\text { time }\end{array}$ \\
\hline Slide 7 & Central question & $\begin{array}{l}\text { How can you, along with a caregiver, } \\
\text { best deal with your problems? }\end{array}$ \\
\hline Slide 8 & $\begin{array}{l}\text { NGT step } 1 \\
\text { with pictogram }\end{array}$ & $\begin{array}{l}\text { Explanation of one on one conversations } \\
\text { on the central question }\end{array}$ \\
\hline Slide 9 & $\begin{array}{l}\text { NGT step } 2 \\
\text { with pictogram }\end{array}$ & $\begin{array}{l}\text { Explanation of group conversations on } \\
\text { the central question }\end{array}$ \\
\hline Slide 10 & $\begin{array}{l}\text { NGT step } 3 \\
\text { with pictogram }\end{array}$ & Explanation of idea clarification \\
\hline Slide 11 & $\begin{array}{l}\text { NGT step } 4 \\
\text { with pictogram }\end{array}$ & Explanation of voting system \\
\hline
\end{tabular}

To begin with, the interviewers stated that, from time to time, everyone suffers from emotional, social and/or communication problems, which was illustrated with the aid of pictograms. Following this, it was made clear that caregivers find it important to know how clients think these problems can best be dealt with. Next, the participants were given an explanation of the four steps of the NGT process, the structure of the research day and the manner of presenting the research data to participants and others. Following this, in accordance with NGT, participants were first interviewed individually and then as a group. The unambiguous single question posed was: 'How can you, along with a caregiver, best deal with your problems?'. To conclude, each participant was asked to choose and rank the 7 most important ideas put forward in response to this question. 
Interview techniques and attitude aspects

During their training, the interviewers had been introduced to a number of conversation techniques derived from SFBT (Macdonald, 2007), specifically those most suited to clients with ID (Schuurman et al. 2004; Roeden \& Bannink, 2007):

Asking further questions. After the participant's initial reaction to the central question the interviewer proceeds with short, open-ended questions such as: 'what do you do then?', or 'what does the caregiver do then?', 'what else?'. In this way participants are encouraged to give further information that is as concrete as possible about ways of dealing with the problems they experience. Asking open-ended questions. Open-ended questions start with how, what, where, when or who. They ensure an active attitude and stimulate reflection on the question posed. A closed-ended question is often answered with yes or no and thus tends to reveal less about the thoughts of the person.

Reacting to silences and to 'I do not know'. People with ID often need more time to react to questions than people without ID. A silence can indicate that the interviewee is collecting his thoughts, catching his breath for a moment, is confused or does not understand the question. If the participant replies: 'I do not know', this is not necessarily a sign that there will be no further response. The interviewer can make use of a number of interventions. He can wait; a silence of six to ten seconds usually draws a response. The interviewer may confirm that he has asked a difficult question and then wait for a reaction. He can ask whether the question was too difficult and elaborate upon the question, making it more comprehensible.

Adopting an attitude of 'not knowing'. The interviewer only asks questions. He does not make any suggestions and refrains from giving advice.

Exploring delayed reactions. A participant may give a reply that relates to an earlier question. In this event it is advisable for the interviewer to continue exploring this reaction through further questions. 


\subsection{Analyses}

Guided by the interviewers, the four NGT steps were followed by the three separate groups (generating individual ideas, round-robin listing of individual ideas, clarifying ideas, ranking ideas). Step four examined how often each idea was chosen and what score it was given (scale 1-7; the higher the score, the higher the priority). The scores were added up (for example: a score 7 by one participant led to a score 7; a score 3 and a score 4 given by two participants also led to a score 7). The highest scoring ideas were the most important and thus received the highest ranking. Ideas with equal scores on the basis of equal priorities received equal rankings. Equal total scores but with different frequencies and priorities were ranked on the basis of frequency (an idea with a score 7 based on a score 3 and a score 4 given by two participants was thus placed above an idea with a score 7 given by a single participant; TuffreyWijne et al., 2007). At the end of the research day the participants were asked to evaluate their experiences with the NGT.

\section{Results}

Question 1: 'What do clients with ID find important in the client-caregiver alliance?'

Each participant put forward on average 8 ideas (range: 5 to 13) in answer to this question. During step 2, identical or virtually identical ideas within a group were combined with the consent of the participants, resulting in 25 ideas in group 1 (6 participants), 33 ideas in group 2 ( 6 participants) and 30 ideas in group 3 ( 5 participants). Although all participants in group 1 were capable of generating ideas, the voting (step 4) of two participants in this group was unreliable. One participant found it increasingly difficult to concentrate as the day progressed, the other had problems ranking the ideas. The ideas of both participants were used, but the final scores in group 1 were only based on the voting of the other 4 participants. Table 2 represents the group results. 
Table 2: Top 10 ideas from each group (with total score and score frequency)

\section{Group 1 (six participants)}

1. The caregiver is reliable (keeps appointments) (16); 4 scores

2. The caregiver really listens to me and takes me seriously (14); 4 scores

2. The caregiver has a sense of humour (14); 3 scores

4. The caregiver gives me compliments (12); 2 scores

5. The caregiver gives me the opportunity to first solve a problem myself (11); 3 scores

5. The caregiver makes time for me (11); 2 scores

7. The caregiver comforts me (7); 1 score

8. Any conflict with my caregiver should be discussed and resolved as soon as possible (5); 1 score

9. I want to be able to select my caregiver myself (4); 2 scores

9. Sitting next to each other while talking (4); 1 score

\section{Group 2 (six participants)}

1. The 'chemistry' needs to be right between the caregiver and me (reliable alliance) (18); 4 scores

2. The caregiver needs to be contactable in case of emergency (13); 3 scores

2 . The caregiver really listens to me (13); 2 scores

4. The caregiver makes time for me (12); 2 scores

5. The caregiver does not come between my boyfriend and me (11); 2 scores

6 . The caregiver does not arrange anything without my knowledge (not behind my back) (8); 2 scores

7. I can select my own caregiver (7); 2 scores

7. The caregiver is future-oriented (not focused on old problems) (7); 1 score

9. The caregiver helps me find a better place to live (6); 2 scores

9. The caregiver treats me as an adult (rather than as a child) (6); 1 score

\section{Group 3 (five participants)}

1. The caregiver allows me to do things myself or solve them myself (if I am competent) (18); 4 scores

2. The caregiver listens and asks questions (12); 3 scores

3. I need a steady caregiver (not a different person each time) (11); 2 scores

4. The caregiver makes time for me (9); 3 scores 
4. The caregiver supports me emotionally (sharing concerns) (9); 2 scores

4. Should I not understand something, the caregiver clarifies it for me (9); 2 scores

7. The caregiver notices if something is bothering me $(8) ; 2$ scores

8. The caregiver is contactable by telephone in case of emergency (7); 2 scores

9. The caregiver encourages me to stand up for myself (6); 1 score

10. The caregiver provides support and encouragement at my side (5); 2 scores

Table 3 lists the combined highest scoring ideas. This also demonstrates that the attitude and approach of the caregiver (empathic, reliable and nonpatronizing) are considered important. The particular type of support seems less influential in terms of treatment success.

\section{Table 3: Highest scoring ideas (rank 1-5) in at least two groups}

1. The caregiver listens well and takes met seriously/or asks questions (three groups; rank 2, 2, 2)

2. The caregiver makes time for me (three groups; rank 4, 4 and 5)

3. The caregiver is reliable (good chemistry; reliable relationship) (two groups; rank 1,1)

4. The caregiver lets me do things myself or solve them myself (if I am competent) (two groups; rank 1,5)

Question 2: 'To what extent do the opinions of clients with ID on the clientcaregiver relationship correspond with the core assumptions in SFBT?' The participants in the research program subscribed to the viewpoint that they themselves need to solve their own problems to as great an extent as possible, with or without the support of caregivers. This corresponds with SFBT assumption 1 ('the client is considered an expert and has the competences to determine his goal and the road to achieving this') and with SFBT assumption 2. ('together with the client the professional searches for solutions'). Reliable relationships, in which caregivers adopt an interested attitude, make time and listen well, were viewed as valuable attributes by the research participants. 
This ties in well with SFBT assumption 3 ('the caregiver adopts a modest attitude, is interested in the client's opinion and is open to being informed by the client'). The key principles in SFBT thus correspond with the opinions of participants regarding a successful alliance with caregivers.

\section{Conclusions}

This research project demonstrates that the NGT is valuable in bringing to the fore the opinions and priorities of clients with ID. Two participants did not succeed in all phases of the study, due to tiredness and misunderstanding the ranking system. Nevertheless, all participants -including these two personsreacted positively to the method. They felt that sufficient time had been given for collecting ideas and for clarifying and combining them within the groups. Some were inspired by other participants, which often led to the active approval of these ideas or to new ideas. All participants appeared to be capable of giving both abstract and practical responses to relatively abstract questions. Examples of abstract responses were: 'a caregiver provides support and encouragement at my side' and 'a caregiver first lets me find a solution myself'. Examples of practical answers were: 'a caregiver is contactable in case of emergency' and 'a caregiver helps me find a place to live'. Participants related to the theme and found it a highly relevant research subject. They even seemed passionate about making their voices heard.

Most participants strongly wanted the research results to become known to the service organization and to caregivers. They indeed found it very important to make the findings available to clients with ID as well as to caregivers and researchers. Suggestions were made for the compilation of a research report in uncomplicated language, clarified with pictograms and with a spoken version for clients with visual handicaps. Some participants found it unfortunate that the voices of clients with severe and profound ID could not be heard through the NGT. In general the NGT process generated many opinions about the 'client-caregiver alliance' theme. In doing so, participants gave valuable information about their preferred way of receiving support.

However, the scope of this research program was limited. The study involved relatively few participants and it concerned a select group of clients with ID. They were clients with mild ID, who were capable of expressing their 
opinions verbally and furthermore had no severe emotional problems or multiple disabilities. These findings can thus not be extrapolated to reach conclusions significant for the entire population of clients with ID without further consideration. The NGT ranking system can threaten the method's validity, especially in smaller research groups, where even a single vote can see an idea climb to the top of the list. Conversely, some (possibly significant) items that receive insufficient votes in small groups, could fare better in larger groups and thus move up the rankings. Consequently, in this study the exact scores and final rankings are shown to make visible how these rankings were achieved. Finally, NGT can only be undertaken with clients who have abstract thinking capacities and who possess verbal competences. Unfortunately, the opinions of those with ID who lack such abilities remain unheard in NGT. Nevertheless, this project does serve as a pilot study for further research. The opinions expressed can, for example, be used as items in standardized questionnaires regarding client-caregiver relationships, which can then become part of more extended research programs. This research project could also be repeated with several research groups.

Any comparisons with research results derived from the general population require careful interpretation. Nevertheless it is valuable -with the necessary reserve- to compare the outcomes with similar research programs. The results found in this study reveal similarities to those derived from research into client-professional working relationships among children and adults in the general population. In answering question 1 of this study ('what do clients with ID find important in the client-caregiver alliance?') it was concluded that clients regard empathy and a reliable, non-patronizing attitude adopted by caregivers as contributing to successful relationships. Consumer research conducted among the general population regarding relationships with professionals (Bachelor, 1995; De Vries, 2007; Orlinsky et al., 2004) gave similar outcomes. Client-professional collaborations based on a sense of equality were highly valued; professionals whose attitudes could be characterized as understanding, respectful, genuine and empathic were also found useful. Studies investigating the opinions of children regarding social care work (Meerdink, 1996) have shown that they want social workers who 'ask but do not interrogate', 'inquire but do not push', 'who are understanding, reliable, take them seriously and value their opinions'. The results of this study 
are strongly echoed by the statements of the aforementioned 1994 Dutch congress on empowerment of people with ID: 'listen to us'; 'take us seriously'; 'give us freedom to make mistakes and solve our own problems'. The key elements of the present citizenship paradigm (as mentioned in the introduction) are inclusion, empowerment and support. The results of this study are also in line with this paradigm: clients expressed -either explicitly or implicitly- their wish to be taken seriously, stressing that they have the ability to solve their own problems, albeit on occasion with support from others.

It can be concluded from this research that clients with mild ID, without any severe additional cognitive or physical limitations, are usually capable of expressing their opinions about a relatively abstract subject matter ('clientcaregiver alliance'). As the modern citizenship paradigm advocates, caregivers and researchers are therefore obliged to inquire into those opinions. We subscribe to the conclusions of Bostwick and Foss (1981) and of Tuffrey-Wijne et al. (2007) that the NGT is valued by the research participants as an effective and sound method for exploring the views of clients with ID. Furthermore, the results indicate that the core assumptions of SFBT fundamentally correspond with the views of clients regarding their preferred way of receiving help. Finally, SFBT is in line with the current citizenship paradigm that is at the centre of intervention strategies for clients with ID. Further consideration and research into how SFBT perspectives can be incorporated into the work of caregivers is therefore recommended.

\section{References}

Anonymous, (1994). Slotverklaring 1e congres van mensen met een verstandelijke handicap. [Manifest of the first congress of people with intellectual disabilities]. www.arduin.nl.

Bachelor, A. (1995). Client's perception of the therapeutic alliance: a qualitative analysis. Journal of Counseling Psychology, 42, 323-337.

Bachelor, A. \& Horvath, A.O. (1999). The therapeutic relationship. In M. A. Hubble, B. L. Duncan, \& S. D. Miller (Eds.), The heart and soul of change: What works in therapy (pp. 133-178). Washington: American Psychological Associatio.

Bannink, F.P (2009). Oplossingsgerichte vragen. Handboek oplossingsgerichte gespreksvoering [Solution focused questions. Handbook 
solution focused interviewing]. Amsterdam: Pearson.

Bostwick, D. \& Foss, G. (1981). Obtaining consumer input; Two strategies for identifying and ranking the problems of mentally retarded adults. Education \& Training of the Mentally Retarded, 16, 207-212.

Delbecq, A.L., Van Ven, A.H. \& Gustafson, D.H. (1975). Group techniques for program planning; A guide to nominal and Delphi processes. Glenview: Scott, Foresman \& Company.

De Vries, S. (2007). Wat werkt? De kern en de kracht van het maatschappelijk werk [What works? The core and the power of social work]. Amsterdam: SWP.

Dobbie, A., Rhodes, M. Tysinger, J.W. \& Freeman, J. (2004). Using a modified nominal group technique as a curriculum evaluation tool. Family Medicine, 36, 4023-4406.

Duncan, B., Miller, S. \& Sparks, J. (2004). The heroïc client. Jossey-Bass, San Francisco.

Llewllynn, P. \& Northway, R. (2008). The views and experiences of people with intellectual disabilities concerning advocacy. Journal of Intellectual Disabilities, 12, 213-228.

Lloyd-Jones, G., Fowell, S. \& Bligh, J.G. (1999). The use of the nominal group technique as an evaluative tool in medical undergraduate education. Medical Education, 33, 8-13.

Macdonald, A.J. (2007). Solution-focused therapy; Theory, research \& practice. London: Sage.

Meerdink, J. (1996). 'Ik wist helemaal niet dat die koffers van mij waren'; De mening van kinderen over hulpverlening. ['I did not even know that those suitcases were mine'; The opinion of children about social work]. Jeugd en Samenleving [Youth and Society], 25, 87-95.

Orlinsky, D.E., Grawe, K. \& Parks, B.K. (1994). Process and outcome in psychotherapy: Noch einmal. In A.E. Bergin \& S.L. Garfield (Eds.), Handbook of psychotherapy and behaviour change (pp. 270-376). New York: John Wiley \& Sons.

Orlinsky, D.E., Ronnestad, M.H. \& Willutzki, U. (2004). Fifty years of psychotherapy outcome research; Continuity and change. In A. E. Bergin \& S.L. Garfield (Eds.), Handbook of psychotherapy and behaviour change (pp. 307-389). New York: John Wiley \& Sons. 
Roeden, J.M. \& Bannink, F.P. (2007). Handboek oplossingsgericht werken met licht verstandelijk beperkte cliënten [Handbook solution focused interventions with clients with mild intellectual disabilities]. Amsterdam: Pearson.

Roeden, J.M., Bannink, F.P., Maaskant, M.A. \& Curfs, L.M.G. (2009). Solution focused brief therapy with clients with intellectual disabilities. Journal of Policy and Practice in Intellectual Disabilities, 6, 253-59.

Roelink, H.M. Pool, A., Grypdonck, M.H. (2002). De dialoog in de zorgrelatie [The dialogue in the caregiving relationship]. Nederlands Tijdschrift voor de Zorg aan verstandelijk gehandicapten [Dutch journal for the care for people with intellectual disabilities], 28, 170-186.

Schuurman, M., Speet, M. \& Kersten, M. (2004). Onderzoek met mensen met een verstandelijke beperking [Research with people with intellectual disabilities]. Utrecht: LKNG.

Selekman, M.D. (1993). Pathways to change; Brief therapy solutions with difficult adolescents. New York: Guilford.

Stoddart, K.P., McDonnel, J. Temple, V. \& Mustata, A. (2001). Is brief better? A modified brief solution-focused therapy approach for adults with a developmental delay. Journal of Systematic Therapies, 20, 24-40.

Tuffrey-Wijne, I., Bernal, J., Butler, G., Hollins, S. \& Curfs L.M.G. (2007). Using Nominal Group Technique to investigate the views of people with intellectual disabilities on end-of-life care provision. Journal of Advanced Nursing, 58, 80-89.

Van Gennep, A.T.G. (2009). Verstandelijke beperkingen als social probleem. [Intellectual disabilities as social problem]. Nederlands Tijdschrift voor de Zorg aan verstandelijk gehandicapten [Dutch Journal for the care for people with intellectual disabilities], 35, 101-124. 



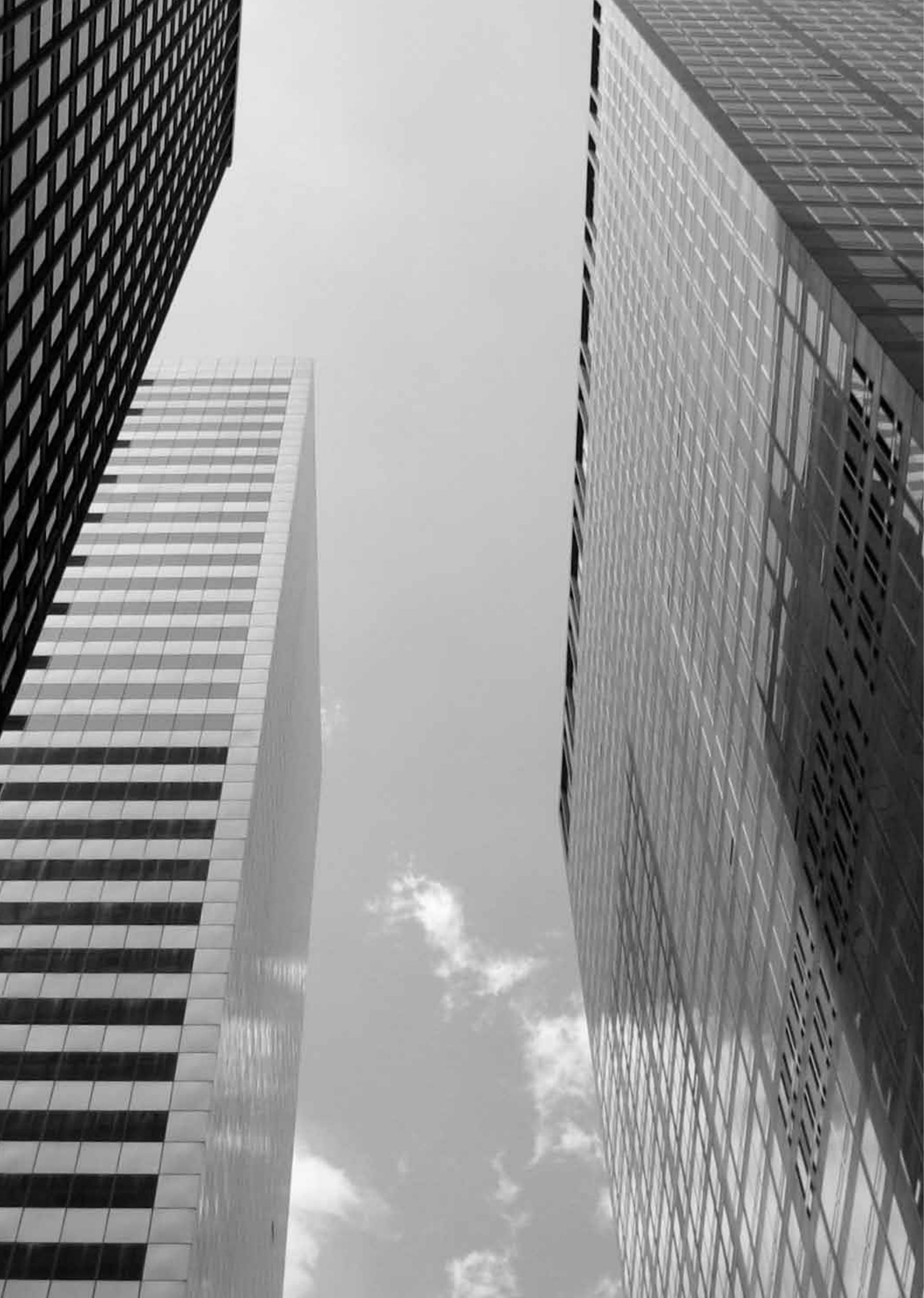




\section{CHAPTER 4}

\section{SOLUTION-FOCUSED BRIEF THERAPY \\ WITH PEOPLE WITH MILD INTELLECTUAL DISABILITIES; A CASE SERIES}

Roeden, J.M., Bannink, F.P., Maaskant, M.A. \& Curfs, L.M.G. (2011).

Solution Focused Therapy (SFT) with People with Mild Intellectual

Disabilities (ID); a Case Series.

Journal of Policy and Practice in Intellectual Disabilities, 8, 4, 247-255. 


\begin{abstract}
Background. Solution-Focused Brief Therapy (SFBT) is a form of behaviour therapy that focuses on evoking desired behaviour rather than on the existing problem behaviour.

Method.To illustrate the use of this form of therapy, the authors undertook of study of 10 case studies of applications of SFBT with people with a mild intellectual disability (MID). For all 10 cases, before SFBT, after SFBT, and during a follow-up after six weeks, the following measurements were taken: assessment of quality of life and assessment of maladaptive behaviour, as well as goal attainment according to people with MID and according to caregivers. Results. It was found that SFBT treatments contributed to improvements in psychological functioning and decreases in maladaptive behaviour. In addition achievement of goal attainments were noted according to both people with MID and their caregivers. The positive changes evident after SFBT proved sustainable during follow-up. Treatment strategies and therapeutic alliances employed were usually assessed as positive by the participants.

Conclusions. Although the study had limitations due to the lack of a control group and the small number of cases, that several case studies showed positive treatments results did indicate the effectiveness of SFBT for people with MID.
\end{abstract}

\title{
Key words
}

Behaviour therapy, Challenging behaviour, Intellectual disabilities, Solution-Focused Brief Therapy 


\section{Introduction}

Psychological problems frequently occur in people with an intellectual disability (ID). Compared to other people, adults with ID are reported to experience many more behaviour problems or psychiatric disorders (Cooper, Smiley, Morrisin, Williamson \& Allan, 2007; Crews, Bonaventura \& Rowe, 1994; Didden, Collin \& Curfs, 2009; Menolascino, Levitas \& Greiner, 1986). Various therapies have been developed to positively influence behaviour, such as environmental adaptations, behaviour therapies, and family therapy (Beail, 2001; Beail, Kellett, Newman \& Warden, 2007; Beail, Warden, Morsley \& Newman 2005; Newman \& Beail, 2002). Solution-focused brief therapy (SFBT; De Shazer, 1985) is a behaviourally orientated treatment that has gained popularity over the past twenty-five years. SFBT represents a short term, goal focused and client-directed therapeutic approach that helps the client focus on solutions rather than problems.

The aim of this study was to illustrate the efficacy of applications, processes, and effectiveness of SFBT in people with mild ID (MID). To proceed, we first explain the assumptions and processes of SFBT and its use for people with ID. Thereafter, we consider the processes and applications of SFBT with people with MID and then describe the results and conclusions.

\section{SFBT: Assumptions and Processes}

One of the central assumptions of SFBT is that the goal of the therapy is defined by the client and that the client has the competencies and resources to realize this goal. During this process, the client is invited to describe what will be different in the future once his or her goal has been reached and to explore exceptions to the problems (times when problem behaviour does not occur). The therapist stimulates the client to describe progression towards the therapy goal in specific, small, behavioural steps. The therapist also suggests tasks such as 'continue with what is working already' in order to stimulate or maintain changes. At the start, variations in the relationship with the client (that is, whether it is visitor, complainant, or customer-relationship) are assessed and identified. In a visitor-relationship the client is referred to the therapist by others. In this relationship the client does not voluntarily seek help and is not experiencing emotional difficulties. In a complainant- 
relationship the client does have a problem and experiences emotional difficulties, but he or she does not (yet) see him or herself as part of the problem and/or the solution. In a customer-relationship the client does see him or herself as part of the problem and/or solution and is motivated to change his or her behaviour. Each type of relationship requires different approaches by the solution-focused therapist towards the client. For example, in the visitorrelationship the therapist may ask what the client thinks the person referring would like to see changed in his or her behaviour and to what extent the client is prepared to cooperate. In the complainant-relationship, the therapist acknowledges the client's difficulties and gives suggestions for observing the moments when the problem is or was there to a lesser extent. In the customer-relationship the client may be given a behaviour assignment (e.g., 'continue with what is working already').

\section{SFBT: Use with people with ID}

SFBT has a number of advantages that makes it attractive for use with people with ID. These include: focus on empowerment and on skills rather than on deficits, unique interventions for each person based upon particular skills and needs, and recognition of the expert status of the individual resulting in a sense of self efficacy within the therapeutic relationship (Roeden, Maaskant \& Curfs, 2011). SFBT regards the client as expert, and thus is in line with the present view on ID that focuses on empowerment and competencies of people with ID (Gallant, Beaulieu \& Carnevalle, 2002; Martin, 2006). Several authors have suggested adjustments to SFBT as it was originally described by de Shazer (1985) for people with ID, due to their specific needs, developmental, emotional and cognitive levels and abilities (Corcoran, 2002; Lentham, 2002; Murphy \& Davis, 2005; Smith 2005, 2006; Roeden \& Bannink, 2007a, 2007b, Roeden, Bannink, Maaskant \& Curfs, 2009; Stoddart, McDonnel, Temple \& Mustata, 2001, Teall, 2000; Westra \& Bannink, 2006a, 2006b).

These recommendations include the use of simple language, flexibility in questioning, and allowing the person with ID enough time to answer questions, develop ideas, and reflect on what is transpiring during sessions. Also it is advantageous to use visual aids such as emoticons and drawings, to involve caregivers and family, to encourage and explain tasks, and to adapt task assignments (such as the use of prompts and written or visual aids). In 
applications to the general population SFBT has been the subject of an increasing number of outcome studies (cf. Bannink, 2010, Macdonald, 2007). Stams, Devocik, Buist \& De Vries (2006) conducted a meta-analysis of SFBT in which they compared 21 studies and noted a modest positive effect of SFBT in a short time (an average of 6 SFBT sessions). However, research literature on the use of SFBT with people with ID is scarce, but that which is available has been shown to have some promising positive treatment effects. Stoddart, McDonnel, Temple \& Mustata (2001), for example, reviewed 16 people with mild to borderline ID receiving SFBT. Clinicians rated the degree to which the outcomes as ascertained from client records were successful on a 5-point Likert-style scale ( 1 = unsuccessful to $5=$ very successful). Using this method, problems relating to poor self-esteem, family relationships, and bereavement were most successfully treated with SFBT (success ratings 3.7 to 5.0), whereas depression and anxiety, couple conflict, and independence issues showed the least improvement (success rating 2.0 to 3.3 ).

Because more information was needed as to the usefulness of applications of SFBT with adults with MID, we conducted an exploratory study of SFBT-procedures with ten people who had experienced adjustment difficulties. We expected that SFBT could assist them in improving their quality of life, in reducing maladaptive behaviours, and in attaining their treatment goals. In addition, we expected that participants in this study would appreciate the SFBT experience. As part of our study, we first described the treatment protocol. Second, we collected data by measuring differences before SFBT, directly after SFBT, and six weeks after SFBT, with regard to three variables or outcomes. These were quality of life, maladaptive behaviour, and goalattainment perceptions according to both the adults with MID and staff. Third, to get at the experiential variables, we collected opinions about the SFBT procedure and the collaborations from out 10 subjects.

\section{Method}

The study was conducted at the program sites of a service provider for children and adults with ID (serving approximately 900 people) in the Netherlands. People enrolled with this provider use various residential services, such as day- 
care, and home-care. This service provider employs, among others, qualified psychological therapists, and one of the services offered is SFBT.

\subsection{Participants and Procedure}

Participants. Ten of the provider's clients were nominated to participate in the study as they all had some 'issue' that warranted change and it was thought that SFBT would be the means to make those changes. The ten participants (labelled $\mathrm{C} 1-\mathrm{C} 10$ in the tables) lived semi-independently and received individual support (ranging from 2 to 14 hours per week) from caregivers employed by the service provider mentioned above. The support they received included help with housekeeping tasks (such as cleaning and cooking), with financial tasks (such as banking), and with social-emotional tasks (such as dealing with other people and conflict management). All participants ( 3 men and 7 women with a mean age of 39 years) in the study had MID determined on the basis of IQ (tested by means of the WISC-III-NL, Wechsler, 2005a or the WAIS-III-NL, Wechsler, 2005b) and adaptive functioning (tested by means of the SRZ-plus - a Dutch adaptive behaviour scale - Kraijer \& Kema, 1994). None of the participants had acute psychiatric conditions. All participants had been referred for SFBT by staff.

All of the participants agreed to participate in the study and provided permission for anonymous publication of the study data. Permission for the research study was given by the Client Council (made up of clients with ID) and by the organization's Client Representative Council (family members or other representatives of people with ID). Both Councils acknowledged that the research proposal corresponded to guidelines for carrying out research projects involving people with ID in the Netherlands.

Procedure. The study was composed of 10 SFBT applications with five sessions each; the sessions and treatment protocol are described in Table 1. The average duration of the five SFBT sessions was 12 weeks. Every SFBT session was attended by at least three people: the person with MID, the staff caregiver, and the therapist. In our application of SFBT we decided that every person with MID would be accompanied by a caregiver; this was because it appeared from the treatment practice of SFBT that the interventions are better 
understood and executed when caregivers perform a supportive role in the treatment procedure (Roeden \& Bannink, 2007a; Stoddart, McDonnel, Temple \& Mustata, 2001; Teall, 2000). The following problems were reported by the 10 participants and staff: alcohol abuse ( 3 adults), anger ( 2 adults), bereavement (1 adult), depression/apathy ( 1 adult), sleeplessness ( 1 adult), low self-esteem (1 adult), and avoidance/anxiety (1 adult). In each application, three data measurements were taken: the first immediately before SFBT, the second immediately after SFBT and the third during a follow-up measurement six weeks after SFBT. The measures provided objective information about the treatment effects derived from standardized measuring instruments and assessment information on the clients' and caregivers' opinions about treatment effects and treatment processes. To be able to determine whether differences existed at individual level between the before, after, and follow-up measurements, the criteria for statistically significant and/or clinically relevant differences for each measure were determined a priori.

Statistical analysis. Because of the relatively small sample size (10 clients), a non-parametric test (Wilcoxon Signed-Rank Test) was used to analyze the data, rather than a parametric test. The Wilcoxon Signed-Rank Test, a nonparametric statistical hypothesis test for repeated measurements, was performed on four variables (quality of life, psychological functioning, social functioning (using the IDQOL-16, see Measures) and goal attainment (using the SQP, see Measures). In order to control the problem of multiple comparisons, the Dunn-Bonferroni correction (Dunn, 1961) was used by dividing the $p$-value by the number of variables: $\mathrm{a} / n=0.05 / 4=0.0125$ (round $0.01)$. 
Table 1: SFBT protocol with sessions, interventions and descriptions

\begin{tabular}{|c|c|c|}
\hline Session & Intervention & Description \\
\hline \multirow[t]{2}{*}{ Intake } & Getting acquainted & $\begin{array}{l}\text { The therapist spends time to get to know the client. } \\
\text { Competencies and resources are being explored. }\end{array}$ \\
\hline & Exploring the problem & $\begin{array}{l}\text { The therapist invites the client to describe his or her } \\
\text { problem and/or to mention his or her goal for the } \\
\text { treatment. }\end{array}$ \\
\hline \multirow[t]{7}{*}{$\begin{array}{l}\text { First } \\
\text { Session }\end{array}$} & Pre-session change & $\begin{array}{l}\text { Since most clients have tried other possibilities before } \\
\text { connecting with a therapist, the therapist can ask } \\
\text { whether what changes have already occurred before } \\
\text { the first session. }\end{array}$ \\
\hline & Goal setting & $\begin{array}{l}\text { The client is invited to describe what would be } \\
\text { different once his/her goal is reached. This could be } \\
\text { done by means of the 'miracle question' ('Imagine a } \\
\text { miracle occurring tonight that would [sufficiently] } \\
\text { solve the problem ... what would be different } \\
\text { tomorrow?'). The therapist may also suggest that } \\
\text { changes are possible (e.g., 'when you look forward } \\
\text { and things have improved, what will you be doing } \\
\text { differently?'). }\end{array}$ \\
\hline & Exploring the exceptions & $\begin{array}{l}\text { The therapist inquires about moments in the past or } \\
\text { present when the problem did not or does not occur } \\
\text { or is less serious and who does what to bring about } \\
\text { these exceptions. }\end{array}$ \\
\hline & Scaling questions & $\begin{array}{l}\text { On a scale of } 10 \text { to } 1 \text { the client indicates his or her } \\
\text { progression towards the goal. Scaling questions help } \\
\text { the client to move away from all-or-nothing goals } \\
\text { toward manageable and measurable steps. }\end{array}$ \\
\hline & Competence questions & $\begin{array}{l}\text { By using competence questions, self compliments are } \\
\text { being provoked with the client. 'How do (did) you do } \\
\text { that?' Direct compliments are aimed at something the } \\
\text { client has done, made or said. }\end{array}$ \\
\hline & The question: 'what else?' & $\begin{array}{l}\text { The therapist may also indicate with the question } \\
\text { 'what else?' that there is more to come. Clients often } \\
\text { respond to this simple query by giving more } \\
\text { information and ideas. }\end{array}$ \\
\hline & Feedback & $\begin{array}{l}\text { At the end of every session feedback with } \\
\text { compliments and usually some homework are given. } \\
\text { The compliments emphasize what the client is already } \\
\text { doing to reach his or her goal. The suggestions } \\
\text { indicate areas requiring the client's attention or } \\
\text { possible further actions to reach his or her goal. } \\
\text { Between the components compliments and } \\
\text { suggestions / tasks a reason (or bridge) is given to } \\
\text { perform those tasks. }\end{array}$ \\
\hline \multirow{3}{*}{$\begin{array}{l}\text { Follow- } \\
\text { up } \\
\text { sessions }\end{array}$} & $\begin{array}{l}\text { The question: } \\
\text { 'What is better?' }\end{array}$ & The standard beginning question is: 'What is better?' \\
\hline & $\begin{array}{l}\text { EARS = Eliciting, } \\
\text { Amplifying, Reinforcing, } \\
\text { Start again }\end{array}$ & $\begin{array}{l}\text { Eliciting, amplifying, and reinforcing of (small) } \\
\text { successes, exceptions to problems, or descriptions of } \\
\text { the desired future and the invitation to the client to } \\
\text { do that again or more often. }\end{array}$ \\
\hline & Feedback & Compliments - bridge - tasks \\
\hline
\end{tabular}


Treatment protocol. The treatment protocol consisted of seven meetings: an intake, five solution-focused sessions, and a follow-up. Every treatment followed the protocol, as summarised in Table 1. During the intake the strengths as well as the problems of the person with MID were assessed. At intake the therapist asked about work, study, hobbies, interests, skills, talents, and significant people in the life of the adult. This information was used in the treatment sessions. The therapist did not ask questions about the details of the problem (because SFBT does not primarily focus on analyzing problems). In the first session, the therapist asked solution-focused questions, as well as queries about the goals of the person with MID, questions about exceptions to problem behaviour, and questions about scaling and competence. Every first (and subsequent) session was ended by giving feedback to the person with MID and to staff.

In the second and subsequent sessions, the therapist started with the 'EARS-question' set. EARS is an acronym for Eliciting, Amplifying, Reinforcing, and Start again, and outlines the therapeutic process. The first question was: 'What is better?'. The individual could respond to that question in four different ways: 'It is better', 'There is no change', 'It is worse', or 'There is a difference in opinion' (in this case between the opinions of the person with MID and the staff caregiver). If the situation was better, the therapist could react to that by amplifying, 'What exactly is (somewhat) better?' by reinforcing, 'How did you manage to do that?', and by starting again, 'What (else) is better?'. - EARS could also be used if the person thought there was no change. The therapist then acknowledged the client's possible disappointment and stressed the point that keeping things stable was also a good accomplishment. Then the therapist requested the individual to explain how he or she did that. If the situation was worsening and the person with MID was disappointed, the therapist also acknowledged this. A reorientation to the goal might be necessary or the therapist could ask the person how he or she managed to keep going under difficult circumstances. That offered a possible re-entry to the EARS set of questions. If there were differences in opinions between the person with MID and the caregiver about the amount of progress, the therapist firstly normalized this situation by suggesting that progress usually happens in steps, and by trial and error. Subsequently, small improvements could be explored 
through EARS. An illustration of a solution-focused consultation is presented in an elaboration of a case description in Table 2. 
Table 2: An example case description of the use of SFBT

\begin{tabular}{l|l}
$\begin{array}{l}\text { SFBT treatment protocol } \\
\text { Intervention }\end{array}$ & $\begin{array}{l}\text { Session particulars } \\
\text { Description }\end{array}$ \\
\hline
\end{tabular}

Getting acquainted

Mr. E. (a 44-year-old man) mentioned that his interests were listening to music and making music (karaoke), gardening, and doing odd jobs. Mr. E. liked to visit people. The caregiver added that Mr. E. didn't mind change, that Mr. E. was precise, helpful and social and that Mr. E. had overcome difficult problems in the past. In SFBT terminology, the therapist and Mr. E. had a client-typical relationship.

\begin{tabular}{l|l} 
Exploring the problem & The problem with Mr. E. was lack of confidence, which was revealed by
\end{tabular} frequently asking for confirmation, pondering about his own functioning, and a tendency towards perfectionism.

Even though incidental excessive alcohol use resulted in temporary relaxation, it also caused a distressing long-term feeling of guilt afterwards.

\section{Pre-session change}

Goal setting

Exploring the exceptions
Mr. E. had already informed a number of bar owners and a family member that he wanted to drink alcohol responsibly.

The therapist asked: 'Suppose we make a video that shows you are doing well... what kinds of things would we see and hear on that video?' Mr. E. said: 'Then I would have self-confidence', and 'Then my head is not so full of 'red' [worrisome] thoughts'. In exchange for the problem, Mr. E. wanted to have 'green' [light] thoughts' and drink alcohol free beer more often instead of beer with alcohol. Green and red were the words that Mr. E. came up with himself to describe his thoughts.

Mr. E. said, 'When I am occupied then I feel better'. Mr. E. suggested that caregivers could assist him in planning a difficult day off. This meant that a well-filled day program during days off or on weekends would keep him from drinking too much alcohol.

Scaling question

The therapist asked, 'Suppose 10 means you have self-confidence and 1 means you don't have self-confidence, what mark do you give yourself at this moment?' Mr. E. indicated he was at a 4 . After asking what that 4 included and what could be done to reach a 5, Mr. E. and his caregiver came up with many ideas while answering these scaling questions: They could practice with chit chat (green thoughts), difficult days could be prepared together, Mr. E. could spend his free time volunteering at the local petting zoo, Mr. E. could tell bar owners that he wanted to drink less alcohol and preferred to drink alcohol free beer instead, and Mr. E. could practice in steps ordering alcohol free beer at a bar. Moreover, they could install a token system for alcoholic beer drinking on the weekend (one token = one beer, a maximum of three beers per evening).

Planning this way, successes could be rewarded with short outings (go somewhere to have coffee). In case of continued success, Mr. E. wanted to reward himself with the purchase of karaoke equipment.

Feedback

Mr. E. viewed himself as part of the problem and the solution (a clienttypical relationship). The therapist gave Mr. E. compliments about his resourcefulness (many ideas for improvement) and formulated a reason/bridge ('you have already started to deal with your problem'). The therapist suggested a task, building on the ideas from Mr. E. and his caregiver. The behavioural task was: 'continue with the things that work already' (for example, creating and using a token system).

Follow-up session(s)
Mr. E. and his caregiver produced a detailed report about Mr. E.'s increasing control over his alcohol use, and Mr. E.'s success in finding leisure activities. The report also noted Mr. E.'s increase in green thoughts, and the intention to celebrate the successes with a karaoke party. 


\subsection{Measures}

Quality of Life. The Intellectual Disability Quality of Life (IDQOL-16; Hoekman, Douma, Kersten, Schuurman \& Koopman, 2001) was used to measure the quality of life of the person being examined. The IDQOL-16 has three subscales: psychological functioning, social functioning and satisfaction about housing. The IDQOL-16 has proved to have a good internal consistency (Cronbrach's a of the various subscales between 0.73 and 0.80 ). Every question had 5 response categories ranging from very pleasant to very unpleasant, made clear by a pictogram (smiley). Raw scores of the subscales were transformed into quartile scores (rating of 1 to 4 ; higher quartiles are indicative of higher satisfaction). For the total scores (1 to 10), high deciles were indicative of higher satisfaction). In this study, an improvement was defined as an increase of one quartile (=25\% improvement) in the subscales of psychological and social functioning, and an increase of 2 deciles ( $=20 \%$ improvement) of the total score (= quality of life). The subscale of satisfaction about housing was not included in the treatment results because housing satisfaction is not a primary goal of SFBT.

Maladaptive behaviour. The Reiss Screen for Maladaptive Behaviour (RSMB; Reiss, Minnen \& Hoogduin, 1994) was used to measure maladaptive behaviour. The RSMB measures the presence of psychological problems. The RSMB was completed by a caregiver who had knowledge of the person being evaluated. The list of questions comprised nine subdivisions: aggression, autism, psychosis, depression (behaviour symptoms), depression (vital symptoms), paranoia, dependent personality disorder, avoidant disorder, and 'other maladaptive behaviour'. The internal consistency of the nine subdivisions ranged from reasonable to good (Cronbach's a: between 0.69 and 0.87). The stability was only calculated for the total score and was good (Pearson's $r$ : 0.81). The inter-rater reliability for the subdivisions ranged from reasonable to good (Pearson's $r$ : between 0.50 and 0.84). For each item the caregiver evaluated behaviour items as to whether it was no problem ( 0 points), to be a problem (1 point), or to be a big problem ( 2 points) for each person. For each subdivision, the RSMB gave cut-off scores, indicative of the presence of psychopathology in people with MID. In this study, improvement of 
maladaptive behaviour was defined as a change in one or more scores in a subdivision from above the cut-off score to below the cut-off score.

Goal attainment according to people with MID. The Scaling Question Progression (SQP) uses a scale of 10 (goal reached) to 1 (goal not reached) on which the individual indicates to what extent he or she has approached or has reached the therapeutic treatment goal (Bannink, 2010). In a study by Fischer (2009) the scale question was used with 3,920 clients to measure emotional coping and daily functioning before and after SFBT. Differences between before and after SFBT varied between +0.9 and +2.1 points for daily functioning and between +0.6 and +1.4 point for emotional coping. In this study, a progression of +2 points (being relatively high) was regarded as clinically relevant.

Goal attainment according to caregivers. Goal Attainment Scaling (GAS; Kiresuk \& Sherman, 1968; Kiresuk, Smith \& Cardillo, 1994; Schlosser, 2004) is a technique used to evaluate an individual's progression towards a goal. For each goal, a 5-point scale ranging from -2 to +2 was established. No differences in goal attainment were scored as 0 . A positive change towards the goal was scored as +1 and a negative change was scored at -1 . Reaching the goal was scored as +2 and a severe regression from the start situation by -2 . In addition, an indicator was chosen. The indicators were measures of the effect of the intervention in the direction of the goal (e.g., 'number of glasses beer per day'). To obtain a GAS, all scores were added and transformed into a standardized GAS-index ${ }^{1}$, described by Kiresuk and Sherman (1968). Improvement, in the present study, was defined as an increase of 10 points (or on this GAS-index. The GAS was completed by caregivers during the therapy sessions.

\footnotetext{
${ }^{1}$ Note. GAS-score: $\mathrm{I}=$ index $=10 \Sigma \mathrm{W} \mathrm{i} \mathrm{Xi} / \sqrt{ }[(1-\mathrm{P}) \Sigma \mathrm{Wi} 2+\mathrm{P}(\Sigma \mathrm{Wi}) 2]$, in which $\mathrm{Xi}=$ the score of the $i$-th scale, $\mathrm{Wi}=$ the weight assigned to the $\mathrm{i}$-th scale, and $\mathrm{P}$ the weighted mean intercorrelation between scales, estimated to be .30. If all goals are considered to be of equal weight, then $\mathrm{Wi}=1$ and the indices can be read from a table compiled by Kiresuk, Smith \& Cardillo (1994). The calculation procedure is such that with a large number of indices the average will be 50 with a standard deviation of 10 . Increases on subscales of +2 ( 2 goals) or + 3 ( 3 goals) are in accordance with an increase of the GAS index larger than the standard deviation $(>10)$.
} 
Treatment strategy and therapeutic alliance. Miller, Duncan and Huble (1997) developed the Session Rating Scale (SRS). A version of the SRS for children was adapted for use with people with ID by Westra (2008). In this adaptation words that could be regarded as childish by adults with ID were replaced. The adapted items were: a) 'the person did not' -versus- 'did listen to me' b) 'the subjects we talked about were not' -versus- 'were important to me', (c) 'the way we worked was not good' - versus- 'was good for me', (d) 'something was missing in the treatment today' -versus- 'I enjoyed the treatment today'. At the end of each meeting, the person with MID provided the therapist with feedback on four areas: a) the relationship, b) goals and subjects, c) strategy or method and d) the session. The person was asked to evaluate the consultation using a 10 -centimetre-long line (the scale) representing each one of the four SRS dimensions. The left hand end of the scale was represented by a sad face 'smiley' and the right hand end of the scale was represented by a happy face 'smiley'. The smileys were used to enable the adult to express satisfaction. The closest centimeter mark, indicated with a cross, to the right or the left determined the score. The SRS (version for adults) was investigated by Duncan, Miller and Sparks (2004) and had good internal consistency (Cronbrach's a : 0.88) and reasonable stability (Pearson's r: 0.64). A statistically significant correlation (Pearson's $r$ : $0.48 ; p<0.01$ ) was found between the SRS and an extensive list of questions with the same measuring pretension (therapeutic alliance). The authors of the SRS recommend asking the client to comment on an aspect of the treatment strategy or the therapeutic alliance, whenever a subscale score is below 9.

\section{Results}

Quality of life, Maladaptive Behaviour and Goal Attainment This study focused on the differences before SFBT, directly after SFBT, and six weeks after SFBT, with regard to (1) quality of life, (2) maladaptive behaviour, (3) goal attainment according to people with MID and (4) goal attainment according to caregivers.

Quality of life. In seven of the ten adults statistically significant improvements were evident directly after SFBT using the IDQOL subscale of psychological 
functioning. In two of ten adults, the same was true for social functioning, and in four of ten adults this was true for quality of life composite score. During follow-up, the differences of psychological functioning and quality of life were sustained in six and four adults, respectively. For social functioning, two adults prolonged or improved positive changes, and two other adults showed improvements only at follow-up. These subsequent improvements of social functioning in the period after SFBT, and before follow-up, might be because some of the steps (towards the goals) required more time than the limited time allotment for the therapy. An example of this is one woman who organized a successful reunion with her sister three weeks after SFBT and three weeks before follow-up, resulting in a higher social functioning score. The differences in scores of all 10 adults were statistically significant (Wilcoxon Signed-Rank test) for the measures of quality of life and psychological functioning (quality of life: session 1 vs. session $5 ; z=-2.7, p<$ 0.01 ; session 1 vs. follow-up: $z=-2.5 ; p<0.01 /$ psychological functioning: session 1 vs. session $5 ; z=-2.7, p<0.01$; session 1 vs. follow-up: $z=-2.4$, $p<0.01)$. No statistically significant changes were seen between social functioning scores.

Maladaptive behaviour. In eight of the ten adults, staff assessed that there were clinically relevant decreases of psychological problems directly after SFBT and during follow-up by means of RSMB-scores. For two of the ten people, this concerned decreases in psychological problems in one domain from the first to the fifth session, respectively, and the follow-up session (from 1 to 0 to 0 scores). For six of the ten adults, there were decreases in several domains (from 6 to 3 to 1 domain; from 2 to 0 to 0 domains; from 7 to 4 to 5 domains; from 5 to 3 to 3 domains; from 7 to 5 to 3 domains and from 7 to 3 to 2 domains). In two adults, caregivers assessed no decreases in psychological problems from the first to the fifth session, respectively, and the follow-up session (from 1 to 1 to 1 domain). Table 3 lists the outcomes of the IDQOL-16 and the RSMB before SFBT, after SFBT, and six weeks after SFBT (follow-up). 


\begin{tabular}{|c|c|c|c|c|c|c|c|c|c|c|c|}
\hline \multirow{2}{*}{$\begin{array}{l}\text { SFBT } \\
\text { Session }\end{array}$} & Cases & C1 & $\mathbf{C 2}$ & C3 & C4 & C5 & C6 & C7 & C8 & C9 & C10 \\
\hline & \multicolumn{11}{|c|}{ IDQOL-subscale: psychological functioning } \\
\hline $\begin{array}{l}1^{\text {st }} \\
\text { session }\end{array}$ & $\begin{array}{l}\text { Raw } \\
\text { Score }\end{array}$ & 1 & 3 & 1 & 1 & 1 & 1 & 1 & 1 & 1 & 2 \\
\hline $\begin{array}{l}5^{\text {th }} \\
\text { session }\end{array}$ & $\begin{array}{l}\text { Raw } \\
\text { score }\end{array}$ & $2^{a}$ & 3 & $3^{\mathrm{a}}$ & $2^{\mathrm{a}}$ & $2^{a}$ & $2^{a}$ & 1 & 1 & $2^{a}$ & $3^{a}$ \\
\hline \multirow[t]{2}{*}{$\begin{array}{l}\text { Follow- } \\
\text { up }\end{array}$} & $\begin{array}{l}\text { Raw } \\
\text { score }\end{array}$ & 1 & 3 & $3^{b}$ & $2^{b}$ & $3^{b}$ & $3^{b}$ & 1 & 1 & $2^{b}$ & $3^{b}$ \\
\hline & \multicolumn{11}{|c|}{ IDQOL-subscale: social functioning } \\
\hline $\begin{array}{l}1^{\text {st }} \\
\text { session }\end{array}$ & $\begin{array}{l}\text { Raw } \\
\text { score }\end{array}$ & 1 & 1 & 3 & 1 & 1 & 1 & 1 & 1 & 1 & 1 \\
\hline $\begin{array}{l}5^{\text {th }} \\
\text { session }\end{array}$ & $\begin{array}{l}\text { Raw } \\
\text { score }\end{array}$ & $2^{a}$ & 1 & 3 & 1 & $2^{a}$ & 1 & 1 & 1 & 1 & 1 \\
\hline \multirow[t]{2}{*}{$\begin{array}{l}\text { Follow- } \\
\text { up }\end{array}$} & $\begin{array}{l}\text { Raw } \\
\text { score }\end{array}$ & $2^{b}$ & 1 & 3 & 1 & $3^{b}$ & $2^{b}$ & $2^{b}$ & 1 & 1 & 1 \\
\hline & \multicolumn{11}{|c|}{ IDQOL-subscale: quality of life } \\
\hline $\begin{array}{l}1^{\text {st }} \\
\text { session }\end{array}$ & $\begin{array}{l}\text { Raw } \\
\text { score }\end{array}$ & 2 & 3 & 4 & 2 & 2 & 1 & 1 & 1 & 1 & 2 \\
\hline $\begin{array}{l}5^{\text {th }} \\
\text { session }\end{array}$ & $\begin{array}{l}\text { Raw } \\
\text { score }\end{array}$ & $5^{a}$ & 3 & 5 & 3 & $6^{a}$ & $4^{a}$ & 1 & 2 & $3^{a}$ & 3 \\
\hline \multirow[t]{2}{*}{$\begin{array}{l}\text { Follow- } \\
\text { up }\end{array}$} & $\begin{array}{l}\text { Raw } \\
\text { score }\end{array}$ & $4^{b}$ & 3 & 5 & 3 & $6^{\mathrm{b}}$ & $6^{\mathrm{b}}$ & 2 & 2 & $4^{b}$ & 3 \\
\hline & \multicolumn{11}{|c|}{ Reiss Screen for Maladaptive Behaviour } \\
\hline $\begin{array}{l}1^{\text {st }} \\
\text { session }\end{array}$ & $\begin{array}{l}\text { Do- } \\
\text { mains }\end{array}$ & 6 & 1 & 1 & 2 & 7 & 1 & 5 & 7 & 7 & 1 \\
\hline $\begin{array}{l}5^{\text {th }} \\
\text { session }\end{array}$ & $\begin{array}{l}\text { Do- } \\
\text { mains }\end{array}$ & $3^{c}$ & $0^{c}$ & $0^{c}$ & $0^{c}$ & $4^{c}$ & 1 & $3^{c}$ & $5^{c}$ & $3^{c}$ & 1 \\
\hline $\begin{array}{l}\text { Follow- } \\
\text { up }\end{array}$ & $\begin{array}{l}\text { Do- } \\
\text { mains }\end{array}$ & $1^{\mathrm{d}}$ & $0^{d}$ & $0^{d}$ & $0^{d}$ & $5^{d}$ & 1 & $3^{d}$ & $3^{d}$ & $2^{d}$ & 1 \\
\hline
\end{tabular}

${ }^{a}$ Positive difference: the differences were statistically significant: increase of $\geq 1$ point $(=1$ quartile or $25 \%$ improvement) in the subscales psychological and social functioning and an increase of $\geq 2$ points ( $=2$ deciles or $20 \%$ improvement) in the subscale quality of life.

${ }^{b}$ Sustained positive statistically significant difference at follow-up.

${ }^{\mathrm{C}}$ The decrease of the number of domains was clinically significant

${ }^{\mathrm{d}}$ Sustained decrease at follow-up.

Goal attainment according to people with MID. Seven of ten adults indicated progressions of two points or more (a clinically relevant difference) on SQP after SFBT and these progressions were sustained during follow-up. The differences in scores of the ten adults were statistically significant (SQP: session 1 vs. session $5 ; z=-2.8, p<0.01$; SQP: session 1 vs. follow-up: $z=$ $-2.7, p<0.01)$. 
Goal attainment according to staff caregivers. In seven of the ten adults, statistically significant improvements of the GAS index (> 10 points), directly after SFBT and during follow-up were evident. Table 4 shows the outcomes of the SQP and of the GAS.

Table 4: Goal attainment according to clients (SQP) and according to caregivers (GAS)

\begin{tabular}{|c|c|c|c|c|c|c|c|c|c|c|c|}
\hline Cases & $\begin{array}{c}\text { Case } \\
\text { Nr. }\end{array}$ & C1 & $\mathbf{C 2}$ & $\mathbf{C 3}$ & $\mathbf{C 4}$ & C5 & C6 & C7 & C8 & $\mathbf{C 9}$ & C10 \\
\hline \multicolumn{12}{|c|}{ Goal Attainment according to clients (SQP) } \\
\hline $\begin{array}{l}\text { After } \\
\text { SFBT }\end{array}$ & $\begin{array}{l}\text { Scale } \\
\text { score }\end{array}$ & $+3^{a}$ & +1 & +1 & $+5^{\mathrm{a}}$ & $+3^{a}$ & $+3^{a}$ & +1 & $+2^{a}$ & $+3^{a}$ & $+2^{\mathrm{a}}$ \\
\hline $\begin{array}{l}\text { Follow } \\
\text {-up }\end{array}$ & $\begin{array}{l}\text { Scale } \\
\text { score }\end{array}$ & $+3^{b}$ & +1 & +1 & $+5^{\mathrm{b}}$ & $+2^{b}$ & $+4^{b}$ & +1 & $+3^{b}$ & $+3^{b}$ & $+2^{b}$ \\
\hline \multicolumn{12}{|c|}{ Goal Attainment according to caregivers (GAS) } \\
\hline \multicolumn{2}{|c|}{ Number of goals } & 3 & 2 & 2 & 3 & 3 & 2 & 2 & 2 & 2 & 2 \\
\hline \multirow[t]{2}{*}{$\begin{array}{l}\text { After } \\
\text { SFBT }\end{array}$} & $\begin{array}{l}\text { Scale } \\
\text { score }^{\mathrm{e}}\end{array}$ & +2 & $+2^{c}$ & $+3^{c}$ & $+3^{c}$ & $+3^{c}$ & $+2^{c}$ & +1 & +1 & $+2^{c}$ & $+2^{c}$ \\
\hline & $\begin{array}{l}\text { GAS } \\
\text { index }\end{array}$ & 59 & $62^{c}$ & $69^{c}$ & $64^{c}$ & $64^{c}$ & $62^{c}$ & 56 & 56 & $62^{c}$ & $62^{c}$ \\
\hline \multirow[t]{2}{*}{$\begin{array}{l}\text { Follow } \\
\text {-up }\end{array}$} & $\begin{array}{l}\text { Scale } \\
\text { score }\end{array}$ & +2 & $+2^{d}$ & $+3^{d}$ & $+3^{d}$ & $+4^{d}$ & $+3^{d}$ & +1 & +1 & $+3^{d}$ & $+2^{d}$ \\
\hline & $\begin{array}{l}\text { GAS } \\
\text { index }\end{array}$ & 59 & $62^{d}$ & $69^{d}$ & $64^{d}$ & $68^{d}$ & $69 d$ & 56 & 56 & $69^{d}$ & $62^{d}$ \\
\hline
\end{tabular}

aPositive difference: the differences were clinically significant ( $\geq+2$ points on the SQP).

bSustained positive difference at follow-up.

'Positive difference: the differences were statistically significant ( $\geq+2$ for 2 goals; $\geq+3$ for 3 goals; > 10 for the GAS index).

${ }^{\mathrm{d}}$ Sustained positive difference at follow-up.

eThe scale of the GAS at the start of therapy is zero.

${ }^{f}$ The GAS-index at the start of therapy is 50 .

Opinions about the strategy and of the collaboration. The third topic concerned the client's opinions about the strategies and of the collaboration between the therapist and people with MID, as measured by the SRS. All adults gave the minimal desired score of 9 to almost all of the item scores. Two incidental lower scores and the following feedback led to adjustments during therapy (for example: 'use simpler language and clarify the tasks' [score 7 on relationship and approach in session 2] and 'give more attention to me and less to the caregiver' [score 8 on relationship in session 2]). 


\section{Conclusions}

In most of the SFBT treatments described in this article, we observed improvements of psychological functioning, decreases in maladaptive behaviour, and positive progressions towards the treatment goals according to both adults with MID and staff. Seven of ten adults with MID reached their treatment goal measured by the SQP. For the others, the progression was zero or one point. Two people (cases C2 \& C3 at the first session were so driven to reach their goal (i.e., being in control of alcohol consumption during the weekend) that they instantly indicated high progression scores of 9 and 10 . In these cases clinically significant progression (SQP $\geq 2$ points) was not possible. However, in both cases progression towards the treatment goal was confirmed by carers by means of statistically significant improvements on the goal attainment index (GAS > 10). The treatment strategies and therapeutic alliances were generally assessed as positive by the people with MID (score of 9 and higher). Discussions about the lower scores led in all cases to workable adjustments (for example, by clarifying tasks after SFBT using pictograms). These results seem to indicate that SFBT could constitute a valuable contribution to the support of people with MID.

Our research study has had some limitations. The first is how we chosed the participants. They were selected by staff at the provider and not randomly. This may affect our results as there may have been an inclination by the chosen adults to be helpful and more compliant. Second is the instrumentation. Any choice of standardized measurement instruments automatically implies restrictions. During SFBT, as every person formulated his or her own goal, it is possible that the chosen goal did not sufficiently matched the measuring pretension of the instruments used. This does not apply to the SQP, because this measurement adjusts itself to the goal of the individual, and is therefore not considered a standardized measurement instrument. It was true for the IDQOL, because the domains of psychological and social functioning within this instrument were broad and could differ from what people with MID found relevant to measure. Moreover, it is difficult to conclude from this study whether the improvements advanced by participating in SFBT can be seen holding over time. Even though SFBT is considered a brief therapy, it was expected that SFBT could assist people with MID in reaching their goals, could 
improve their psychological and social functioning, and could reduce psychological problems in a relatively short time. Although some gains were made by the interventions, it remains uncertain if these improvements will last over time (for example, longer than one year). A third limitation was our design. We used a design that did not draw up a control group. We only studied a treatment group and compared measurements taken before SFBT, after SFBT, and at follow-up. Without comparison data from a control group, it cannot be excluded that the treatment goals of the participants could not have been reached without SFBT. In addition, the small number of participants limits generalization of the findings. To what extend our findings will apply to other people with MID is unknown. However, despite these limitations, that several case studies showed positive treatment results does point to the potential of using SFBT for people with MID. Further research into the effects of SFBT that includes a control group is needed to further assess the value of SFBT.

We conclude that SFBT provides an additional approach of available therapeutic approaches for use with people with ID. There are several reasons why we make this statement. First, SFBT focuses on skills rather than on deficits and recognises the expert status of people with MID. This is in line with the present view of ID that focuses on empowerment. Second, we agree with Stoddart et al., (2001) who note the strengths of using SFBT with people with ID. They note, "SFBT is a highly, structured, active, and directive approach. It focuses on concrete and immediate issues. The approach partializes problems by setting limited and clearly defined goals, and it fosters an early and positive relationship between clients and therapists" (p. 36). Third, SFBT encourages the involvement of carers in the therapeutic process. Because of their involvement in SFBT, professionals may develop more positive perspectives on the people with MID and may become more aware of their resiliencies, resources and competencies, and in particular their abilities to come up with solutions themselves (Lloyd \& Dallos, 2006, 2008). Finally, there is evidence (Macdonald, 2007) that SFBT works equally well for all socioeconomic groups. Although it was exploratory, this study's findings are important, because most psychotherapy research and many psychiatric studies show that outcomes are generally better for the higher socioeconomic groups. Yet people with MID are often economically disadvantaged and usually belong to lower socioeconomic groups; the findings that they too can benefit from SFBT is encouraging. We 
therefore can conclude that SFBT can be regarded as a valuable therapy, although we would also propose that further research in this area is needed.

\section{References}

Bannink, F.P. (2010). 1001 solution-focused questions. New York: Norton.

Beail, N. (2001). Recidivism following psychodynamic psychotherapy amongst offenders with intellectual disabilities. British Journal of Forensic Practice, 3, 33-37.

Beail, N., Kellett, S., Newman, D.W. \& Warden, S. (2007). The dose-effect relationship in psychodynamic psychotherapy with people with intellectual disabilities. Journal of Applied Research in Intellectual Disabilities, 20, 448-454.

Beail, N., Warden, S., Morsley, K. \& Newman, D. (2005). Naturalistic evaluation of the effectiveness of psychodynamic psychotherapy with adults with intellectual disabilities. Journal of Applied Research in Intellectual Disabilities, 18, 245-251.

Cooper, S.A., Smiley, E., Morrison, J., Williamson, A. \& Allan, L. (2007). Mental ill-health in adults with intellectual disabilities: prevalence and associated factors. British Journal of Psychiatry, 190, 27-35.

Corcoran, J. (2002). Developmental adaptations of solution-focused family therapy. Brief Treatment and Crisis Intervention, 2, 301-313.

Crews, W.D., Bonaventura, S. \& Rowe, F. (1994). Dual diagnosis. Prevalence of psychiatric disorders in a large state residential facility for individuals with mental retardation. American Journal on Mental Retardation, 98, 724-731.

De Shazer, S. (1985). Keys to solution in brief therapy. New York: Norton.

Didden, R., Collin, P. \& Curfs, L. (2009). Psychopathologie bij mensen met een Verstandelijke beperking [Psychopathology in people with intellectual disabilities]. In W. Vandereycken, C. Hoogduin, \& P. Emmelkamp (Eds.), Handboek Psychopathologie [Handbook of Psychopathology] (pp. 614-637). Houten: Bohn Stafleu van Loghum.

Duncan, B.L., Miller, S.D. \& Sparks, A. (2004). The heroic client. A revolutionary way to improve effectiveness through client-directed, outcomeinformed therapy. New York: Jossey-Bass.

Dunn, O.J. (1961). Multiple comparisons among means. Journal of the American Statistical Association, 56, 52-64. 
Fischer, R.L. (2009). Assessing client change in individual and family counseling. Research on Social Work Practice, 11, 102-111.

Gallant, M.H., Beaulieu, M.C. \& Carnevalle, F.A. (2002). Partnership: an analysis of the concept within the nurse-client relationship. Journal of Advanced Nursing, 40, 149-157.

Hoekman, J., Douma, J.C.H., Kersten, M.C.O., Schuurman, M.I.M. \& Koopman, H.M. (2001). IDQOL-Intellectual Disability Quality of Life: de ontwikkeling van een instrument ter bepaling van de 'kwaliteit van bestaan' van mensen een verstandelijke handicap [Developing an instrument to determine the 'quality of life' for people with intellectual disabilities]. Nederlands Tijdschrift voor de Zorg aan verstandelijk gehandicapten [Dutch Journal for the care for people with intellectual disabilities], 27, 207-225.

Kiresuk, T. \& Sherman, R. (1968). Goal attainment scaling: a general method for evaluating comprehensive mental health programmes. Community Health Journal, 4, 443-453.

Kiresuk, T., Smith, A. \& Cardillo, J. (1994). Goal attainment scaling: Applications, theory, and measurement. London: Erlbaum

Kraijer, D.W. \& Kema, G.N. (1994). Sociale redzaamheidsschaal, SRZ-P voor zwakzinnigen van hoger niveau. Handleiding [Manual for the SRZ social skills scale for people with mild intellectual disabilities]. Lisse: Swets Test Service.

Lentham, J. (2002). Brief solution-focused therapy. Child and Adolescent Mental Health, 7, 189-192.

Lloyd, H. \& Dallos, R. (2006). Solution-focused brief therapy with families who have a child with intellectual disabilities. A description of the content of initial sessions and the processes. Clinical Child Psychology and Psychiatry, 11, 367-386.

Lloyd, H. \& Dallos, R. (2008). First session solution-focused brief therapy with families who have a child with severe intellectual disabilities. Mothers' experiences and views. Journal of Family Therapies, 30, 5-28.

Macdonald, A. (2007). Solution-focused therapy: Theory, research \& practice. London: Sage.

Martin, R. (2006). A real life - a real community: The empowerment and full participation of people with an intellectual disability in their community. Journal of Intellectual and Developmental Disability, 31, 125-127. 
Menolascino, F.J., Levitas, A. \& Greiner, C. (1986). The nature and types of mental illness in the mentally retarded. Psychopharmacology Bulletin, 22, 1046-1054.

Murphy, J.J. \& Davis, M.W. (2005). Video exceptions. An empirical case study involving a child with developmental disabilities. Journal of Systematic Therapies, 24, 66-79.

Newman, D.W. \& Beail, N. (2002). Monitoring change in psychotherapy with people with intellectual disabilities: The application of the assimilation of problematic experiences scale. Journal of Applied Research in Intellectual Disabilities, 15, 48-60.

Reiss, S., Minnen, A. \& Van Hoogduin, K. (1994). Handleiding; de Nederlandse versie van de Reiss Screen for Maladaptive Behaviour [Dutch Manual of the Reiss Screen for Maladaptive Behaviour]. Orland Park: International Diagnostic Systems.

Roeden, J.M. \& Bannink, F.P. (2007a). Handboek oplossingsgericht werken met licht verstandelijk beperkte cliënten [Handbook solution-focused interventions with clients with intellectual disabilities]. Amsterdam: Pearson.

Roeden, J.M. \& Bannink, F.P. (2007b). Hoe organiseer ik een etentje? Oplossingsgerichte gedragstherapie met een verstandelijk beperkte vrouw [How to organize a dinner? Solution-focused behaviour therapy with a woman with intellectual disabilities]. Gedragstherapie, 40, 251-268.

Roeden, J.M., Bannink, F.P., Maaskant, M.A. \& Curfs, L.M.G. (2009). Solution-focused brief therapy with persons with intellectual disabilities. Journal of Policy and Practice in Intellectual Disabilities, 6, 253-259.

Roeden, J.M., Maaskant, M.A. \& Curfs, L.M.G. (2011). The views of clients with mild intellectual disabilities regarding their working relationships with caregivers. Journal of Applied Research in Intellectual Disabilities, 24, 398-406. Schlosser, R.W. (2004). Goal Attainment Scaling as a clinical measurement technique in communication disorders: a critical review. Journal of Communication Disorders, 37, 217-239.

Smith, I.C. (2005). Solution-focused brief therapy with people with learning disabilities. A case study. British Journal of Learning Disabilities, 33, 102-105. Smith, I.C. (2006). Ideas for solution-based working with people who have intellectual disabilities. Solution New, 2, 21-25. 
Stams, G.J., Dekovic, M., Buist, K. \& De Vries, L. (2006). Effectiviteit van oplossingsgerichte korte therapie: een meta-analyse [The efficacy of solutionfocused therapy: a meta-analysis]. Gedragstherapie, 39, 81-94.

Stoddart, K.P., McDonnel, J., Temple, V. \& Mustata, A. (2001). Is brief better? A modified brief solution-focused therapy approach for adults with a developmental delay. Journal of Systematic Therapies, 20, 24-40.

Teall, B. (2000). Using solution-focused interventions in an ecological frame. A case illustration. Social Work in Education, 22, 54-61.

Wechsler, D. (2005a). WISC-III-NL, Wechsler Intelligence Scale for ChildrenIII. Amsterdam: Pearson.

Wechsler, D. (2005b). WAIS-III-NL, Wechsler Intelligence Scale for AdultsIII. Amsterdam: Pearson.

Westra, J. \& Bannink, F.P. (2006a). 'Simpele' oplossingen! Oplossingsgericht werken bij mensen met een lichte verstandelijke beperking, deel 1 ['Simple' solutions! Solution focused interviewing with intellectually disabled clients, part 1]. Psychopraxis, 8, 158-116.

Westra, J. \& Bannink, F.P. (2006b). 'Simpele' oplossingen! Oplossingsgericht werken bij mensen met een lichte verstandelijke beperking, deel 2 ['Simple' solutions! Solution focused interviewing with intellectually disabled clients, part 2]. Psychopraxis, 8, 213-218.

Westra, J. (2008). Effectmeting van therapie met licht verstandelijk beperkte cliënten [Measuring therapy effects clients with mild intellectual disabilities]. In 'Are you being served'-congress (p. 77). Veldhoven: VGCt-Abstractbook. 



\section{CHAPTER 5}

\section{PROCESSES AND EFFECTS OF SOLUTION-FOCUSED BRIEF THERAPY WITH PEOPLE WITH INTELLECTUAL DISABILITIES; A CONTROLLED STUDY}




\section{Abstract}

Background. Solution-Focused Brief Therapy (SFBT) is a form of behaviour therapy that focuses on evoking desired behaviour rather than on existing problem behaviour. SFBT has a number of advantages that makes it attractive for use in people with ID. These include: focus on empowerment, unique interventions for each person based on their particular skills, and recognition of the expert status of the individual resulting in a sense of self-efficacy. Method. To investigate the effects of SFBT, we conducted a controlled pre- and post-test and follow-up study with 20 people with mild ID (MID) receiving SFBT and 18 people with MID receiving care as usual (CAU). We expected that SFBT could help people with MID in (1) reaching treatment goals, (2) improving quality of life (i.e., psychological and social functioning), (3) reducing maladaptive behaviour and (4) increasing resilience (autonomy and social optimism).

Results. Two of the 20 clients quit SFBT prematurely. Most clients receiving SFBT (13 of 18 clients) showed clinically relevant progressions (more than 2 points on a 1 to 10 scale) towards their treatment goals after SFBT (13 of 18 clients) and at follow-up (14 of 18 clients). Directly after therapy, the SFBT group performed statistically significantly better than the CAU group on psychological functioning, social functioning, maladaptive behaviour, autonomy, and social optimism. The effect sizes of these improvements were medium to large. At 6 weeks follow-up, the improvements in psychological functioning, social functioning, and maladaptive behaviour were still statistically significant compared to $\mathrm{CAU}$, with medium to large effect sizes. Conclusions. Although the study had limitations due to the short follow-up period and the non-random selection of participants, the statistically significant differences between the SFBT and CAU groups and the medium to large effect sizes, indicate the potential effectiveness of SFBT for people with MID.

\section{Keywords}

Solution-Focused Brief Therapy, Therapy Effect Research, Intellectual Disabilities, Behaviour therapy 


\section{Introduction}

Psychological problems frequently occur in people with intellectual disabilities (ID). Compared with the general population, people with ID are reported to experience behaviour problems and/or psychiatric disorders twice as often (Cooper et al., 2007). Recent research and clinical practice experience have shown that clients with ID can benefit from individual, couple, family, and group psychotherapy. For example, Beail et al. (2005) posited that psychotherapy is effective in people with ID, and demonstrated reduced psychological distress and interpersonal problems as well as increased selfesteem.

One approach used in psychotherapy, Solution-Focused Brief Therapy (SFBT; De Shazer, 1985), has gained popularity over the past 25 years. SFBT is a short-term, goal-focused and client-directed therapeutic approach that helps clients focus on solutions rather than on problems. In SFBT, the client is considered an expert with regard to his or her own situation. One of the central assumptions is that the goal of the therapy is defined by the client and that he or she has the competences and resources to realize this goal. The therapist is an expert in asking solution-focused questions that stimulate the client to formulate his or her goal. The attitude of the therapist is one of 'leading from one step behind' and 'not knowing', meaning that the therapist asks questions and does not give advice. The therapist stimulates the client to describe progression towards the therapy goal in small, specific, behavioural steps. The therapist also suggests tasks such as 'continue with what is working already' in order to stimulate or maintain changes. At the start, variations in the relationship with the client (i.e., whether it is a visitor, complainant, or customer relationship) are identified. In a visitor relationship, the client is referred to the therapist by others, has not voluntarily sought help, and is not experiencing emotional difficulties. In a complainant relationship, the client is experiencing emotional difficulties, but does not (yet) see him- or herself as part of the problem and/or the solution. In a customer relationship, the client does see him- or herself as part of the problem and/or solution and is motivated to change his or her behaviour. Each type of relationship requires different approaches by the solution-focused therapist towards the client. For example, in the visitor relationship the therapist may ask what the client thinks 
the person who referred would like to see changed in his or her behaviour and to what extent the client is prepared to cooperate. In the complainant relationship, the therapist acknowledges the client's difficulties and gives suggestions for observing the moments when the problem is or was present to a lesser extent. In the customer relationship, the client may be given a behaviour assignment (e.g., 'continue with what is working already'). More information about SFBT is given in the treatment protocol in the Method section.

SFBT has a number of advantages that makes it attractive for use in people with ID. These include a focus on empowerment and skills rather than on deficits, unique interventions for each person based on particular skills and needs, and recognition of the expert status of the individual resulting in a sense of self-efficacy within the therapeutic relationship (Roeden et al., 2009). In addition, Macdonald (2007) found no statistically significant differences in the effects of SFBT between socioeconomic groups. This is an important finding, as all other psychotherapies are more effective for clients from higher socioeconomic groups (Meyers \& Auld, 2006), whereas individuals with ID often belong to the lower socioeconomic segments of the community.

To improve the applicability of SFBT for people with ID, several authors have suggested modifications to SFBT as De Shazer (1985) originally described it. These recommendations include the use of simple language, flexibility in questioning, and allowing the person with ID enough time to answer questions, develop ideas, and reflect on what transpires during the sessions. Also advantageous is using visual aids such as emoticons and drawings, involving carers and family, encouraging and explaining tasks, and adapting task assignments (Corcoran, 2002; Lentham, 2002; Murphy \& Davis, 2005; Roeden \& Bannink, 2007; Roeden et al., 2009; Smith, 2005, 2006; Stoddart et al., 2001; Teall, 2000; Westra \& Bannink, 2006a, 2006b).

Two meta-analyses have reviewed SFBT outcomes in the general population across a wide range of studies. Stams et al. (2006) conducted a meta-analysis of 21 studies investigating the effects of SFBT, using Cohen's $d$ to measure effect sizes. This meta-analysis found an overall small effect size for SFBT (Cohen's $d=0.37 ; 95 \%$ CI: $0.19<d<0.55, p<0.001$ ). Studies that compared SFBT with 'no treatment' $(n=4)$ yielded a medium effect size of Cohen's $d(d=0.57 ; p<0.01)$. Studies that compared SFBT with other 
treatments ( $n=7$ ) yielded a small and not statistically significant effect size of Cohen's $d$ ( $d=0.16$; ns. ). Kim (2008) conducted a second meta-analysis examining the effectiveness of SFBT (22 comparison group studies) for different types of outcomes: externalizing behaviour problems, internalizing behaviour problems and family or relationship problems. This meta-analysis found small but positive treatment effects favouring the SFBT groups. However, only the overall weighted mean effect size for internalizing problems, such as depression, anxiety, self-concept, and self-esteem, was statistically significant at the $p<0.05$ level, indicating that the treatment effect of the SFBT groups was better than that of the control groups. SFBT appeared to be less effective with externalizing behaviour problems such as hyperactivity, conduct problems, aggression, and family and relationship problems. In a review of SFBT outcome research Gingerich et al. (2012) stated: "SFBT is as good or slightly better than other accepted treatments, but it is clearly better than no treatment at all" (p. 106).

Several process studies found that SFBT techniques increase clients' resilience, optimism and self-control (Beyebach et al., 1996; Shilts et al., 1997; Corcoran \& Ivery, 2004; Quick \& Gizzo, 2007). For example, Quick and Gizzo (2007) interviewed 108 clients who were receiving SFBT. The clients credited the therapy model with making them more optimistic and resilient. By the end of the last session, they felt statistically significantly more in control of the problems for which they had sought SFBT.

Research literature on the effects of SFBT in people with ID is scarce, but the available literature reveals some promising positive treatment effects. Stoddart et al. (2001) reviewed 16 people with mild to borderline ID receiving SFBT. Clinicians rated the degree to which the outcomes as ascertained from client records were successful on a 5-point Likert-style scale ( 1 = unsuccessful to 5 = very successful). Using this method, problems relating to poor selfesteem, family relationships, and bereavement were most successfully treated with SFBT (success ratings 3.7 to 5.0), whereas depression and anxiety, couple conflict, and independence issues showed the least improvement (success rating 2.0 to 3.3). Roeden et al. (2011) undertook 10 case studies of applications of SFBT in people with mild ID. It was found that SFBT treatments contributed to increased psychological functioning and decreased maladaptive behaviour. In addition, goal attainment was reported both by people with mild 
ID and their carers. The positive changes evident after SFBT proved sustainable during follow-up. Both studies, however, are subject to limitations due to the lack of control groups, which means it is possible that the treatment effects could have been reached without SFBT as well.

More insight is clearly needed regarding the effects of SFBT in this population. Thus, we conducted a controlled pre- and post-test study with 20 people with mild ID (MID) receiving SFBT and 18 people with MID receiving care as usual (CAU). We expected that SFBT could help people with MID in (1) reaching treatment goals, (2) improving quality of life, (3) reducing maladaptive behaviour, and (4) increasing resilience. We therefore investigated differences in these variables in both groups (SFBT and CAU) at several points in time: before starting SFBT, directly after SFBT, and 6 weeks after SFBT.

The key questions in this study are: 'To what extent do clients in the SFBT group reach their treatment goals, and to what extent does the SFBT group outperform the CAU group with regard to improved quality of life, reduced maladaptive behaviour and increased resilience?'

\subsection{Participants and procedure}

The study was conducted at the programme sites of a service provider for children and adults with ID of all levels (serving approximately 900 people) in the Netherlands. People registered with this provider use various services, such as residential services, day care, and home care. This service provider supports approximately 120 clients with MID.

The provider employs qualified psychological therapists and offers SFBT adapted for clients with MID. The 38 study participants were referred for SFBT by their staff, as all were experiencing problems that warranted change. All these clients had been screened as having clinically significant maladaptive behaviour using the Reiss Screen for Maladaptive Behaviour (RSMB, Reiss, 1988). The inclusion criteria for participation were as follows: (1) aged between 18 and 60 years of age, (2) IQ between 50 and 70, and (3) sum scores on the RSMB higher than 7 (see Measures section), indicating the presence of maladaptive behaviour. Exclusion criteria were (1) the presence of acute and severe psychiatric conditions (e.g., psychosis, major depression or 
bipolar disorder, schizophrenia or suicide risk), and (2) the referral problem required long-term multidisciplinary intervention (e.g., the treatment of anorexia nervosa). All participants $(n=38)$ lived semi-independently and received individual support (ranging from 2 to 14 hours per week) from staff employed by the service provider mentioned above. The support they received included help with housekeeping tasks (such as cleaning and cooking), with financial tasks (such as banking), and with social-emotional tasks (such as dealing with other people and conflict management). All participants in the study had MID determined on the basis of IQ, tested by means of the WISCIII-NL (Wechsler 2005a) or the WAIS-III-NL (Wechsler 2005b). Their adaptive functioning was tested by means of the SRZ-plus (a Dutch adaptive behaviour scale, Kraijer \& Kema, 1994).

Twenty participants received solution-focused sessions (SFBT group) and 18 controls received care as usual (CAU group). The first 20 clients who were experiencing problems that warranted change, enrolled in SFBT. They were compared with 18 clients receiving CAU, matched for age, IQ, adaptive and maladaptive functioning. As it was considered unethical to withhold a potentially effective treatment from those who might benefit from SFBT, all clients in the CAU group were placed on a waiting list for SFBT. CAU is most dissimilar with SFBT in terms of the role of staff. As applied in the setting mentioned above, CAU is a type of coaching that focuses on the problemsolving model. In this model, the description of client problems and the formulation of client goals, the coaching plan and the interventions are primarily performed by staff. In CAU staff suggest or prescribe the solutions, serving as the experts who advise clients on the actions to take to alleviate their problems. Before the start of the study, no statistically significant differences were found between the two groups with regard to age, IQ, adaptive functioning, or maladaptive functioning. Table 1 provides the means and standard deviations for all variables mentioned, for both the SFBT and the CAU group. 
Table 1: SFBT and CAU groups according to sample size (absolute numbers), drop-outs, age, IQ, adaptive and maladaptive functioning (means and SD's)

\begin{tabular}{|c|c|c|c|}
\hline $\begin{array}{l}\text { Study group } \\
\text { characteristics }\end{array}$ & SFBT & CAU & $\begin{array}{l}\text { Comparison data } \\
\text { Mann-Whitney } U \\
\text { test* }\end{array}$ \\
\hline Sample size & $n=20$ & $n=18$ & \\
\hline Drop-out & $n=2$ & & \\
\hline Age & $\begin{array}{l}43.4(\mathrm{SD}= \\
16.4)\end{array}$ & $\begin{array}{l}41.5(\mathrm{SD}= \\
12.6)\end{array}$ & $z=-0.1, p=0.92$ \\
\hline IQ* & $61.3(\mathrm{SD}=6.4)$ & $62.9(\mathrm{SD}=4.9)$ & $z=0.8, p=0.44$ \\
\hline $\begin{array}{l}\text { Adaptive } \\
\text { functioning } * *\end{array}$ & $6.6(\mathrm{SD}=0.8)$ & $6.9(\mathrm{SD}=0.8)$ & $z=1.1, p=0.27$ \\
\hline $\begin{array}{l}\text { Maladaptive } \\
\text { functioning } * * *\end{array}$ & $11.6(S D=7.4)$ & $9.6(\mathrm{SD}=8.6)$ & $z=-1.1, p=0.26$ \\
\hline
\end{tabular}

* $\quad$ Measured by the WISC or WAIS-IQ-test

** Measured by the SRZ-plus questionnaire (see method section)

*** Measured by the Reiss Maladaptive Behaviour Scales (see method section)

In each treatment, three data measurements were taken: the first immediately before SFBT; the second immediately after SFBT and the third, a follow-up measurement, 6 weeks after SFBT. Three measurements were also taken in the CAU group: the first baseline measurement; the second measurement after 15 weeks (the mean length of all SFBT-treatments) and the third, a follow-up measurement after $15+6=21$ weeks.

The two solution-focused therapists in this study had a master's degrees in behaviour therapy. Their additional training programme on SFBT included the history and philosophy of SFBT, the tenets of SFBT, the session format and structure of SFBT, video examples from the developers of SFBT, role playing, and supervised practice with clients with ID.

All participants agreed to participate in the study and provided permission for anonymous publication of the study data. Permission for the study was given by the Client Council (composed of clients with ID) and by the organization's Client Representative Council (comprising family members or other representatives of people with ID). Both councils acknowledged that the research proposal corresponded to guidelines for carrying out research projects involving people with ID in the Netherlands. 


\subsection{SFBT protocol}

Every SFBT session was attended by at least three people: the person with MID, a staff member, and the therapist. In our application of SFBT every person with MID was accompanied by a carer as experience with SFBT has shown that the interventions are better understood and executed when carers perform a supportive role in the treatment procedure (Roeden \& Bannink, 2007; Stoddart et al., 2001; Teall, 2000). Each participant with ID consented to the presence of the staff member. The treatment protocol consisted of 6 meetings: (1) intake, (2) first session, and (3) four subsequent sessions. Every treatment had the same format, much of which is taken from De Shazer et al. (2007). A follow-up meeting was organized to obtain post-treatment measurements, including goal attainment.

(1) Intake

Getting acquainted. First the therapist spends time getting to know the client. Competences and resources are explored, and the overall attitude is positive, respectful, and hopeful. 'Exploring the problem'. The therapist invites the client to describe his or her problem and/or to indicate his or her goal for the treatment. The therapist acknowledges the problem, which confirms to the client that the therapist is not underestimating the seriousness of the problem.

(2) First session

Pre-session change. Since most clients have tried other options before meeting with a therapist, the therapist asks about any changes that have already been made before the first session. Goal-setting. The client is invited to describe what would be different once his/her goal is reached. All the goal-directed questions are framed using the future tense for example by means of the miracle question: 'Imagine a miracle occurring tonight that would (sufficiently) solve the problem. What would be different tomorrow?'. The therapist tries to elicit smaller goals rather than larger ones. Clients are encouraged to frame their goal as the presence of a solution rather than the absence of a problem, by means of the question: 'What do you want to see instead of the problem?'. Exploring the exceptions. The therapist inquires about moments in the past or present when the problem did not or does not occur or is less serious and who does what to bring about these exceptions. Scaling. On a scale of 1 to 10 , the client indicates his or her progression towards the goal. Scaling questions help 
the client to move away from all-or-nothing goals towards manageable and measurable steps. Competence questions. The use of competence questions encourages self-compliments by the client. 'How do (did) you do that?'. Resilience or coping questions. Most people have previously solved many problems. The therapist therefore may ask: 'How do (did) you manage to go on under such difficult circumstances?' or 'This sounds hard, how are you managing to cope with this?'. Feedback. Each session ends with feedback, usually involving compliments for each person present and suggestions for a task. The suggestions indicate areas requiring the client's attention (observation task) or possible further actions (behaviour task) to reach his or her goal, such as 'think or observe what in your present life you want to keep the same' or 'pretend on one day each week that the miracle has happened'. (3) Subsequent sessions.

In the subsequent sessions the therapist uses the EARS question set. EARS is an acronym for Eliciting, Amplifying, Reinforcing, and Start again, and outlines the therapeutic process. The first question is: 'What is better?'. The individual can respond in three different ways: 'It is better', 'There is no change', or 'It is worse'. If the situation is better, the therapist can respond by amplifying ('What exactly is (somewhat) better?), reinforcing ('How did you manage to do that?') and starting again ('What (else) is better?'). EARS can also be used if the person thinks there is no change. The therapist acknowledges the client's potential, emphasizes that keeping things stable is also a good accomplishment, and asks the individual to explain how he or she managed that. If the situation is worsening and the person with MID is disappointed, the therapist also acknowledges this. A reorientation to the goal may be necessary or the therapist can ask the person resilience questions, which may offer reentry to the EARS questions. 'Consolidation questions' are used at the end of the therapy to increase the likelihood that the client will keep on working towards the desired goal, e.g., 'What do you have to do to make sure that these results keep happening?'.

As stated in the section SFBT protocol, the clients were accompanied by a staff member who supported them during the SFBT trajectory. The measurements (in both the SBT and CAU conditions) were performed by the therapists/researchers. The staff member assisted the client in answering and interpreting the questions. Following Teall (2000) and Smith (2006), we 
reasoned that help from a familiar person in answering questions and interviewing by a certified professional (the therapist/researcher) would lead to more valid responses.

\subsection{Measures}

Goal attainment was only measured in the SFBT group. Differences between the SFBT and CAU groups were measured with regard to quality of the life, maladaptive behaviour, and resilience.

Goal attainment. The Scaling Question Progression (SQP) uses a scale of 1 (goal not reached) to 10 (goal reached) on which the client indicates to what extent $\mathrm{s} /$ he has approached or has reached her/his therapeutic treatment goal (Bannink, 2010). In a study by Fischer (2009), the scale question was used with 3,920 clients to measure emotional coping and daily functioning before and after SFBT. Differences between before and after SFBT varied between +0.9 and +2.1 points for daily functioning and between +0.6 and +1.4 points for emotional coping. In this study, a progression of +2.0 points (being relatively high) was considered clinically relevant.

Quality of Life. The Intellectual Disability Quality of Life (IDQOL-16; Hoekman et al. 2001) was used to measure the client's quality of life. The IDQOL-16 has three subscales: psychological functioning, social functioning and satisfaction about housing. Sum scores are indications of an individual's perceived quality of life. The satisfaction about housing subscale was not included in the treatment results because housing satisfaction is not a primary goal of SFBT. The IDQOL-16 has been shown to have good internal consistency (Cronbrach's a of the various subscales were between 0.73 and 0.80 ). Each question has five response categories ranging from very unpleasant to very pleasant, indicated by a pictogram (smiley).

In the IDQOL, the raw scores on the subscales can be transformed into quartile scores (rating of 1 to 4 ). Higher quartiles are indicative of higher satisfaction. The ranges of these quartiles are presented in table 2 . 
Maladaptive behaviour. The Reiss Screen for Maladaptive Behaviour (RSMB; Reiss et al., 1994) was used to measure maladaptive behaviour. The RSMB measures the presence of psychological problems, and was completed by a staff member who had knowledge of the person concerned. The list of questions comprised nine subdivisions: aggression, autism, psychosis, depression (behaviour symptoms), depression (vital symptoms), paranoia, dependent personality disorder, avoidant disorder, and 'other maladaptive behaviour'. The internal consistency of the nine subdivisions ranged from reasonable to good (Cronbach's a ranged between 0.69 and 0.87 ). Stability was calculated only for the total score and was found to be good (Pearson's $r=$ 0.81). The inter-rater reliability for the subdivisions was reasonable to good (Pearson's $r$ ranged between 0.50 and 0.84 ). The staff evaluated each behaviour item as to whether it was no problem ( 0 points), a problem (1 point), or a big problem ( 2 points) for each person. The sum score of the RSMB is a general indication of the level of maladaptive behaviour of an individual with ID. Normative information for adults with ID is provided in the original RSMB manual by Reiss (1988). For the subpopulation clients with MID, sum scores higher than 7 indicate the presence of maladaptive behaviour (Dutch norms, Reiss et al., 1994) and are considered to be a threshold for clinically significant problems.

Resilience. The Positive Outcome Scale (POS; Appelo, 2005) is a 10-item selfreport instrument that assesses resilience, with 7 items on autonomy and 3 on social optimism. Sum scores are indications of an individual's perceived resilience. The reliability (Cronbach's a: 0.88), test-retest reliability (Pearson's $r=0.71$ and 0.77 for the two subscales), and validity (correlations of about 0.60 with different measures for self-efficacy) proved to be sufficient (Appelo, 2005). Each question has four response categories ranging from $1=$ completely untrue to 4 = completely true. The POS manual provides scores for 'policlinic, low-educated people with psychopathology'. Table 2 shows the ranges of these scores for both subscales. 


\subsection{Reasons for dropout}

In this study, dropout was defined as 'any termination of the treatment by the client before the fifth SFBT-session'. Within three days of termination, dropout clients were asked to rate a series of 10 explanations for dropping-out, using a dichotomous (yes/no) response format. The explanations included: (1) there was insufficient progress in the treatment, (2) trust in the treatment was gone, (3) the treatment was too difficult, (4) the approach did not allow for enough freedom, (5) the treatment was stopped as a result of pressure by family or partner, (6) the treatment was stopped as a result of conflict or disagreement with the staff, (7) the treatment was not a personal choice, (8) the treatment jeopardized school, work or spare time (9), the treatment was stopped due to a bad or disappointing working relationship with the therapist, and (10) the treatment did not cover useful therapy goals.

\subsection{Statistical analyses}

Statistical analyses were used to test for changes on the IDQOL, RSMB, and POS over time. Given the relatively small sample sizes (SFBT: 18 clients; CAU: 18 clients, 2 dropouts), non-parametric tests (the Wilcoxon signed-rank test and Mann-Whitney test) were used to analyse the data, rather than parametric tests. The Wilcoxon test was used to investigate differences within the SFBT group and within the CAU group. The changes in scores on the IDQOL-16, RSMB, and POS before SFBT and after SFBT, and before SFBT and at follow-up, were analysed for statistical significance. The direction of the difference (positive or negative change) was calculated using the Sign test. The MannWhitney test was used to investigate differences between the SFBT group versus the CAU group. The non-parametric tests were performed on the key variables of goal attainment (via SQP), quality of life (i.e., psychological functioning, social functioning; via IDQOL-16), maladaptive behaviour (via RSMB), and resilience (i.e., autonomy and social optimism; via POS). To control the problem of multiple comparisons, the Dunn-Bonferroni correction (Dunn 1961) was used by dividing the $p$-value by the number of variables: $p / n$ $=0.05 / 5=0.01$. Scaling (SQP) is not an intervention in CAU, thus no SQP data were available for the CAU group. 


\subsection{Effect size}

Effect size is an objective and standardized measure of the magnitude of observed effects (Field, 2009). The American Psychological Association recommends the use of effect size in the results of any published work. Pearson's correlations coefficient $r$ can be used as an effect size measure, lying between 0 (no effect) and 1 (perfect effect). The equation to convert a nonparametric $z$-score into the effect size, $r$, is $r=z / \sqrt{ } \mathrm{N}$ (Field, 2009, p. 550 and p. 558) in which $z$ is the $z$-score of the Wilcoxon or Mann-Whitney test and $N$ is the number of observations. The criteria established by Cohen (1988) were used to interpret effect sizes: no effect, $r<0.10$; small effect, $r \geq 0.10$ and < 0.30 ( $1 \%-9 \%$ of the total variance); medium effect, $r \geq 0.30$ and $<0.50$ (9$25 \%$ of the total variance); and large effect, $r \geq 0.50$ ( $>25 \%$ of the total variance). We regarded the effect of SFBT as substantial only when (1) the differences in scores between SFBT and CAU were statistically significant ( $p \leq$ 0.01 , Dunn-Bonferroni correction) and (2) the effect size was at least medium $(r \geq 0.30)$.

\section{Results}

Twenty clients received SFBT. Eighteen clients completed the therapy and two dropped out of treatment (see 'Reasons for dropout' below). These dropouts did not complete the measurements directly after SFBT or at follow-up. Eighteen clients received CAU. No statistically significant differences were found between the SFBT ( $n=18$, excl. 2 drop outs) and the CAU group with regard to pre-treatment mean scores of relevant measurements: IDQOL-16 (SFBT: 57.7 [SD = 6.7] versus CAU: 61.4 [SD $=7.4$ ]; $z=-1.6, p=0.11$ ), RSMB (SFBT: 11.6 [SD = 7.4] versus CAU: 9.6 [SD $=8.6], z=-1.1 ; p=0.26$ ) and POS (SFBT: $29.3[\mathrm{SD}=3.7]$ versus CAU: $29.5[\mathrm{SD}=3.3] ; z=-0.10, p=$ 0.93). 


\subsection{Reasons for dropout}

Two clients dropped out of treatment for different reasons, which they indicated on the dropout list within three days of discharge. The first client reported the following two reasons for dropping out: (1) trust in the treatment was gone and (2) the treatment was stopped due to a disappointing working relationship with the therapist. The second client also gave two reasons: (1) the treatment was stopped as a result of pressure by the family or partner and (2) the treatment was not a personal choice. Both clients were asked, but chose not to fill in the IDQOL and POS questionnaires, leaving data from 18 SFBT clients for the statistical analyses.

3.2 Goal attainment associated with initial problems in the SFBT group.

Goal attainment (or progression towards the goal) was measured by using the SQP. No SQP data were available for the CAU group, since no goals were formulated in CAU. During the intakes, the following problems were reported by the participants and their staff in the SFBT group: alcohol abuse (3 clients), anger (2 clients), bereavement (2 clients), depression/apathy (2 clients), sleeplessness ( 1 client), low self-esteem ( 3 clients), avoidance/anxiety (1 client), couples conflict ( 2 clients), and self-help issues ( 2 clients). The two dropouts reported problems with being in public places and being inactive in social relationships. During the first session, all clients formulated treatment goals, prompted by the solution-focused key question: 'What do you want to see instead of the problem?'. This led to the following goals addressing the problems mentioned above: alcohol control (3 clients), anger management (2 clients), coping with bereavement ( 2 clients), happiness/initiative ( 2 clients), a good night's sleep ( 1 client), self-confidence (3 clients), courage ( 1 client), a good relationship ( 2 clients), and mastering self-help or aspects thereof ( 2 clients).

Thirteen of 18 clients showed progressions of 2 points or more on the SQP after SFBT, as did 14 of 18 clients at follow-up. The differences in the scores of the 18 clients were statistically significantly higher after SFBT (mean progression +2.2 points; $z=-3.8 ; p<0.01$ ) and at follow-up (mean progression +2.4 points; $z=-3.7 ; p<0.01$ ). The remaining clients showed 
less improvements on the SQP (after SFBT, 1 client +0.5 point and 4 clients +1 point; at follow-up, 1 client 0 points and 3 clients +1 point).

Before SFBT, the problems reported in both the SFBT group and the CAU group fell within the clinically significant range (average scores for maladaptive behaviour 11.6 and 9.6 respectively, both higher than the cut-off score of 7). After SFBT, those who received SFBT showed greater progress up to 6 weeks after treatment compared to those who received CAU. In contrast to the CAU group, the mean maladaptive scores receiving SFBT dropped below the threshold of 7 points.

\subsection{Differences within groups}

The differences in scores for both the SFBT and CAU groups for all measurements are presented in table 2. At the start of the study, both groups had average scores in the lowest quartiles of the quality of life measures, indicating low satisfaction ratings on psychological and social functioning. The initial average resilience scores of both groups also fell within the lower ('policlinic') ranges.

After SFBT and at follow-up, the SFBT group performed better (Wilcoxon test: $p \leq 0.01$ ), on psychological functioning (IDQOL-16), reduced maladaptive behaviour (RSMB) and autonomy (POS); the CAU group did not (Wilcoxon test: $p>0.05)$. After SFBT, positive changes were evident in 16 of the 18 clients for psychological functioning, in 11 of 18 clients for social functioning, in all clients for reduced maladaptive behaviour, in 11 of 14 clients for autonomy, and in 8 of 14 clients for social optimism (Sign test: $p<0.01$ for all measures). At follow-up, the improvements in psychological functioning, reduced maladaptive behaviour and autonomy were sustained (in 13 of 16, 16 of 18, and 10 of 14 clients respectively; Sign test: $p<0.01$. The effect sizes were at least medium. The changes after SFBT for social optimism just reached statistical significance ( $p=0.01$ ), but did not at follow-up. Changes in social functioning did not reach statistical significance in the SFBT group, although there were medium effect sizes. There were no statistically significant changes in social functioning and social optimism in the CAU group ( $p>0.05)$. 
Table 2: Within-group differences (SFBT and CAU) in psychological and social functioning (IDQOL), maladaptive behaviour (RSMB), autonomy and social optimism (POS) of the before, after and follow-up measurements and mean changes

\begin{tabular}{|c|c|c|c|c|c|c|c|c|c|}
\hline \multicolumn{2}{|c|}{ Measurement } & $n$ & Group & $\begin{array}{l}\text { Before } \\
\text { Mean } \\
\text { Ratio }^{a}\end{array}$ & $\begin{array}{l}\text { After } \\
\text { Mean }\end{array}$ & $\begin{array}{l}\text { Mean } \\
\text { change; } \\
\text { Signed- } \\
\text { rank test } \\
\text { Effect } \\
\text { size }^{b}\end{array}$ & $n$ & $\begin{array}{l}\text { Follow- } \\
\text { up } \\
\text { Mean } \\
\text { Ratio }^{a}\end{array}$ & $\begin{array}{l}\text { Mean } \\
\text { change; } \\
\text { Signed- } \\
\text { rank test } \\
\text { Effect } \\
\text { size }\end{array}$ \\
\hline \multirow[t]{4}{*}{ IDQOL } & \multirow{2}{*}{$\begin{array}{l}\text { Psychological } \\
\text { Functioning } \\
\text { 1th quartile: } \\
\text { [5-19] } \\
\text { 2nd quartile: } \\
\text { [20-21] } \\
\text { 3rd quartile: } \\
\text { [22-24] } \\
\text { 4th quartile: } \\
{[25 \geq]}\end{array}$} & 18 & SFBT & $\begin{array}{c}16.4 \\
16 / 18^{\#}\end{array}$ & 19.9 & $\begin{array}{l}+3.5 \\
z=-3.6 \\
p<0.01 \\
r=0.60 \\
\text { large* }\end{array}$ & 16 & $\begin{array}{c}20.1 \\
13 / 16\end{array}$ & $\begin{array}{l}+3.7 \\
z=-2.7 \\
p<0.01 \\
r=0.48 \\
\text { medium* }\end{array}$ \\
\hline & & 18 & CAU & $\begin{array}{l}18.0 \\
8 / 18\end{array}$ & 17.7 & $\begin{array}{l}-0.3 \\
z=-0.4 \\
p=0.71 \\
r=0.07 \\
\text { no effect }\end{array}$ & 16 & $\begin{array}{l}18.6 \\
9 / 16\end{array}$ & $\begin{array}{l}+0.6 \\
z=-0.8 \\
p=0.39 \\
r=0.14 \\
\text { small }\end{array}$ \\
\hline & \multirow{2}{*}{$\begin{array}{l}\text { Social } \\
\text { functioning } \\
1 \text { th quartile: } \\
\text { [6-24] } \\
\text { 2nd quartile: } \\
\text { [25-26] } \\
\text { 3rd quartile: } \\
\text { [27-29] } \\
\text { 4th quartile: } \\
{[30 \geq]}\end{array}$} & 18 & SFBT & $\begin{array}{c}21.9 \\
11 / 18\end{array}$ & 23.3 & $\begin{array}{l}+1.4 \\
z=-2.0 \\
p=0.04 \\
r=0.33 \\
\text { medium }\end{array}$ & $16^{c}$ & $\begin{array}{c}24.3 \\
11 / 16\end{array}$ & $\begin{array}{l}+2.4 \\
z=-2.0 \\
p=0.04 \\
r=0.35 \\
\text { medium }\end{array}$ \\
\hline & & 18 & CAU & $\begin{array}{l}24.1 \\
3 / 18\end{array}$ & 23.3 & $\begin{array}{l}-0.8 \\
z=-1.7 \\
p=0.10 \\
r=0.28 \\
\text { small }\end{array}$ & 16 & $\begin{array}{l}24.3 \\
3 / 16\end{array}$ & $\begin{array}{l}+0.2 \\
z=-0.5 \\
p=0.63 \\
r=0.08 \\
\text { no effect }\end{array}$ \\
\hline \multirow[t]{2}{*}{ RSMB } & \multirow{2}{*}{$\begin{array}{l}\text { Maladaptive } \\
\text { Behaviour } \\
\text { Cut off score } \\
\text { for } \\
\text { maladaptive } \\
\text { behaviour = } 7\end{array}$} & 18 & SFBT & $\begin{array}{c}11.6 \\
18 / 18\end{array}$ & 5.9 & $\begin{array}{l}-5.7 \\
z=-3.7 \\
p<0.01 \\
r=0.62 \\
\text { large* }\end{array}$ & 18 & $\begin{array}{c}6.7 \\
16 / 18\end{array}$ & $\begin{array}{l}-4.9 \\
z=-3.4 \\
p<0.01 \\
r=0.57 \\
\text { large* }\end{array}$ \\
\hline & & 18 & CAU & $\begin{array}{c}9.6 \\
10 / 18\end{array}$ & 8.3 & $\begin{array}{l}-1.3 \\
z=-1.4 \\
p=0.16 \\
r=0.23 \\
\text { small }\end{array}$ & 18 & $\begin{array}{c}8.9 \\
8 / 18\end{array}$ & $\begin{array}{l}-0.7 \\
z=0 \\
p=0.97 \\
r=0, \text { no } \\
\text { effect }\end{array}$ \\
\hline \multirow[t]{4}{*}{ POS } & \multirow{2}{*}{$\begin{array}{l}\text { Autonomy } \\
\text { Range for } \\
\text { policlinic low- } \\
\text { educated } \\
\text { people: } \\
\text { [15-23] }\end{array}$} & $14^{d}$ & SFBT & $\begin{array}{c}19.8 \\
11 / 14\end{array}$ & 22.3 & $\begin{array}{l}+2.5 \\
z=-2.9 \\
p<0.01 \\
r=0.55 \\
\text { large* }\end{array}$ & 14 & $\begin{array}{c}22.1 \\
10 / 14\end{array}$ & $\begin{array}{l}+2.3 \\
z=-2.5 \\
p<0.01 \\
r=0.47 \\
\text { medium* }\end{array}$ \\
\hline & & 18 & CAU & $\begin{array}{l}19.6 \\
5 / 18\end{array}$ & 20.1 & $\begin{array}{l}+0.5 \\
z=-0.9, p \\
=0.36 \\
r=0.15 \\
\text { small }\end{array}$ & 16 & $\begin{array}{l}20.7 \\
7 / 16\end{array}$ & $\begin{array}{l}+1.1 \\
z=-2.0 \\
p=0.05 \\
r=0.35 \\
\text { medium }\end{array}$ \\
\hline & \multirow{2}{*}{$\begin{array}{l}\text { Social } \\
\text { Optimism } \\
\text { Range: Range } \\
\text { for policlinic } \\
\text { low-educated } \\
\text { people: } \\
\text { [7-11] }\end{array}$} & 14 & SFBT & $\begin{array}{c}9.5 \\
8 / 14\end{array}$ & 10.5 & $\begin{array}{l}+1.0 \\
z=-2.6 \\
p=0.01 \\
r=0.49 \\
\text { medium } *\end{array}$ & 14 & $\begin{array}{l}10.6 \\
9 / 14\end{array}$ & $\begin{array}{l}+1.1 \\
z=-1.8 \\
p=0.07 \\
r=0.34 \\
\text { medium }\end{array}$ \\
\hline & & 18 & CAU & $\begin{array}{c}9.9 \\
3 / 18\end{array}$ & 9.7 & $\begin{array}{l}-0.2 \\
z=-1.3 \\
p=0.37 \\
r=0.22 \\
\text { small }\end{array}$ & 16 & $\begin{array}{c}9.8 \\
2 / 16\end{array}$ & $\begin{array}{l}-0.1 \\
z=-1.0 \\
p=0.33 \\
r=0.18 \\
\text { small }\end{array}$ \\
\hline
\end{tabular}


${ }^{a}$ Ratio: number of clients who changed in the desired direction / total number of participants.

${ }^{b}$ Effect sizes: no effect, $r<0.10$; a small effect, $r \geq 0.10$ and $<0.30$; a medium effect, $r \geq 0.30$ and $<0.50$ and a large effect, $r \geq 0.50$. ${ }^{C}$ Quartile scores of subscales.

${ }^{\mathrm{d}}$ Lower sample sizes due to missing values.

*Differences over time within groups are statistically significant $(p \leq 0.01)$ on the Wilcoxon test and the effect size is at least 'medium'.

\subsection{Differences between groups}

The key issue in this study is whether or not the changes in scores between the measurements differ between the SFBT group and the CAU group. Table 3 shows the results of these analyses. Not all clients completed all questionnaires in full: the exact number of respondents is given in the relevant tables. For this reason, the pairs of observations differed to some extent within and between groups in tables 2 and 3. The analyses revealed that the SFBT group performed better than the CAU group directly after SFBT with regard to all key variables: psychological functioning, social functioning, maladaptive behaviour, autonomy and social optimism (differences between groups for all variables $p$ $<0.01$ ). The effect sizes were large, medium, large, medium, and large respectively. At follow-up, the differences were no longer statistically significant anymore for autonomy and social optimism ( $p=0.19$ and $p=0.05$, respectively). However, the results were sustained at follow-up for psychological functioning, social functioning and maladaptive behaviour $(p<$ 0.01 ). The effect sizes for these three variables were medium, medium, and large respectively.

It may be concluded that SFBT gives better results on psychological functioning, social functioning and maladaptive behaviour than CAU. The results for autonomy and social optimism (resilience) were not sufficiently sustained at follow-up. 
Table 3: Between-group differences (SFBT versus CAU) in psychological and social functioning (IDQOL), maladaptive behaviour (RSMB), autonomy and social optimism (POS) of the before, after and follow-up; number of clients and mean changes

\begin{tabular}{|c|c|c|c|c|c|c|c|c|}
\hline \multicolumn{2}{|c|}{ Measurement } & \multirow{2}{*}{$\begin{array}{c}n \\
\\
\\
18\end{array}$} & \multirow{2}{*}{$\begin{array}{l}\text { Group } \\
\text { SFBT }\end{array}$} & \multirow{2}{*}{$\begin{array}{l}\begin{array}{l}\text { Mean } \\
\text { change } \\
\text { after } \\
\text { SFBT }\end{array} \\
+3.5\end{array}$} & \multirow{3}{*}{$\begin{array}{l}\begin{array}{l}\text { Mann- } \\
\text { Whitney test } \\
\text { Effect size }^{\mathbf{a}}\end{array} \\
\\
z=-3.7 \\
p<0.01 \\
r=0.62 \\
\text { large } \neq\end{array}$} & \multirow{2}{*}{$\begin{array}{c}n \\
n \\
16\end{array}$} & \multirow{2}{*}{ 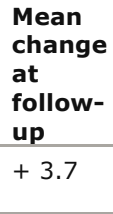 } & \multirow{3}{*}{$\begin{array}{l}\text { Mann-Whitney } \\
\text { test } \\
\text { Effect size } \\
z=-2.7 \\
p<0.01 \\
r=0.48 \\
\text { medium }\end{array}$} \\
\hline IDQOL & $\begin{array}{l}\text { Psycho- } \\
\text { logical }\end{array}$ & & & & & & & \\
\hline & $\begin{array}{l}\text { Functio- } \\
\text { ning }\end{array}$ & 18 & CAU & -0.8 & & 16 & +0.6 & \\
\hline & \multirow{2}{*}{$\begin{array}{l}\text { Social } \\
\text { function- } \\
\text { ning }\end{array}$} & 18 & SFBT & +1.4 & \multirow{2}{*}{$\begin{array}{l}z=-2.6 \\
p=0.01 \\
r=0.43 \\
\text { medium } \ddagger\end{array}$} & 16 & +2.4 & \multirow{2}{*}{$\begin{array}{l}z=-2.6 \\
p<0.01 \\
r=0.46 \\
\text { medium } \ddagger\end{array}$} \\
\hline & & 18 & CAU & -0.6 & & 16 & +0.2 & \\
\hline \multirow[t]{2}{*}{ RSMB } & \multirow{2}{*}{$\begin{array}{l}\text { Mal- } \\
\text { adaptive } \\
\text { Behavior }\end{array}$} & 18 & SFBT & -5.7 & \multirow{2}{*}{$\begin{array}{l}z=-3.5 \\
p<0.01 \\
r=0.58 \\
\text { large } \ddagger\end{array}$} & 18 & -4.9 & \multirow{2}{*}{$\begin{array}{l}z=-3.3 \\
p<0.01 \\
r=0.55, \text { large* }\end{array}$} \\
\hline & & 18 & CAU & -1.3 & & 18 & -0.7 & \\
\hline \multirow[t]{4}{*}{ POS } & \multirow[t]{2}{*}{$\begin{array}{l}\text { Auto- } \\
\text { nomy }\end{array}$} & 14 & SFBT & +2.5 & \multirow{2}{*}{$\begin{array}{l}z=-2.7 \\
p<0.01 \\
r=0.48 \\
\text { medium } \ddagger\end{array}$} & 14 & +2.3 & \multirow{2}{*}{$\begin{array}{l}z=-1.3 \\
p=0.19 \\
r=0.24, \text { small }\end{array}$} \\
\hline & & 18 & CAU & +0.5 & & 16 & +1.1 & \\
\hline & \multirow{2}{*}{$\begin{array}{l}\text { Social } \\
\text { optimism }\end{array}$} & 14 & SFBT & +1.0 & \multirow{2}{*}{$\begin{array}{l}z=-2.9 \\
p<0.01 \\
r=0.51 \\
\text { large } ł\end{array}$} & 14 & +1.1 & \multirow{2}{*}{$\begin{array}{l}z=-2.0 \\
p=0.05 \\
r=0.37 \\
\text { medium }\end{array}$} \\
\hline & & 18 & CAU & -0.2 & & 16 & -0.1 & \\
\hline
\end{tabular}

${ }^{a}$ Effect sizes: no effect, $r<0.10$; a small effect, $r \geq 0.10$ and $<0.30$; a medium effect, $r \geq 0.30$ and $<0.50$ and a large effect, $r \geq 0.50$.

bower sample sizes due to missing values.

4 Differences over time between groups are statistically significant $(p \leq 0.01)$ on the MannWhitney test after SFBT and the effect size is at least 'medium'. 


\section{Conclusions}

The results of this study indicate that SFBT can constitute a valuable contribution to the support of people with MID. Most clients in this study showed clinically relevant progressions (more than 2 points on a 1 to 10 scale) towards their treatment goals after SFBT (13 of 18 clients) and at follow-up (14 of 18 clients).

Directly after therapy, the SFBT group showed greater improvements than the CAU group on psychological functioning, social functioning, maladaptive behaviour, autonomy and social optimism. At follow-up, 6 weeks after therapy, the improvements on the first three measures mentioned were sustained. Overall, these results are similar to recent SFBT outcome research in the general population, showing that SFBT is more effective than 'treatment as usual' (Macdonald, 2007; Gingerich et al., 2012) with medium effect sizes (Stams et al., 2006).

This study has some limitations concerning the choice and type of outcomes, the length of the follow-up period and the research design. Firstly, any choice of standardized instruments automatically implies restrictions. During SFBT, each individual formulated his or her own goal. It is possible that the chosen goal did not sufficiently match the measuring pretention of the instruments used. This does not apply to the SQP, because this measurement adjusts itself to the individual's goal. However, it does hold for the IDQOL and the POS, as the quality of life domains and the resilience domains within these instruments were broad and could differ from what people with mild ID considered to be relevant outcomes. Secondly, it is difficult to conclude from this study whether the improvements attributed to SFBT can hold over time. Although gains were made through the interventions, it remains uncertain whether these improvements will last over time (for example, longer than one year). Thirdly, the choice of participants may be subject to discussion. All SFBT clients were referred by staff and not randomly allocated to both conditions. It is possible that the selected clients tended to be more cooperative in therapy and the outcomes could be more favourable to SFBT compared to a random selection. There are, however, several obstacles to conducting randomized controlled trials in the ID-field (see Oliver et al., 2002 for a review). Randomized trials are not always practical or acceptable given the need to 
involve staff in deciding to start therapy, providing informed consent, and assisting clients during therapy. The involvement of staff was deemed necessary in this controlled study.

Despite these limitations, we conclude that SFBT has several strenghts and advantages that makes it a useful additional approach for use in people with ID. Firstly, SFBT focuses on skills rather than on deficits, and recognizes the expert status of people with MID. This is in line with the present view of ID that focuses on elements such as empowerment. Secondly, our findings support Stoddart et al.'s (2001) discussion of the strengths of using SFBT in people with ID: "SFBT is a highly structured, active, and directive approach. It focuses on concrete and immediate issues. The approach partializes problems by setting limited and clearly defined goals, and it fosters an early and positive relationship between clients and therapists" (p. 36). As stated in the introduction, people with ID are reported to experience behaviour problems and/or psychiatric disorders twice as often as the general population (Cooper et al., 2007). SFBT can support them in overcoming or at least reducing such problems in a structured and focused manner, emphasizing the individual's unique contribution. In this study, we focused on clients with clinically significant problems. In this study, we focused on clients with clinically significant problems. However, SFBT can also be used for less severe problems, such as housekeeping issues (see Roeden et al., 2009 for the use of SFBT with a less severe problem). Thirdly, SFBT encourages the involvement of staff in the therapeutic process. This may help staff to develop more positive views of people with MID and to become more aware of their resilience, resources and competences, and in particular their ability to come up with solutions themselves (Lloyd \& Dallos, 2006; 2008). Indeed, solution-focused principles and techniques developed in a therapeutic context can easily be adapted to a staff context. This also implies possibilities to use SFBT as tool for non-therapeutic coaching. As in SFBT, staff actually can develop a strengthsbased mindset: focusing on solutions rather than problems, on strengths rather than weaknesses, and asking more than telling. Solution-focused therapists can be seen as specialists who can be employed on a temporary basis to assist clients with MID in achieving their therapy objectives. These temporary contributions become more sustainable if professionals also work in a solution-focused manner in their everyday practice. This entails adopting a 
solution-focused attitude by staff and making use of solution-focused conversation skills in supporting clients. Finally, unlike other therapies, there is empirical evidence that SFBT is equally effective for all socioeconomic groups (Macdonald, 2007). Yet people with MID are often economically disadvantaged and usually belong to lower social groups; the finding that they too can benefit from SFBT is certainly encouraging.

We therefore conclude that SFBT can be regarded as a valuable therapy. Nevertheless, further research in this area is needed, and should involve randomization, larger sample sizes, standardized measures, prolonged followup measurements, and comparisons with other established therapies.

\section{References}

Appelo, M.T. (2005). Positieve Uitkomsten Lijst; PUL [Positive Outcome Scale; POS]. Nijmegen: Cure \& Care Publishers.

Bannink F.P. (2010). 1001 solution-focused questions. New York: Norton.

Beail, N., Warden, S., Morsley, K. \& Newman, D. (2005). Naturalistic evaluation of the effectiveness of psychodynamic psychotherapy with adults with intellectual disabilities. Journal of Applied Research in Intellectual Disabilities, 18, 245-251.

Beyebach, M., Morejon, A.R., Palenzuela, D.L. \& Rodriguez-Aria, J.L. (1996). Research on the process of solution-focused therapy. In S.D. Miller, M.A. Hubble \& B.L. Duncan (Eds.), Handbook of solution-focused brief therapy (pp. 299-334). San Franciso: Jossey-Bass.

Cohen, J. (1988). Statistical power analysis for the behavioural sciences. Hillsdale: Lawrence Erlbaum.

Cooper, S.A., Smiley, E., Morrison, J., Williamson, A. \& Allan, L. (2007). Mental ill-health in adults with intellectual disabilities: prevalence and associated factors. British Journal of Psychiatry, 190, 27-35.

Corcoran, J. (2002). Developmental adaptations of solution-focused family therapy. Brief treatment and Crisis Intervention, 2, 301-313.

Corcoran, J. \& Ivery, J. (2004). Parent and child attributions for child behaviour: Distinguishing factors for engagement and outcome. Families in Society: The Journal of Contemporary Social Services, 85, 101-106.

De Shazer, S. (1985). Keys to solution in brief therapy. New York: Norton. 
De Shazer, S., Dolan, Y.M., Korman, H., Trepper, T., McCollum, E.E. \& Berg, I.K. (2007). More than miracles: The state of the art of solution-focused therapy. New York: Routledge Press.

Dunn, O.J. (1961). Multiple comparisons among means. Journal of the American Statistical Association, 56, 52-64.

Field, A. (2005). Discovering Statistics using SPSS. London: Sage.

Fischer, R.L. (2009). Assessing client change in individual and family counseling. Research on Social Work Practice, 11,102-111.

Gingerich, W.J., Kim, J.S., Stams, G.J.J.M. \& Macdonald, A.J. (2012). Solution-focused Therapy Outcome Research. In C. Franklin, T.S. Trepper, W.J. Gingerich \& E.E. McCollum (Eds.), Solution-focused Brief Therapy; A Handbook of Evidence-Based Practice (95-111). New York: Oxford University Press.

Green, S. (2012). Solution-focused Life Coaching. In C. Franklin, T.S. Trepper, W.J. Gingerich \& E.E. McCollum (Eds.), Solution-focused Brief Therapy; A Handbook of Evidence-Based Practice (pp. 342-353). New York: Oxford University Press.

Hoekman, J., Douma, J.C.H., Kersten, M.C.O., Schuurman, M.I.M. \& Koopman, H.M. (2001). IDQOL-Intellectual Disability Quality of Life: de ontwikkeling van een instrument ter bepaling van de 'kwaliteit van bestaan' van mensen een verstandelijke handicap [Developing an instrument to determine the 'quality of life' for people with intellectual disabilities]. Nederlands Tijdschrift voor de Zorg aan verstandelijk gehandicapten [Dutch Journal for the care for people with intellectual disabilities], 27, 207-225.

Kim, J.S. (2008). Examining the effectiveness of solution-focused brief therapy: A meta-analysis. Research on Social Practice, 18, 107-116.

Kraijer, D.W. \& Kema, G.N. (1994). Sociale redzaamheidsschaal, SRZ-p voor zwakzinnigen van hoger niveau. Handleiding [Manual for the SRZ social skills scale for people with mild intellectual disabilities]. Lisse: Swets Test Service.

Lentham, J. (2002). Brief solution-focused therapy. Child and Adolescent Mental Health, 7, 189-192.

Lloyd, H. \& Dallos, R. (2006). Solution-focused brief therapy with families who have a child with intellectual disabilities. A description of the content of initial sessions and the processes. Clinical Child Psychology and Psychiatry, 11, 367-386. 
Lloyd, H. \& Dallos, R. (2008). First session solution-focused brief therapy with families who have a child with severe intellectual disabilities. Mothers' experiences and views. Journal of Family Therapies, 30, 5-28.

Macdonald, A. (2007). Solution-focused therapy: Theory, research \& practice. Sage, London: Sage.

Meyers, J.M. \& Auld, F. (2006). Some variables related to outcome of psychotherapy. Journal of Clinical Psychology, 11, 51-54.

Murphy, J.J. \& Davis, M.W. (2005). Video exceptions. An empirical case study involving a child with developmental disabilities. Journal of Systematic Therapies, 24, 66-79.

Oliver, P.C., Piachaud, J., Done, J., Regan, A., Cooray, S. \& Tyrer, P. (2002). Difficulties in conducting a randomized controlled trial of health service interventions in intellectual disability: implications for evidence-based practice. Journal of Intellectual Disability Research, 46, 340-345.

Reiss, S. (1988). The Reiss Screen for Maladaptive Behavior Test Manual. Orland Park: International Diagnostic Systems, Inc.

Quick, E. \& Gizzo, D.P. (2007). The 'doing what works' group: A quantitative and qualitative analysis of solution-focused group therapy. Journal of Family Psychotherapy, 18, 65-84.

Reiss, S., Minnen, A. \& van Hoogduin, K. (1994). Handleiding; de Nederlandse versie van de Reiss Screen for Maladaptive Behaviour [Dutch Manual of the Reiss Screen for Maladaptive Behaviour]. Orland Park, IL: International Diagnostic Systems.

Roeden, J.M. \& Bannink, F.P. (2007). Handboek oplossingsgericht werken met licht verstandelijk beperkte cliënten [Handbook solution-focused interventions with clients with intellectual disabilities]. Amsterdam: Pearson.

Roeden, J.M., Bannink, F.P., Maaskant, M.A. \& Curfs, L.M.G. (2009). Solution-focused brief therapy with persons with intellectual disabilities. Journal of Policy and Practice in Intellectual Disabilities, 6, 253-259.

Roeden, J.M., Maaskant, M.A., Bannink, F.P. \& Curfs, L.M.G. (2011). Solution-Focused Brief Therapy with People with Mild Intellectual Disabilities: a Case Series. Journal of Policy and Practice in Intellectual Disabilities, 4, 247255.

Shilts, L., Rambo, A. \& Hernandez, L. (1997). Clients helping therapists find solutions in their therapy. Contemporary Family Therapy, 19, 117-132. 
Smith, I.C. (2005). Solution-focused brief therapy with people with learning disabilities. A case study. British Journal of Learning Disabilities, 33, 102-105.

Smith, I.C. (2006). Ideas for solution-based working with people who have intellectual disabilities. Solution News, 2, 21-25.

Stams, G.J., Dekovic, M., Buist, K. \& De Vries, L. (2006). Effectiviteit van oplossingsgerichte korte therapie: een meta-analyse [The efficacy of solutionfocused therapy: A meta-analysis]. Gedragstherapie, 39, 81-94.

Stoddart, K.P., McDonnel, J., Temple, V. \& Mustata, A. (2001). Is brief better? A modified brief solution-focused therapy approach for adults with a developmental delay. Journal of Systematic Therapies, 20, 24-40.

Teall, B. (2000). Using solution-focused interventions in an ecological frame. A case illustration. Social Work in Education, 22, 54-61.

Wechsler, D. (2005a). WISC-III-NL, Wechsler Intelligence Scale for ChildrenIII. Amsterdam: Pearson.

Wechsler, D. (2005b). WAIS-III-NL, Wechsler Intelligence Scale for AdultsIII. Amsterdam: Pearson.

Westra, J. \& Bannink, F.P. (2006a). 'Simpele' oplossingen! Oplossingsgericht werken bij mensen met een lichte verstandelijke beperking, deel 1 ['Simple' solutions! Solution focused interviewing with intellectually disabled clients, part 1]. PsychoPraxis, 8, 158-116.

Westra, J. \& Bannink, F.P. (2006b). 'Simpele' oplossingen! Oplossingsgericht werken bij mensen met een lichte verstandelijke beperking, deel 2 ['Simple' solutions! Solution focused interviewing with intellectually disabled clients, part 2]. Psychopraxis, 8, 213-218. 


\section{g. 500 : ni}

dexh ina

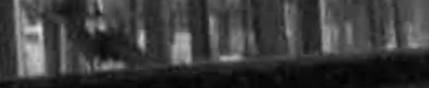

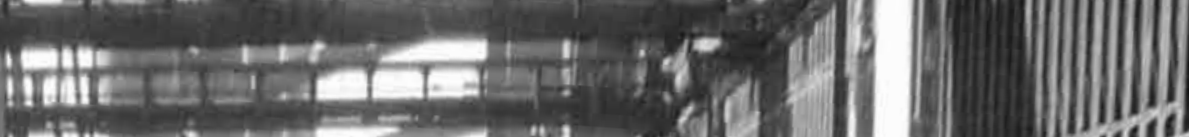
4)

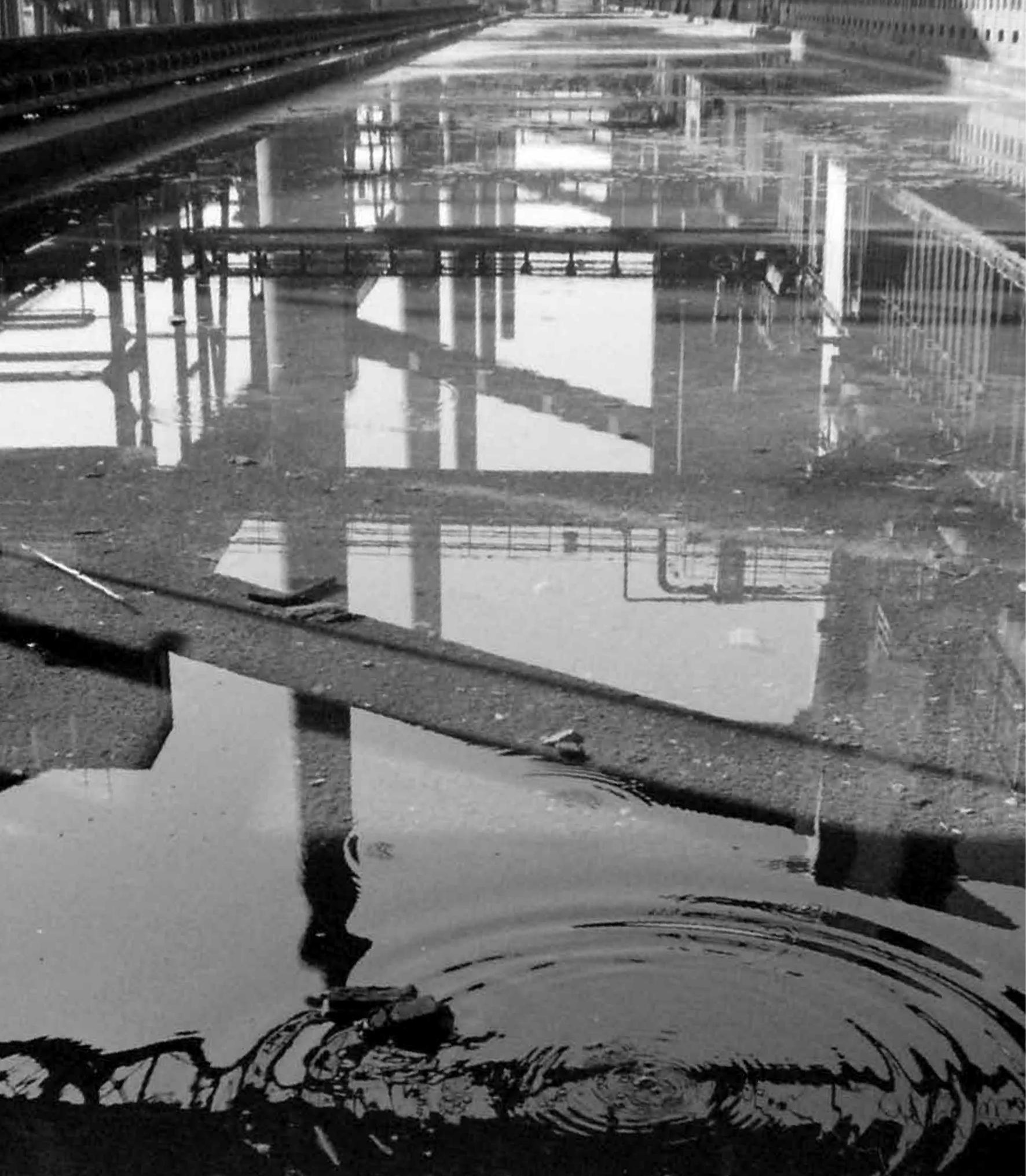




\title{
CHAPTER 6
}

\author{
ASSESSING CLIENT-CAREGIVER RELATIONSHIPS \\ AND THE APPLICABILITY OF THE \\ 'STUDENT-TEACHER RELATIONSHIP SCALE' \\ FOR PEOPLE WITH INTELLECTUAL DISABILITIES
}

Roeden, J.M., Maaskant, M.A., Koomen, H.M.Y., Candel, M.J.J.M. \& Curfs, L.M.G. (2011). Assessing client-caregiver relationships and the applicability of the 'student-teacher relationship scale' for people with intellectual disabilities.

Research in Developmental Disabilities, 33, 104-110. 


\section{Abstract}

Background. Improvements in client-caregiver relationships may lead to improvements in the quality of life of clients with intellectual disabilities (ID). For this reason, interventions aimed at influencing these relationships are important. To gain insight into the nature and intention of these relationships in the ID population, suitable measurement instruments are needed. This study examines the applicability of an existing relationship questionnaire designed for primary education, called the Student-Teacher Relationship Scale (STRS) on the basis of the following research questions: (1) What is the factor structure of the STRS? (2) Are there associations between STRS scales and other conceptually comparable instruments? (3) Is the STRS reliable?

Method. The participants in this study were 46 caregivers, who assessed 350 client-caregiver relationships. Psychometric research was conducted into the factor structure $(n=350)$, construct validity $(n=146)$, internal consistency $(n=350)$ and test-retest reliability $(n=177)$ of the STRS and the reliability of the individual scores $(n=350)$ among a study population of people with moderate and severe ID.

Results. The three-factor model of the STRS as used in primary education (1. closeness, 2. conflict, 3. dependency) was, despite minor deviations, also found in the ID population. Research into the construct validity of the STRS showed statistically significant correlations with other scales with which similarities could be expected. The internal consistency and test-retest reliability of the STRS in the population studied were very good. The $95 \%$ confidence intervals of the means were small, and these measurements can be regarded as reliable.

Conclusions. The STRS can also be used to evaluate the effects of interventions aiming to influence client-caregiver relationships. In research, it can help to bring about greater insight into the influence of the client-caregiver relationships on problem behaviour and how to reduce it.

\section{Keywords}

Client-Caregiver Relationships, Intellectual Disabilities, Student-Teacher Relationship Scale, Psychometric Qualities 


\section{Introduction}

The academic literature over the last 20 years has increasingly pointed to the importance of positive relationships between clients with intellectual disabilities (ID) and caregivers, as a precondition for the client's good quality of life (Schuengel, Kef, Damen \& Worm, 2010) and/or to reduce problem behaviour (Hastings, 2005). In studies on the significance of these relationships, both 'attachment theory' and 'ecological theory' play an important role. Attachment theory emphasises the development of meaningful relationships, with insecure attachment being one of the causes of problem behaviour. Interventions grounded in attachment theory for clients with ID are applied in Došen's (2007) integrative therapy and in Sterkenburg, Janssen, and Schuengel's (2008a,b) attachment-based behaviour therapy. In the latter, the development of an attachment relationship led to decreased problem behaviour in children with ID. In ecological theories, the cause of problem behaviour is primarily sought in the social environments of clients with ID. Interventions focus on reducing negative interactions between caregivers and clients with ID. Hastings, Daley, Burns and Beck (2006) and Weigel, Langdon, Collins, and O'Brien (2006) suggest that, as negative criticism by caregivers is closely tied to problem behaviour in clients with ID, interventions should aim to reduce 'high emotions' by caregivers (criticism, hostility, over-involvement). Thus, research into interventions focused on improving client-caregiver relationships is important as it may help to reduce problem behaviour and improve the quality of life of clients with ID. To gain insight into the nature and intention of these relationships - and to be able to measure intervention effects - suitable measurement instruments are needed. However, for the ID population these instruments are not presently available or are still being developed (Hastings, 1997; Willems, Embregts, Stams \& Moonen, 2010).

Studies on professional care giving relationships in education have reported beneficial effects of positive student-teacher relationships and adverse effects of negative relationships for adjustment outcomes such as fun at school, problem behaviour and school performance (Baker, 2006; Birch \& Ladd, 1997; Hamre \& Pianta, 2001; Hughes, 2011; Valiente, Lemery-Chalfant, Swanson \& Reiser, 2008). The Student-Teacher Relationship Scale (STRS; Pianta, 2001) is a commonly used questionnaire to measure the affective 
quality of professional care giving relationships in primary education. Koomen, Verschueren, and Pianta (2007) and Koomen, Verschueren, van Schooten, Jak, and Pianta (2011) adjusted the STRS for use in the Netherlands and for use with children from 3 to 12 years of age (in the US it has been used with children from 4 years and 1 month to 8 years and 8 months). The STRS is used to determine teachers' perceptions of their relationships with individual students. Since the studies by Birch and Ladd (1997) and Pianta, Steinberg, and Rollins (1995), the literature on student-teacher relationships has been dominated by a model consisting of three relationship dimensions: 'closeness', 'conflict' and 'dependency'. These dimensions are based on concepts from attachment theory, and are also measured by the STRS. The closeness subscale measures the teacher's perceived degree of affection, warmth, open communication, engagement, confidence and security. This subscale is seen as a positive relationship dimension. In contrast, the conflict subscale measures negativity, conflicts, unpredictability, anger and forceful behaviour, and is considered a negative relationship dimension. Likewise, the dependency subscale measures excessive demand for help and attention and strong responses to separation, and is also regarded as a negative relationship dimension. The questionnaire as a whole measures the general quality of the relationship as perceived by the teacher. Dekker (2008) validated the STRS among teachers and students in secondary special education for children with emotional and behavioural disturbances ( $n=123$, ages 13 to 18, including 24 students with mild ID). The results showed that the factor structure of the special education population was virtually identical to that of the general primary education population.

This study examines the applicability of the STRS for the relationships between clients with ID and caregivers, on the basis of the following research questions: (1) What is the factor structure of the STRS, and to what extent are the same dimensions (closeness, conflict, dependency) found in the ID population as in primary school students? (2) Is the construct validity of the STRS in the ID population supported by relationships with conceptually comparable scales? (3) What is the internal consistency and the test-retest reliability of the STRS, and the reliability of the individual scores on the STRS subscale items? 


\section{Method}

\subsection{Participants and Procedures}

The participants in this study were 46 caregivers (42 women, 4 men) working in 19 activity groups spread across 4 activity centres of a large organisation for service provision to approximately 900 clients with ID. All caregivers had worked in this organisation for more than 6 months, and for at least 2.5 days per week. In the 19 activity groups studied, the STRS was filled in for 76 (48\%) people with severe ID and 82 (52\%) people with moderate ID. Each activity group had between 1 and 3 caregivers, who assessed the clientcaregiver relationships. In total, data was obtained for 350 client-caregiver relationships, and was used to calculate the factor structure, the internal consistency of the STRS and the $95 \%$ confidence intervals for the means of the STRS subscales.

To avoid over-burdening staff with too many questionnaires, in 2 of the 4 activity centres (10 groups) the research focus was on construct validity, and in the remaining 2 activity centres ( 9 groups) on test-retest reliability. For the construct validity research, both the STRS and directly thereafter the Temperament Scale (TVZ, Blok, Van den Berg \& Feij, 1990: see below) were filled in for 146 client-caregiver relationships, as both scales have conceptual similarities (non-response: 17 incomplete TVZ questionnaires). For the testretest reliability of the questionnaire, the same caregivers filled in the STRS for 177 client-caregiver relationships twice, with a two-week interval (nonresponse: 10 questionnaires not completed during the retest).

Permission for the study was granted by the Client Council (comprised of service users with ID) and by the Representative Council (comprised of family members or representatives of service users with ID) of the service provider. The council confirmed that the study complied with the local organisational guidelines for internal evaluation. All participants in the study agreed to anonymous publication of the research data. 


\subsection{Instruments}

In this study, the STRS (adapted version; Koomen et al., 2007) is used to measure the relationships between clients with ID and caregivers. The term 'student' has been changed to 'client'. Staff rated the extent to which they agreed with each statement in the STRS using a 5-point Likert scale ( $1=$ Definitely does not apply, 2 = Does not really apply, 3 = Neutral, not sure, $4=$ Applies somewhat and $5=$ Definitely applies). Psychometric research in Dutch school settings (Koomen et al., 2007) showed that the original STRS dimensions of closeness, conflict and dependency were supported by a confirmatory factor analysis. It also showed that internal consistency was 'respectable' to 'very good' according to DeVellis's (2003) criteria: Cronbach's alphas ranged from 0.77 to 0.90 .

The 'Temperament Scale for people with ID' (TVZ; Blok et al., 1990) measures a number of personal characteristics, including temperament. The TVZ is filled in by caregivers across 7 subscales: 'adaptation', 'intensity', 'sensitivity', 'mood', 'persistence', 'soothability' and 'approachability' as well as a composite scale 'difficult temperament'. The TVZ scales of approachability, intensity and difficult temperament were selected for the research into the STRS's construct validity due to their conceptual similarities with the STRS scales of closeness and conflict. Approachability measures accessibility/positive orientation to the environment, while intensity measures acting-out behaviour. Difficult temperament measures intense responses, poor distractibility, negative response to changes and depressive mood. Staff rated the extent to which they agreed with each item in the TVZ using a 5-point Likert scale ( $1=$ Never, 2 = Rarely, 3 = Sometimes, 4 = Often and 5 = Always). In psychometric research, the TVZ subscales were supported by a factor analysis (Blok et al., 1990). The internal consistency was shown to be 'respectable' to 'very good' according to DeVellis's (2003) criteria (Cronbach's alphas ranged from 0.75 to 0.86$)$. 


\subsection{Statistical Analyses}

\subsubsection{Factor structure}

Principal factor analysis was used to calculate the factor structure of the STRS. This has advantages compared to principal component analysis when the aim of the research, as in this study, is a first exploration of a data structure (Field, 2009). The suitability of the dataset for factor analysis was determined using the Kaiser-Meyer-Olkin (KMO) index and the Bartlett test of sphericity. The higher the KMO (range 0-1), the more suitable the dataset (Hutcheson \& Sofroniou, 1999). The Bartlett test needs to be statistically significant ( $p<$ $0.05)$. Oblimin rotation was the chosen rotation method, because based on earlier STRS research (Koomen et al., 2007) the underlying factors could be assumed to be interrelated (e.g., positive correlations between the STRS scales of conflict and dependency and negative correlations between the scales closeness and conflict). The value 0.40 was used as a cut-off point for significant factor loadings (Field, 2009). The number of STRS factors was chosen on the basis of the Cattell scree plot (Cattell, 1966). The eigenvalues for successive factors can be shown in a line plot. The optimal number of factors corresponds with the place where the smooth decrease of eigenvalues appears to level off to the right of the plot.

It should be mentioned that caregivers rated their relationships with more than one client. In addition, several clients worked in the same department of the vocational centre. Consequently, hierarchical data structures (caregivers rating more than one client and several clients working in the same department of a vocational centre) could be possible. Such hierarchical structures can be identified via multilevel analyses. However, these additional analyses did not reveal statistically significant influences of the variables 'caregiver' and 'department' on the STRS scores. Therefore, neither variable was included in the factor analysis.

\subsubsection{Construct validity}

The similarities between the STRS scales and the TVZ scales were calculated using Pearson correlation coefficients. These correlations were also calculated for the individual STRS scales. Due to the conceptual similarities, statistically significant positive correlations were expected between the subscales of 
closeness (STRS) and approachability (TVZ), between conflict (STRS) and intensity (TVZ) and between conflict (STRS) and difficult temperament (TVZ). Due to conceptual contrasts, statistically significant negative correlations were expected between the subscales of closeness (STRS) and intensity (TVZ), between closeness (STRS) and difficult temperament (TVZ), and between conflict (STRS) and approachability (TVZ).

Based on research by Koomen et al. (2007), statistically significant correlations between the individual STRS scales were also expected. They found (1) a statistically significant positive correlation between the scales of conflict and dependency $(r=0.42 ; p<0.01)$ and (2) a statistically significant negative correlation between the scales of closeness and conflict $(r=-0.40 ; p$ $<0.001)$ and (3) a statistically significant positive but low correlation between the scales of closeness and dependency $(r=0.05 ; p<0.05)$.

\subsubsection{Reliability}

For each STRS scale and for the total score, the internal consistency was calculated using Cronbach's alpha. Test-retest reliability was calculated using the intraclass correlation coefficient (ICC), a measure for quantifying the agreement between two (or more) repeatedly measured values. The reliability of the individual scores was determined by calculating the standard error of measurement SEM $=\mathrm{SD} * \sqrt{ }(1-\mathrm{ICC}))$ and the $95 \%$ confidence interval (CI) around the mean subscale scores (95\% CI $=\bar{x} \pm 1.96 * \mathrm{SEM})$. A CI can be used to calculate the precision of a measurement. In repeated random spot checks from the same population, the confidence interval - in this case the $95 \%$ CI - will in $95 \%$ of cases cover the true value. The narrower the interval, the more precise the research results.

\section{Results}

\subsection{Factor structure}

The dataset was suitable for factor analysis, given the high values of the Kaiser-Meyer-Olkin index (0.88; 'very good' according to Hutcheson and Sofroniou [1999] and the statistical significance of the Bartlett test of sphericity $[p<0.001])$. On the basis of the Kaiser criterion, according to which 
factors are only formed if the eigenvalue is larger than 1, four factors were initially found. One factor, however, was represented by only one item ('this client is sneaky or manipulative with $\mathrm{me}^{\prime}$ ) and was thus redundant in view of the aim of factor analysis (i.e., to find underlying factors that represent multiple items). On the basis of the Cattell scree plot, three factors were selected. A three-factor model is consistent with the factor structure of the STRS as found among American primary school students (Pianta, 2001) and Dutch primary school students (Koomen et al., 2007). The principal factor analysis was therefore performed again, with three factors sought. Table 1 shows the result of this final factor analysis. 
Table 1: Principal Factor Analysis of the STRS after Oblimin Rotation

\begin{tabular}{|c|c|c|c|c|}
\hline \multirow[b]{2}{*}{$\begin{array}{l}\text { Item } \\
\text { Number }\end{array}$} & \multirow[b]{2}{*}{ Questions } & \multicolumn{3}{|c|}{$\begin{array}{l}\text { Rotated factor loadings } \\
\text { Factor loadings }\end{array}$} \\
\hline & & $\begin{array}{l}1 \\
\text { Conflict }\end{array}$ & $\begin{array}{l}2 \\
\text { Closeness }\end{array}$ & $\begin{array}{l}3 \\
\text { Dependency }\end{array}$ \\
\hline 2 & $\begin{array}{l}\text { This client and I always seem to be struggling with } \\
\text { each other }\end{array}$ & 0.75 & & \\
\hline 11 & This client easily becomes angry with me & 0.73 & & \\
\hline 13 & This client feels that I treat him/her unfairly & 0.70 & & \\
\hline 18 & $\begin{array}{l}\text { This client remains angry or is resistant after being } \\
\text { disciplined }\end{array}$ & 0.67 & & \\
\hline 26 & This client is sneaky or manipulative with me & 0.65 & & \\
\hline 23 & $\begin{array}{l}\text { This client's feelings toward me can be unpredictable } \\
\text { or can change suddenly }\end{array}$ & 0.60 & & \\
\hline 16 & $\begin{array}{l}\text { This client sees me as a source of punishment and } \\
\text { criticism }\end{array}$ & 0.53 & & \\
\hline $17^{1}$ & $\begin{array}{l}\text { This client expresses hurt or jealousy when I spend } \\
\text { time with other clients }\end{array}$ & 0.52 & & \\
\hline 24 & $\begin{array}{l}\text { Despite my best efforts, I'm uncomfortable with how } \\
\text { this client and I get along }\end{array}$ & 0.49 & & \\
\hline 25 & $\begin{array}{l}\text { This client whines or cries when he/she wants } \\
\text { something from me }\end{array}$ & 0.43 & & \\
\hline 22 & $\begin{array}{l}\text { When this client is in a bad mood, I know we're in } \\
\text { for a long and difficult day }\end{array}$ & 0.40 & & \\
\hline 9 & This client seems to feel secure with me & & 0.73 & \\
\hline 21 & $\begin{array}{l}\text { This client allows himself/herself to be encouraged } \\
\text { by me }\end{array}$ & & 0.72 & \\
\hline 28 & $\begin{array}{l}\text { My interactions with this client make me feel } \\
\text { effective and confident }\end{array}$ & & 0.69 & \\
\hline 7 & When I praise this client, he/she beams with pride & & 0.67 & \\
\hline 3 & If upset, this client will seek comfort with me & & 0.67 & \\
\hline 1 & $\begin{array}{l}\text { I share an affectionate, warm relationship with this } \\
\text { client }\end{array}$ & & 0.66 & \\
\hline 12 & This client tries to please me & & 0.65 & \\
\hline 5 & This client values his/her relationship with me & & 0.64 & \\
\hline 15 & It is easy to be in tune with what this client is feeling & & 0.64 & \\
\hline 27 & $\begin{array}{l}\text { This client openly shares his/her feelings and } \\
\text { experiences with me }\end{array}$ & & 0.62 & \\
\hline 10 & This client is overly dependent on me & & & -0.82 \\
\hline 6 & $\begin{array}{l}\text { This client fixes his/her attention on me the whole } \\
\text { day long }\end{array}$ & & & -0.76 \\
\hline 8 & This client reacts strongly to separation from me & & & -0.62 \\
\hline 19 & This client needs to be continually confirmed by me & & & -0.65 \\
\hline $20^{2}$ & Dealing with this client drains my energy & & & -0.48 \\
\hline 14 & $\begin{array}{l}\text { This client asks for my help when he/she really does } \\
\text { not need help }\end{array}$ & & & -0.46 \\
\hline \multicolumn{2}{|c|}{ Eigenvalue } & 6.1 & 5.3 & 1.1 \\
\hline \multicolumn{2}{|c|}{ Percentage of explained variation } & 24.5 & 21.4 & 5.8 \\
\hline \multicolumn{2}{|c|}{ Cronbach's alpha } & .87 & .89 & .81 \\
\hline \multicolumn{2}{|c|}{ Mean } & 20.4 & 39.7 & 14.8 \\
\hline \multicolumn{2}{|c|}{ Standard deviation } & 7.2 & 6.5 & 5.1 \\
\hline
\end{tabular}

Notes: Only factor loadings $>0.40$ are shown; ${ }^{1}$ Item 17 is placed in the dimension conflict (original dimension: dependency); ${ }^{2}$ Item 20 is placed in the dimension dependency (original dimension: conflict). Item numbers are consistent with the original STRS items. 
Only minor differences with the factor structure from primary education were found. In the ID population, item 17 ('this client expresses hurt or jealousy when I spend time with other clients') loaded on the factor of conflict rather than on dependency, as in the Dutch primary school population. In addition, item 20 ('dealing with this client drains my energy') loaded on the factor of dependency rather than on conflict, as in the Dutch primary school population. For this reason, for the ID population items 17 and 20 were placed in the scales of conflict and dependency respectively. Item 4 ('this client is uncomfortable with physical affection or touch from me') had a factor loading below the set cut-off value of 0.40 , and was thus excluded from the analyses.

\subsection{Construct validity}

Table 2 shows the correlations between the STRS scales and the TVZ scales, and between the individual STRS scales. In all analyses, the positive and negative correlations between the relationship dimensions of the STRS and the temperament characteristics of the TVZ were in line with expectations. However, the negative correlation expected (and indeed found) between the scales of closeness and difficult temperament was not statistically significant. The negative correlations between the scales of closeness and intensity and between conflict and approachability were statistically significant, but 'very weak' according to Floyd et al.'s (2006) criteria. The remaining correlations were statistically significant and 'moderate', in Floyd's terms.

The correlation pattern between the individual STRS scales was only partly consistent with what was expected based on the correlation pattern found in the primary school population. The statistically significant positive correlation expected between the scales of conflict and dependency was confirmed in the ID population $(r=0.56 ; p<0.01$ in the ID population compared to $r=0.42 ; p<0.001$ in primary education). The negative correlation expected between the scales of closeness and conflict was indeed found in the ID population, but was very weak and not statistically significant $(r=-0.08 ; \mathrm{ns}$. in the ID population in comparison with $r=-0.40 ; p<0.001$ in primary education). A somewhat less weak statistical significant correlation was found between closeness and dependency in the ID population $(r=0.20$; 
$p<0.01$ in the ID population compared with $r=0.05 ; p<0.05$ in primary school).

Table 2: Correlations (Pearson's correlation coefficients) between the STRS and TVZ scales $(n=146)$ and between the individual STRS scales $(n=350)$

\begin{tabular}{|c|c|c|c|c|}
\hline & \multicolumn{4}{|c|}{ TVZ scales } \\
\hline \multirow{3}{*}{$\begin{array}{l}\mathbf{S} \\
\mathbf{T} \\
\mathbf{R} \\
\mathbf{S}\end{array}$} & & Approachability & Intensity & $\begin{array}{l}\text { Difficult } \\
\text { Temperament }\end{array}$ \\
\hline & Closeness & $0.40 * * a$ & $-0.29 * * a$ & $-0.11^{\mathrm{a}}$ \\
\hline & Conflict & $-0.20 * a$ & $0.60 * * a$ & $0.60 * * a$ \\
\hline \multirow{5}{*}{$\begin{array}{l}S \\
T \\
R \\
S\end{array}$} & \multicolumn{4}{|c|}{ STRS subscales } \\
\hline & & Closeness & Conflict & Dependency \\
\hline & Closeness & -- & $-0.08^{a}$ & $0.20 * * a$ \\
\hline & Conflict & $-0.08^{a}$ & -- & $0.56 * * a$ \\
\hline & Dependency & $0.20 * * a$ & $0.56 * * a$ & -- \\
\hline
\end{tabular}

$* * p<0.01 ; * p<0.05$.

${ }^{a}$ in line with expected correlation.

\subsection{Reliability}

The Cronbach's alphas (internal consistency, $n=350$ ) of the STRS scales and for the total score were 0.89 for closeness, 0.87 for conflict, 0.81 for dependency and 0.87 for the total score; that is, 'very good' according to DeVellis's (2003) criteria. The intraclass correlation coefficients (test-retest reliability, $n=177$ ) of the STRS scales were 0.89 for closeness, 0.92 for conflict, 0.85 for dependency and 0.92 for the total score; that is, 'excellent' according to Cicchetti and Sparrow's (1981) criteria. The means were reliable parameters, given the narrow confidence intervals: closeness $39.7 \pm 0.7$, conflict $20.4 \pm 0.8$, dependency $14.7 \pm 0.5$. Table 3 shows the measures indicated for each subscale and for the total score, including the $95 \%$ confidence intervals for the means. 
Table 3: Internal consistency (Cronbach's alpha), test-retest reliability (ICC), $95 \%$ confidence intervals (95\% CI) and ranges of the STRS scales

\begin{tabular}{|l|c|c|c|c|}
\hline Dimensions & Closeness & Conflict & Dependency & Total score \\
\hline $\begin{array}{l}\text { Cronbach's a } \\
\mathrm{n}=350\end{array}$ & 0.89 & 0.87 & 0.81 & 0.87 \\
\hline $\begin{array}{l}\text { ICC } \\
\mathrm{n}=177\end{array}$ & 0.89 & 0.92 & 0.85 & 0.92 \\
\hline $\begin{array}{l}\text { Mean } \\
\mathrm{n}=350\end{array}$ & 39.7 & 20.4 & 14.7 & 106.9 \\
\hline $\begin{array}{l}\mathbf{9 5 \%} \mathbf{C I}^{2} \\
\mathrm{n}=350\end{array}$ & $39.0-40.4$ & $19.6-21.2$ & $14.2-15.2$ & $105.8-108.0$ \\
\hline Range $^{3}$ & $10-50$ & $11-55$ & $6-24$ & $27-135$ \\
\hline
\end{tabular}

${ }^{1}$ ICC $=$ intraclass correlation coefficient.

${ }^{2} 95 \%$ CI covering the average score per subscale.

${ }^{3}$ Range $=$ minimum and maximum scores per subscale.

\section{Conclusions}

This study examined the applicability of the STRS among clients with ID. The factor structure in the ID population appeared to be closely comparable with that of primary school students. Item 4, 'this client is uncomfortable with physical affection or touch from me', was excluded as its factor loading was too low. This item also had the lowest loading in the studies by Koomen et al. (2007) and Dekker (2008). In people with ID, and particularly in those with an autism spectrum disorder, physical contact is often experienced as unpleasant. This casts doubt over item 4, as it is intended to be a positive relationship characteristic within the closeness dimension but is not experienced as such by clients with ID and caregivers. Thus, in addition to statistical issues, there are also substantive reasons for not including this question in the STRS for clients with ID. Due to the factor structure, item 20 ('dealing with this client drains my energy') was included in the dependency dimension. In clients with ID, and particularly with severe ID ( $48 \%$ in the population studied), dependency is also caused by severe physical disabilities and caregivers can find that dealing with these clients calls for extra energy. Thus, it seems reasonable to include it in the dependency dimension. Item 17 ('this client expresses hurt or jealousy when I spend time with other clients') was placed in the conflict dimension due to its factor loading. Teachers perhaps more readily accept jealous behaviour in children, because this behaviour is not unusual at a young age. It may be 
seen as inappropriate in adulthood, however, making caregivers less likely to accept jealous behaviour in adults with ID, which could give rise to conflict.

Construct validity was examined by comparing the STRS with the TVZ and analysing the associations between the individual STRS scales. The consistency between the STRS and TVZ was in line with expectations, although some correlation coefficients appeared to be quite low. These relatively low correlations (3 x 'very weak' and 3 x 'moderate' according to Floyd's [2006] criteria) may be attributed to the fact that, in addition to their conceptual similarities, there are considerable differences between these instruments. The STRS is underpinned by relational constructs, which take into account the share of the clients, the share of the caregivers and the interactions between the two groups. The TVZ, in contrast, only measures the caregivers' perceptions of the clients' temperaments.

In the study on the relationships between the individual STRS scales a negative correlation was found between conflict and closeness, but this correlation was very weak and not statistically significant. This contrasts with the primary education research, in which a statistically significant moderate negative correlation was found. This difference could relate to the different professional attitudes of caregivers versus teachers; caregivers may choose consciously to work with clients who display problem behaviour (including conflict). Thus, dealing with conflict is perhaps more inherent in the profession than in education, and causes no or little harm to the positive relationship (closeness). This notion is reinforced by the lack of a statistically significant negative correlation between closeness (STRS) and difficult temperament (TVZ).

The reliability of the STRS scales was very good: the internal consistency was 'very good' according to DeVellis's (2003) criteria, and the test-retest reliability of all STRS scales was 'excellent' according to Cicchetti and Sparrow's (1981) criteria. The 95\% confidence intervals for the means were small and thus reliable. Overall, the STRS appears to be a sound tool for measuring the relationship between caregivers and clients with ID.

One limitation should be noted, however: the STRS was only studied in vocational centres and filled in for clients with moderate and severe ID. The results can thus not be generalised to the ID population as a whole, because no data were included for people with mild and with profound ID. 
Measurement instruments need good psychometric qualities if they are to be applied responsibly in practice. In view of these results, the STRS can be used to screen or evaluate relationship patterns between clients with moderate and severe ID and caregivers. Differences between caregivers in scores for the same clients could then give rise to discussions on how caregivers can approach these clients. The STRS can also be used to evaluate the effects of interventions aiming to influence client-caregiver relationships. In research, it can help to bring about greater insight into the influence of the client-caregiver relationships on problem behaviour and how to reduce it.

\section{References}

Baker, J.A. (2006). Contributions of teacher-child relationships to positive school adjustment during elementary school. Journal of School Psychology, 44, 211-229.

Birch, S.H. \& Ladd, G.W. (1997). The teacher-child relationship and children's early school adjustment. Journal of School Psychology, 35, 61-79.

Blok, J.B., van den Berg, P.Th. \& Feij, J.A. (1990). Handleiding bij de Temperamentsschaal voor verstandelijk gehandicapten. Amsterdam: Pearson.

Cattell, R.B. (1966). The scree test for the number of factors. Multivariate Behavioural Research, 1, 245-276.

Cicchetti, D.V. \& Sparrow, S.S. (1981). Developing criteria for establishing interrater reliability of specific items: Applications to assessment of adaptive behaviour. American Journal of Mental Deficiency, 86, 127-137.

Dekker, S. (2008). De Leerling-leerkrachtrelatie in het Voortgezet Speciaal Onderwijs. Amsterdam: University of Amsterdam.

DeVellis, R.F. (2003). Scale development: Theory and applications (2nd ed.). Thousand Oaks: Sage.

Došen, A. (2007). Integrative treatment in persons with intellectual disability and mental health problems. Journal of Intellectual Disability Research, 51, 6674.

Field, A. (2009). Discovering statistics using SPSS. London: Sage.

Floyd, R.G., McCormack, A.C., Ingram, E.L., Davis, A.E., Bergeron, R. \& 
Hamilton, G.(2006). Relations between the Woodcock-Johnson III clinical clusters and measures of executive function system. Journal of Psychoeducational Assessment, 24, 303-317.

Hamre, B.K. \& Pianta, R.C. (2001). Early teacher-child relationships and the trajectory of children's school outcomes through eighth grade. Child Development, 72, 625-638.

Hastings, R.P. (1997). Measuring staff perceptions of challenging behaviour: the Challenging Behaviour Attributions Scale (CHABA). Journal of Intellectual Disability Research, 41, 495-501.

Hastings, R.P. (2005). Staff in special education settings and behaviour problems: Towards a framework for research and practice. Educational Psychology, 25, 207-221.

Hastings, R.P., Daley, D., Burns, C. \& Beck, A. (2006). Maternal distress and expressed emotion: Cross-sectional and longitudinal relationships with behaviour problems in children with intellectual disabilities. American Journal on Mental Retardation, 111, 48-61.

Hughes, J.N. (2011). Longitudinal effects of teacher and student perceptions of teacher-student relationship qualities on academic adjustment. Elementary School Journal, 112, 38-60.

Hutcheson, G. \& Sofroniou, N. (1999). The multivariate social scientist: Introductory statistics using generalized linear models. London: Sage.

Koomen, H.M.Y., Verschueren, K., Pianta, R.C. (2007). Leerling Leerkracht Relatie Vragenlijst. Houten: Bohn Stafleu van Loghum.

Koomen, H.M.Y., Verschueren, K., Van Schooten, E., Jak, S. \& Pianta, R.C. (2012). Validating the Student-Teacher Relationship Scale: testing factor structure and measurement invariance across child gender and age in a Dutch normative sample. Journal of School Psychology, 50, 215-234.

Pianta, R.C., Steinberg, M.S. \& Rollins, K.B. (1995). The first two years of school: Teacher-child relationships and deflections in children's classroom adjustment. Development and Psychopathology, 7, 295-312.

Pianta, R.C. (2001). STRS: Student-teacher relationship scale: Professional manual. Odessa, FL: Psychological Assessment Resources, Inc. Schuengel, C., Kef, S., Damen, S. \& Worm, M. (2010). 'People who need people': Attachment and professional caring. Journal of Intellectual Disability Research, 54, 38-47. 



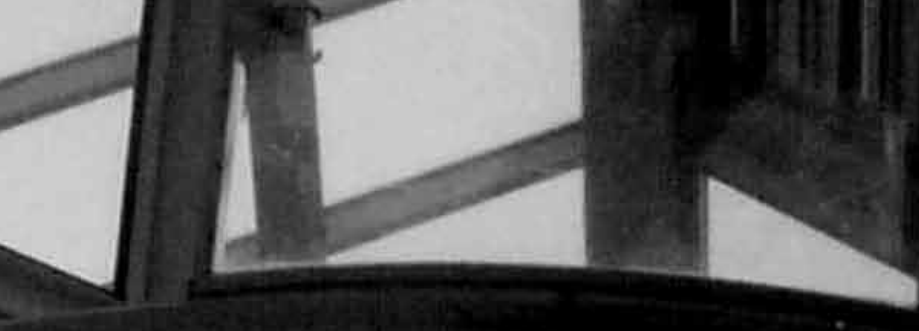




\section{SOLUTION-FOCUSED COACHING OF STAFF OF PEOPLE WITH SEVERE AND MODERATE INTELLECTUAL DISABILITIES; A CASE SERIES}

Roeden, J.M., Maaskant, M.A., Bannink, F.P. \& Curfs, L.M.G. (2012). Solution-Focused Coaching of Staff of People with Severe and Moderate Intellectual Disabilities (ID); a Case Series.

Journal of Policy and Practice in Intellectual Disabilities, 3, 185-194. 


\section{Abstract}

Background. Solution-Focused Coaching (SFC) represents a short-term, futurefocused and person-directed therapeutic approach that helps people focus on solutions rather than problems.

Method. Thirteen cases of SFC of staff dealing with people with severe and moderate intellectual disabilities (S/MID) are described. In all 13 cases, the progress towards the team goal, proactive thinking of staff, and the quality of the relationship between staff and people with S/MID, were measured directly before SFC, directly after SFC, and 6 weeks after SFC.

Results. After SFC, progress towards the team goal was found in 7 out of 13 teams, improvement of proactive thinking was found in 5/10 teams and improvement of the quality of the relationship was found in 7/13 teams. With regard to individual staff members improvement of proactive thinking was found in 12/34 staff members and improvement of the quality of the relationship was found in 22/42 staff members.

Discussion. Discussion centres on the extent to which SFC can improve selfefficacy and proactive thinking in teams. Suggestions are given as to how SFC can modify the quality of the relationship between staff and individuals with ID.

\section{Keywords}

Solution-Focused Coaching of Staff, Systemic Therapy, Intellectual Disabilities 


\section{Introduction}

Recently there has been an expansion in therapeutic interventions offered to people with ID, in order to decrease problems or to increase the quality of support or quality of life. These approaches include those that focus on family and caregiver systems (Collins, 1999; Fidell, 2000; Frankish \& Terry, 2003; Willems, Embregts, Stams \& Moonen, 2010). In this range of therapies, Solution-Focused Brief Therapy (SFBT; De Shazer, 1985) is a relatively new, behaviourally orientated therapy.

SFBT with clients with ID. SFBT represents a short-term, future-focused and person-directed therapeutic approach that helps people focus on solutions rather than on problems. Solution-Focused Coaching (SFC, see below) is based on SFBT. One of the central assumptions of SFBT is that the client defines the goal of the therapy and that the client has the competencies and resources to realise this goal. The person is invited to describe what will be different in the future once the person's goal is reached (goal setting). This could be done by means of the miracle question: 'Imagine a miracle occurring tonight that would (sufficiently) solve the problem, what will you be doing differently? How will other people know that things have improved?'. Another important element in SFBT is exploring the exceptions. The therapist asks questions regarding the moments in the client's life when the problem does not occur or is less serious and what is done to realise these exceptions. Scaling questions (10 = very good, 0 = very bad) are used in order to measure progress during therapy. These questions also are used to measure and stimulate hope, motivation, and confidence that the goal can be reached. In this way, this helps the client move away from 'all or nothing' goals, and strive for smaller, manageable and measurable steps. The therapist promotes descriptions of progress in these specific, small, behavioural steps. To stimulate or maintain changes, the therapist suggests homework assignments such as 'continue with what is working already'. During SFBT, the relationship (visitor, complainant or customer-relationship) with the person is assessed. In a visitor-relationship, the person is mandated or referred by others. He or she does not voluntarily seek help and is not experiencing emotional difficulties. In a complainantrelationship, the person is experiencing emotional difficulties. However, s/he 
does not (yet) or does not any longer see him/herself as part of the problem and/or the solution. In a customer-relationship the person experiences a problem and sees themselves as part of the problem and/or solution, and is motivated to change that behaviour. Each type of relationship requires a different approach by the therapist (Roeden \& Bannink, 2007; Bannink, 2010).

SFBT does not focus on people with ID specifically, but is suitable for them with some adaptations. Several authors suggest adjustments to SFBT for people with ID, due to their specific needs, developmental levels and abilities (Corcoran, 2002; Lentham, 2002; Smith, 2005, 2006). With these adjustments, SFBT was shown to be useful for people with mild ID (Stoddart, McDonnel, Temple \& Mustata, 2001; Roeden \& Bannink, 2007; Roeden, Bannink, Maaskant \& Curfs, 2009; Roeden, Maaskant, Bannink \& Curfs, 2011; Smith, 2005, 2006).

Rationale for utilizing SFC with staff. SFBT with people with profound, severe or moderate ID is not possible, because they lack sufficient verbal and cognitive abilities to describe their goals, perform homework assignments and evaluate their progress. In these instances, Solution-Focused Coaching (SFC) of staff working with people with profound, severe or moderate ID may provide an alternative (Westra \& Bannink, 2006a, 2006b). SFC in fact is the same as SFBT, albeit that the people in SFC are not individuals (with ID), but staff members of a team (for people with ID). In SFC, the team formulates a goal and a strategy to reach this goal. In this process, the therapist is called a coach. However, little is known about the usefulness of SFC for staff working with people with ID. Only scarce research on this topic is available (Lloyd \& Dallos, 2006, 2008; Rhodes, 2000; Stoddart et al., 2001). Rhodes (2000) found that SFC is a useful approach for staff working with people with ID. In particular, the focus on strengths was valued and the way staff members generated solutions that built on their competencies. Stoddart et al. (2001) treated 16 people with mild ID and with a range of problems, using SFBT. They also actively involved staff in the treatment procedures. Staff members developed more positive perspectives about the person because of their involvement in SFBT. They became more aware of the person's resiliencies, resources and competencies, and in particular the person's abilities to come up with solutions her/himself. Lloyd and Dallos $(2006,2008)$ found that mothers of children with severe ID experienced SFC as a useful approach to build useful 
relationships, to highlight self-efficacy and to encourage helpful coping styles. As Wheeler (2001) reported, SFC can be particularly helpful for caregivers in encouraging a sense of self-efficacy and proactive thinking, in altering negative perceptions and in enhancing positive attachment.

Several studies regarding the process of SFC (Bozeman, 1999; Jordin \& Quinn, 1994; Quick \& Gizzo, 2007; Shilts, Rambo \& Hernandez, 1997) found that the solution-focused techniques increase clients' hopes and expectations to accomplish their goals. Other studies (Bonsi, 2005; Gingerich, de Shazer \& Weiner-Davis, 1988; Speicher-Bocija, 1999) demonstrated that clients were also more likely to talk about positive change when solution-focused coaches asked about successes and exceptions to problems, or focused on goals. Concoran and Ivery (2004) demonstrated a positive association between clients' strengths identified by coaches on the one hand and positive outcomes on the other hand.

Recent research highlighted that staff supporting persons with ID experience moderate levels of burnout (Skirrow \& Hatton, 2007). Violent client behaviour (Hatton, Brown, Caine \& Emerson, 1995), high support needs (Dyer \& Quine, 1998), imbalanced relationships with clients (Van Dierendonck, Schaufeli \& Buunk, 1996) and challenging behaviour (Chung \& Harding, 2009; Jenkins, Rode \& Lovell, 1997; Prosser et al., 1997) showed to be associated with higher levels of burnout and other negative psychological outcomes. In dealing with all these support problems, SFC could be useful, because it offers staff a hopeful, outcome-oriented, competence-based set of interventions.

Aim of this study. Because more insight is needed in the usefulness of SFC in staff working in the ID-field, we conducted an exploratory study of 13 SFC-procedures with teams of staff members. These teams experienced difficulties in supporting people with severe and moderate ID (S/MID). We expected that SFC (1) could assist teams in reaching their team goals, (2) could improve proactive thinking in teams, and (3) could positively influence the relationship between staff and people with ID. In addition, we expected that staff would appreciate SFC. We therefore explored three topics. Firstly, we described the treatment protocol. Secondly, we measured differences directly before SFC, directly after SFC and 6 weeks after SFC, with regard to (1) progression towards the goal during SFC according to staff, (2) proactive thinking in teams, and (3) the quality of the relationship between staff and 
people with S/MID. Thirdly we measured the staff members' opinion of the SFC procedure and of the collaboration between coach and staff.

\section{Method}

\subsection{Participants and procedures}

The study was conducted at a service provider for children and adults with ID (approximately 900 people). People with ID use the residential services of this service provider, as well as services like respite-care, day-care and home-care. The service provider offers clients therapies, such as behaviour therapy and SFBT. SFC to teams is offered as well.

Staff members involved in this study were direct care workers who provided residential or vocational support for people with ID. A total of 42 staff members (all females), working in 13 teams, participated in this study. The teams consisted of 2-4 staff members. The mean age of staff members was 40.4 years $(S D=11.1$ years). Years worked in the ID-sector ranged from 1 year to 33 years with a mean of 12.7 ( $S D=8.6$ years). $46 \%$ was employed as direct care staff, and $54 \%$ as occupational therapy staff. $95 \%$ of the staff had a 3 year professional training in the domain nursing, social work or occupational therapy, which is standard in the Netherlands for direct care staff; $5 \%$ had a high school degree in nursing, teaching or social science. Staff who worked at the service provider agency and experienced a support problem with a client with ID, could apply for SFC with solution-focused coaches. Staff mentioned support problems such as violent client behaviour, imbalanced relationships (e.g., 'we give more than we receive'), communication problems, lack of progress with clients. Staff members gained a global understanding of SFC through attending an information meeting and by reading literature (Roeden, Bannink, Maaskant \& Curfs, 2009).

The two solution-focused coaches in this study had a master's degree in counselling. Their additional training program on solution-focused coaching included the history and philosophy of SFC, the tenets of SFC, session format and structure of SFC, video examples of founders of SFC, role playing and supervised practice with clients with ID. 
Permission for the study was granted by the Client Council (comprised of service users with ID) and by the Representative Council (comprised of family members or representatives of service users with ID) of the service provider. The council confirmed that the study complied with the local organisational guidelines for internal evaluation. All participants in the study agreed to anonymous publication of the research data.

\subsection{Treatment protocol}

In this study, 13 teams participated in SFC. For every case, measurements were taken directly before SFC, directly after SFC, and 6 weeks after SFC. The SFC-process according to session, intervention and description is summarised in table 1. During intake (session 1), the SFBT coach becomes acquainted with staff members through enquiries about the competencies of individual staff members and of the staff as a team. Subsequently, the support problems experienced by staff are explored. Two questions are then asked: 'What is the support problem with this person?' and 'What is the problem for staff members?'. The support problem focuses on one particular person with S/MID. During session 1 , the coach asks Solution-Focused questions, such as questions concerning the goals of staff, exceptions, scale questions and competency questions. Every session concludes with the coach giving feedback to staff members. A detailed example of a Solution-Focused consultation is described in the findings section. 


\section{Table 1: SFC-protocol according to session, intervention and} description

\begin{tabular}{|c|c|c|}
\hline Session & Intervention & Description \\
\hline \multirow[t]{2}{*}{ Intake } & 1. Getting acquainted & $\begin{array}{l}\text { The coach spends time to get to know the team. } \\
\text { Competencies and resources are explored. }\end{array}$ \\
\hline & $\begin{array}{l}\text { 2. Exploring the } \\
\text { problem }\end{array}$ & $\begin{array}{l}\text { The coach invites the team to describe their problem and/or } \\
\text { to mention their goal for coaching. The coach acknowledges } \\
\text { the problems of the team. }\end{array}$ \\
\hline \multirow[t]{7}{*}{$\begin{array}{l}\text { First } \\
\text { Session }\end{array}$} & 3. Pre-session change & $\begin{array}{l}\text { Since most teams have tried other possibilities before } \\
\text { connecting with a coach. The coach can ask whether and/or } \\
\text { what changes have already occurred before the first } \\
\text { session. }\end{array}$ \\
\hline & 4. Goal setting & $\begin{array}{l}\text { The team is invited to describe what would be different once } \\
\text { their goal is reached. This could be done by means of the } \\
\text { miracle question: 'Imagine a miracle occurring tonight that } \\
\text { would (sufficiently) solve the problem ... what would be } \\
\text { different tomorrow?' The coach may also suggest that } \\
\text { changes are possible (e.g., 'When you look forward and } \\
\text { things have improved, what will you be doing differently?') } \\
\text { or by using the video question: 'Suppose we make a video } \\
\text { showing the most desirable support situation. What do we } \\
\text { see and hear on this video?'. }\end{array}$ \\
\hline & $\begin{array}{l}\text { 5. Exploring the } \\
\text { exceptions }\end{array}$ & $\begin{array}{l}\text { The coach inquires about moments in the past or present } \\
\text { when the problem does not occur or is less serious and who } \\
\text { does what to bring about these exceptions. }\end{array}$ \\
\hline & 6. Scaling questions & $\begin{array}{l}\text { On a scale of } 10 \text { to } 1 \text { the team indicates their progression } \\
\text { towards their goal. Scaling questions help the team to move } \\
\text { away from all-or-nothing goals toward manageable and } \\
\text { measurable steps. }\end{array}$ \\
\hline & $\begin{array}{l}\text { 7. Competence } \\
\text { questions }\end{array}$ & $\begin{array}{l}\text { By using competence questions, self compliments are } \\
\text { provoked with the team. 'How do (did) you do that?' Direct } \\
\text { compliments aim to highlight something the team has done, } \\
\text { made or said. }\end{array}$ \\
\hline & $\begin{array}{l}\text { 8. The question: 'What } \\
\text { else?' }\end{array}$ & $\begin{array}{l}\text { The coach may also indicate with the question 'What else?' } \\
\text { indicating that there is more to come. Teams often respond } \\
\text { to this simple query by giving more information and ideas. }\end{array}$ \\
\hline & 9. Feedback & $\begin{array}{l}\text { At the end of every session feedback with compliments and } \\
\text { usually some homework are given. The compliments } \\
\text { emphasise what the team is already doing to reach their } \\
\text { goal. The suggestions indicate areas requiring the team's } \\
\text { attention or possible further actions needed to reach their } \\
\text { goal. Between the components of compliments and } \\
\text { suggestions/tasks a reason (or bridge) is given to perform } \\
\text { those tasks. }\end{array}$ \\
\hline \multirow{4}{*}{$\begin{array}{l}\text { Follow- } \\
\text { up } \\
\text { sessions }\end{array}$} & $\begin{array}{l}10 \text { The question: } \\
\text { 'What is better?' }\end{array}$ & The standard beginning question is: 'What is better?'. \\
\hline & $\begin{array}{l}\text { 11. EARS = Eliciting, } \\
\text { Amplifying, } \\
\text { Reinforcing, Start } \\
\text { again }\end{array}$ & $\begin{array}{l}\text { Eliciting, amplifying, and reinforcing of (small) successes, } \\
\text { exceptions to problems, or descriptions of the desired future } \\
\text { and the invitation to the team to do that again or more } \\
\text { often. }\end{array}$ \\
\hline & 12 Feedback & Compliments - reason/bridge - task. \\
\hline & 13 Consolidation & $\begin{array}{l}\text { Consolidation questions such as: 'What do you have to keep } \\
\text { doing to make sure that these results keep happening? How } \\
\text { are able to stay on track?'. }\end{array}$ \\
\hline
\end{tabular}


In session 2, the coach starts with the EARS-question-set. EARS is an acronym for Eliciting, Amplifying, Reinforcing, Start again. It outlines the therapeutic process. The first question is 'What is better?' (Eliciting). Staff members can respond to that question in four different ways: 'It is better', 'There is no change', 'It is worse', or 'There is a difference in opinions' (in this case, between staff members). If it is better, the coach can react to that by amplifying, 'What exactly is (somewhat) better?', by reinforcing, 'How did you manage to do that?' and by starting again, 'What (else) is better?'. EARS can also be utilised when staff believe there is no change. The coach acknowledges staff when they feel disappointed and emphasises that keeping a situation stable is an accomplishment and can sometimes be the highest achievable goal at that moment. The coach reviews with staff members how they accomplished that stability. When the situation had become worse, the coach also acknowledges staff members if they were disappointed, and a reorientation to the goal could be necessary. Alternatively, the coach can ask how staff were able to persevere under such difficult circumstances, which might then open up the discussion to the EARS set of questions. If there is a difference in opinions between staff members about the amount of progress, the coach first normalises this situation, by establishing that progress usually occurs in a systematic fashion and through trial and error. Subsequently, small improvements can be explored through EARS (Bannink, 2010). Consolidation questions (Selekman, 1993) were used at the end of the sessions to increase the likelihood that staff would keep on working on the desired goals. An example of such a consolidation question is: 'What do you have to keep doing to make sure that these results keep happening?'.

\subsection{Measures}

Measures focused on coaching effects of SFC (progression towards the goal, proactive thinking and quality of relationship between clients and staff) and also on staff members' opinions about the SFC procedure and the collaboration between coach and staff.

Progression towards the goal. The Scale Question Progression (SQP; Bannink, 2010) ranges from 10 (most desirable support situation) to 1 (least desirable 
support situation). It indicates to what extent a team goal has been approached or has been reached. The SQP was rated by all staff members independently. The scores used for analyses were average scores for each of the 13 teams. In solution-focused scale questioning, it is customary to ask the people concerned what they regard as a relevant improvement. In this study, the members of the 13 teams were asked about such an improvement. They decided that an average progression of 2 points could be regarded as a relevant improvement.

Proactive thinking. Proactive thinking was measured using part of the StaffClient Interactive Behaviour Inventory (SCIBI; Willems, Embregts, Stams \& Moonen, 2010).The 30-item SCIBI measures both intrapersonal staff behaviour (proactive thinking, self-reflection, critical expressed emotion) and interpersonal staff behaviour (assertive control, hostile, friendly and support seeking behaviour) in response to challenging behaviour of people with ID. These seven factors were supported by a factor analysis (Willems et al., 2010). The internal consistency of the SCIBI was satisfactory (Cronbach's alpha $>0.68$ ) for all scales.

Staff members were asked to complete the SCIBI-scale of proactive thinking (abbreviated as: SCIBI-PAT). The SCIBI-PAT is a 3 item self-report questionnaire using a 5-point Likert Scale, ranging from completely inapplicable (1) to completely applicable (5). The items are: 'In working with this client, I think about how (first item), what (second item) or why (third item) I am going to do things'.

Quality of the relationship between staff and people with ID The relationship between people with ID and staff members was measured using the Student Teacher Relationship Scale (STRS, authorised translation; Koomen, Verschueren \& Pianta, 2007; Koomen, Verschueren, Van Schooten, Jak \& Pianta, 2012). The 28-item STRS represents the view of the teacher on three relationship dimensions: closeness (11 items), conflict (12 items) and dependency (5 items). The total STRS-score represents the quality of the relationship. In consultation with the author of the STRS, the terms 'student' and 'teacher' were substituted by 'person with ID' and 'staff member' respectively. Staff rated the extent to which they agreed with each statement 
(for example: 'I share an affectionate, warm relationship with this person') using a 5-point Likert Scale, ranging from definitely does not apply (1) to definitely applies (5). Closeness reflects the degree of openness, warmth and security in the relationship according to the teacher/staff member. Conflict refers to the degree to which a teacher/staff member perceives interactions as negative, discordant, unpredictable and unpleasant. Dependency denotes the developmentally inappropriate degree of overreliance and possessiveness of the child/adult with ID in the relationship. Psychometric research in school settings showed a satisfactory internal consistency for all scales (Cronbach's a between 0.77 and 0.90). The STRS domains of closeness, conflict, and dependency were supported by a factor analysis. Roeden, Maaskant, Koomen, Candel \& Curfs (2012) studied the psychometric qualities of the STRS in an IDsetting. The factor structure matched with the factor structure found in educational settings. The internal consistency was good for all subscales and the total score (Cronbach's a between 0.81 and 0.89 ), as well as the testretest reliability (intraclass correlations coefficients between 0.85 and 0.92 ). In the present study, staff completed the STRS, and their raw scores were averaged per team, resulting in mean scores per team.

\subsection{Procedure and collaboration}

The assessment of staff about the procedure and the collaboration was measured using the Session Rating Scale (SRS). The SRS (Duncan, Miller \& Sparks, 2004) is a short list of 4 items, evaluating each conversation about the procedure and the collaboration between the solution-focused coach and staff members. The items refer to: a) the relationship, 'I felt I wasn't (versus I was) listened to, understood and respected', b) goals and subjects: 'We did not (versus we did) talk about the subjects I wanted to talk about', c) the procedure or method: 'The way in which the coach approaches my problems does not match (versus does match) my style', d) total session: 'Something was missing in the contact we had today (versus in general I found the contact we had to be OK)'. The 4 items were represented by 4 visual analogue scales of 10 centimetres. The left end of the line (score $=0$ ) represented the most negative response, the right end (score $=10$ ) the most positive response. The closest centimetre mark, indicated by a cross, determined the score. The 
authors of the SRS recommend asking the respondent to comment on (an aspect of) the coaching strategy or the collaboration whenever a subscale score is below 9. Duncan's research found that the SRS had a good internal consistency (Cronbrach's a: 0.88) and a reasonable stability (Pearson's $r$ : 0.64). Factor analysis was not conducted because of the small size of the list (4 items). The SRS is intended to stimulate the discussion between therapists and clients about the treatment (in the present study: between coach and staff), and -based on that- to improve the procedure and collaboration. In this study, the SRS was completed in every session.

\subsection{Analyses}

It was explicitly chosen to analyze the SCIBI-PAT and STRS data both on team level and on individual level. In this way it was measured whether or not teams as a whole did profit from SFC, rather than only measuring the, possibly contrasting, changes of individual staff members. The SQP scores were average teams scores and were only analysed on team level, because this goal was set and defined by the teams as a whole. Because of the relatively small sample size of teams $(n=13)$ a non-parametric test (Wilcoxon Signed-Rank Test) was used to analyse the team data. The Wilcoxon signed-rank test is a non-parametric statistical hypothesis test for repeated measurements. Scores of individual staff members were compared by means of the paired $t$-test. The paired t-test was used to compare the values of means from two related samples, e.g., before and after an intervention.

Statistically significant differences in scores between teams, do not reveal differences between individual staff members per se. Therefore, the Reliable Change Index (RCI; Jacobson \& Truax, 1991) was used. The RCI is a statistic that determines the magnitude of change, necessary of a given individual self-report measure, to be statistically significant. The RCI for individual staff members is computed as follows: RCI $=x 2-x 1$ / Sdiff, where $x 1$ represents a person's pre-test score and $x 2$ represents that same subject's post-test score. Sdiff is computed from the standard error of measurement: $\left(\sqrt{ } 2\left(S_{E}\right)^{2}\right.$. When the RCI is larger than $1.96(p<0.05)$, it is likely that post-test scores reflect real changes. RCI's of SCIBI-PAT -scores and STRS-scores were 
computed for both individual staff members and teams. The staff's opinion about the SFC-procedures were analysed qualitatively by using the SRS.

\section{Results}

\subsection{Treatment protocol}

The average duration of SFC (session 1-3) with teams was 9 weeks. A variety of supporting problems were reported by staff such as: 'We have too many conflicts with this person'; 'We are insufficiently involved with this person'; 'We are inadequately able to reduce aggression in this person'. These problems resulted in goals formulated by teams, such as: 'When working with this person we want harmony ...', 'we want involvement ...', 'we want safety...' and so on.

The first topic of this explorative study was about the conduct of SFC of staff working with people with S/MID. To give insight into SFC, we give an extensive description of the first SFC-session of team 1 regarding their support of L., a woman with moderate ID. The SFC-process includes getting acquainted, exploring the problem, pre-session change, goal setting, exploring the exceptions, scaling questions and feedback. In this case, these interventions were dealt with as described below.

Getting acquainted. 'What are the strengths of this team and the individual staff members?' Positive staff member characteristics were: being flexible and open minded, and able to critically assess own actions. L. was viewed as a spirited woman, full of temperament and her wilfulness was appreciated. Exploring the problem. 'What is the support problem? What is the problem for staff members?'

There were many conflicts with L. Staff members could not get through to her and were often frustrated. Other people were bothered by L.'s grumpy and meddlesome behaviour and were afraid of her. There was no harmony between the staff and L..

Pre-session change. 'What has changed since the application?' Since the intake, staff members had given thought to their negative relationship with L. and had adjusted their approach. They asked her informative questions about leisure activities more often. They started each 
day with an open mind about her, even when she entered the room in a grumpy mood, and they gave her compliments more often.

Goal setting. 'Suppose we make a video in the near future, showing how well staff will interact with L.. What are some of the things you would like to see and hear on that video?'

Staff wanted good harmony with L.. The video question was answered as follows: 'We would be attentive, inviting and complimentary towards L.'. Staff members subsequently gave descriptions of concrete actions: 'We would have short conversations with L. six times a day, we would take adequate time to show interest in L.'s stories, photographs and drawings, about things she recently encountered and we would say that we appreciate her sharing these things with us'. Staff also described a (video) image of their changed opinions of L. during collegial dialogues: 'From now on we no longer call the interaction of L. with some other people meddlesome; instead we will call it helpful.'. Exploring exceptions. 'When does the problem not occur or is it less serious?' Staff members described a part of the day when they were satisfied about their interaction with L.: 'Take for example the time we cleaned the rabbit hutch. We were paying attention especially to things that L. already did well, like refilling the water dish. We found it really rewarding to encourage her in that task and, in the mean time, simplify for her the more difficult task of giving food.'. Scaling questions: 'Suppose 10 = a good relationship between staff and L. and 1 = a poor relationship between staff and L. What number would you give?' Staff members indicated an average number of 4.5 as a start and wanted to strive for an average number of 8.0. One step forward (from 4.5 to 5.5 ) would mean that staff members daily gave positive attention for 5 minutes to L. at a number of specified moments.

Feedback. Staff viewed themselves as part of the problem and/or solution (customer-relationship). The coach complimented staff members for their interest and involvement in L. and thought that these staff characteristics would lead to a good relationship with her. The coach subsequently proposed a number of tasks. Observation task: 'Notice when the relationship between you and L. is good and tell me more about that next time'. Behavioural tasks: 'Keep doing what already works (e.g., start for example each day open minded and pay attention to (partial) tasks that are already being executed well by L., ) 
and do part of the portrayed video image (e.g., react attentively, spontaneously and inviting towards L. at specific points during the day).'. Follow-up session(s). Staff reported that things were going better. The coach asked for details about the improvements, explored meticulously the exceptions to the support problem, and reinforced the successes. At the end of the SFC, staff reported that good harmony with L. was established.

3.2 Progression towards the goal, proactive thinking in teams, and the quality of the relationship

This study also focused on differences directly before SFC, directly after SFC and 6 weeks after SFC, with regard to (1) progression towards the goal during SFC according to staff, (2) proactive thinking in teams, and (3) the quality of the relationship between staff and people with S/MID (topic 2). Table 2 lists the average scores and changes in scores on the SQP (goal attainment), the average scores and changes of the SCIBI-PAT (proactive thinking), and the average scores and changes of the STRS (quality of the relationship), as well as the test-statistics for all variables.

Progression towards the goal

Progression towards the goal only was analysed on team level. Directly after SFC, it showed that the teams experienced a statistically significant increase in goal attainment. The mean increase directly after SFC was 1.9 points (from 5.3 to 7.2). Further analyses showed that 7 out of the 13 teams indicated a substantial progression towards the team goal (i.e., 2 or more points) on the SQP. Four other teams experienced an increase as well, but this increase was between 1 and 2 points; two teams showed hardly any changes (less than 1.0 point after SFC). At follow-up, the mean increase of the teams was 2.2 points (from 5.3 to 7.5). Results also showed that 9 out of 13 teams indicated a progression of 2 or more points. All the afore-mentioned increases were statistically significant $(p<0.05)$.

\section{Proactive thinking}

PAT-scores were used to gain insight into staff members' proactive thinking. Directly after SFC, the mean increases on SCIBI-PAT-scores were 1.0 point 
(individual staff members: from 11.1 to 12.1 ) and 1.0 point (teams: from 11.1 to 12.1$)$. These differences both were statistically significant $(p<0.05)$. At follow-up these differences were slightly larger (respectively 1.2 and 1.2 points) and both statistically significant $(p<0.05)$. Only 34 staff members (10 teams) completed the SCIBI-PAT. The SCIBI (including the PAT), was only recently published and was therefore not available for the first three teams that applied for SFC. However, the SCIBI was available for the remaining 10 teams (respectively 8 staff members) that participated in this study.

Real change (RCI's $>1.96$ ) in proactive thinking was found in 12 of the 34 staff members and in 5 out of 10 teams after SFC. At follow-up that was true for 15 of the 34 staff members, and in 6 out of 10 teams.

\section{Quality of the relationship}

The quality of the relationship between people with ID and staff members was measured using the STRS. Both individual staff members and staff in general experienced statistically significant increases in the quality of relationship $(p<$ .05). Individual staff members scored 9.6 points higher directly after SFC and 9.2 points higher at follow-up (from 96.9 to respectively 106.5 and 106.1 ). For teams these increases were 9.1 and 8.9 points (from 96.8 to respectively 105.9 and 105.7).

A real change (RCI's $>1.96$ ) of the relationship was measured in 22 of the 42 staff members and in 7 out of 13 teams directly after SFC and also at follow-up. These improvements in the quality of the relationship (both RCI and statistical significance) were due to decreases in STRS conflict scores and/or increases of STRS closeness scores. No real changes (RCI's) or statistical significant changes were seen between STRS dependency scores. 
Table 2: Differences in proactive thinking (PAT) and quality of the relationship (STRS) of the before, after and follow-up measurements of individual staff members and of teams

\begin{tabular}{|c|c|c|c|c|c|c|c|c|}
\hline \multicolumn{9}{|c|}{ Individual Staff Members } \\
\hline Scales & $\boldsymbol{N}$ & $n^{\mathrm{c}}$ & $\begin{array}{c}\text { Session } \\
\mathbf{1} \\
\text { Mean }\end{array}$ & $\begin{array}{l}\text { Ses- } \\
\text { sion } 3 \\
\text { Mean }\end{array}$ & $\begin{array}{c}\text { Mean } \\
\text { Change; } \\
\text { t-test }\end{array}$ & $n^{c}$ & $\begin{array}{c}\text { Follow } \\
\text { up } \\
\text { Mean }\end{array}$ & $\begin{array}{c}\text { Mean } \\
\text { Change; } \\
\text { t-test }\end{array}$ \\
\hline PAT & 34 & 12 & 11.1 & 12.1 & $\begin{array}{c}+1.0 \\
t=3.5^{\mathrm{a}}\end{array}$ & 15 & 12.3 & $\begin{array}{c}+1.2 \\
t=4.8^{\mathrm{a}}\end{array}$ \\
\hline $\begin{array}{l}\text { STRS } \\
\text { Closeness }\end{array}$ & 42 & 12 & 41.4 & 45.2 & $\begin{array}{c}+3.8 \\
t=5.1^{\mathrm{a}}\end{array}$ & 15 & 45.1 & $\begin{array}{c}+3.7 \\
t=3.3^{\mathrm{a}}\end{array}$ \\
\hline $\begin{array}{l}\text { STRS } \\
\text { Conflict }\end{array}$ & 42 & 19 & 29.3 & 23.6 & $\begin{array}{c}-5.7 \\
t=-6.2^{\mathrm{a}}\end{array}$ & 20 & 24.1 & $\begin{array}{c}-5.2 \\
t=-5.6^{\mathrm{a}}\end{array}$ \\
\hline $\begin{array}{l}\text { STRS } \\
\text { Depen- } \\
\text { ency }\end{array}$ & 42 & 1 & 17.2 & 17.1 & $\begin{array}{c}-0.1 \\
t=-0.4^{\mathrm{b}}\end{array}$ & 2 & 16.9 & $\begin{array}{c}-0.3 \\
t=-1.0^{\mathrm{b}}\end{array}$ \\
\hline $\begin{array}{l}\text { STRS } \\
\text { Quality of } \\
\text { Relation- } \\
\text { ship }\end{array}$ & 42 & 22 & 96.9 & 106.5 & $\begin{array}{c}+9.6 \\
t=6.8^{\mathrm{a}}\end{array}$ & 22 & 106.1 & $\begin{array}{c}+9.2^{\mathrm{a}} \\
t=5.7^{\mathrm{a}}\end{array}$ \\
\hline \multicolumn{9}{|c|}{ Teams } \\
\hline Scales & $\boldsymbol{N}$ & $n^{\mathrm{c}}$ & $\begin{array}{c}\text { Session } \\
1 \\
\text { Mean }\end{array}$ & $\begin{array}{l}\text { Ses- } \\
\text { sion } 3 \\
\text { Mean }\end{array}$ & $\begin{array}{c}\text { Mean } \\
\text { Change; } \\
\text { Wilcoxon } \\
\text { test }\end{array}$ & $\boldsymbol{n}^{\mathrm{c}}$ & $\begin{array}{l}\text { Follow- } \\
\text { up } \\
\text { Mean }\end{array}$ & $\begin{array}{c}\text { Mean } \\
\text { Change; } \\
\text { Wilcoxon } \\
\text { test }\end{array}$ \\
\hline SQP & 13 & 7 & 5.3 & 7.2 & $\begin{array}{c}+1.9 \\
z=-3.2^{a}\end{array}$ & 9 & 7.5 & $\begin{array}{c}+2.2 \\
z=-3.2^{a}\end{array}$ \\
\hline PAT & 10 & 5 & 11.1 & 12.1 & $\begin{array}{c}+1.0 \\
z=-2.6^{a}\end{array}$ & 6 & 12.3 & $\begin{array}{c}+1.2 \\
z=-2.7^{a}\end{array}$ \\
\hline $\begin{array}{l}\text { STRS } \\
\text { Closeness }\end{array}$ & 13 & 2 & 40.9 & 44.7 & $\begin{array}{c}+3.8 \\
z=-2.9^{a}\end{array}$ & 2 & 44.7 & $\begin{array}{c}+3.8 \\
z=-2.1^{\mathrm{a}}\end{array}$ \\
\hline $\begin{array}{l}\text { STRS } \\
\text { Conflict }\end{array}$ & 13 & 7 & 29.1 & 23.8 & $\begin{array}{c}-5.3 \\
z=-3.0^{a}\end{array}$ & 9 & 24.0 & $\begin{array}{c}-5.1 \\
z=-2.6^{a}\end{array}$ \\
\hline $\begin{array}{l}\text { STRS } \\
\text { Depen- } \\
\text { ency }\end{array}$ & 13 & 0 & 17.0 & 17.0 & $\begin{array}{c}0 \\
z=-0.6^{b}\end{array}$ & 0 & 16.9 & $\begin{array}{c}-0.1 \\
z=-.1^{\mathrm{b}}\end{array}$ \\
\hline $\begin{array}{l}\text { STRS } \\
\text { Quality of } \\
\text { Relation- } \\
\text { ship }\end{array}$ & 13 & 7 & 96.8 & 105.9 & $\begin{array}{c}+9.1 \\
z=-3.1^{a}\end{array}$ & 7 & 105.7 & $\begin{array}{c}+8.9 \\
z=-2.6^{a}\end{array}$ \\
\hline
\end{tabular}

a Positive difference: the differences between before and after measurements are statistically significant $(p<0.05)$ on paired $t$-test or Wilcoxon Ranked-Sign Test.

${ }^{b}$ Difference is not statistically significant.

${ }^{\mathrm{C} N u m b e r}$ of staff members or teams with SQP improvements $\geq 2$ points or with a Real Change Index $(\mathrm{RCI})>1.96 ;(p<0.05)$. 
Staff opinions about the procedure and of the collaboration between coach and staff

Finally, the STRS was used to obtain the staff members' opinion of the procedure and of the collaboration between coach and staff (third topic). Scores below 9 on the items relationship, goals and subjects, procedure or method, or total session were reasons for the coach to investigate what, according to staff members, could be improved concerning the procedure or collaboration. In most instances, staff members gave scores of 9 or higher on all items. In one team, however, lower scores were given ( 7 and 8 ) on item 3 (procedure or method). A few staff members believed that SFC could not sufficiently contribute to reaching the goal (i.e., handling aggression). A recent unfavourable relocation of the person was seen as an explanation for worsening of behaviour (continuing aggression). In addition, in two teams, staff members gave scores of 7 and 8 respectively on item 4 (the session as a whole) and commented that some steps towards the goal took more time than the duration of the coaching trajectory (session 1 through 3). Staff also commented on high scores (9 and higher) on the SRS such as 'We now pay attention to competencies, successes, and positive exceptions to supporting all our people'; 'SFC has resulted in a better relationship with this person'; 'These Solution-Focused questions motivated us in a pleasant way to have detailed thoughts about our work'; 'SFC makes us more aware of our own actions'; 'SFC makes us convinced that we can accomplish the things we want to accomplish'.

\section{Conclusions}

The goal of SFBT is to help people make the desired changes in their lives, or, as in the present study, through SFC, to help staff make the desired changes in their work (Bannink, 2010). Measurements before and after SFC have shown that in several areas (1) goal attainment (2) proactive thinking and (3) quality of relationship) positive changes occurred, which demonstrated that SFC could be a valuable approach for staff working with people with S/MID.

All teams indicated progress towards the team goal. However, 7 out of 13 teams scored above the cutoff point of 2, and two teams showed hardly any changes (less than 1.0 point after SFC). The complexity of the support problem 
was said to be the cause of this lack in progress. Staff also mentioned that improvement hardly was possible after such a short period of time.

SFC stimulates dealing with support problems in a behavioural, proactive way (Wheeler, 2001). Improvement of proactive thinking was found in 5 out of 10 teams after SFC and in 6 out of 10 teams at follow-up. It might be possible that differences in experience of staff could account for this absence of progress. In addition, former experiences of staff, and consequently how they support clients, could have influenced the results. In their validation study of the SCIBI, Willems et al. (2010) found that higher levels of proactive thinking (subscale of the SCIBI) were indeed positively associated with more experience and with higher educational level.

SFC can be a useful approach to build useful relationships (Lloyd \& Dallos, 2006; 2008). Statistically significant improvement of the quality of the relationship (QOR) was found in 7 out of 13 teams, directly after SFC and at follow-up. QOR also measures 'closeness', 'conflict' and 'dependency'. It showed that 'conflict' changed most of these variables: 7 out of 13 teams after SFC and 9 out of 13 teams at follow-up. This was followed by 'closeness' in 2 out of 13 teams after SFC and at follow-up, and 'dependency' in 0 out of 13 teams both after SFC and at follow-up. It is plausible that the progress in QORscores mainly was due to progress in reducing conflicts, and somewhat weakened by lack of progress regarding dependency and closeness.

The procedure and collaboration was predominantly evaluated positive by all teams (scores of 9 and higher).

The present study has some limitations concerning the design and the choice and kind of measurement instruments. We only studied an experimental group by comparing measurements taken directly before SFC, after session 3 of SFC, and during follow-up. Without data from control groups to compare, it cannot be confirmed that the teams' goals would have been reached without SFC. In addition, the teams applied for SFC themselves, indicating that they wished to change their current situation. They therefore can be regarded as selective. The small number of research subjects limits generalisations of the findings for other teams. Nevertheless, this case-series with positive outcomes, does give indications about the possible effectiveness of SFC.

Any choice of standardised measurement instruments automatically implies restrictions. During SFC, every team formulated its own goal. It is 
possible that the chosen team goal did not sufficiently match the measuring pretention of the instruments being used. This however does not count for the SQP, because this measurement adjusts itself to the goal of the team,. This problem of matching measuring pretentions however is true, for example for the STRS, because the dimensions, closeness, conflict, dependency and quality of the relationship of this instrument could differ from what staff members found relevant to measure. The use of several instruments simultaneously can partly, though not completely, solve this problem. Moreover, all instruments used were self-report instruments and thus reflect the staff members' opinions. Future research could also focus on staff reports verified by observation.

The findings in the present study are in line with results of earlier research on the value of SFBT applied to caregivers (parents or professionals) of people with ID. Lloyd and Dallos $(2005,2006)$, for example, reported that some SFC components like control, choice and conversations about resilience, coping and skills may enhance the sense of self-efficacy and proactive thinking in caregivers. Self-efficacy is the idea that someone can influence a desired outcome themselves by behaving in a certain way (Bannink, 2009). Proactive thinking is the tendency to initiate change rather than react to events (Kirby \& Kirby, 2006). In the present study, 9 out of the 13 teams reached the goals that they specified as desirable, and 6 out of 10 teams increased proactive thinking at follow-up. Because reaching the goal was based on ideas from staff members about existing skills and earlier successes, it is possible that the expectations of the staff member's own effectiveness (self-efficacy) and the tendency to take action (proactive thinking) will increase. Other researchers emphasised that SFC can lead to relationships between staff and people with ID that are more positive. For example, Wheeler (2001) suggested that SFC alters negative perceptions, interrupts a pattern of blame and enhances positive attachment. Stoddart et al. (2001) perceived that staff members were influenced by the solution-focused interventions. They began to see more positively the resources, strengths and characteristics of the people with ID. Also in the present study, SFC seemed to contribute to changes in the perception of people with ID by staff, possibly resulting in better relationships (more closeness in 2 out of 13 teams at follow-up and less conflict in 9 out 13 teams at follow-up). No decreases were seen in dependency scores. A possible explanation is that the relationship of dimension dependency in people with ID, 
who need lifelong support from staff, is less changeable than the dimensions of closeness and conflict.

Future investigation of SFC, preferably using a randomised controlled design, could test the hypothesis that SFC increases self-efficacy and proactive thinking in teams, positively alters staff's perceptions of people with ID and is considered as a useful approach by teams as well. As a substantial amount of teams that support people with S/MID experience difficulties in supporting these people, it is fruitful to look for ways to solve these difficulties. In former times, the tendency was to mainly focus on people with ID as being the one and only cause of support problems, thereby ignoring the role of staff in these relationships. SFC on the contrary, also focuses on the important role of staff. Further exploration of the usefulness of SFC and is consequently very meaningful. Special attention can be paid to the influence of characteristics of teams (e.g., methods of working, internal differences) and/or staff members (e.g., level of education, job satisfaction, years of experience) on the level of progress on goal attainment, proactive thinking and quality of the relationship with clients.

\section{References}

Bannink, F.P. (2009). Positieve psychologie in de praktijk [Positive psychology in practice]. Amsterdam: Hogrefe Uitgevers.

Bannink, F.P. (2010). 1001 Solution-Focused questions. New York: Norton.

Bonsi, E. (2005). An empirical investigation of the usefulness of solution talk in solution-focused therapy. Unpublished doctoral dissertation. Lincoln: University of Nebraska-Lincoln.

Bozeman, B.N. (1999). The efficacy of solution-focused therapy techniques on perception of hope in clients with depressive symptoms. Unpublished doctoral dissertation. New Orleans: Baptist Theological Seminary.

Chung, M.C. \& Harding, C. (2009). Investigating burnout and psychological well-being of staff working with people with intellectual disabilities and challenging behaviour. The role of personality. Journal of Applied Research in Intellectual Disabilities, 22, 549-560.

Collins, S. (1999). Treatment and therapeutic interventions. Psychological approaches and services. Tizard Learning Disability Review, 4, 20-27. 
Corcoran, J. (2002). Developmental adaptations of Solution-Focused family therapy. Brief Treatment and Crisis Intervention, 2, 301-313.

Corcoran J. \& Ivery J. (2004). Parent and child attributions for child behaviour: Distinguishing factors for engagement and outcome. Families in Society: The Journal of Contemporary Social Services, 85, 101-106.

De Shazer, S. (1985). Keys to solution in brief therapy. New York: Norton.

Duncan, B.L., Miller, S.D. \& Sparks, A. (2004). The heroic client. A revolutionary way to improve effectiveness through client-directed, outcomeinformed therapy. New York: Jossey-Bass.

Dyer, S. \& Quine, L. (1998). Predictors of job satisfaction and burnout among the direct care staff of a community learning disability service. Journal of Applied Research in Intellectual Disabilities, 11, 320-332.

Fidell, B. (2000). Exploring the use of family therapy with adults with a learning disability. Journal of Family Therapy, 22, 308-323.

Frankish, P. \& Terry, S. (2003). Modern therapeutic approaches in learning disability services. Tizard Learning Disability Review, 8, 3-10.

Gingerich, W.J., de Shazer, S. \& Weiner-Davis, M. (1988). Constructing change: A research view of interviewing. In E. Lipchik (Ed.), Interviewing (pp. 21-32). Aspen: Rockville.

Hatton, C., Brown, A., Caine, A. \& Emerson, E. (1995). Stressors, coping strategies and stress-related outcomes among direct care staff in staff houses for people with learning disabilities. Mental Handicap Research, 8, 252-271.

Jacobson, N.S. \& Truax, P. (1991). Clinical significance: A Statistical Approach to Defining Meaningful Change in Psychotherapy Research. Journal of Consulting and Clinical Psychology, 59, 12-19.

Jenkins, R., Rose, J. \& Lovell, C. (1997). Psychological well-being of staff working with people who have challenging behaviour. Journal of Intellectual Disability Research, 41, 502-511.

Jordin, K.B. \& Quinn, W.H. (1994). Session two outcome of the formula first session task in problem- and solution-focused approaches. American Journal of Family Therapy, 22, 3-16.

Kirby, E.G. \& Kirby, S.L. (2006). Improving task performance: The relationship between morningness and proactive thinking. Journal of Applied Social Psychology, 36, 2715-2729. 
Koomen, H., Verschueren, K. \& Pianta, R. (2007). Leerling Leerkracht Relatie Vragenlijst [Student Teacher Relationship Scale]. Houten: Bohn Stafleu van Loghum.

Koomen, H.M.Y., Verschueren, K. Van Schooten, E., Jak, S. \& Pianta, R.C. (2012). Validating the Student-Teacher Relationship Scale: Testing Factor Structure and Measurement Invariance across Child Gender and Age in a Dutch Normative Sample. Journal of School Psychology, 50, 215-234.

Lentham, J. (2002). Brief Solution-Focused therapy. Child and Adolescent Mental Health, 7, 189-192.

Lloyd, H. \& Dallos, R. (2006). Solution-Focused brief therapy with families who have a child with intellectual disabilities. A description of the content of initial sessions and the processes. Clinical Child Psychology and Psychiatry, 11, 367-386.

Lloyd, H. \& Dallos, R. (2008). First session Solution-Focused brief therapy with families who have a child with severe intellectual disabilities. Mothers' experiences and views. Journal of Family Therapies, 30, 5-28.

Prosser, D., Johnson, S., Kuipers, E., Szmikler, G., Bebbingtom, P. \& Thornicroft, G. (1997). Perceived sources of work stress and satisfaction among hospital and community mental health staff, and their relation to mental health, burnout and job satisfaction. Journal of Psychomatic Research, 43, 51-59.

Quick. E. \& Gizzo, D.P. (2007). The 'doing what works' group: A quantitative and qualitative analysis of solution-focused group therapy. Journal of Family Psychotherapy, 18, 65-84.

Rhodes, J. (2000). Solution-Focused consultation in a residential setting. Clinical Psychology Forum, 141, 29-33.

Roeden, J.M. \& Bannink, F.P. (2007). Handboek oplossingsgericht werken met licht verstandelijk beperkte cliënten [Handbook Solution-Focused interventions with clients with intellectual disabilities]. Amsterdam: Pearson.

Roeden, J.M., Bannink, F.P., Maaskant, M.A. \& Curfs, L.M.G. (2009). Solution-Focused Brief Therapy with Clients with Intellectual Disabilities. Journal of Policy and Practice in Intellectual Disabilities, 6, 253-259.

Roeden, J.M., Maaskant, M.A., Bannink, F.P. \& Curfs, L.M.G. (2011). Solution-Focused Brief Therapy with People with Mild Intellectual Disabilities; a 
Case Series. Journal of Policy and Practice in Intellectual Disabilities, 8, 247255.

Roeden, J.M., Maaskant, M.A., Koomen, H.M.Y., Candel, M. J.J.M. \& Curfs, L.M.G. (2012). Assessing client-caregiver relationships and the applicability of the 'student-teacher relationship scale' for people with intellectual disabilities. Research in Developmental Disabilities, 33, 104-110.

Selekman, M.D. (1993). Pathways to Change: Brief therapy solutions with difficult adolescents. New York: Guilford.

Shilts, L., Rambo A. \& Hernandez, L. (1997). Clients helping therapists find solutions in their therapy. Contemporary Family Therapy, 19, 117-132.

Skirrow, P. \& Hatton, C. (2007). Burnout amongst direct care workers in services for adults with intellectual disabilities. A systematic review of research findings and initial normative data. Journal of Applied Research in Intellectual Disabilities, 20, 131-144.

Smith, I.C. (2005). Solution-Focused brief therapy with people with learning disabilities. A case study. British Journal of Learning Disabilities, 33, 102-105.

Smith, I.C. (2006). Ideas for solution-based working with people who have intellectual disabilities. Solution News, 2, 21-25.

Speicher-Bocija, J.D. (1999). Comparison of the effects of solution-focused and problem-focused interviews on clients' immediate verbal responses. Unpublished doctoral dissertation. Akron: University of Akron.

Stoddart, K.P., McDonnel, J., Temple, V. \& Mustata, A. (2001). Is brief better? A modified brief Solution-Focused therapy approach for adults with a developmental delay. Journal of Systematic Therapies, 20, 24-40.

Van Dierendock, D., Schaufeli, W.B. \& Buunk, B.P. (1996). Inquity among human service professionals: Measurement and relation to burnout. Basic and Applied Social Psychology, 18, 429-451.

Westra, J. \& Bannink, F.P. (2006a). 'Simpele' oplossingen! Oplossingsgericht werken bij mensen met een lichte verstandelijke beperking, deel 1 ['Simple' solutions! Solution-Focused interviewing with intellectually disabled persons, part 1]. PsychoPraxis, 8, 158-116.

Westra, J. \& Bannink, F.P. (2006b) 'Simpele' oplossingen! Oplossingsgericht werken bij mensen met een lichte verstandelijke beperking, deel 2 ['Simple' solutions! Solution-Focused interviewing with intellectually disabled persons, part 2]. PsychoPraxis, 8, 213-218. 
Wheeler, J. (2001). A helping hand: Solution-Focused brief therapy and child and adolescent mental health. Clinical Child Psychology and Psychiatry, 6, 293306.

Willems, A.P.A.M., Embregts, P.J.C.M., Stams, G.J.J.M. \& Moonen, X.M.H. (2010). The relation between intrapersonal and interpersonal staff behaviour towards clients with ID and challenging behaviour: a validation study of the Staff-Client Interactive Behaviour Inventory. Journal of Intellectual Disability Research, 54, 40-51. 


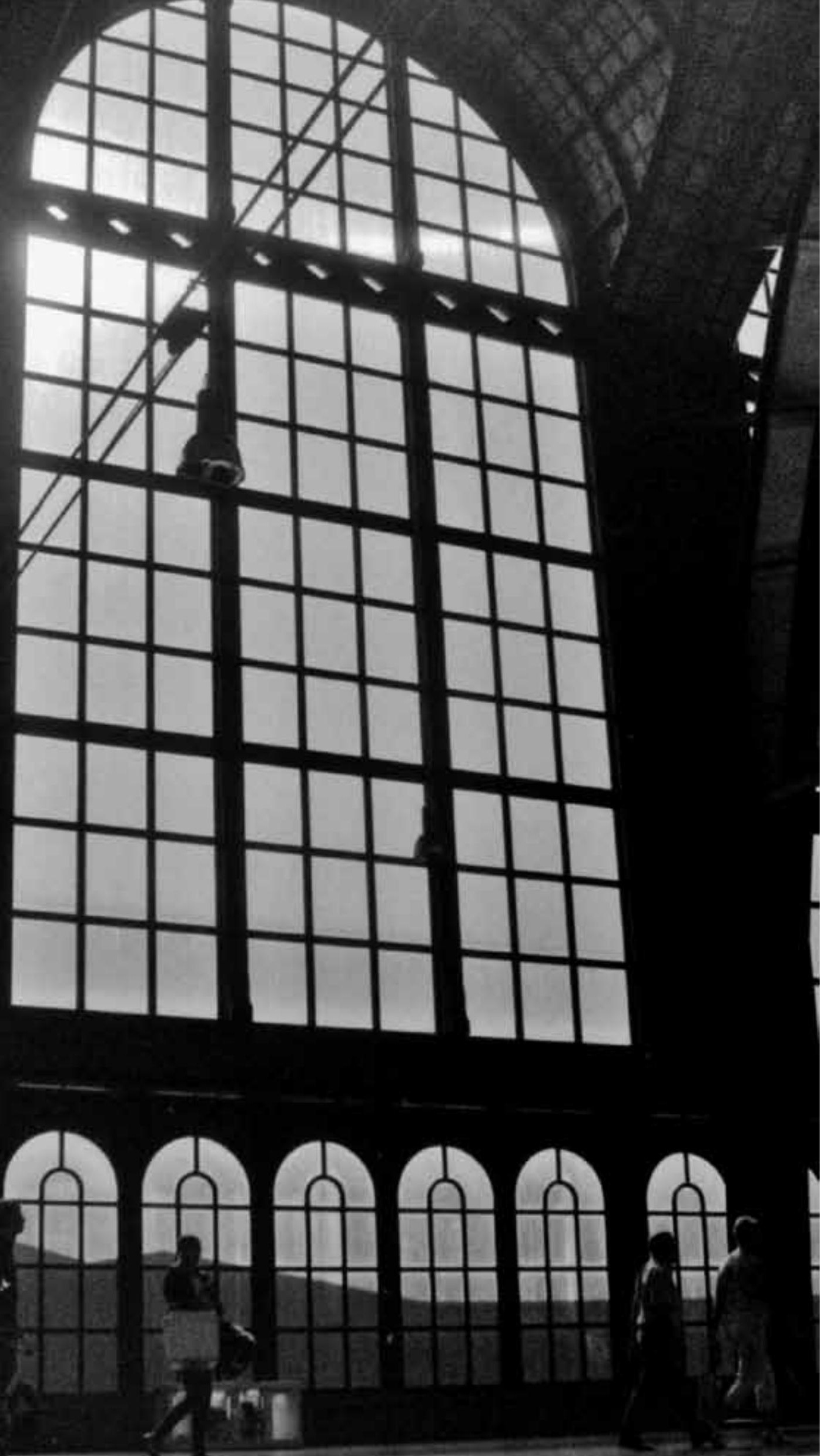




\section{CHAPTER 8}

\section{THE NOMINAL GROUP TECHNIQUE AS AN EVALUATION TOOL FOR SOLUTION-FOCUSED COACHING}

Roeden, J.M., Maaskant, M.A. \& Curfs, L.M.G. (2012).

The nominal group technique as an evaluation tool for solution-focused coaching.

Journal of Applied Research in Intellectual Disabilities, Accepted for publication. 


\section{Abstract}

Background. Solution-focused coaching (SFC) helps individuals or groups to achieve their preferred outcomes by evoking and co-constructing solutions. SFC has been shown to be helpful for persons with ID as well as for teams coaching people with ID. Nominal Group Technique (NGT) helps to organize people's thoughts with regard to a single question. This study examines the perceived strengths of SFC and recommendations for SFC for teams coaching people with ID via NGT, as well as the extent to which the NGT results reflect the results of an SFC questionnaire.

Method. In total, 54 staff members participated in SFC. Of these, 18 participated in NGT, while 36 completed the SFC questionnaire. The strengths of and recommendations for SFC were obtained via NGT. Interrater agreement was calculated via Cohen's kappa.

Results. The strengths of SFC include 'exploring hidden successes' and 'focusing on solutions'. It was recommended that 'the results be consolidated in follow-up meetings'. The participants agreed on the content of the strengths and recommendations, but differed in terms of priorities (kappa $\leq 0.1$ ). Conclusions. NGT is a valuable tool in exploring people's opinions and priorities, but further research is needed to elucidate the perceived priorities of SFC for teams coaching persons with ID.

\section{Introduction}

Solution-focused coaching (SFC) is a competence-based approach aimed at assisting individuals or groups to make desired changes in their personal or work life (O'Connell \& Palmer, 2007). The specific skills and strategies used in SFC include many of the approaches used in solution-focused therapeutic settings (De Shazer et al., 2007). The approach is also useful for coaching teams coaching people with intellectual disabilities (ID). Only scarce research on this topic is available (Rhodes, 2000; Stoddart et al., 2001; Wheeler, 2001; Lloyd \& Dallos, 2006, 2008; Roeden et al., 2012). Rhodes (2000) found that SFC is a useful approach for staff working with people with ID. In particular, the focus on strengths was valued and the way staff members generated solutions that built on their competencies. Stoddart et al. (2001) treated 16 
people with mild ID and with a range of problems, using SFC. They also actively involved staff in the treatment procedures. Staff members developed more positive perspectives about the person with ID because of their involvement in SFC. They became more aware of the person's resiliencies, resources and competencies, and in particular the person's abilities to come up with solutions her/himself. Lloyd and Dallos $(2006,2008)$ found that mothers of children with severe ID experienced SFC as a useful approach to build useful relationships, to highlight self-efficacy and to encourage helpful coping styles. Roeden et al. (2012) conducted a case-series investigating SFC in staff dealing with support problems in people with severe and moderate ID. After SFC, improvement of self-efficacy was found in 12/34 staff members and improvement of the quality of the relationship between staff and clients with ID was found in 22/42 staff members. Wheeler (2001) reported that SFC can be particularly helpful for caregivers in encouraging a sense of self-efficacy and proactive thinking, in altering negative perceptions and in enhancing positive attachment.

Staff of persons with ID experience several support problems that also influence their (job) functioning. For example, recent research highlighted that staff experience moderate levels of burnout (Skirrow \& Hatton, 2007). Also violent client behaviour (Hatton et al., 1995), high client support needs (Dyer \& Quine, 1998), imbalanced relationships with clients (Van Dierendonck et al., 1996) and challenging behaviour of clients (Jenkins et al., 1997; Prosser et al., 1997; Chung \& Harding, 2009) showed to be associated with higher levels of burnout and other negative psychological outcomes in staff. In dealing with all these support problems, SFC could be useful, because it offers staff a hopeful, outcome-oriented, competence-based set of interventions.

The following principles are considered important in solution-focused strategies: 1. SFC is based on solution building rather than problem solving. The SF coach focuses on the team's desired future rather than on past problems. 2. Exploring exceptions. No problem happens all the time. There are exceptions (hidden successes) when the problem could have occurred but did not. The team and coach can make use of this fact to co-construct solutions. 3 . Staff define the goal of coaching. The coach invites staff to create a detailed picture of what the support will be like once the goal is reached. Ideally, the 
description will contain the 'who,' 'what,' 'where,' 'when,' and 'how' of goal attainment.

In this study, we evaluate SFC using the Nominal Group Technique (NGT, Delbecq et al., 1975). NGT provides a structured method for collecting and organizing the thoughts of a group of people with regard to a particular question. For example, it has been used to explore the opinions of clients of residential service providers (Tuffrey-Wijne et al., 2007; Roeden et al., 2010). After introducing a question -in this study a question concerning the evaluation of SFC- the procedure continues with four basic steps: (1) generating individual ideas, (2) round-robin listing of individual ideas, (3) clarifying the ideas, (4) selecting and ranking the ideas.

"The primary advantage of the NGT is the enhanced opportunity for all participants to contribute many ideas and to minimize the domination of the process by more confident or outspoken individuals" (Jones, 2004; p. 23). However, it is important to recognize a major disadvantage of the NGT as well. The lack of generalizability of the results to the wider population due to the specific characteristics of the participants (both in terms of who is nominated to attend, and who agrees to participate), requires a follow-up survey to make final decisions about the issues concerned (Fox, 1989; Lloyd-Jones et al., 1999; Jones, 2004). In this study, the impracticability of involving many participants in the NGT led to the decision to use the items derived from the NGT, to create a questionnaire which was distributed to a larger group of respondents.

The research questions in this study are as follows: (1) 'What are the strengths of SFC, and what recommendations to improve SFC do staff members make via NGT?'; and (2) 'To what extent do the opinions of staff members via NGT reflect the opinions of staff members via a standardized questionnaire, regarding both the perceived strengths of SFC and the perceived recommendations for SFC?'. 


\section{Method}

\subsection{Participants and procedures}

The study was conducted at a Dutch service provider for approximately 900 children and adults with ID. Staff members involved in this study were direct care workers who provided residential or vocational support for people with ID. Teams of staff members facing a support problem with an individual with ID (e.g., aggressive behaviour towards staff) could apply for SFC. In 2011, 13 teams consisting of 54 staff members were coached in line with the principles of SFC. Of these staff, 18 were chosen at random to participate in the NGT procedure, while the remaining 36 filled in the SFC questionnaire (SFCQ).

The research was non-invasive, and all interviewees agreed to participate in the study. Ethical approval is not required in the Netherlands for this type of study, and thus was not requested. Nevertheless, permission for the study was given by the Client Council (made up of people with ID) and by the organization's Client Representative Council (family members or other representatives of people with ID).

\subsection{SFC procedure}

During session 1, the SFC coach uses the following interventions: (1) Setting goals. The coach invites the team to indicate the goal they would like to achieve through the coaching. (2) Using scale questions. On a scale of 1 to 10 , the team indicates their progression towards their goal. This helps them to move away from all-or-nothing goals towards manageable and measurable steps. (3) Looking for exceptions to the problem. The coach enquires about times when the problem does not seem to occur or is less serious, and who does what to bring about these exceptions. (4) Giving compliments. The coach validates what the team is doing that is already working. (5) Assigning tasks. At the end of every session some tasks are typically suggested, indicating areas requiring the team's attention or possible further actions needed to reach their goal. In subsequent sessions, the coach starts with the EARS question set, which stands for Eliciting, Amplifying, Reinforcing, Start again. The first question is 'what is better?' (Eliciting), followed by 'what exactly is (somewhat) 
better?' (Amplifying), 'how did you manage to do that?' (Reinforcing) and 'what (else) is better?' (Start again).

\subsection{NGT procedure}

The total NGT group ( $n=18$ ) was randomly divided into three subgroups of six people, who took part in a NGT procedure on three separate days. Each NGT session lasted a maximum of three hours. The time between SFC and NGT was a maximum of two months.

Introduction. Prior to the NGT sessions, all staff members received a transcription of the SFC sessions in which they themselves had taken part. They then watched a 20-minute film showing SFC interventions being performed by a team other than their own.

(1) Generating individual ideas. During this phase, each carer wrote down as many answers as possible to two central questions: 1 . What are the strengths of SFC? and 2. How would you recommend that SFC be improved? Twenty minutes were set aside to answer each question.

(2) Round-robin listing of individual ideas. After the individual phase, the six carers came together in a group and read out their ideas. If one participant's idea inspired a new idea in another, this idea was also added to the list.

(3) Clarification of the ideas. In this phase, all ideas were formulated such that they meant precisely the same thing to each carer. Ideas of similar themes were then grouped together, provided that all staff members agreed on this grouping.

(4) Selecting and ranking the ideas. Each carer was asked to choose the seven best ideas on the basis of their own insight and preferences, and to rank them from most (score 7) to least (score 1 ) important.

\subsection{SFC Questionnaires (SFCQ)}

Thirty-six staff members who took part in the SFC but not in the NGT procedure filled in the SFCQ no later than six weeks after the NGT sessions. This questionnaire was composed of two parts. Part A, on the strengths of SFC, was based on the answers that the NGT participants had given to the first NGT 
question, and consisted of 16 items. Part B, on the recommendations for SFC, was based on the answers of the NGT participants to the second NGT question, and consisted of 13 items. Both parts were answered on a 5-point Likert scale ranging from 1 (= strongly disagree) to 5 (= strongly agree). All answers from the three NGT subgroups were included in the SFCQ, regardless of how frequently they had occurred or what NGT score they had been given (see table 1$)$. 
Table 1: Strengths of SFC, recommendations for SFC, NGT aggregate scores, NGT ranks, SFCQ aggregate scores, NGT quartiles, SFCQ quartiles and percentages of SFCQ agreement

\begin{tabular}{|c|c|c|c|c|c|c|}
\hline Strengths of SFC & $\begin{array}{l}\text { NGT } \\
\text { Sum }\end{array}$ & $\begin{array}{l}\text { NGT } \\
\text { Rank }\end{array}$ & $\begin{array}{l}\text { SFC } \\
\mathbf{Q} \\
\text { Sum }\end{array}$ & $\begin{array}{l}\text { NGT } \\
Q^{\prime} \mathbf{s}^{1}\end{array}$ & $\begin{array}{l}\text { SFC } \\
Q^{\prime} \mathbf{S}^{1}\end{array}$ & $\begin{array}{c}\text { Agree- } \\
\text { ment } \\
\%\end{array}$ \\
\hline $\begin{array}{l}\text { Development of a detailed picture of goal attainment (behaviour, } \\
\text { cognition, interaction) }\end{array}$ & 74 & 1 & 164 & 4 & 4 & $89 \%$ \\
\hline Focus on (hidden) successes & 46 & 2 & 161 & 4 & 3 & $94 \%$ \\
\hline Focus on solution building rather than problem solving & 41 & 3 & 161 & 4 & 3 & $83 \%$ \\
\hline Giving the team a set of compliments & 35 & 4 & 164 & 4 & 4 & $97 \%$ \\
\hline Promotion of self-confidence in the team & 34 & 5 & 158 & 3 & 2 & $97 \%$ \\
\hline Focus on uniform care for a client & 32 & 6 & 158 & 3 & 2 & $86 \%$ \\
\hline Focus on teamwork related to one client & 31 & 7 & 145 & 3 & 1 & $72 \%$ \\
\hline Generalisation of successful coaching from one client to another & 30 & 9 & 162 & 3 & 3 & $97 \%$ \\
\hline Focus on one concrete team goal, formulated in a positive manner & 30 & 9 & 145 & 3 & 1 & $86 \%$ \\
\hline Focus on changing team behaviour (rather than client behaviour) & 23 & 10 & 153 & 2 & 1 & $89 \%$ \\
\hline Stimulation of reflection among the team & 22 & 11 & 168 & 2 & 4 & $100 \%$ \\
\hline Step-by-step approach to reaching the team goal & 15 & 12 & 157 & 2 & 2 & $94 \%$ \\
\hline Use of many approaches to reach a team goal & 12 & 13 & 152 & 1 & 1 & $89 \%$ \\
\hline Use of competences already present in the team & 9 & 14 & 163 & 1 & 3 & $97 \%$ \\
\hline $\begin{array}{l}\text { Principle that each team has many workable solutions at its } \\
\text { disposal }\end{array}$ & 8 & 16 & 165 & 1 & 2 & $97 \%$ \\
\hline Capacity to resolve stagnating care situations & 8 & 16 & 155 & 1 & 4 & $92 \%$ \\
\hline \multicolumn{4}{|c|}{ Kappa and mean \% of agreement } & \multicolumn{2}{|c|}{$\begin{array}{l}\text { Kappa }=0.1 \\
p=0.56\end{array}$} & $\begin{array}{l}\text { Mean } \\
=91 \%\end{array}$ \\
\hline Recommendations for SFC & $\begin{array}{l}\text { NGT } \\
\text { Sum }\end{array}$ & $\begin{array}{l}\text { NGT } \\
\text { Rank }\end{array}$ & $\begin{array}{l}\text { SFC } \\
\mathbf{Q} \\
\text { Sum }\end{array}$ & $\begin{array}{l}\text { NGT } \\
Q^{\prime} \mathbf{s}^{1}\end{array}$ & $\begin{array}{l}\text { SFC } \\
\mathbf{Q} \\
\mathbf{Q}^{\prime} \mathbf{s}^{1}\end{array}$ & $\begin{array}{c}\text { Agree- } \\
\text { ment } \\
\%\end{array}$ \\
\hline Organising a follow-up meeting to consolidate the results & 83 & 1 & 163 & 4 & 4 & $94 \%$ \\
\hline Giving information about the SFC methodology in advance & 67 & 2 & 143 & 4 & 3 & $78 \%$ \\
\hline Involving all team members in the SFC process & 56 & 3 & 155 & 4 & 3 & $92 \%$ \\
\hline $\begin{array}{l}\text { Giving information about the role of team members and coach in } \\
\text { advance }\end{array}$ & 53 & 4 & 121 & 3 & 1 & $47 \%$ \\
\hline $\begin{array}{l}\text { Giving information about the duration and intensity of SFC in } \\
\text { advance }\end{array}$ & 50 & 5 & 132 & 3 & 2 & $61 \%$ \\
\hline Explaining SFC to colleagues who are not directly involved & 48 & 6 & 150 & 3 & 3 & $92 \%$ \\
\hline Guiding of the process by an independent coach & 33 & 7 & 108 & 3 & 1 & $22 \%$ \\
\hline $\begin{array}{l}\text { Emphasising that SFC is aimed at the team goal and not at client } \\
\text { behaviour }\end{array}$ & 32 & 8 & 146 & 2 & 3 & $75 \%$ \\
\hline Emphasising that the team can seek advice from the coach & 24 & 9 & 140 & 2 & 3 & $75 \%$ \\
\hline Conducting a problem analysis & 19 & 10 & 117 & 2 & 1 & $39 \%$ \\
\hline Using simple language in solution-focused questions & 13 & 11 & 134 & 1 & 2 & $67 \%$ \\
\hline Emphasising that SFC approaches the team goal step by step & 8 & 12 & 136 & 1 & 3 & $58 \%$ \\
\hline Emphasising in advance that self-reflection will be required & 7 & 13 & 136 & 1 & 3 & $64 \%$ \\
\hline \multicolumn{4}{|c|}{ Kappa and mean \% of agreement } & \multicolumn{2}{|c|}{$\begin{array}{l}\text { Kappa }= \\
-0.1 \\
p=0.37\end{array}$} & $\begin{array}{l}\text { Mean } \\
=66 \%\end{array}$ \\
\hline
\end{tabular}

${ }^{1} Q^{\prime} \mathrm{s}=$ Quartiles. 


\subsection{Data analyses}

Rankings. To answer research question 1, the voting in the NGT process examined how often each idea was chosen and what score it was given (scale 1-7; the higher the score, the higher the priority). The highest scoring ideas were evaluated as the most important and received the highest ranking. Ideas with equal scores on the basis of equal priorities received equal rankings.

Interrater agreement. To answer research question 2, the rank order of the NGT aggregate scores across the three groups was compared with the rank order of the aggregate response to parts A and B of the SFCQ. The aggregate scores for the NGT and the SFCQ were divided into four categories ranging from 1 (low total score) to 4 (high total score), by calculating quartiles. To determine the degree of agreement between the NGT and SFCQ, Cohen's kappa (Cohen, 1960) was computed. A value equal to +1 implies perfect agreement between raters, -1 implies perfect disagreement and 0 implies coincidental agreement. The percentages of the responses agree and strongly agree were calculated per question for both parts of the SFCQ. In addition, the combined average percentage - (strongly) agree - of all questions was calculated.

\section{Results}

Research question 1: 'What are the strengths of SFC, and what recommendations to improve SFC do staff members make via NGT?' During the NGT process, similar ideas within a group were combined with the consent of the staff members, resulting in 16 strengths and 7 recommendations in group one, 15 strengths and 7 recommendations in group two and 16 strengths and 10 recommendations in group three. Given that the answers of the three groups were largely similar, they could be clustered into 16 strengths and 13 recommendations. The highest scoring NGT statements showed similarities with various solution-focused interventions and techniques: NGT rank 1: 'creating a detailed picture of goal attainment'; NGT rank 2: 'exploring exceptions'; NGT rank 3: 'focus on solution building rather than problem solving'. The highest scoring recommendations were: 'organise a SFC follow-up 
meeting'; 'involve all team members in SFC' and 'inform the team about SFC in advance'.

Research question 2: 'To what extent do the opinions of staff members via NGT reflect the opinions of staff members via a standardized questionnaire, regarding both the perceived strengths of SFC and the perceived recommendations for SFC?' In filling in the 16 items of part A of the SFCQ ('strengths of SFC'), 91\% of the 36 staff members indicated that they either agreed or fully agreed with the statements from the NGT interviews. In total, $89 \%$ (fully) agreed with the statement with the highest NGT priority ('creating a detailed picture of goal attainment'), while 94\% (fully) agreed with the recommendation with the highest NGT priority ('organise a SFC follow-up meeting'). On average, $66 \%$ (fully) agreed with the recommendations from the NGT interviews. However, the interrater agreement between the rank orders (quartiles) of the NGT and SFCQ was low and not statistically significant (SFC strengths: Cohen's $\mathrm{k}=0.10, \mathrm{p}=0.56$; SFC recommendations: Cohen's $\mathrm{K}=-0.10, p=0.37$; see table 1 ).

\section{Conclusions}

The NGT is a valuable tool for exploring group opinions and priorities, allowing everyone's opinions to be heard and judged equally. Advantages of the NGT include: (1) the generation of a large number of creative ideas (in this study: 16 strengths and 13 recommendations of SFC), (2) the ease of interpreting (the results are available immediately after the session), and (3) the comparatively efficient use of time (in this study: three hours).

Disadvantages of the NGT include: (1) the limited number of topics that can be covered (in this study: one central issue concerning the evaluation of SFC), (2) the lack of anonymity, which may limit participants' willingness to express their views, and (3) the lack of generalizability of the results to the wider population (Fox 1989; Jones 2004). However in this study, with regard to this last limitation, the opinions on SFC among all three groups were largely uniform. This level of consensus allowed the NGT statements to be converted into an opinion questionnaire - the SFCQ - which meant that the NGT data could be obtained on a larger scale. In this way, NGT can serve to underpin the construct validity of a standardized questionnaire. 
The SFCQ respondents largely agreed with the NGT statements ( $91 \%$ for the strengths; $66 \%$ for the recommendations). However, they differed from the NGT participants in terms of the priorities they set. Because the strengths and recommendations were divided into quartiles, two statements may be similar in terms of priority, but placed in different quartiles. Conversely, statements with a clearly different priority may have been placed in the same quartile, which could have influenced the results. Further, this study design does not indicate whether the two types of research give rise to major differences in prioritisation; an issue that should be clarified in further research.

Strenghts of SFC mentioned by staff included the formulation of a team goal in a positive way, the promotion of self-confidence in the team, the use of competences already present in the team, the focus on solution buiding and the capacity to resolve stagnating care situations. These strengths are similar to results found in prior SFC research (Rhodes, 2000; Stoddart et al., 2001; Wheeler, 2001; Lloyd \& Dallos, 2006, 2008; Roeden et al., 2012). It thus can be concluded that SFC can be particularly helpful for staff in encouraging positive perspectives, self-confidence, self-efficacy, solution building and coping. It thereby also could positively influence the quality of support to persons with ID and consequently their quality of life.

\section{References}

Chung, M.C. \& Harding, C. (2009). Investigating burnout and psychological well-being of staff working with people with intellectual disabilities and challenging behaviour. The role of personality. Journal of Applied Research in Intellectual Disabilities, 22, 549-560.

Cohen, J.A. (1960). A coefficient for agreement for nominal scales. Educational and psychological measurement, 20, 37-46.

De Shazer, S., Dolan, Y.M., Korman, H., Trepper, T.S., McCollum, E.E. \& Berg, I.K. (2007). More than miracles: The state of art of solution-focused therapy. New York: Routledge Press.

Delbecq, A.L., Van Ven, A.H. \& Gustafson, D.H. (1975). Group techniques for program planning; A guide to nominal and Delphi processes. Glenview: Scott, Foresman \& Company. 
Dyer, S. \& Quine, L. (1998). Predictors of job satisfaction and burnout among the direct care staff of a community learning disability service. Journal of Applied Research in Intellectual Disabilities, 11, 320-332.

Fox, D. (1989). The improved Nominal Group Technique (INGT). Journal of management Development, 8, 20-27.

Hatton, C., Brown, A., Caine, A. \& Emerson, E. (1995). Stressors, coping strategies and stress-related outcomes among direct care staff in staff houses for people with learning disabilities. Mental Handicap Research, 8, 252-271.

Jenkins, R., Rode, J. \& Lovell, C. (1997). Psychological well-being of staff working with people who have challenging behaviour. Journal of Intellectual Disability Research, 41, 502-511.

Jones, S.C. (2004). Using the Nominal Group Technique to select the most appropriate topics for postgraduate research students' seminars. Journal of University Teaching and Learning Practice, 1, 20-34.

Lloyd, H. \& Dallos, R. (2008). First session Solution-Focused brief therapy with families who have a child with severe intellectual disabilities. Mothers' experiences and views. Journal of Family Therapies, 30, 5-28.

Lloyd-Jones, G., Fowell, S. \& Bligh, J. G. (1999). The use of the nominal group technique as an evaluative tool in medical undergraduate education. Medical Education, 33, 8-13.

O'Connell, B. \& Palmer, S. (2007). Solution-focused coaching. In Palmer \& A. Whybrow (Eds.), Handbook of coaching psychology: A guide for practitioners (pp. 278). London: Sage.

Prosser, D., Johnson, S., Kuipers, E., Szmikler, G., Bebbingtom, P. \& Thornicroft, G. (1997). Perceived sources of work stress and satisfaction among hospital and community mental health staff, and their relation to mental health, burnout and job satisfaction. Journal of Psychomatic Research, 43, 51-59.

Rhodes, J. (2000). Solution-Focused consultation in a residential setting. Clinical Psychology Forum, 141, 29-33.

Roeden, J.M., Bannink, F.P., Maaskant, M.A. \& Curfs, L.M.G. (2010). The views of clients with mild intellectual disabilities regarding their working relationships with caregivers. Journal of Applied Research in intellectual Disabilities, 24, 398-406. 
Roeden, J.M., Maaskant, M.A., Bannink, F.P. \& Curfs, L.M.G. (2012). Solution-Focused Coaching of Staff of People with Severe and Moderate Intellectual Disabilities; a Case Series. Journal of Policy and Practice, 3, 185194.

Skirrow, P. \& Hatton, C. (2007). Burnout amongst direct care workers in services for adults with intellectual disabilities. A systematic review of research findings and initial normative data. Journal of Applied Research in Intellectual Disabilities, 20, 131-144.

Stoddart, K.P., McDonnel, J., Temple, V. \& Mustata, A. (2001). Is brief better? A modified brief Solution-Focused therapy approach for adults with a developmental delay. Journal of Systematic Therapies, 20, 24-40.

Tuffrey-Wijne, I., Bernal, J., Butler, G., Hollins, S. \& Curfs L.M.G. (2007). Using Nominal Group Technique to investigate the views of people with intellectual disabilities on end-of-life care provision. Journal of Advanced Nursing, 58, 80-89.

Van Dierendonck, D., Schaufeli, W.B. \& Bunk, B.P. (1996). Inquity among human service professionals: Measurement and relation to burnout. Basic and Applied Social Psychology, 18, 429-451.

Wheeler, J. (2001). A helping hand: Solution-Focused brief therapy and child and adolescent mental health. Clinical Child Psychology and Psychiatry, 6, 293306. 


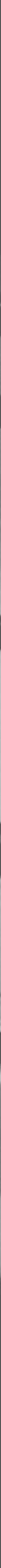




\section{CHAPTER 9}

\section{PROCESSES AND EFFECTS OF SOLUTION-FOCUSED COACHING OF STAFF OF PEOPLE WITH INTELLECTUAL DISABILITIES; A CONTROLLED STUDY}

Roeden, J.M., Maaskant, M.A., Bannink, F.P. \& Curfs, L.M.G. (2012). Solution-Focused Coaching of Staff of People with Severe and Moderate Intellectual Disabilities (ID); a Controlled Study. 


\section{Abstract}

Background. Solution-Focused Coaching (SFC) is an outcome-oriented, competence based approach aimed at assisting individuals or groups to make desired changes in their personal or work life. The aim of this study was to study whether or not SFC teams performed better after SFC than teams who received coaching as usual (CAU).

Method. 18 teams who experienced a support problem with a client with ID received SFC. 26 control teams received coaching as usual from psychologists as usual. For both SFC teams and CAU teams the following measurements were taken before SFC, after SFC and during a follow-up: (1) measures of proactive behaviour in teams and (2) measures of the quality of the staff-client relationships. SFC was compared with CAU on these two measures. Goalattainment was only measured in the SFC teams, since CAU teams did not formulate team goals.

Results. The SFC teams improved statistically significantly more on the variables proactive thinking and quality of the relationships than the CAU teams. This counted for both individual staff members (numbers of respondents varying between $n=45$ and $n=59$ ) and teams (respectively $n=$ 18 and $n=26$ ). The differences between both groups sustained at follow-up. The SFC teams also indicated a statistically significant progression towards the team goal.

Conclusions. The results showed that the SFC teams outperform the CAU teams. The implications for practice and future research are discussed.

\section{Keywords}

Solution-Focused Coaching of Staff, Systemic Therapy, Controlled Study, Intellectual Disabilities 


\section{Introduction}

Solution-Focused Coaching (SFC) is an outcome-oriented, competence based approach aimed at assisting individuals or groups to make desired changes in their personal or work life (O'Connell \& Palmer, 2007). The specific skills and strategies utilized in SFC include many of the approaches utilized in a solutionfocused therapeutic settings, originally called Solution-Focused Brief Therapy (SFBT, De Shazer, 1985). Two meta-analyses reviewed SFBT outcomes in the general population across a wide range of studies. Stams et al. (2006) conducted a meta analysis of 21 studies investigating the effects of SFBT using Cohen's $d$ to measure effect size. This meta analysis found an overall small effect size of Cohen's $d=0.37$ (Cohen, 1988) for SFBT. Studies that compared SFBT with 'no treatment' ( $n=4)$ yielded a medium effect size of $d=0.57$. Studies that compared SFBT with other treatments $(n=7)$ yielded an small effect size of only $d=0.16$. Kim (2008) conducted a second meta-analysis examining the effectiveness of SFBT (22 comparison group studies) for different types of outcomes: externalizing behaviour problems, internalizing behaviour problems, and family or relationship problems. This meta-analysis found that SFBT demonstrated small but positive treatment effects favouring the SFBT groups. However, only the overall weighted mean effect size for internalizing problems such as depression, anxiety, self-concept and selfesteem, was significant at the $p<0.05$ level, indicating that the treatment effect of the SFBT groups was better than that of the control groups. SFBT appeared to be less effective with externalizing behaviour problem such as hyperactivity, conduct problems, aggression, and family and relationship problems. In a review of SFBT outcome research Gingerich, Kim, Stams \& Macdonald (2011) state: "SFBT is as good or slightly better than other accepted treatments, but it is clearly better than no treatment at all" (p.106). Recent studies of Knekt and Lindfors (2004) and Knekt et al. (2008a, 2008b) conformed most closely to generally accepted standards for effectiveness studies. These studies employed a large sample, used random assignment, and outcomes were assessed multiple times over a 3-year period. SFBT as compared with two other evidence-based treatments: short-term psychodynamic psychotherapy (SPP), and long-term psychodynamic therapy (LPP). SFBT and SPP had equivalent outcomes over the 3 years of the study. 
The LPP treatments produced outcomes more slowly, but at the end of the 3 years they were better than the two short-term treatments.

SFC in fact is the same as SFBT, albeit that people in SFC are not individuals, but teams. In SFC, the therapist is called coach. The following principles are considered as important solution-focused strategies: (1) SFC is based on solution building rather than problem solving. The SF-coach focuses on the desired future formulated by staff rather than on past problems. (2) Exploring exceptions. No problem happens all the time. There are exceptions (hidden successes) - that is, times when the problem could have happened, but did not. The team and the coach to co-construct solutions can use this fact. (3) Team members define the goal of coaching. Team members are invited by the coach to create a detailed picture of what the support will be like once the goal is reached. Ideally, the description will contain the 'who,' 'what,' 'where,' 'when,' and 'how' of goal attainment. 4. Scaling questions (10 = most desirable support situation; 1 = least desirable support situation) are used in order to measure progress during coaching. These questions help teams to move away from 'all or nothing' goals towards smaller, manageable and measurable steps. (5) Homework assignments. To stimulate or maintain changes, the therapist suggests tasks such as 'continue with what is working already'.

Research in the general population showed that SFC is effective. However, little is known about the usefulness of SFC for staff working with people with ID. Only scarce research on this topic is available (Lloyd \& Dallos, 2006, 2008; Rhodes, 2000; Stoddart, McDonnel, Temple \& Mustata, 2001). Rhodes (2000) found that SFC is a useful approach for staff working with people with ID. In particular, the way staff members generated solutions that built on their competencies was values. Stoddart et al. (2001) treated 16 persons with mild ID and with a range of problems using SFBT, and actively involved staff in the treatment procedures. Staff developed more positive perspectives about the persons concerned because of their involvement in SFBT. They became more aware of the resiliencies, resources and competencies of the persons with ID to come up with solutions themselves. Lloyd and Dallos $(2006,2008)$ found that mothers of children with severe ID experienced SFC as a useful approach to build useful relationships, to highlight self-efficacy and to encourage helpful coping styles. As Wheeler (2001) reported, SFC can be particularly helpful for staff in encouraging a sense of 
self-efficacy and proactive thinking, in altering negative perceptions and in enhancing positive attachment.

Several studies found that SFBT/SFC techniques, and the model in general, engender clients' optimism about accomplishing goals (Corcoran \& Ivery, 2004; Dine, 1995; Jordan, 1994, 1997; Shilts, Rambo \& Hernandez, 1997). Both clients and staff appreciated the positive atmosphere of SFC. They described a validating, proactive, and empowering experience and appreciate the focus on their strengths and success (Green, 2012; Roeden, Maaskant \& Curfs, 2011).

Because more insight is needed regarding the effects of SFC, we conducted a controlled pre- and post-test study of solution-focused coaching (SFC) in 18 teams compared with coaching as usual (CAU) in 26 teams. These 44 teams experienced difficulties in supporting people with severe and moderate ID (S/MID). We expected that SFC could (1) assist staff in reaching their goal, (2) improve proactive thinking in staff, (3) positively influence the relationships between staff and people with ID. We therefore measured differences with regard to these variables. We did that in both circumstances (SFC and CAU) in several time frames: before starting SFC, directly after finishing SFC and 6 weeks after finishing SFC.

The key questions in this study are: 'to what extent do SFC teams reach their team goals, and to what extent do SFC teama outperform CAU teams with regard to improved proactive thinking and increased quality of the relationships between staff and people with ID?'

\section{Method}

\subsection{Participants and procedures}

The study was conducted at a Dutch service provider for children and adults with ID (serving approximately 900 people). People registred with this provider use various services such as residential care, home care and day care. Staff members involved in this study were direct care workers who provided residential or vocational support for people with ID. The SFC teams consisted of the first 18 teams that applied for SFC. These teams experienced difficulties in supporting clients with S/MID. Such support problems were for example: 
aggressive behaviour of a client towards staff, or finding it difficult to interact comfortably with a client (see the result section for more details). The control group consisted of 26 teams that received coaching as usual. Consequently, a total 44 teams consisting of 118 staff members (mean: 2-3 staff members per team) participated in this study. As it was considered unethical to withhold a potentially effective coaching from those who might benefit from SFC, all teams in the CAU group were offered to receive SFC after the study. The teams receiving SFC $(n=18)$ were compared with the teams receiving CAU $(n=26)$ at the start of the study. It showed that the differences in age of the staff and working experiences were not statistically significant. Table 1 provides the team characteristics for both the SFBT and the CAU teams.

\section{Table 1: SFBT and CAU teams according to number of teams, number of team members (absolute numbers) and age, years of working experience (Mean, SD)}

\begin{tabular}{|l|l|l|l|}
\hline $\begin{array}{c}\text { Condition / } \\
\text { test values } \\
\text { Characteristics }\end{array}$ & SFC & $\begin{array}{l}\text { CAU } \\
\boldsymbol{p} \text {-values; }\end{array}$ \\
\hline $\begin{array}{l}\text { Number of } \\
\text { teams }\end{array}$ & 18 & 26 & -- \\
\hline $\begin{array}{l}\text { Number of staff } \\
\text { members }\end{array}$ & 59 & 59 & -- \\
\hline Age & $\begin{array}{l}40.2 \\
(\mathrm{SD}=10.8)\end{array}$ & $\begin{array}{l}39.1 \\
(\mathrm{SD}=11.8)\end{array}$ & $\begin{array}{l}t=0.51 ; \\
p=0.61\end{array}$ \\
\hline $\begin{array}{l}\text { Working } \\
\text { experience }\end{array}$ & $\begin{array}{l}12.5 \\
(\mathrm{SD}=8.6)\end{array}$ & $\begin{array}{l}t=0.63 ; \\
(\mathrm{SD}=5.8)\end{array}$ \\
\hline
\end{tabular}

Three data measurements were taken in all teams (SFC and CAU): the first immediately before SFC; the second immediately after SFC (9 weeks after the start) and the third, a follow-up measurement 6 weeks after SFC.

Permission for the study was granted by the Client Council (comprised of service users with ID) and by the Representative Council (comprised of family members or representatives of service users with ID) of the service provider. The Councils confirmed that the study complied with the local organisational guidelines for internal evaluation. All participants in the study agreed to anonymous publication of the research data. 


\subsection{Solution-Focused Coaching (SFC)}

Staff gained a global understanding of SFC through attending an information meeting and by reading relevant literature. The SFC-process according to session, intervention and description is summarised in table 2. As is usual in SFC, during intake (session 1), the SFC coach becomes acquainted with staff members through enquiries about the competencies of individual staff members and of the staff as a team. The support problem focuses on one particular person with S/MID. Subsequently, the support problems experienced by staff are explored. Two questions are then asked: 'What is the support problem with this person?' and 'What is the problem for staff members?'. During session 1, the coach asks Solution-Focused questions, such as questions concerning the goals of staff, exceptions, scale questions and competency questions. Every session concludes with the coach giving feedback to staff members.

In session 2, the coach starts with the EARS-question-set. EARS is an acronym for Eliciting, Amplifying, Reinforcing, Start again. It outlines the therapeutic process. The first question is 'What is better?' (Eliciting). Staff members can respond to that question in four different ways: 'It is better', 'There is no change', 'It is worse', or 'There is a difference in opinion' (in this case, between staff members). If it is better, the coach can react to that by amplifying, 'What exactly is (somewhat) better?', by reinforcing, 'How did you manage to do that?' and by starting again, 'What (else) is better?' EARS can also be utilised when staff believe there is no change (Trepper et al., 2012). 


\section{Table 2: SFC-protocol according to session, intervention and description}

\begin{tabular}{|c|c|c|}
\hline Session & Intervention & Description \\
\hline Intake & 1. Getting acquainted & $\begin{array}{l}\text { The coach spends time to get to know the team. } \\
\text { Competencies and resources are explored. }\end{array}$ \\
\hline \multirow[t]{8}{*}{$\begin{array}{l}\text { First } \\
\text { session }\end{array}$} & $\begin{array}{l}\text { 2. Exploring the } \\
\text { problem }\end{array}$ & $\begin{array}{l}\text { The coach invites the team to describe their problem and/or } \\
\text { to mention their goal for coaching. The coach acknowledges } \\
\text { the problems of the team. }\end{array}$ \\
\hline & 3. Pre-session change & $\begin{array}{l}\text { Since most teams have tried other possibilities before } \\
\text { connecting with a coach. The coach can ask whether and/or } \\
\text { what changes have already occurred before the first } \\
\text { session. }\end{array}$ \\
\hline & 4. Goal setting & $\begin{array}{l}\text { The team is invited to describe what would be different once } \\
\text { their goal is reached. This could be done by means of the } \\
\text { miracle question: 'Imagine a miracle occurring tonight that } \\
\text { would (sufficiently) solve the problem ... what would be } \\
\text { different tomorrow?' The coach may also suggest that } \\
\text { changes are possible (e.g., 'When you look forward and } \\
\text { things have improved, what will you be doing differently?') } \\
\text { or by using the video question: 'Suppose we make a video } \\
\text { showing the most desirable support situation. What do we } \\
\text { see and hear on this video?'. }\end{array}$ \\
\hline & $\begin{array}{l}\text { 5. Exploring the } \\
\text { exceptions }\end{array}$ & $\begin{array}{l}\text { The coach inquires about moments in the past or present } \\
\text { when the problem does not occur or is less serious and who } \\
\text { does what to bring about these exceptions. }\end{array}$ \\
\hline & 6. Scaling questions & $\begin{array}{l}\text { On a scale of } 10 \text { to } 1 \text { the team indicates their progression } \\
\text { towards their goal. Scaling questions help the team to move } \\
\text { away from all-or-nothing goals toward manageable and } \\
\text { measurable steps. }\end{array}$ \\
\hline & $\begin{array}{l}\text { 7. Competence } \\
\text { questions }\end{array}$ & $\begin{array}{l}\text { By using competence questions, self compliments are } \\
\text { provoked with the team. 'How do (did) you do that?' Direct } \\
\text { compliments aim to highlight something the team has done, } \\
\text { made or said. }\end{array}$ \\
\hline & $\begin{array}{l}\text { 8. The question: 'What } \\
\text { else?' }\end{array}$ & $\begin{array}{l}\text { The coach may also indicate with the question 'What else?' } \\
\text { indicating that there is more to come. Teams often respond } \\
\text { to this simple query by giving more information and ideas. }\end{array}$ \\
\hline & 9. Feedback & $\begin{array}{l}\text { At the end of every session feedback with compliments and } \\
\text { usually some homework are given. The compliments } \\
\text { emphasise what the team is already doing to reach their } \\
\text { goal. The suggestions indicate areas requiring the team's } \\
\text { attention or possible further actions needed to reach their } \\
\text { goal. Between the components of compliments and } \\
\text { suggestions/tasks a reason (or bridge) is given to perform } \\
\text { those tasks. }\end{array}$ \\
\hline \multirow[t]{4}{*}{$\begin{array}{l}\text { Follow- } \\
\text { up } \\
\text { sessions }\end{array}$} & $\begin{array}{l}10 \text { The question: } \\
\text { 'What is better?' }\end{array}$ & The standard beginning question is: 'What is better?'. \\
\hline & $\begin{array}{l}\text { 11. EARS = Eliciting, } \\
\text { Amplifying, } \\
\text { Reinforcing, Start } \\
\text { again }\end{array}$ & $\begin{array}{l}\text { Eliciting, amplifying, and reinforcing of (small) successes, } \\
\text { exceptions to problems, or descriptions of the desired future } \\
\text { and the invitation to the team to do that again or more } \\
\text { often. }\end{array}$ \\
\hline & 12 Feedback & Compliments - reason/bridge - task. \\
\hline & 13 Consolidation & $\begin{array}{l}\text { Consolidation questions such as: 'What do you have to keep } \\
\text { doing to make sure that these results keep happening? How } \\
\text { are able to stay on track?'. }\end{array}$ \\
\hline
\end{tabular}




\subsection{Coaching as usual (CAU)}

Staff members support clients with ID daily, with regard to for example activities of daily living, social skills, working skills and household activities. Psychologists on their turn offer coaching to staff members by advising and supporting them to care for clients adequately. They advise on how to construct, implement and evaluate optimal support, and advise in case of challenging behaviour, how to gain insight in possible causes of such behaviour and how to reduce it.

CAU is most dissimilar with SFBT in terms of the role of the coach. As applied in the setting mentioned above, CAU is a type of coaching that focuses on the problem-solving model. The problem analysis, the coaching plan and interventions are primarily performed formulated by the coach. In CAU the coach suggests the solutions, serving as an expert who advises the team on the actions to take to alleviate the support problem.

\subsection{Instruments}

We measured differences within and between teams with regard to goal attainment according to staff, proactive thinking in teams and the quality of the relationships between staff and clients with ID.

Goal attainment was measured by using the Scale Question Progression (SQP; Bannink, 2010). De SQP ranges from 10 (most desirable support situation) to 1 (least desirable support situation). It indicates to what extent a team goal has been approached or has been reached. Since CAU teams did not formulate team goals, the scaling questions were not asked in the CAU teams. Consequently, SQP data were not available for the CAU teams. The SQP was rated by all staff members in the SFC group independently. The scores used for analyses were average scores for each of the 18 teams. In solution-focused scale questioning, it is customary to ask the people concerned what they regard as a relevant improvement. In this study, the members of the 18 teams were asked about such an improvement. They decided that an average progression of 2 points could be regarded as a relevant improvement. Proactive thinking was measured using part of the Staff-Client Interactive Behaviour Inventory (SCIBI; Willems, Embregts, Stams \& Moonen, 2010).The 
30-item SCIBI measures both intrapersonal staff behaviour (proactive thinking, self-reflection, critical expressed emotion) and interpersonal staff behaviour (assertive control, hostile, friendly and support seeking behaviour) in response to challenging behaviour in people with ID. These seven factors were supported by a factor analysis (Willems et al., 2010). The internal consistency of the SCIBI was satisfactory (Cronbach's alpha > 0.68) for all scales. Staff members were asked to complete the SCIBI-scale of proactive thinking (abbreviated as: SCIBI-PAT). The SCIBI-PAT is a 3 item self-report questionnaire using a 5-point Likert Scale, ranging from completely inapplicable (1) to completely applicable (5). The items are: 'in working with this client, I think about how, (first item), what (second item) or why (third item) I am going to do things'.

The quality of the relationships between people with ID and staff members was measured using the Student Teacher Relationship Scale (STRS, authorised translation; Koomen, Verschueren \& Pianta, 2007; Koomen, Verschueren, Van Schooten, Jak \& Pianta (2012). The 28-item STRS represents the view of the teacher on three relationship dimensions: closeness (11 items), conflict (12 items) and dependency (5 items). The total STRS-score represents the quality of the relationship. In consultation with the author of the STRS, the terms 'student' and 'teacher' were substituted by 'person with ID' and 'staff member' respectively. Staff rated the extent to which they agreed with each statement (for example: 'I share an affectionate, warm relationship with this person') using a 5-point Likert Scale, ranging from $1=$ definitely does not apply to 5 = definitely applies. Closeness reflects the degree of openness, warmth and security in the relationship according to the teacher/staff member. Conflict refers to the degree to which a teacher/staff member perceives interactions as negative, discordant, unpredictable and unpleasant. Dependency denotes the developmentally inappropriate degree of overreliance and possessiveness of the child/adult with ID in the relationship. Psychometric research in school settings showed a satisfactory internal consistency for all scales (Cronbach's a between 0.77 and 0.90). The STRS domains of closeness, conflict, and dependency were supported by a factor analysis. Roeden, Maaskant, Koomen, Candel \& Curfs (2011) studied the psychometric qualities of the STRS in an ID-setting, using the terminology 'person with ID' and 'staff member'. The factor structure matched with the factor structure found in 
educational settings. The internal consistency was good for all subscales and the total score (Cronbach's a between 0.81 and 0.89), as well as the testretest reliability (intraclass correlations coefficients between 0.85 and 0.92 ). In the present study, staff members individually completed the STRS, and their raw scores were summed up and averaged per team, resulting in mean scores per team.

\subsection{Statistical analyses}

It was chosen to analyze the SCIBI-PAT and the STRS data on both individual and team level. In this way, similar and possible contrasting outcomes between some individual staff members on the one hand and team outcomes on the other hand could be elucidated. The average SQP-scores were only analysed on team level.

\subsubsection{Paired t-test and Wilcoxon signed-rank test}

Dependent tests were used to investigate differences within groups. The differences in pairs of means (respectively before SFC and after SFC, and before SFC and at follow-up) within the SFC teams and - in the same timeframe - within the CAU teams, were calculated. Data of individual staff members were calculated, using the dependent $t$-test. To control the problem of multiple comparisons (four STRS-variables and one POS-variable), the Dunn-Bonferroni correction (Dunn, 1961) was used by dividing the $p$-value by the number of variables: $p / n=0.05 / 5=0.01$. Given the relatively small numbers of teams ( $n=18 / n=26)$, the non-parametric test for related conditions (Wilcoxon signed-rank-test) was used to analyze the team data.

\subsubsection{Independent t-test / Mann-Whitney $U$ test}

Differences in scores of staff members of SFC teams versus CAU teams were compared using the independent $t$-test. Because of the small number of teams ( $n=18 / n=26)$, the non-parametric test for unrelated conditions (MannWhitney $U$ test) was used to analyze the team data (SFC vs. CAU). Statistical analyses were used to test for changes on the on the SCIBI-PAT and STRS over time. The Dunn-Bonferroni correction $(p / n=0.05 / 5=0.01)$ was also used in these comparisons. 


\subsubsection{Effect size}

Effect size (ES) is 'an objective and standardized measure of the magnitude of observed effects' (Field, 2009, p. 56). The American Psychological Association recommends the use of effect size in the results of any published work. Pearson's correlations coefficient $r$ can be used as an effect size measure lying between 0 (no effect) and 1 ( perfect effect). In paired $t$-tests the original standard deviations were used to compute ES for correlated samples. In this calculation the pooled standard deviation is corrected for the amount of correlation between the measures to prevent an overestimate of the actual ES (Dunlop, Cortina, Vaslow \& Burke, 1996). The $r$ is computed from Cohen's $d$ (Cohen, 1988): $r=d / \sqrt{ }\left(d^{2}+4\right)$ in which $\left.d=\mathrm{M}_{1}-\mathrm{M}_{2} / \sqrt{ } \mathrm{SD}_{1}{ }^{2}+\mathrm{SD}_{2}{ }^{2}\right) / 2$. In independent $t$-tests the equation to convert a $t$-score into the effect size, $r$, is as follows: $r=\sqrt{ }\left(t^{2} / t^{2}+d f\right)$ (Rosnow \& Rosenthal, 2005), in which $t$ is the $t$ score of the Student's $t$-test and df is the degrees of freedom of the test. The criteria established by Cohen (1988) were used to interpret the effect sizes: no effect: $r<0.10$; a small effect: $r \geq 0.10$ and $<0.30$ (1\%-9\% of the total variance); a medium effect: $r \geq 0.30$ and $<0.50$ (9-25\% of the total variance) and a large effect: $r \geq 0.50$ ( $>25 \%$ of the total variance). We regarded the effect of SFC as substantial only when (1) the differences in scores between SFC and CAU were statistically significant $(p<0.01)$ and $(2)$ the ES were at least medium.

\section{Results}

Eighteen teams participated in SFC. All teams completed the coaching. Twentysix teams received CAU. No statistical significant differences were found between the SFC and the CAU teams with regard to pre-treatment mean scores of the quality of the relationship (SFC: 96.4 [SD $=11.0]$ vs. CAU: 98.9 $[S D=7.2] ; z=-0.8 ; p=0.44)$. However the SFC and the CAU teams differed statistically significant in initial scores on proactive thinking (SFC: 10.6 [SD = $1.3]$ vs. CAU: $11.7[\mathrm{SD}=1.3] ; z=-2.2, p<0.05)$. 
3.1 Goal attainment associated with initial support problems in the SFC teams

Goal attainment (or progression towards the team goal) was measured by using the SQP. No SQP data were available for the CAU teams, since team goals were not asked for in the CAU teams. During intake, the following support problems were reported by the staff members in SFC: avoidance of support (2 teams), discord / hostility in the relationship (6 teams), too much control in the support ( 2 teams), excessive demands of attention ( 4 teams), disturbed communication (4 teams).

During the first session staff formulated team goals prompted by the solution-focused key question: 'What do you want to see instead of the support problem?' This led to the following goals addressing the problems mentioned above: compliance in the support (2 teams), harmony in the relationship (6 teams), offering autonomy in the support ( 2 teams), creating respectful distance in the support (4 teams), open and reciprocal communication (4 teams).

Eight of 18 teams indicated progressions of 2 points or more on the SQP after SFC, and 10 of 18 teams at follow-up. The differences in scores of the 18 teams at start versus after SFC were statistically significant (mean progression +1.9 points [SD $=0.9 ; z=-3.7 ; p<0.01$ ) and also at start versus follow-up (mean progression +2.3 points $[S D=0.9 ; z=-3.7 ; p<0.01$ ). The other teams (10 respectively 8 teams) also made progress, but less than the defined 2 points.

3.2 Differences within groups with regard to proactive thinking and quality of relationship

The differences in scores for both the SFC teams and CAU teams for all measurements concerning individual staff members are presented in table 3. The additional results of teams as a whole (non-parametric analyses) are only described in the text (see 3.2). Not all staff members completed all questionnaires to their fully extent. The exact number of respondents is given in the tables concerned. The results showed that the SFC teams (individual staff members) performed overall better $(p<0.01)$ after SFC and at follow-up, except for dependency ( $p>0.2$, no ES). The variables 'closeness' and 'conflict' 
however, only had a small effect size. The CAU teams showed no statistically significant differences with regard to all variables, except for the QOR at follow-up ( $p<0.01$, small ES). 
Table 3: Within-group differences in proactive thinking (SCIBI-PAT) and quality of the relationship (STRS) of the before, after and followup measurements of SFC and CAU individual team members

\begin{tabular}{|c|c|c|c|c|c|c|c|c|c|c|}
\hline $\begin{array}{l}\text { Group } \\
\text { data } \\
\text { Instru- } \\
\text { ments }\end{array}$ & $n$ & Group & $\begin{array}{l}\text { Before } \\
\text { Mean }^{a} \\
(\mathrm{SD})^{\mathrm{a}}\end{array}$ & $\begin{array}{l}\text { After } \\
\text { Mean } \\
\text { (SD) }\end{array}$ & $\begin{array}{l}\text { Mean } \\
\text { change; } \\
t \text {-test; } \\
\text { Effect size } \\
(\text { ES) }\end{array}$ & $n$ & Group & $\begin{array}{l}\text { Before } \\
\text { Mean }^{\mathrm{a}} \\
(\mathrm{SD})^{\mathrm{a}}\end{array}$ & $\begin{array}{l}\text { Follow-up } \\
\text { Mean } \\
\text { (SD) }\end{array}$ & $\begin{array}{l}\text { Mean change; } \\
t \text {-test; } \\
\text { Effect size } \\
(\text { ES) }\end{array}$ \\
\hline \multirow[t]{2}{*}{$\begin{array}{l}\text { SCIBI- } \\
\text { PAT } \\
\text { Proactive } \\
\text { Thinking }\end{array}$} & $51^{\mathrm{c}}$ & SFC & $\begin{array}{l}10.5 \\
(1.7)\end{array}$ & $\begin{array}{l}12.2 \\
(1.6)\end{array}$ & $\begin{array}{l}+1.7 \\
t=-5.4, p< \\
0.01 \\
r=0.46 \\
\text { medium ES* }\end{array}$ & $51^{\mathrm{c}}$ & SFC & $\begin{array}{l}10.6 \\
(1.8)\end{array}$ & $\begin{array}{l}12.4 \\
(1.5)^{\mathrm{a}}\end{array}$ & $\begin{array}{l}+1.8 \\
t=-7.1 \\
p<0.01 \\
r=0.48 \\
\text { medium ES* }\end{array}$ \\
\hline & $50^{\circ}$ & CAU & $\begin{array}{l}11.8 \\
(1.9)\end{array}$ & $\begin{array}{l}11.7 \\
(1.9)\end{array}$ & $\begin{array}{l}-0.1 \\
t=0.4 \\
p=0.69 \\
r=0.03 \\
\text { no ES }\end{array}$ & $45^{\mathrm{c}}$ & CAU & $\begin{array}{l}11.8 \\
(2.1)\end{array}$ & $\begin{array}{l}11.5 \\
(2.1)\end{array}$ & $\begin{array}{l}-0.3 \\
t=1.0 \\
p=0.32 \\
r=0.07 \\
\text { no ES }\end{array}$ \\
\hline \multirow[t]{2}{*}{$\begin{array}{l}\text { STRS } \\
\text { Closeness }\end{array}$} & 59 & SFC & $\begin{array}{l}38.0 \\
(6.6)\end{array}$ & $\begin{array}{l}41.0 \\
(5.6)\end{array}$ & $\begin{array}{l}+3.0 ; \\
t=-5.7 \\
p<0.01 \\
r=0.24, \\
\text { small ES }\end{array}$ & $58^{\mathrm{c}}$ & SFC & $\begin{array}{l}38.1 \\
(6.6)\end{array}$ & $\begin{array}{l}41.5 \\
(6.4)\end{array}$ & $\begin{array}{l}+3.4 \\
t=-4.3, \\
p<0.01 \\
r=0.25, \\
\text { small ES }\end{array}$ \\
\hline & 59 & CAU & $\begin{array}{l}37.8 \\
(7.0)\end{array}$ & $\begin{array}{l}38.2 \\
(7.4)\end{array}$ & $\begin{array}{l}+0.4 ; \\
t=-1.0, \\
p=0.34 \\
r=0.03, \\
\text { no ES }\end{array}$ & $51^{\mathrm{c}}$ & CAU & $\begin{array}{l}37.9 \\
(7.1)\end{array}$ & $\begin{array}{l}39.3 \\
(6.5)\end{array}$ & $\begin{array}{l}+1.4 ; \\
t=-2.1 \\
p<0.05 \\
r=0.10 \\
\text { small ES }\end{array}$ \\
\hline \multirow[t]{2}{*}{$\begin{array}{l}\text { STRS } \\
\text { Conflict }\end{array}$} & 59 & SFC & $\begin{array}{l}26.2 \\
(8.3)\end{array}$ & $\begin{array}{l}21.8 \\
(6.9)\end{array}$ & $\begin{array}{l}-4.4 ; \\
t=6.0 \\
p<0.01 \\
r=0.28, \\
\text { small ES }\end{array}$ & $57^{\mathrm{c}}$ & SFC & $\begin{array}{l}26.2 \\
(8.2)\end{array}$ & $\begin{array}{l}21.9 \\
(7.9)\end{array}$ & $\begin{array}{l}-4.3 ; \\
t=5.7 \\
p<0.01 \\
r=0.26, \\
\text { small ES }\end{array}$ \\
\hline & 59 & CAU & $\begin{array}{l}22.5 \\
(7.1)\end{array}$ & $\begin{array}{l}21.6 \\
(7.6)\end{array}$ & $\begin{array}{l}-0.9 ; \\
t=1.6, \\
p=0.12 \\
r=0.06, \\
\text { no ES }\end{array}$ & $51^{\mathrm{c}}$ & CAU & $\begin{array}{l}21.9 \\
(7.1)\end{array}$ & $\begin{array}{l}20.7 \\
(7.0)\end{array}$ & $\begin{array}{l}-1.2 ; \\
t=1.8, \\
p=0.08 \\
r=0.08, \\
\text { no ES }\end{array}$ \\
\hline \multirow[t]{2}{*}{$\begin{array}{l}\text { STRS } \\
\text { Depen- } \\
\text { dency }\end{array}$} & 59 & SFC & $\begin{array}{l}17.1 \\
(4.3)\end{array}$ & $\begin{array}{l}16.7 \\
(4.1)\end{array}$ & $\begin{array}{l}-0.4 ; \\
t=1.2, \\
p=0.22 \\
r=0.05, \\
\text { no ES }\end{array}$ & $57^{\mathrm{c}}$ & SFC & $\begin{array}{l}17.4 \\
(4.2)\end{array}$ & $\begin{array}{l}16.9 \\
(5.0)\end{array}$ & $\begin{array}{l}-0.5 ; \\
t=0.9, \\
p=0.36 \\
r=0.05, \\
\text { no ES }\end{array}$ \\
\hline & $58^{\mathrm{c}}$ & CAU & $\begin{array}{l}16.8 \\
(5.4)\end{array}$ & $\begin{array}{l}16.7 \\
(5.7)\end{array}$ & $\begin{array}{l}-0.1 ; \\
t=0.4, \\
p=0.71 \\
r=0.01, \\
\text { no ES }\end{array}$ & $51^{\mathrm{c}}$ & CAU & $\begin{array}{l}17.0 \\
(5.5)\end{array}$ & $\begin{array}{l}16.8 \\
(5.6)\end{array}$ & $\begin{array}{l}-0.2 ; \\
t=0.4, \\
p=0.71 \\
r=0.02, \\
\text { no ES }\end{array}$ \\
\hline \multirow[t]{2}{*}{$\begin{array}{l}\text { STRS } \\
\text { Quality } \\
\text { of } \\
\text { Relation- } \\
\text { ship }\end{array}$} & 59 & SFC & $\begin{array}{l}96.7 \\
(11.9)\end{array}$ & $\begin{array}{l}104.5 \\
(10.5)\end{array}$ & $\begin{array}{l}+7.8 ; \\
t=-7.2, \\
p<0.01 \\
r=0.33, \\
\text { medium ES* }\end{array}$ & $57^{\mathrm{c}}$ & SFC & $\begin{array}{l}96.4 \\
(12.0)\end{array}$ & $\begin{array}{l}104.6 \\
(12.7)\end{array}$ & $\begin{array}{l}+8.2 \\
t=-6.6 \\
p<0.01 \\
r=0.31 \\
\text { medium ES* }\end{array}$ \\
\hline & $58^{\mathrm{c}}$ & CAU & $\begin{array}{l}100.4 \\
(8.4)\end{array}$ & $\begin{array}{l}102.0 \\
(11.6)\end{array}$ & $\begin{array}{l}+1.6 ; \\
t=-1.6, \\
p=0.12 \\
r=0.08, \\
\text { no ES }\end{array}$ & $51^{\mathrm{c}}$ & CAU & $\begin{array}{l}101.0 \\
(8.5)\end{array}$ & $\begin{array}{l}103.8 \\
(11.3)\end{array}$ & $\begin{array}{l}+2.8 ; \\
t=-2.8, \\
p<0.01 \\
r=0.14, \\
\text { small ES }\end{array}$ \\
\hline
\end{tabular}


${ }^{a}$ Means and standard deviations may vary (also compared to table 4) due to missing values in pairs of observations.

${ }^{b}$ Effect sizes (ES): no effect, $r<0.10$; a small effect, $r \geq 0.10$ and $<0.30$; a medium effect, $r \geq$ 0.30 and $<0.50$ and a large effect, $r \geq 0.50$.

c Lower sample sizes due to missing values.

*Differences over time within groups are statistically significant $(p<0.01)$ on the paired $t$-test and the effect size is at least 'medium'.

Non-parametric analyses confirmed these findings: compared to the before measurement the SFC teams performed statistically significant better $(p<$ 0.01) on all variables after SFC and at follow-up, except for 'dependency'. Analyses on team level revealed no statistically significant changes in CAU teams.

\subsection{Differences between groups}

The key issue in this study is whether or not the changes in scores between the measurements differ between the SFC teams and the CAU teams. Table 4 shows the results of these analyses of individual staff members. The analyses revealed that the SFC teams performed better than the CAU teams directly after SFC and at follow-up with regard to two key variables: proactive thinking (SCIBI-PAT) and the quality of the relationships (QOR). The effect sizes after SFC and at follow-up were all medium. QOR is a composite measure, representing closeness, conflict and dependency. After SFC, the differences between the SFC teams and the CAU teams for individual staff members regarding 'closeness' and 'conflict' were statistically significant $(p<0.01)$ with medium effect sizes. The changes at follow-up concerning closeness did not reach statistical significance anymore $(p=0.06)$ and the effect size declined to small. No statistical significant changes were seen between STRS dependency scores in both the SFC and CAU teams.

Non-parametric analyses on team level also revealed that the SFC teams performed statistically significant better than the CAU teams on proactive thinking and on the quality of the relationships, after SFC and at follow-up (SIBI-PAT after SFC: $z=-3.2, p<0.01$; SCIBI-PAT at follow-up: $z=-4.6, p<$ 0.01 / QOR after SFC: $z=-3.3, p<0.01$; QOR at follow-up: $z=-3.4, p<$ $0.01)$. Similar to the analyses on individual level, no statistical significant team changes were found for the variables closeness at follow-up $(z=-1,5, p=$ 
0.15 ) and dependency (after SFC: $z=-0.8 ; p=0.42$, at follow-up: $z=-0.6$; $p=0.53)$.

It can be concluded that the non-parametric analyses on team level confirmed the parametric analyses on individual level. Overall, the key issue in this study whether SFC teams outperform CAU teams on SCIBI-PAT and QOR after SFC, can be answered positively.

Table 4: Between-group differences (SFBT versus CAU) in proactive thinking (SCIBI-PAT) and quality of the relationship (STRS) of individual team members

\begin{tabular}{|c|c|c|c|c|c|c|c|c|}
\hline $\begin{array}{l}\text { Group data } \\
\text { Instruments }\end{array}$ & $n$ & Group & $\begin{array}{l}\text { Mean } \\
\text { change } \\
\text { after } \\
\text { SFC }\end{array}$ & $\begin{array}{l}t \text {-test } \\
\text { Effect size } \\
(E S)^{a}\end{array}$ & $n$ & Group & $\begin{array}{l}\text { Mean } \\
\text { change } \\
\text { at } \\
\text { follow- } \\
\text { up }\end{array}$ & $\begin{array}{l}\text { t-test } \\
\text { Effect size } \\
(E S)^{a}\end{array}$ \\
\hline \multirow{2}{*}{$\begin{array}{l}\text { SCIBI-PAT } \\
\text { Proactive } \\
\text { Thinking }\end{array}$} & $51^{b}$ & SFC & +1.6 & \multirow{2}{*}{$\begin{array}{l}t=4.4 \\
p<0.01 \\
r=0.40 \\
\text { medium } \\
\text { ES* }\end{array}$} & $51^{b}$ & SFC & +1.7 & \multirow{2}{*}{$\begin{array}{l}t=5.4 \\
p<0.01 \\
r=0.49 \\
\text { medium } \\
\text { ES* }\end{array}$} \\
\hline & $50^{b}$ & CAU & -0.1 & & 45 & CAU & -0.3 & \\
\hline \multirow[t]{2}{*}{$\begin{array}{l}\text { STRS } \\
\text { Closeness }\end{array}$} & 59 & SFC & +3.0 & \multirow{2}{*}{$\begin{array}{l}t=3.7 \\
p<0.01 \\
r=0.32 \\
\text { medium } \\
\text { ES* }\end{array}$} & $58^{b}$ & SFC & +3.5 & \multirow{2}{*}{$\begin{array}{l}t=1.9 \\
p=0.06 \\
r=0.18 \\
\text { small ES }\end{array}$} \\
\hline & 59 & CAU & +0.4 & & $51^{b}$ & CAU & +1.5 & \\
\hline \multirow[t]{2}{*}{$\begin{array}{l}\text { STRS } \\
\text { Conflict }\end{array}$} & 59 & SFC & -4.4 & \multirow{2}{*}{$\begin{array}{l}t=-3.7 \\
p<0.01 \\
r=0.32 \\
\text { medium } \\
\text { ES* }\end{array}$} & $57^{b}$ & SFC & -4.3 & \multirow{2}{*}{$\begin{array}{l}t=-3.0 \\
p<0.01 \\
r=0.28 \\
\text { small ES }\end{array}$} \\
\hline & 59 & CAU & -0.9 & & $51^{b}$ & CAU & -1.8 & \\
\hline \multirow[t]{2}{*}{$\begin{array}{l}\text { STRS } \\
\text { Dependency }\end{array}$} & 59 & SFC & -0.5 & \multirow{2}{*}{$\begin{array}{l}t=-0.6 \\
p=0.58 \\
r=0.06 \\
\text { no ES }\end{array}$} & $57^{b}$ & SFC & -0.5 & \multirow{2}{*}{$\begin{array}{l}t=-0.1 \\
p=0.90 \\
r=0.0 \\
\text { no ES }\end{array}$} \\
\hline & $58^{b}$ & CAU & -0.1 & & $51^{b}$ & CAU & -0.0 & \\
\hline \multirow{2}{*}{$\begin{array}{l}\text { STRS } \\
\text { Quality of } \\
\text { Relationship }\end{array}$} & 59 & SFC & +7.8 & \multirow{2}{*}{$\begin{array}{l}t=4.2 \\
p<0.01 \\
r=0.36 \\
\text { medium } \\
\text { ES* }\end{array}$} & $57^{b}$ & SFC & +7.9 & \multirow{2}{*}{$\begin{array}{l}t=3.2 \\
p<0.01 \\
r=0.30 \\
\text { medium } \\
\text { ES* }\end{array}$} \\
\hline & $58^{b}$ & CAU & +1.6 & & $51^{b}$ & CAU & +2.4 & \\
\hline
\end{tabular}

${ }^{a}$ Effect sizes (ES): no effect, $r<0.10$; a small effect, $r \geq 0.10$ and $<0.30$; a medium effect, $r \geq$ 0.30 and $<0.50$ and a large effect, $r \geq 0.50$.

${ }^{\mathrm{b}}$ Lower sample sizes due to missing values.

*Differences over time within groups are statistically significant $(p<0.01)$ on the independent $t$ test and the effect size is at least 'medium'. 


\section{Conclusions}

The results of this study indicate that SFC can constitute a valuable contribution to the coaching of staff supporting people with ID. Eight of 18 teams in this study showed clinically relevant progressions (more than 2 points on a 1 to 10 scale) towards their team goals after SFC. At follow-up 10 of 18 teams achieved their team goals. The mean change in goal attainment of the 18 teams at start versus follow-up was +2.3 points and statistically significant $(p<0.01)$. However, at follow-up, one team showed hardly any change (less than 1.0 point after SFC) and 7 teams progressed only between 1.0 and 2.0 points. The complexity of the support problems was said to be the cause of this lack in progress in these teams. Staff also mentioned that improvement hardly was possible after such a short period of time.

The key question in this study, whether the SFC teams perform better on proactive thinking and on the quality of the relationships than the CAU teams after coaching, can be answered positively. The findings support the potential of SFC as an effective way of dealing with support problems in a proactive way (Wheeler, 2001). SFC may stimulate staff to think about and improve the 'how, what and why' elements of dealing with support problems. Because reaching the team goal was based on ideas from staff about earlier successes, it is possible that the expectations of the staff members' own effectiveness and the tendency to take action (proactive thinking) indeed increased. Moreover, SFC can be considered as a useful approach to build positive relationships between staff and clients with ID (Lloyd \& Dallos, 2006; 2008). This is relevant, because literature over the last 20 years has increasingly pointed to the importance of positive relationships between clients with ID and staff, as a precondition for the clients' good quality of life (Schuengel, Kef, Damen \& Worm, 2010) and/or to reduce problem behaviour (Hastings, 2005). The improvements in the quality of the relationships in this study were due to decreases in conflict scores and/or increases of closeness scores directly after SFC. No changes were seen in dependency scores. A possible explanation is that the dimension of dependency in people with ID, who need lifelong support from staff, is less changeable than the dimensions of closeness and conflict. 
The results are similar to recent research, showing that the solutionfocused therapy is more effective than 'treatment as usual' (Macdonald, 2007; Gingerich et al., 2012) with medium effect sizes (Stams et al., 2006). Although in general the SFC teams progressed statistically significant more than the CAU teams, the last-mentioned also showed a small-sized improvement $(p<0.01)$ on the quality of the relationships at follow-up (see table 3). Possibly, recall bias and/or attention bias did occur in both groups. Staff completed the questionnaires three times within 21 weeks. Certain staff members might remember their responses more or less (recall bias) and might give more favourable responses (attention bias) regarding for example their perceived relationships with clients with ID.

The present study has some limitations concerning selection process of participants and the choice and type of measurement instruments. Firstly, the teams applied for SFC themselves, indicating that they wished to change their current situation. They therefore can be regarded as selective. In addition, participants were not random allocated to the SFC or CAU condition. Although at the start, the SFC teams did not differ statistically significantly from the CAU teams on the measures age, length of working experience and quality of the relationships, there were initial differences in pro-active thinking. Part of the effect size on this variable may be attributable to these group differences. Secondly, any choice of standardised measurement instruments automatically implies restrictions. During SFC, every team formulated its own goal. It is possible that the chosen team goal did not sufficiently match the measuring pretention of the instruments being used. This does not apply to the SQP, because this measurement adjusts itself to the goal of the team. However, it does hold for the SCIBI-PAT and the STRS, as these variables could differ from what staff members considered to be relevant to measure. The use of several instruments simultaneously can partly, though not completely, solve this problem. Moreover, all instruments used were self-report instruments and thus reflect the staff members' opinions.

We however conclude that SFC provides an additional approach of available styles of coaching of staff. In former times, the tendency was to mainly focus on people with ID as being the one and only cause of support problems, thereby ignoring the role of staff in these relationships. SFC on the contrary, also focuses on the important role of staff. Further exploration of the 
usefulness of SFC is thus meaningful. We propose that further research in this area is needed, preferably using a randomised controlled design, standardized measures, prolonged follow-up interventions and comparisons with other established methods of coaching.

\section{References}

Bannink, F.P. (2010). 1001 Solution-Focused questions. New York: Norton. Corcoran, J. (2002). Developmental adaptations of Solution-Focused family therapy. Brief Treatment and Crisis Intervention, 2, 301-313.

Corcoran, J. \& Ivery, J. (2004). Parent and child attributions for child behaviour: distinguishing factors for engagement and outcome. Families in Society: The Journal of Contemporary Social Services, 85, 101-106.

Cohen, J. (1988). Statistical power analysis for the behavioural sciences. Hillsdale, NJ: Lawrence Erlbaum,

De Shazer, S. (1985). Keys to solution in brief therapy. New York: Norton.

Dine, K.R. (1995). Visions of the future: The miracle question and the possibility for change. Unpublished doctoral dissertation. Boston:

Massachusetts School of Professional Psychology.

Dunlop, W.P., Cortina, J.M., Vaslow, J.B. \& Burke, M.J. (1996). Meta-analysis of experiments with matched groups or repeated measures designs. Psychological Methods, 1, 170-177.

Field, A. (2009). Discovering statistics using SPSS. London: Sage.

Gingerich, W.J., Kim, J.S., Stams, G.J.J.M. \& Macdonald, A.J. (2012) Solution-focused Therapy Outcome Research. In C. Franklin, T.S. Trepper, W.J. Gingerich \& E.E. McCollum (Eds.), Solution-focused Brief Therapy; A Handbook of Evidence-Based Practice (pp. 95-111). New York: Oxford University Press.

Green, S. (2012). Solution-focused Life Coaching. In C. Franklin, T.S. Trepper, W.J. Gingerich \& E.E. McCollum (Eds.), Solution-focused Brief Therapy; A Handbook of Evidence-Based Practice (pp. 342-353). New York: Oxford University Press.

Hastings, R.P. (2005). Staff in special education settings and behaviour problems: Towards a framework for research and practice. Educational Psychology, 25, 207-221. 
Jordan, K.B. \& Quinn, W.H. (1994). Session two outcome of the formula First session task in problem- and solution-focused approaches. American Journal of Family Therapy, 22, 3-16.

Jordan, K.B. \& Quinn, W.H. (1994). Male and female client perception of session two outcome of problem- and solution-focused approaches. Family Therapy, 24, 23-37.

Kim, J.S. (2008). Examining the effectiveness of solution-focused brief therapy: A meta-analysis. Research on Social Work, 32, 49-64.

Knekt, P. \& Lindfors, O. (2004). A randomized trial of the effects of four forms of psychotherapy on depressive and anxiety disorders (Studies in Social Security and Health 77). Helsinki: The Social Insurance Institution.

Knekt, P., Lindfors, O., Härkänen, T., Välikoski, M., Virtala, E. Laaksonen, M.A. (2008a). Randomized trial on the effectiveness of long- and short-term psychodynamic psychotherapy and solution-focused therapy on psychiatric symptoms during a 3-year follow-up. Psychological Medicine, 38, 689-703.

Knekt, P., Lindfors, O., Laaksonen, M.A., Raitasalo, R., Haaramo, P., Järvikoski, A. (2008b). Effectiveness of long- and short-term psychotherapy on work ability and functional capacity - a randomized clinical trial on depressive and anxiety disorders. Journal of Affective Disorder, 107, 95-106.

Koomen, H., Verschueren, K. \& Pianta, R. (2007). Leerling Leerkracht Relatie Vragenlijst [Student Teacher Relationship Scale]. Houten: Bohn Stafleu van Loghum.

Koomen, H.M.Y., Verschueren, K. van Schooten. E., Jak, S. \& Pianta, R.C. (2012). Validating the Student-Teacher Relationship Scale: Testing Factor Structure and Measurement Invariance across Child Gender and Age in a Dutch Normative Sample. Journal of School Psychology, 50, 215-234.

Lloyd, H. \& Dallos, R. (2006). Solution-Focused brief therapy with families who have a child with intellectual disabilities. A description of the content of initial sessions and the processes. Clinical Child Psychology and Psychiatry, 11, 367-386.

Lloyd, H. \& Dallos, R. (2008). First session Solution-Focused brief therapy with families who have a child with severe intellectual disabilities. Mothers' experiences and views. Journal of Family Therapies, 30, 5-28. 
O'Connell, B. \& Palmer, S. (2007). Solution-focused coaching. In S. Palmer \& A. Whybrow (Eds.), Handbook of coaching psychology: A guide for practitioners (pp. $\mathrm{xx}-\mathrm{xx}$ ). London: Sage Publications.

Macdonald, A., (2007). Solution-focused therapy: Theory, research \& practice. London: Sage.

Rhodes, J. (2000). Solution-Focused consultation in a residential setting. Clinical Psychology Forum, 141, 29-33.

Roeden, J.M., Maaskant, M.A., Bannink, F.P. \& Curfs, L.M.G. (2011). Solution-Focused Brief Therapy with People with Mild Intellectual Disabilities; a Case Series. Journal of Policy and Practice in Intellectual Disabilities, 8, 247255.

Roeden, J.M., Maaskant, M.A., Koomen, H.M.Y., Candel, M.J.J.M. \& Curfs, L.M.G. (2012). Assessing client-caregiver relationships and the applicability of the 'student-teacher relationship scale' for people with intellectual disabilities. Research in Developmental Disabilities, 33, 104-110.

Roeden, J.M., Maaskant, M.A. \& Curfs, L.M.G. (2012).The nominal group technique as an evaluation tool for solution-focused coaching. Journal of Applied Research in Intellectual Disabilities, in press.

Rosnow, R.L. \& Rosenthal, R. (1996). Computing contrasts, effect sizes, , and counternulls on other people's published data: General procedures for research consumers. Psychological Methods, 1, 331-340.

Schuengel, C., Kef, S., Damen, S. \& Worm, M. (2010). 'People who need people': Attachment and professional caring. Journal of Intellectual Disability Research, 54, 38-47.

Shilts, L., Rambo, A. \& Hernandez, L. (1997). Clients helping therapists find solutions in their therapy. Contemporary Family Therapy, 19, 117-132.

Stams, G.J., Dekovic, M., Buist, K. \& De Vries, L. (2006). Effectiviteit van oplossingsgerichte korte therapie: een meta-analyse [The efficacy of solutionfocused therapy: a meta-analysis]. Gedragstherapie, 39, 81-94. 



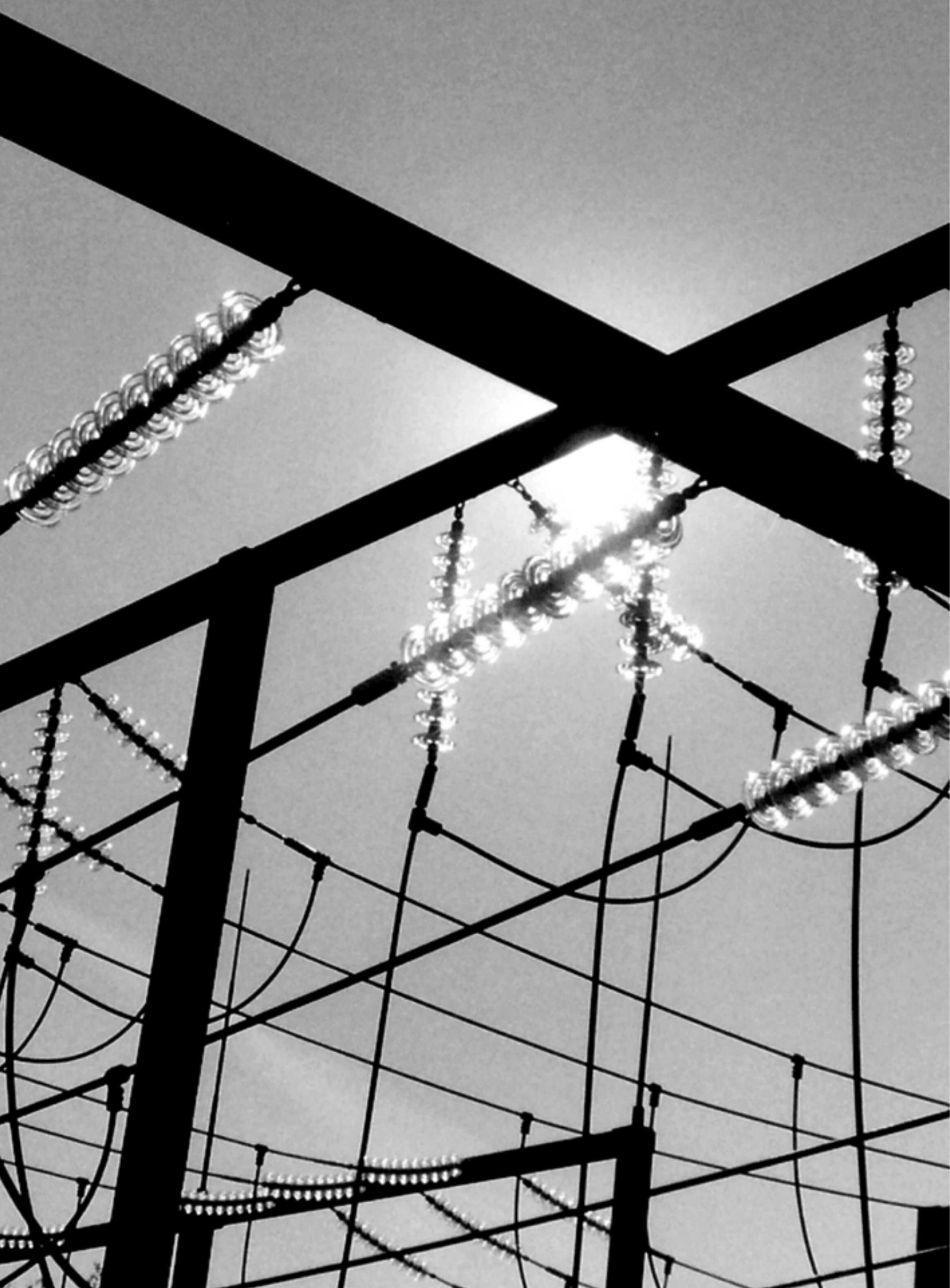


CHAPTER 10

GENERAL DISCUSSION 


\subsection{Results in a broader perspective}

The aim of this thesis was to study the processes and effects of SFBT and SFC. The results indicate that both interventions contribute to improving the quality of life of people with ID. This final chapter discusses the results of the studies on the processes and effects of SFBT and SFC. Firstly, the general conclusions of the SFBT studies are presented followed by the methodological limitations and the practical advantages of SFBT. A comparison is made between SFBT and behaviour therapy. Secondly, the general conclusions of the SFC studies are described, followed by the methodological limitations and the practical advantages of SFC. Finally, suggestions concerning the implementation and applicability of SFBT and SFC are given.

\subsection{SFBT: conclusions, methodological considerations, practical advantages}

\subsubsection{Conclusions on the processes and effects of SFBT}

A literature search was performed to examine the nature and evidence of the use of SFBT in general and in people with ID. This revealed that several adaptations of SFBT for people with ID are necessary such as, the use of simple language, flexibility in questioning, as well as modifications related to exploring previous successes and goal setting.

SFBT applications are suitable if (1) the client has a goal before treatment or is able to formulate one during therapy; $(2)$ the client is able to communicate (if not, SFBT can still be used with caregivers of the client); and (3) the therapist does not see himself or herself as the expert whose task is to advise the client.

The Nominal Group Technique (NGT) was used to discover the opinions of clients with mild ID (MID) with respect to successful working relationships with caregivers. The NGT provides a structured method for collecting and organising thoughts of groups of people with regard to a single question, in this case case: 'How can you, along with a caregiver, best deal with your problems?'. The results showed that clients find it important for caregivers to deliver their 
support in a reliable, empathic and non-patronising way. These characteristics seem to be more important than the particular types of support. Furthermore, the NGT-results in this study showed that the clients' preferred ways of receiving help correspond with the basic assumptions of SFBT.

In a cases series, using a SFBT protocol, the processes of SFBT were explored in 10 clients with MID. It was found that SFBT treatments helped to improve psychological functioning and to decrease maladaptive behaviour. Both the clients with MID and staff noted that the goals set were achieved. The participants usualy assessed the treatment strategies and therapeutic alliances as positive.

The effects of SFBT were investigated, using a controlled pre- and post-test design and a follow-up study with 18 people receiving SFBT and 18 people receiving care as usual (CAU). Directly after therapy, the SFBT group improved statistically significantly more on quality of life and resilience than the CAU group. At 6 weeks follow-up, the improvements in psychological functioning, social functioning and reduced maladaptive behaviour remained statistically significant, compared to CAU. The effect sizes of these improvements were medium to large.

These results are in line with SFBT outcome research in the general population, showing that SFBT is more effective than treatment as usual (Gingerich et al., 2012; Macdonald, 2007) with medium effect sizes (Stams et al., 2006). Meta-analyses of the effectiveness of a broad range of therapeutic interventions in clients with ID, comparing treatment groups with untreated controls, also pointed to a moderate degree (a mean of 3.15 on a scale of 1-5) of positive changes in outcome measures (Prout \& Nowak-Drabik, 2003).

\subsubsection{Methodological limitations}

The studies described above (SFBT cases series and SFBT control study) are subject to several methodological limitations concerning:

(1) the small sample sizes;

(2) the non-random selection of participants;

(3) the choice of instruments; 
(4) the administration of instruments;

(5) the brief follow-up period.

\section{Small sample sizes}

Given the small smaple sizes (between 10 and 18 participants), it was necessary to perform non-parametric analyses. Non-parametric tests are generally considered to be less powerful than their parametric counterparts. However, this only holds if the assumptions of the parametric tests are met (Field, 2009), which was not the case in the SFBT case series and control study. To compensate for the less powerful non-parametric analyses conservative criteria for statistical significance were used. The results were only considered substantial if the significance levels were equal to or smaller than 0.01 and if the effect sizes were at least medium. However, to strengthen the findings of these studies larger sample sizes should be used in future research.

The non-random selection of participants

The first 18 clients who were experiencing problems that warranted change, enrolled in SFBT. They were compared with 18 clients receiving CAU, matched for age, IQ, adaptive and maladaptive functioning. The participants of the CAU group were placed on a delayed waiting list for SFBT. All SFBT clients were referred by staff rather than randomly assigned to groups. It is possible that the selected clients tended to be more cooperative in therapy and the outcomes could be more favourable to SFBT.

There are several obstacles to conducting randomised controlled trials in the field of ID (see Oliver et al., 2002 for a review). Given the need to involve staff in deciding to start therapy, providing informed consent and assisting clients during therapy, randomised trials are not always practical or acceptable. The control study described in chapter 5 showed that staff involvement was deemed necessary.

Nevertheless, study populations randomly allocated to SFBT, CAU and/or other established treatments are still the most accurate way of confirming whether improvements are attributable to therapeutic interventions. 
The choice of instruments

Any choice of standardised instruments automatically implies restrictions. As every participant formulates his or her own goal during SFBT, it is possible that the chosen goal is not sufficiently suited to the measuring pretention of the instruments used. Therefore, the measuring pretentions used in this study were necessarily broad: psychological functioning, social functioning, maladaptive behaviour, social optimism and autonomy.

Future research on SFBT will need to make use of strengths-based assessment, which Epstein and Sharma (1998) define as "the measurement of those emotional and behavioural skills, competencies, and characteristics that create a sense of personal accomplishment; enhance one's ability to deal with adversity and stress; and promote one's personal, social and academic development" (p. 3). The Positive Outcome Scale (Appelo, 2005) used in the control study is an example of such a strengths-based instrument. To date, strengths-based assessments have been used in areas such as education (Epstein et al., 2000) and parenting (Storm \& Cooledge, 1987). Unfortunately, appropriate and valid strengths-based instruments remain scarce (Smock, 2012), especially in the field of ID.

The administration of instruments

Each SFBT session was attended by at least three people: the client with MID, a staff member, and the therapist/researcher. This decision was made because it appeared from the treatment practice of SFBT that the interventions are better understood and executed when carers perform a supportive role in the treatment procedure. The administrations of the measurements (in both the SBT and CAU condition) were also performed by the therapists/researchers. The staff member assisted the client in answering and interpreting the questions. Following Teall (2000) and Smith (2006), we reasoned that help from a familiar person in answering questions and interviewing by a certified professional (the therapist/researcher would lead to valid responses.

However, this meant that the participants were not blinded to the treatment condition or the treatment results. This may have caused 'expectation bias' which occurs when observers may err in measuring data toward the expected outcome. The challenge for future research is to combine three necessary elements in interviewing clients with MID: (1) creating a 
familiar atmosphere, (2) ensuring professionalism in interviewing and (3) ensuring blind research conditions.

The brief follow-up period

It is unclear from this study whether the improvements made by the SFBT participants will be maintained over time. Although gains were observed directly after the interventions and at follow-up after 6 weeks, it remains uncertain whether they will last. Prolonged follow-up measurements (e.g., after one year) are recommended for future research.

\subsubsection{Reflections on the advantages of SFBT}

Despite the research shortcomings mentioned above, SFBT has several benefits compared to care as usual (i.e., the standard form of support provided by most service providers in the Netherlands). Additionally, clients with MID appreciated the solution-focused assumptions and the treatment strategies. These research findings have important practical implications.

The studies described above have several specific strengths relating to:

(1) the connection between SFBT and the citizenship paradigm including empowerment and quality of life;

(2) the connection between SFBT and the client-professional alliance.

\section{Citizenship paradigm}

The citizenship paradigm is the prevailing model in the support of people with ID (Luckasson et al., 1992; Tøssebro et al., 2012; Van Gennep, 1997). The core values of this model are: full participation in society, client self-direction (empowerment), support rather than care, and the promotion of quality of life. As shown in table 1 and in the introduction, the solution-focused approach contributes to this citizenship model. 


\begin{tabular}{|c|c|}
\hline Citizenship paradigm & Solution-focused approach \\
\hline The client as citizen & $\begin{array}{l}\text { The client is an expert on his/her own life; } \\
\text { The client makes use of the resources in his/her } \\
\text { environment. }\end{array}$ \\
\hline $\begin{array}{l}\text { Control lies with the } \\
\text { client } \\
\text { (empowerment) }\end{array}$ & $\begin{array}{l}\text { The client formulates his/her own objective; } \\
\text { The client constructs a step-by-step plan to reach } \\
\text { this objective. }\end{array}$ \\
\hline $\begin{array}{l}\text { Support rather than } \\
\text { care }\end{array}$ & $\begin{array}{l}\text { The professional adopts an attitude of 'not } \\
\text { knowing'; asks questions; does not direct and does } \\
\text { not prematurely offer solutions; } \\
\text { The professional accepts the client's vision. }\end{array}$ \\
\hline Quality of life & $\begin{array}{l}\text { The solution-focused approach helps to: } \\
\text { increase psychological functioning; } \\
\text { increase social functioning; } \\
\text { increase resilience; } \\
\text { decrease problem behaviour. }\end{array}$ \\
\hline
\end{tabular}

Client-professional alliance

Lambert (1992) and Wampold \& Bhati (2004) suggested that at least 30\% of successful therapy outcomes could be attributed to relationship between the therapist and the client. Although this percentage is tentative, there is no doubt that a collaborative and empowering alliance will increase positive therapy outcomes. Indeed, the NGT study (chapter 3) and comparable studies (Clarkson et al., 2009; Roeleveld et al., 2011) showed that clients with MID appreciate positive relationships with professionals. In the cases-series (chapter 4) all clients with MID evaluated the solution-focused approach positively.

Trepper et al. (2012) described the nature of the solution-focused working alliance as follows: "With SFBT, the therapist is seen as a collaborator and consultant, there to help clients to achieve their goals. The overall attitude is positive, respectful and hopeful. There is a general assumption that people are resilient and continuously utilise this resilience to make changes" (p. 23). 
According to Bannink (2010): "As early as the first session and all subsequent sessions the solution-focused therapist pays attention to his or her relationship with the client: does it constitute a visitor, a complainant, or a customer relationship?" (p. 31). The distinction is essential in determining the questions that the therapist asks. Moreover it is common practice in SFBT to ask the client for feedback (e.g., by using the Session Rating Scale developed by Duncan et al., 2004; see chapter 4).

'Leary's rose' (Leary, 1957) can be applied to the collaborative relationship between professionals and clients with ID. Leary distinguishes between two dimensions that always play a role in human relationships. The first dimension is 'superiority': who is leading and who is following? The second is 'proximity': do the parties involved want to work together, or are they working against each other? When these dimensions are brought together they form 'Leary's rose'. The main positions are: 'above and together', 'below and together ', 'below and opposed' and 'above and opposed'. In the case of problem behaviour the client usually adopts the 'above and opposed' position (also called the 'superior-aggressive' position) towards others, including the professional. The solution-focused professional takes the 'below and together position' as much as possible (the stance of 'leading from one step behind and not knowing', see chapter 2.1), which may cause the client to move to the 'above and together' position, in which the client is expert. (Bannink, 2010, p. 39-41).

\subsubsection{Comparisons with 'behaviour therapy (BT)'}

\section{Similarities with BT}

SFBT and BT share various similarities and differences. To elucidate these similarities and differences, BT is briefly illustrated and compared with SFBT below.

BT is an approach that focuses on a set of methods designed for reinforcing desired behaviour and eliminating undesired behaviour. SFBT can be seen as a form of BT. For example the learning principle 'operant conditioning' is followed in both BT and SFBT. SFBT makes use of the principles of operant conditioning during the sessions. Discussions and implementations of desired behaviour are 
strengthened by the therapist (positive reinforcement of 'solution-talk'). Discussions and implementations of undesired behaviour are neglected or faded out (frustrative non-reward of 'problem-talk'), due to the minimum possible attention paid to this by the therapist.

Many questions and tasks in SFBT are primarily behavioural. Competence questions for example focus on behaviour: 'How do (did) you do that?'. The client is invited to give detailed behavioural descriptions of his desired future. Scaling questions can assist the client to perform and develop future behaviour step by step (called 'shaping' in BT). Also task assignments are behaviourally oriented (e.g., 'do something different' or 'pretend that (parts of) the desired future has happened').

'Functional behaviour analysis' has become a hallmark of BT and can be used in SFBT as well. In functional analysis, each problem is analysed in terms of the ABC's (Didden et al., 2003) the Antecedents, Behaviours and Beliefs, and Consequences. Each of these factors may increase or decrease the probability that the problem behaviour will occur. In BT, a functional behaviour analysis is made of the ABC's of problem behaviour, whereas in SFBT a functional behaviour analysis is made of the exceptions of the problem behaviour. The solution-focused therapist may choose to use both solutionfocused and problem-focused functional behaviour analyses (cf. Bannink, 2012 for a detailed explanation). The compatibility between SFBT and BT is high. BT can easily be used as an addendum to SFBT and vice versa (Roeden \& Bannink, 2007).

\section{Differences with $B T$}

Bannink (2007, p. 215) stated: "In BT the therapist is the expert who tells the client what he or she needs to do to alleviate his or her problem. SFBT views the client as someone who is capable of solving his or her problem himself or herself and who already possesses knowledge of the necessary modification procedures and the ability to use them". The attitude of the therapist is one of 'leading from one step behind' and 'not knowing' (meaning that the therapist asks questions and does not give advice). 
Other differences concern the focus on problem analysis in BT (as opposed to the focus on goal analysis in SFBT) and the registrations of situations in which undesired behaviours occur in BT (as opposed to 'exceptions' being registrations of situations of desired behaviour in SFBT).

\subsection{SFC: conclusions, methodological considerations and practical implications}

\subsubsection{Conclusions on the processes and effects of SFC}

Because the Student-Teacher Relationship Scale was used to assess the effects of SFC in teams (see chapter 9), it was also investigated psychometrically. The three-factor model of the original STRS (1. closeness, 2. conflict, 3. dependency) was confirmed for the ID population. The reliability and validity of the STRS was shown to be good.

In a case series, the processes of SFC were explored with 13 teams of staff members who supported clients with severe or moderate ID. The SFC protocol was similar to the SFBT protocol described above (see also chapter 7). It was found that SFC contributed to improvements in goal attainment, proactive thinking and the quality of relationships between staff and clients with ID.

The perceived strengths of SFC and recommendations for SFC were evaluated via the Nominal Group Technique (NGT). Strengths of SFC mentioned by staff included the formulation of a team goal in a positive way, the promotion of self-confidence in the team, the use of competences already present in the team, the focus on solution building and the capacity to resolve stagnating care situations. These strengths are similar to results found in prior SFC research (Rhodes, 2000; Wheeler, 2001). It can be concluded that SFC may be particularly helpful for staff in encouraging positive perspectives, selfconfidence, self-efficacy, solution building and coping.

The effects of SFC were investigated, using a controlled pre- and post-test design and a follow-up study with 18 teams receiving SFC and 26 teams 
receiving coaching as usual (CAU). Directly after coaching, the SFC teams improved statistically significantly more than the CAU teams on the variables proactive thinking and quality of the relationships between clients and staff. The differences between the groups were sustained at follow-up. The SFC teams also showed a statistically significant progression towards the team goal.

\subsubsection{Methodological considerations}

The studies described above (SFC case series and controlled study) are subject to several methodological limitations concerning:

(1) the small sample size;

(2) the non-random selection of participants;

(3) the choice of instruments;

(4) the brief follow-up period.

Small sample size

The perceived strengths of SFC and recommendations for SFC through the Nominal Group Technique were investigated in a small study population ( $n=$ 18 ). Future research on a larger scale could strengthen the preliminary results found in this study.

The non-random selection of teams

Eighteen teams (largely the first 18 teams that registered) experiencing a support problem with a client with ID received SFC. They were compared with 18 teams receiving $C A U$, which had been placed on a delayed waiting list for SFC. The SFC and CAU conditions were not randomly assigned. Nevertheless, the SFC teams initially did not differ statistically significant from the CAU teams on the measures, age, length of working experience and quality of the relationships (first outcome measure). However, there were initial differences in proactive thinking (second outcome measure). Part of the effect size on this variable may be attributable to these group differences. 
The choice of instruments

Any choice of standardised measurement instruments has limitations. As every team formulated its own goal during SFC, it is possible that the chosen team goal did not sufficiently matched the measuring pretention of the instruments being used. Based on literature (Lloyd \& Dallos, 2006, 2008; Wheeler, 2011), we expected that SFC could assist staff in reaching their team goals, improve proactive thinking among staff and positively influence the relationships between staff and people with ID. We therefore selected these variables as outcome measures. Future research should focus on the development of additional, preferably strengths-based instruments appropriate for use with staff in the ID field.

\section{The brief follow-up period}

It remains unclear from this study whether the gains made through SFC will last over time, for example longer than one year. A prolonged research period is necessary to investigate long term effects. In evaluations of SFC, staff strongly recommended that results achieved during SFC, should be consolidated by way of several follow-up meetings over a longer period of time.

Despite the research limitations mentioned above, SFC has several benefits compared to coaching as usual (i.e., the standard form of coaching in most service providers in the Netherlands). Additionally, teams appreciated the solution-focused assumptions and the coaching strategies.

\subsubsection{Practical implications of SFC}

The opinions of teams about SFC were investigated (chapter 8). Staff reported the following strengths of SFC:

- SFC focuses on successes;

- SFC may promote self-confidence in the team;

- SFC focuses on uniform support of individual clients;

- SFC may provide generalisation from one client to another;

- SFC stimulates reflection of the team;

- SFC offers a step-by-step approach to reach the team goal; 
- SFC develops a detailed picture of the team goal;

- SFC uses many approaches to reach a team goal;

- SFC uses competences and workable solutions already present in the team;

- SFC has the capacity to resolve stagnating support situations.

\subsection{Implementation, relevance and applicability of SFBT and SFC}

10.4.1 The implementation of SFBT and SFC

The applications of SFBT and SFC as described in chapters 4 and 7 are temporary interventions (5 SFBT sessions and 3 SFC sessions, respectively). SF therapists and SF coaches can be seen as specialists who can be employed on a temporary basis to assist clients with MID in achieving their therapy objectives (SFBT), or to help teams achieve team goals (SFC). These temporary contributions become more sustainable if professionals also work in a solution-focused manner in their everyday practice. This entails adopting a solution-focused attitude and making use of solution-focused conversation skills in supporting clients. When conversations with clients are not possible, a team can decide itself to address client and support problems in a solutionfocused manner. This can be referred to as Solution-Focused Support (SFS). SFS is not a temporary intervention, but can be integrated sustainably in daily care (cf. evaluation of SFC, chapter 8).

An important precondition for implementation is the training of professionals. This training must involve three target groups: (1) therapists (SFBT), (2) coaches (SFC) and (3) staff (SFS).

10.4.2 The relevance and applicability of SFBT and SFC

This thesis ends with a call for application of the SF approach in the field of ID, and for the extension of effect studies. 


\section{SFBT}

The studies described in the first part of this thesis (the literature review, group interviews, case series and controlled study) showed that, in a treatment protocol geared towards the target group, SFBT can be performed with good results among clients with ID.

Clients place high value on this therapy and only 2 of the 20 clients terminated the therapy prematurely. This positive evaluation can be attributed to two aspects. First, clients want a therapist (or caregiver) who is interested, respectful and non-judgemental, and who asks questions. Second, most clients want to solve their own problems as far as possible, albeit often with the caveat that help in the matter is welcome. Both these aspects correspond with important core values in the solution-focused approach.

SFBT offers clients with MID good opportunities to improve their quality of life. Therapy objectives were addressed or achieved in the majority of the clients treated, and there was a significant increase in quality of life and in resilience and a reduction in maladaptive behaviour.

In general, it can be concluded that SFBT fits well with important components of the prevailing citizenship paradigm, particularly the aims of improving quality of life and empowering clients with ID.

\section{SFC}

The research described in the second part of the thesis (the measurement of client-caregiver relationships, case series, team evaluations and controlled study) showed that, in a protocol geared towards teams, SFC can help to solve the problems that teams face in supporting clients with ID.

Team members appreciated the working method and, during interviews, identified the strengths and recommendations of the methodology. The teams also valued the fundamental principles of SFC.

All 18 teams completed the SFC sessions. Measurements showed that SFC offers good prospects for teams in approaching or achieving their joint goal. There was a demonstrable improvement in proactive thinking and clientcaregiver relations in most teams and among the individual team members. 
SFBT, SFC and SFS

SFBT and SFC are complementary. The addition of SFS (see previous section) can ensure that the temporary interventions SFBT and SFC achieve a more sustainable effect. However, further research is needed on the effects of SFBT, SFC and SFS. Not only can the methodology be improved, but it would also be worthwhile studying exactly which elements of these methods are responsible for the effects. This could help to increase the combined value of SFBT, SFC and SFS.

\section{References}

Appelo, M.T. (2005). Positieve Uitkomsten Lijst; PUL [Positive Outcome Scale; POS]. Nijmegen: Cure \& Care Publishers.

Bannink, F.P. (2010). 1001 solution-focused questions. New York: Norton.

Bannink, F.P. (2012). Practicing Positive CBT. From reducing distress to building success. New York: Black-Wiley.

Clarkson, R., Murphy, G.H. Coldwell, J.B. \& Dawson, D.L. (2009). What characteristics do service users with intellectual disability value in direct support staff within residential forensic services? Journal of Intellectual \& Developmental Disability, 34, 283-9.

Didden, R., Duker, P. \& Seys, D. (2003). Gedragsanalyse en -therapie bij mensen met een verstandelijke beperking. Maarssen: Elsevier gezondheidszorg.

Duncan, B.L., Miller, S.D. \& Sparks, A. (2004). The heroic client: A revolutionary way to improve effectiveness through client-directed, outcomeinformed therapy. New York: Jossey-Bass.

Epstein, M. H. \& Sharma, H. M. (1998). Behavioral and Emotional Rating Scale: A strength based approach to assessment. Austin: Pro-ed.

Epstein, M. H., Harniss, M. K., Robbins, V., Wheeler, L., Cyrulik, S., Kriz, M. (2002). Strength-based approaches to assessment in schools. In M. Weist, S. Evans, \& N. Tashman (Eds.), School mental health handbook, (pp. 285-299). New York: Kluwer Academic/ Plenum.

Field, A. (2005). Discovering Statistics using SPSS. London: Sage. 
Gingerich, W.J., Kim, J.S., Stams, G.J.J.M. \& Macdonald, A.J. (2012). In C. Franklin, T.S. Trepper, W.J. Gingerich \& E.E. McCollum (Eds.), Solutionfocused Brief Therapy; A Handbook of Evidence-Based Practice (pp. 95-111). New York: Oxford University Press.

Lambert, M.J (1992). Psychotherapy outcome research. In J.C. Norcross \& M.R. Goldfried (Eds.). Handbook of psychotherapy (pp. 94-129). New York: Basic Books.

Leary, T. (1957). Interpersonal Diagnosis of Personality. New York: Ronald. Lloyd, H. \& Dallos, R. (2006). Solution-focused brief therapy with families who have a child with intellectual disabilities. A description of the content of initial sessions and the processes. Clinical Child Psychology and Psychiatry, 11, 367-386.

Lloyd, H. \& Dallos, R. (2008). First session solution-focused brief therapy with families who have a child with severe intellectual disabilities. Mothers' experiences and views. Journal of Family Therapies, 30, 5-28.

Luckasson, R., Coulter, D.L., Polloway, E.A. Reiss, S., Schalock, R.L., Snell, M.E., Spitalnik, D.M. \& Stark, J.A. (1992). Mental Retardation. Definition, Classification and Systems of Support. Washington: AAMR.

Macdonald, A. J. (2007). Solution-focused therapy. Theory, research \& practice. London: Sage.

Oliver, P.C., Piachaud, J., Done, J., Regan, A., Cooray, S. \& Tyrer, P. (2002). Difficulties in conducting a randomized controlled trial of health service interventions in intellectual disability: implications for evidence-based practice. Journal of Intellectual Disability Research, 46, 340-345.

Rhodes, J. (2000). Solution-Focused consultation in a residential setting. Clinical Psychology Forum, 141, 29-33.

Roeden, J. M. \& Bannink, F. P. (2007b). Hoe organiseer ik een etentje? Oplossingsgerichte gedragstherapie met een verstandelijk beperkte vrouw [How to organise a dinner? Solution focused behaviour therapy with a woman with intellectual disabilities]. Gedragstherapie [Behaviour Therapy], 40, 251-268.

Roeleveld, E., Embregts, P.J.C.M., Hendriks, L. \& Boogaard, K. Van den (2011). Zie mij als mens! Belangrijke competenties voor begeleiders volgens mensen met een verstandelijke beperking. Arnhem: HAN University Press.

Smith, I.C. (2006). Ideas for solution-based working with people who 
have intellectual disabilities. Solution News, 2, 21-25.

Smock, S. (2012). A review of Solution-Focused, Standardized Outcome Measures and Other Strenghts-Oriented Outcome Measures. In C. Franklin, T.S. Trepper, W.J. Gingerich \& E.E. McCollum (Eds.), Solution-focused Brief Therapy; A Handbook of Evidence-Based Practice (pp. 55-72). New York: Oxford University Press.

Stams, G.J., Dekovic, M., Buist, K. \& De Vries, L. (2006). Effectiviteit van oplossingsgerichte korte therapie. Een meta-analyse. Gedragstherapie, 39, 8194.

Storm, R. \& Cooledge, N. (1987). Parental strengths and needs inventory research manual. Tempe: Arizona State University.

Teall, B. (2000). Using solution-focused interventions in an ecological frame. A case illustration. Social Work in Education, 22, 54-61.

Tøssebro, J., Bonfils, I.S., Teittinen, A., Tideman, M., Traustadóttir, R. \& Vesala, H.T. (2012). Normalization Fifty years Beyond-Current Trends in the Nordic Countries. Journal of Policy and Practice in Intellectual Disabilites, 2, 134-146.

Trepper, T.S., McCollum, E.E., De Jong, P., Korman, H., Gingerich, W.J. \& Franklin, C. (2012). Solution-Focused Brief Therapy Treatment Manual. In C. Franklin, T.S. Trepper, W.J. Gingerich \& E.E. McCollum (Eds.), Solutionfocused Brief Therapy; A Handbook of Evidence-Based Practice (pp. 20-36). New York: Oxford University Press.

Van Gennep (1997). Paradigma-verschuiving in de visie op zorg voor mensen met een verstandelijke handicap; oratie. Maastricht: Universiteit van Maastricht.

Wampold, B.E. \& Bhati, K.S. (2004). Attending to the Omissions: A historical Examination of Evidende-Based Practice Movements. Professional Psychology: Research and Practice, 35, 563-570.

Wheeler, J. (2001). A helping hand: Solution-Focused brief therapy and child and adolescent mental health. Clinical Child Psychology and Psychiatry, 6, 293306. 


\section{Summary}

Chapter 1 provides an overview of the main sources of inspiration for this thesis: (1) the improvement of the quality of life of clients with mild intellectual disabilities (MID), (2) the importance of good working relationships between clients with MID and caregivers, and (3) the empowerment of clients with ID. Solution-Focused Brief Therapy (SFBT) and Solution-Focused Coaching (SFC) are expected to contribute to achieving these three goals. This expectation results in eight research questions, which are explored in chapters 2 to 9 of the thesis. Chapter 1concludes with the structure of the thesis.

Chapter 2 answers the first research question: 'What are the adaptations of SFBT that make it useful for the ID population?'. SFBT is a short-term, goaland client-oriented therapy aimed at constructing solutions rather than focusing on problems. To date, SFBT has rarely been applied in clients with ID. The authors investigated how a modified form of SFBT can be suitable for clients with ID.

The following modifications for SFBT in clients with ID are recommended in the literature: (1) using simple language, (2) adapting the course and duration of the sessions, (3) paying extended attention to familiarisation by the therapist, (4) adapting the formulation of questions relating to exploring exceptions, goal setting and scaling, (5) fostering active involvement by the client's social environment, and (6) adapting the homework assignments, including the use of visual aids.

Chapter 3 answers the second research question: 'What do clients with ID find important in the client-caregiver alliance?'. The research also considers the degree to which clients' opinions on the desired cooperation are in accordance with the principles of SFBT.

Previous research showed that achieving positive therapy effects is partly dependent on good working relationships between clients and therapists as well as between clients and permanent caregivers. Good cooperation increases the chances of positive outcomes in the daily/weekly support of 
clients. To this end, the Nominal Group Technique (NGT) was used to identify the opinions of 18 clients with ID on their desired cooperation with caregivers.

The results of the NGT interviews showed that clients place great value on caregivers having a reliable, empathic and non-patronising attitude. This attitude was found to be even more important than the type of support. Highscoring NGT statements correspond with important solution-focused principles; for example, the NGT quote "let us solve problems ourselves as far as possible" is in accordance with the SFBT principle: "the client is expert, and formulates his/her own objective and a plan to reach this objective". NGT also proved to be a valuable tool for generating the opinions of clients with ID.

Chapter 4 answers the third research question: 'How can SFBT be used with clients with ID?'. Application of SFBT was illustrated using a case series (10 clients with ID), a treatment protocol and a detailed case description. The treatment protocol consisted of six meetings with the following intervention format: (1) an intake: getting acquainted and exploring the problem; (2) first session: goal setting, exploring the exceptions, scaling questions, competence questions and feedback; (3) four follow-up meetings using the 'EARS' question set, which stands for 'Eliciting, Amplifying, Reinforcing, and Start again' with respect to the client's actions. An example case description was also provided.

After SFBT, an improvement in psychological functioning (according to clients) and a reduction in problem behaviour (according to caregivers) was observed. According to both the clients and the caregivers, therapy objectives were achieved for most clients. The therapy outcomes were maintained at 6 weeks follow-up. The clients gave a predominantly positive evaluation of evaluated the working method and the cooperation with therapists.

Chapter 5 answers the fourth research question: 'What are the processes and effects of SFBT in clients with ID, compared to care as usual?'. Eighteen clients with ID were treated in accordance with an SFBT protocol and compared with 18 clients who received care as usual (CAU). Measurements were performed before SFBT, immediately after SFBT and 6 weeks later during a follow-up.

Two clients terminated SFBT prematurely. Most clients in the SFBT group (13 out of 18 after SFBT and 14 out of 18 at 6 weeks follow-up) showed a 
clinically relevant improvement of more than 2 points on a scale of 1 to 10 on the self-formulated therapy objective. The differences between the SFBT and CAU groups were statistically significant $(p<0.01)$ with respect to (1) improved quality of life (psychological and social functioning), (2) reduced problem behaviour, and (3) increased social optimism and autonomy (resilience). The effect sizes of these changes were medium to large.

Chapter 6 answers the fifth research question: 'What is the applicability of the 'Student-Teacher Relationship Scale (STRS)' for the relationships between clients with ID and caregivers?'. Improvements in client-caregiver relationships may lead to improvements in the quality of life of clients with intellectual disabilities (ID). For this reason, interventions aimed at influencing these relationships are important. To gain insight into the nature and intention of these relationships in the ID population, suitable measurement instruments are needed. This study examined the applicability of an existing questionnaire, the Student-Teacher Relationship Scale (STRS), originally developed for use in primary education. The STRS was completed by 46 caregivers concerning 350 client-caregiver relationships. The questionnaires were completed for clients with moderate and severe intellectual disabilities (M/SID). Psychometric research was conducted into the factor structure $(n=350)$, construct validity ( $n=177)$, internal consistency $(n=350)$ and test-retest reliability of the STRS. In addition, the reliability of the individual scores was calculated ( $n=$ 350).

The original three-factor model ('closeness', 'conflict' and 'dependency' dimensions) used in primary education was, subject to minor differences, found to be applicable in the ID population. Statistically significant differences were found compared to other scales with more or less comparable measurement assumptions. The internal consistency and test-retest reliability of the STRS in the population studied were very good. The $95 \%$ confidence intervals of the means were small, and the measurements can thus be regarded as reliable.The STRS is an applicable instrument, for example to measure the effects of interventions aimed at improving the relations between clients and caregivers. 
Chapter 7 answers the sixth research question: 'How can SFC be used in teams supporting clients with ID?'. The principles of SFC are in accordance with those of SFBT, but focus on a team of caregivers experiencing a care problem with a client with severe or moderate ID. The term 'therapist' in this process is replaced by the term 'coach'. Application of the SFC was illustrated using a case series (13 teams), a coaching protocol and a detailed case description.

After SFC, improvements were observed in proactive thinking (5 of the 10 teams) and quality of the relationship between clients with severe or moderate ID and caregivers ( 7 of the 13 teams). Team objectives were realised in 7 of the 13 teams. The results were maintained at 6 weeks followup.

Chapter 8 answers the seventh research question: 'How is SFC judged by teams supporting clients with ID?'. The research also considers the degree to which caregivers' opinions are in accordance with the principles of the solutionfocused approach. The Nominal Group Technique (NGT) was used to identify the opinions of 18 caregivers on the strengths of SFC as well as their recommendations for SFC. The NGT statements were then used to compile an opinion questionnaire that was presented to 36 other SFC participants.

High-scoring NGT statements were in line with important solutionfocused principles; for example, the NGT statement "The focus on solutions worked well in our team" is in accordance with the solution-focused principle "Analysing solutions rather than analysing problems". NGT also yielded important recommendations, such as consolidating the results of SFC in followup sessions. In addition, NGT proved to be a valuable method for generating group opinions as well as a useful source for constructing a standardised opinion questionnaire on SFC.

Chapter 9 answers the eighth research question: 'What are the processes and effects of SFC, compared to coaching as usual?'. Eighteen teams experiencing a care problem with a client with M/SID took part in SFC, while 26 teams received coaching as usual (CAU). Measurements were performed befor SFC, immediately after SFC and at 6 weeks follow-up. The SFC teams showed a statistically significant progression towards the team goal after SFC and during follow-up. The SFC teams improved statistically significantly more $(p<0.01)$ 
than the CAU teams on the variables 'proactive thinking' and 'quality of the relationships'. The differences between the groups were maintained at followup. The effect sizes were at least medium.

Chapter 10 considers the results of all eight studies from a broader perspective, discussing the limitations of the research designs and the strengths of the solution-focused approach. It presents a brief proposal for the implementation of an integrated solution-focused approach in the support of clients with ID, introducing Solution-Focused Support (SFS) as a method of giving temporary interventions like SFBT and SFC a more sustainable effect. The chapter concludes with a call for a more solution-focused approach in general. 



\section{Samenvatting}

In hoofdstuk 1 wordt een overzicht gegeven van de belangrijkste inspiratiebronnen voor deze thesis: (1) de verbetering van de kwaliteit van bestaan van cliënten met lichte verstandelijke beperkingen (LVB), (2) het belang van goede werkrelaties tussen cliënten met LVB en begeleiders en (3) de empowerment van cliënten met LVB. De verwachting is dat SolutionFocused Brief Therapy (SFBT) en Solution-Focused Coaching (SFC) kunnen bijdragen aan genoemde drie strevingen. Deze verwachting mondt uit in een achttal onderzoeksvragen, die in de hoofdstukken 2 tot met 9 van deze thesis worden beantwoord. Het hoofdstuk besluit met een leeswijzer.

In hoofdstuk 2 wordt antwoord gegeven op de eerste onderzoeksvraagstelling: 'Welke aanpassingen zijn nodig om SFBT geschikt te maken voor cliënten met lichte verstandelijke beperkingen?'. SFBT is een kortdurende, doelgerichte en cliëntgerichte therapie gericht op het construeren van oplossingen in plaats van het analyseren van problemen. SFBT wordt nu nog weinig toegepast met cliënten met LVB. De auteurs onderzochten hoe SFBT in een aangepaste vorm geschikt kan zijn voor cliënten met LVB.

Aanpassingen voor SFBT met cliënten met LVB die in de literatuur worden aanbevolen zijn: (1) gebruik van eenvoudige taal, (2) aanpassing van verloop en duur van de sessies, (3) uitgebreide aandacht voor kennismaking door de therapeut, (4) aangepaste formulering van de 'vraag naar uitzonderingen', de 'vraag naar het doel' en 'schaalvragen', (5) stimulering van actieve betrokkenheid van de omgeving van de cliënten (6) aanpassingen bij het aanbieden van taken, waaronder gerbuik van visuele hulpmiddelen.

In hoofdstuk 3 wordt antwoord gegeven op de tweede onderzoeksvraagstelling: 'Wat vinden cliënten met LVB belangrijk in de samenwerking met begeleiders?'. Het onderzoek richt zich tevens op de vraag in hoeverre de meningen van cliënten over de gewenste samenwerking overeen komen met de uitgangspunten van SFBT. Eerder onderzoek toonde aan dat positieve effecten van therapieën deels afhankelijk zijn van goede werkrelaties tussen cliënten en therapeuten. Dat geldt ook voor de werkrelaties tussen cliënten en vaste begeleiders. Een goede samenwerking 
verhoogt de kans op goede uitkomsten in de dagelijkse / wekelijkse ondersteuning van de cliënten. De Nominale Groep Techniek(NGT) werd gebruikt om de meningen van 18 cliënten met LVB te verkrijgen over hun gewenste samenwerking met begeleiders.

De resultaten van de NGT interviews toonden aan dat cliënten veel waarde hechten aan een betrouwbare, empathische en niet-betuttelende houding van begeleiders. De bejegening wordt zelfs belangrijker gevonden dan het type ondersteuning. Hoog scorende NGT uitspraken correspondeerden met belangrijke oplossingsgerichte uitgangspunten. Bijvoorbeeld, de overeenkomst tussen het NGT-citaat: "Laat ons zoveel mogelijk zelf problemen oplossen" en het SFBT-uitgangspunt: "De cliënt is expert, formuleert zijn eigen doel en de weg naar dat doel'. NGT bleek bovendien een waardevol instrument om de meningen van cliënten met LVB te genereren.

In hoofdstuk 4 wordt antwoord gegeven op de derde onderzoeksvraagstelling: 'Hoe wordt SFBT uitgevoerd met cliënten met LVB?'. Toepassing van SFBT werd geïllustreerd aan de hand van een case serie (10 cliënten met LVB), een behandelprotocol en een uitgeschreven casus. Het behandelprotocol bestond uit zes bijeenkomsten met het volgende format met interventies: (1) een intake: kennismaking en probleemerkenning (2) eerste sessie: doelformulering, exploreren van uitzonderingen, schaalvragen, competentievragen en feedback (3) vier vervolgbijeenkomsten met de 'EARSquestion-set', een acronym voor 'Eliciting, Amplifying, Reinforcing, and Start again' van acties van de cliënt. Ook is een casus uitgeschreven.

Na SFBT werd een verbetering geconstateerd van psychologisch functioneren (volgens cliënten) en een reductie van probleemgedrag (volgens begeleiders). Therapiedoelen werden bij de meeste cliënten gerealiseerd volgens zowel de cliënten als de begeleiders. De therapieresultaten bleken behouden na een follow-up van 6 weken. De werkwijze en de samenwerking met de therapeut werd door de cliënten overwegend positief beoordeeld.

In hoofdstuk 5 wordt antwoord gegeven op de vierde onderzoeksvraagstelling: 'Hoe verloopt het proces van SFBT en wat is het effect van SFBT vergeleken met reguliere begeleiding (care as usual: CAU)?'. Achttien cliënten met LVB werden behandeld volgens een SFBT-protocol en vergeleken met 18 cliënten 
die reguliere begeleiding kregen (CAU). Metingen werden uitgevoerd voor SFBT, onmiddellijk na SFBT en 6 weken later tijdens een follow-up.

Twee cliënten beëindigden SFBT voortijdig. De meeste cliënten uit de SFBT groep (13 van de 18 na SFBT en 14 van de 18 na een follow-up van 6 weken) lieten een klinisch relevante vooruitgang zien van meer dan 2 punten op een schaal van 1 tot 10 naar het zelf geformuleerde therapiedoel. De verschillen tussen de SFBT en de CAU groep waren statistisch significant ( $p<$ 0.01 ) ten aanzien van (1) een verbetering van kwaliteit van leven (psychologisch en sociaal functioneren), (2) reductie van probleemgedrag, en (3) een toename van sociaal optimisme en autonomie (veerkracht). De effect groottes van deze veranderingen waren 'medium' tot 'groot'.

In hoofdstuk 6 wordt antwoord gegeven op de vijfde onderzoeksvraagstelling: 'Wat is de bruikbaarheid van de 'Student-Teacher Relationship Scale (STRS)' voor de relaties tussen cliënten met VB en begeleiders?'. Verbeteringen van de relaties tussen cliënten en begeleiders kunnen leiden tot een verhoging van de kwaliteit van leven van laatstgenoemden. Interventies gericht op de verbetering van die relaties zijn dus belangrijk. Om inzicht in de aard en betekenis van die relaties te krijgen zijn geschikte meetinstrumenten nodig.

Deze studie onderzocht de bruikbaarheid van een bestaande vragenlijst genaamd de 'Student-Teacher Relationship Scale (STRS)', oorspronkelijk ontwikkeld voor het basisonderwijs. De STRS werd ingevuld door 46 begeleiders over 350 cliënt-begeleider relaties. De vragenlijsten werden ingevuld voor cliënten met ernstige en matige verstandelijke beperkingen (E/MVB). Psychometrisch onderzoek werd verricht naar de factorstructuur ( $n=$ $350)$, de construct validiteit $(n=177)$, de interne consistentie $(n=350)$ en de test-hertest betrouwbaarheid van de STRS. Daarnaast werd de betrouwbaarheid van individuele scores berekend ( $n=350)$.

Het oorspronkelijke driefactoren model (dimensies 'nabijheid', 'conflict' en 'afhankelijkheid') uit het onderwijs werd behoudens kleine verschillen ook terug gevonden in de VB-populatie. Er werden statistisch significante correlaties vastgesteld met andere schalen met min of meer vergelijkbare meetpretenties. De interne consistentie en test-hertest betrouwbaarheid van de STRS in de VB-populatie waren zeer goed. De 95\% betrouwbaarheidsintervallen rondom gemiddelden waren klein en de meting is 
dus betrouwbaar. De STRS kan gezien worden als een bruikbaar instrument, bijvoorbeeld om het effect van interventies gericht op relatieverbetering tussen cliënten en begeleiders te meten.

In hoofdstuk 7 wordt antwoord gegeven op de zesde onderzoeksvraagstelling: 'Hoe wordt Solution-Focused Coaching (SFC) uitgevoerd met begeleiders van cliënten met VB?'. De principes van SFC komen overeen met die van SFBT, maar zijn gericht op een team van begeleiders dat een begeleidingsprobleem ervaart met een cliënt met ernstige of matige VB. De term 'therapeut' in dit proces wordt vervangen door de term 'coach'. Toepassing van SFC werd geïllustreerd aan de hand van een case serie (13 teams), een coaching protocol en een uitgeschreven teamcasus.

Na SFC werd een verbetering geconstateerd van 'proactief denken' (5 van de 10 teams) en van de 'kwaliteit van de relatie' tussen cliënten met ernstige of matige VB en begeleiders ( 7 van de 13 teams). Teamdoelen werden bij 7 van de 13 teams gerealiseerd. De resultaten bleken behouden na een follow-up van 6 weken.

In hoofdstuk 8 wordt antwoord gegeven op de zevende onderzoeksvraagstelling: 'Hoe wordt SFC beoordeeld door teams van begeleiders van cliënten met VB?'. Het onderzoek richtte zich tevens op de vraag in hoeverre de meningen van begeleiders overeen komen met de uitgangspunten van de oplossingsgerichte benadering. De Nominale Groep Techniek (NGT) werd gebruikt om de meningen van 18 begeleiders te verkrijgen over de sterke punten van SFC en over aanbevelingen voor SFC. De NGT-uitspraken werden vervolgens gebruikt om een opinievragenlijst samen te stellen die werd voorgelegd aan 36 andere deelnemers aan SFC.

Hoog scorende NGT uitspraken kwamen overeen met belangrijke oplossingsgerichte uitgangspunten. Bijvoorbeeld, de overeenkomst tussen het NGT-citaat: "De focus op oplossingen werkte positief in ons team" en het oplossingsgerichte uitgangspunt: 'Analyse van oplossingen komt in de plaats van de analyse van problemen'. NGT leverde ook belangrijke aanbevelingen op, zoals het advies om de resultaten van SFC te consolideren in vervolgbijeenkomsten. NGT bleek bovendien een waardevolle methode voor het 
genereren van meningen van een groep en als bron voor het construeren van een gestandaardiseerde opinievragenlijst over SFC.

In hoofdstuk 9 wordt antwoord gegeven op de achtste onderzoeksvraagstelling: 'Hoe verloopt het proces van SFC en wat is het effect van SFC vergeleken met reguliere coaching (coaching care as usual: CAU)?'.

Achttien teams die een begeleidingsprobleem met een cliënt met E/MVB ervoeren namen deel aan SFC. Zesentwintig teams werden regulier gecoacht (coaching as usual: CAU). Metingen werden uitgevoerd voor SFC, onmiddellijk na SFC en 6 weken later tijdens een follow-up. De OC teams lieten een statistisch significante progressie zien naar het team doel na SFC en tijdens follow-up. De SFC teams verbeterden statistisch significant meer $(p<0.01)$ dan de CAU teams op de variabelen 'proactief denken' en de 'kwaliteit van de relaties'. De verschillen tussen beide groepen hielden stand tijdens follow-up. De effect groottes waren minimaal 'medium'.

In hoofdstuk 10 worden de resultaten van alle acht studies beschouwd vanuit breder perspectief. De beperkingen van de onderzoeksdesigns en de kracht van oplossingsgericht werken worden belicht. Tot slot wordt beknopt een voorstel tot implementatie van een integrale oplossingsgerichte benadering in de ondersteuning van mensen met VB gepresenteerd. Solution-Focused Support (SFS) wordt geïntroduceerd en gepropageerd als een werkwijze om tijdelijke interventies als SFBT en SFC een duurzamer effect te geven in de ondersteuning van cliënten met VB. Er wordt afgesloten met een pleidooi voor oplossingsgericht werken in het algemeen. 



\section{List of publications}

International peer-reviewed journals

Roeden, J.M. \& Zitman, F.G. (1995). Ageing in adults with Down syndrome in institutionally-based and community-based residences. Journal of Intellectual Disability Research, 39, 399-407.

Roeden, J.M., Helbig, G. \& Zitman, F. G. (1995). A new, DSM-IV-compatible, structured interview for the diagnosis of depression in adults with Down syndrome. European Journal on Mental Disability, 2, 23-30.

Roeden, J.M. \& Zitman, F.G. (1997). A longitudinal comparison of cognitive and adaptive changes in subjects with Down's syndrome and an intellectually disabled control group. Journal of Applied research in Intellectual Disabilities, $10,289-302$.

Roeden, J.M., Bannink, F.P., Maaskant, M.A. \& Curfs, L.M.G. (2009). Solution Focused Brief Therapy with Persons with Intellectual Disabilities. Journal of Policy and Practice in Intellectual Disabilities, 6, 253-259.

Roeden, J.M., Maaskant, M.A. \& Curfs, L.M.G. (2010). The Views of Clients with Mild Intellectual Disabilities regarding their Working Relationships with Caregivers. Journal of Applied Research in Intellectual Disabilities, 24, 398406.

Roeden, J.M., Bannink, F.P., Maaskant, M.A. \& Curfs, L.M.G. (2011). Solution Focused Therapy (SFT) with People with Mild Intellectual Disabilities (ID); a Case Series. Journal of Policy and Practice in Intellectual Disabilities, 8, 247255.

Roeden, J.M., Maaskant, M.A., Koomen, H.M.Y., Candel, M.J.J.M. \& Curfs, L.M.G. (2011). Assessing client-caregiver relationships and the applicability of the 'student-teacher relationship scale' for people with intellectual disabilities. Research in Developmental Disabilities, 33, 104-110.

Roeden, J.M., Maaskant, M.A., Bannink, F.P. \& Curfs, L.M.G. (2012). Solution-Focused Brief Coaching of Staff of People with Severe and Moderate Intellectual Disabilities (ID); a Case Series. Journal of Policy and Practice in Intellectual Disabilities, 3, 185-194. 
Roeden, J.M., Maaskant, M.A. \& Curfs, L.M.G. (2012).The Nominal Group Technique as an evaluation tool for solution-focused coaching. Journal of Applied Research in Intellectual Disabilities. Accepted.

National peer-reviewed journals

Roeden, J.M. \& Zitman, F.G. (1994). Cognitieve, adaptieve en psychopathologische veranderingsprocessen bij oudere mensen met het syndroom van Down; een overzicht van relevante literatuur. Nederlands Tijdschrift voor Zorg aan mensen met verstandelijke beperkingen, 1, 21-34.

Roeden, J. M. \& Bannink, F. P. (2007b). Hoe organiseer ik een etentje? Oplossingsgerichte gedragstherapie met een verstandelijk beperkte vrouw [How to organise a dinner? Solution focused behaviour therapy with a woman with intellectual disabilities]. Gedragstherapie[Behaviour Therapy], 40, 251-268.

Published abstracts

Roeden, J.M. (1989). Signaallijst Depressie voor Zwakzinnigen. Verkrijgbaar bij J. Roeden, Vlasakkerkamp 19, 7772 MK, Hardenberg. In D. Kraijer \& J. Plas, Handboek psychodiagnostiek en verstandelijke beperking, (p.114). Lisse: Swets \& Zeitlinger.

Roeden, J.M. (1996). Cognitive and adaptive changes in aging people with Down syndrome; a longitudinal and controlled study. In Dutch Contributions to the 10th World Congress of the IASSMD, 46, 1996, Utrecht: NGBZ, BBI.

Roeden, J.M. (2007). Simpele oplossingen: oplossingsgerichte cognitieve gedragstherapie met mensen met een verstandelijke beperking. Abstractboek, najaarscongres VGCt, p. 63.

Roeden, J.M. (2008). Kan ik u helpen? Visie van licht verstandelijk beperkte cliënten op therapeutische samenwerking. Abstract boek, najaarscongres VGCt, p.76.

Roeden, J., Bannink, F., Maaskant, M. \& Curfs, L. (2010). Solution- focused brief therapy (SFBT) with clients with ID. Journal of Applied Research in Intellectual Disabilities, 23, 434. 
Roeden, J., Maaskant, M. \& Curfs, L. (2010). The views of clients with mild ID regarding their working relationships with caregivers. Journal of Applied Research in Intellectual Disabilities, 23, 454.

Roeden, J., Bannink, F., Beek, M. Maaskant, M. \& Curfs, L. (2010). Solution focused coaching of caregivers with ID. Journal of Applied Research in Intellectual Disabilities, 23, 454.

Roeden, J., Maaskant, M., Curfs, L. (2012). Processes and effects of solutionfocused coaching of staff of people with intellectual disabilities: A controlled study. Journal of Intellectual Disability Research, 56, 779.

Velema, A., Roeden, J., Maaskant, M. \& Curfs, L. (2012). Psychometric properties of the 'Student Teacher Relationship Scale': Measuring caregiverclient relationships. Journal of Intellectual Disability Research, 56, 800.

\section{Books}

Roeden, J.M. \& Bannink, F.P. (2007). Handboek oplossingsgericht werken met licht verstandelijk beperkte cliënten. Amsterdam: Pearson.

Roeden, J.M. (2012). De oplossingsgerichte begeleider. Een gids voor oplossingsgericht werken in de verstandelijk gehandicaptenzorg. Schoorl: Pirola. 



\section{Dankwoord}

Vele mensen hebben de afgelopen vier jaar direct of indirect meegewerkt bij de uitvoering van het onderzoek en het schrijven van de dissertatie. Allen wil ik graag bedanken.

Prof. dr. Leopold Curfs, mijn promotor. U bood mij de kans. Vakkundig werd mijn neiging tot praktijkgericht denken door u wetenschappelijk bijgesteld.

Dr. MARIAN MAASKANT, mijn copromotor. Jouw naam schrijf ik met hoofdletters. Op een schaal van 1 tot 10 voor samenwerking, stonden wij vier jaar lang op de hoogste trede. Jouw continue steun is met geen pen te beschrijven. Daar begin ik dus ik niet aan.

Fredrike, grootmeester van het oplossingsgerichte gedachtegoed. Jouw positieve psychologie heeft gewerkt.

Alle cliënten en begeleiders. Jullie voortdurende inbreng was doorslaggevend voor de ontwikkeling van het oplossingsgerichte denken. De ware, altijd sprankelende inspiratie voor de praktijk en het onderzoek, kwam van jullie. Alle collega's. Bedankt dat jullie mijn vluchtigheid en verstrooidheid verdroegen.

Kees en Marianne, leidinggevenden in de Baalderborg Groep. Jullie gunden mij, als vanzelfsprekend, mijn eigen weg. Mieke, 100\% oplossingsgerichte collega. Onze samenwerking smaakt naar meer. Wim, geestelijk verzorger. Jij maakte van mij een morderne monnik, ook al blijf ik een beginner. Anno, collega van het eerste uur. Wij delen vele mooie en wonderlijke interesses: van SPSS tot Siegfried. Manny, coördinerend begeleider. Al jaren ontwikkelen wij de ambulante begeleiding. 'Manny makes the world go round'.

Kees en Alph, uitgevers van Pirola. Snel effectief maakten jullie van stapels papier een prachtige gids voor begeleiders en een proefschrift. 
Kees en Loes, huisvrienden. Altijd stonden jullie klaar voor mij en voor ons. Vrije tijd werd dankzij jullie echt vrije tijd. Kees, onze uitstapjes met krentenbollen en kaas zijn onovertroffen. Loes, dank je dat ik Kees steeds mag lenen.

Marion, lieve zwinger. Voor eeuwig ben jij de eerste die mij liet kennismaken met oplossingsgericht werken.

Livia, lieve Livia. Met jou lukt alles. 'Partners for life' en 'partners in crime'. We werken te veel. Dat gaan we anders doen. Toch?

Lieve mam, allergrootste fan: "Dat had pap nog mote mèt make". Tiny vaan Pie is debij. 


\section{Curriculum Vitae}

John Roeden werd op 15 juni 1958 geboren in Maastricht en groeide op in diezelfde stad. Hij volgde een Atheneum $\beta$ opleiding en behaalde zijn diploma in 1977. In Maastricht doorliep hij vervolgens het Conservatorium met als hoofdvak Schoolmuziek en bijvak Piano. Het examen, akte B, werd in 1983 behaald.

$\mathrm{Na}$ zijn vervangende dienstplicht als begeleider in een gezinsvervangend tehuis voor mensen met verstandelijke beperkingen in Soest, was hij twee jaar werkzaam als muziektherapeut in Bartimeushage, een instelling voor mensen met visuele en verstandelijke beperkingen. Vanaf 1985 volgde hij de opleiding Geestelijke Gezondheidkunde aan de Universiteit van Maastricht. Het doctoraal diploma werd in 1989 behaald. In 1989 werd hij aangesteld als psychodiagnosticus en onderzoeksmedewerker in Sterrenberg te Huis ter Heide, eveneens een instelling voor mensen met verstandelijke beperkingen. $\mathrm{Hij}$ verrichtte onder meer onderzoek naar problematische veroudering bij mensen met het syndroom van Down. Vanaf 1997 werd zijn werk als orthopedagoog vervolgd in Baalderborg Groep te Hardenberg. De getuigschriften voor de postdoctorale opleidingen Gezondheidszorgpsycholoog en Cognitief Gedragstherapeut werden respectievelijk in 1999 en 2006 verkregen. In 2008 behaalde hij het certificaat van IVN-natuurgids.

Vanaf 2008 is hij tevens docent aan de postdoctorale GITP opleiding met als onderwerp: oplossingsgerichte therapie. Als consulent is hij verbonden aan het centrum voor consultatie en expertise met als specialisatie het Lesch-Nyhan syndroom. Sinds 2008 werkte hij aan zijn promotie onderzoek onder leiding van Prof. Dr. L.M.G. Curfs en copromotor Dr. M.A. Maaskant. Hij presenteerde de resultaten van het onderzoek onder meer in internationale congressen (IASSID) in Rome, Italië en Halifax, Canada. In 2010 werd de Vereniging Gehandicapten Nederland 'aanmoedigingsprijs voor beste onderzoekspublicatie' aan hem uitgereikt.

John Roeden woont samen met Livia Leysen in Bruchterveld, Overijssel. 